UNIVERSIDADE TECNOLÓGICA FEDERAL DO PARANÁ PROGRAMA DE PÓS-GRADUAÇÃO EM ENGENHARIA ELÉTRICA E INFORMÁTICA INDUSTRIAL

RODRIGO LUIZ FRIGOTTO

ANÁLISE DA QUALIDADE DE ÁUDIO NO SERVIÇO MÓVEL AERONÁUTICO

DISSERTAÇÃO

CURITIBA 
RODRIGO LUIZ FRIGOTTO

\title{
ANÁLISE DA QUALIDADE DE ÁUDIO NO SERVIÇO MÓVEL AERONÁUTICO
}

\begin{abstract}
Dissertação apresentada ao Programa de Pósgraduação em Engenharia Elétrica e Informática Industrial da Universidade Tecnológica Federal do Paraná como requisito parcial para obtenção do grau de "Mestre em Ciências" - Área de Concentração: Telecomunicações e Redes.
\end{abstract}

Orientador: Prof. Dr. Alexandre de Almeida Prado Pohl

\section{CURITIBA}




\section{Dados Internacionais de Catalogação na Publicação}

F912a Frigotto, Rodrigo Luiz

Análise da qualidade de áudio no serviço móvel aeronáutico / Rodrigo Luiz Frigotto.-- 2018.

$160 \mathrm{f}$.: il.; $30 \mathrm{~cm}$.

Disponível também via World Wide Web. Texto em português com resumo em inglês.

Dissertação (Mestrado) - Universidade Tecnológica Federal

do Paraná. Programa de Pós-graduação em Engenharia Elétrica e

Informática Industrial. Área de Concentração: Telecomunicações

e Redes, Curitiba, 2018.

Bibliografia: f. 103-106.

1. Controle do tráfego aéreo. 2. Processamento de sinais. 3. Interferência (Som). 4. Sistemas de processamento de voz Controle de qualidade. 5. Codificador de voz. 6. Sistemas de comunicação sem fio. 7. Subjetividade. 8. Métodos de simulação. 9. Engenharia elétrica - Dissertações. I. Pohl, Alexandre de Almeida Prado, org. II. Universidade Tecnológica Federal do Paraná. Programa de Pós-Graduação em Engenharia Elétrica e Informática Industrial. III. Título.

CDD: Ed. $22--621.3$

Biblioteca Central do Câmpus Curitiba - UTFPR Bibliotecária: Luiza Aquemi Matsumoto CRB-9/794 


\title{
TERMO DE APROVAÇÃO DE DISSERTAÇÃO № $\underline{795}$
}

\begin{abstract}
A Dissertação de Mestrado intitulada "Análise da Qualidedade de Áudio no Serviço Móvel Aeronáutico" defendida em sessão pública pelo(a) candidato(a) Rodrigo Luiz Frigotto, no dia 13 de abril de 2018, foi julgada para a obtenção do título de Mestre em Ciências, área de concentração Telecomunicações e Redes, e aprovada em sua forma final, pelo Programa de Pós-Graduação em Engenharia Elétrica e Informática Industrial.
\end{abstract}

\section{BANCA EXAMINADORA:}

Prof(a). Dr(a). Alexandre de Almeida Prado Pohl - Presidente - (UTFPR)

Prof(a). Dr(a). Mylène Christine Queiros de Farias - (UnB)

Prof(a). Dr(a). Alberto Yoshihiro Nakano - (UTFPR)

A via original deste documento encontra-se arquivada na Secretaria do Programa, contendo a assinatura da Coordenação após a entrega da versão corrigida do trabalho.

Curitiba, 13 de abril de 2018. 
Aos meus queridos: Mamma Ivani, papaizinho Elomar, mãe de coração Tânia, e minha irmãzinha querida Naná, pelo apoio, sempre! Este trabalho só foi possível graças à dedicação e empenho de muitas pessoas, às quais eu também dedico este trabalho. 


\section{AGRADECIMENTOS}

Agradeço sobretudo à Deus e à minha família.

Ao Prof.Dr. Alexandre Pohl, pelas necessárias e sempre bem-vindas orientações.

Ao Comando da Aeronáutica e DECEA (Departamento de Controle do Espaço Aéreo), pela confiança depositada.

Á Profa. Dra Mylene Christine Queiroz de Farias e Prof. Dr. Alberto Nakano pela avaliação minuciosa e preciosas recomendações ofertadas.

Ao Estúdio BOOM Sound Design pela disponibilização de infraestrutura impecável e excelentes profissionais, os Engenheiros de Som Guilherme Izidro e Lucas Pereira.

À Tania T. Nakanishi, Naomi Nakanishi, Maria Tomaschitz e Marcus Julius Zanon pelo acervo de frases utilizadas na pesquisa.

À Aerotronic Eletrônica e Instrumentos de Aeronaves, por ceder, sem custo, componentes eletrônicos essenciais e de difícil aquisição para a execução dos testes em vôo.

À equipe do GEIV (Grupamento de Ensaios em Vôo), pela realização dos ensaios de vôo de alto custo em altitudes elevadas, que seriam impossíveis com os equipamentos e recursos do CINDACTA II, cedendo recursos materias e humanos para a pesquisa. Em especial, aos Ten Cel Mauro Carrinho de Moura (Comandante do GEIV), Cap Sérgio Marcos da Rocha Correa, Cap Jair Vinicius Romano, Sgt Vitor Lima Silva, Sgt Fábio Augusto Alves, Sgt Felipe Jacobs Machado, Sgt Mariana Rodrigues da Silva, Sgt Thiago Abdala Razuk e tripulação do vôo GEIV.

Ao CEP da UTFPR, pela avaliação célere e prudente das atividades que envolveram seres humanos, em especial à Professora Frieda Saicla Barros.

Ao Helard Becerra Martinez e Professora por ceder para teste o algoritmo de avaliação objetiva sem referência que desenvolveram.

Aos queridos colegas de CINDACTA II:

À equipe da CAV e CCD do CINDACTA II, pelas coordenações nos testes com aeronaves, em especial ao Cel Jose Carlos Gomes, Maj Mauro Massahiro Okabayashi e Sgt Ismael da Silva Soares. 
Ao então Chefe da Divisão Operacional e atual Comandante do CINDACTA II, Cel Marcos Kentaro Adachi, pelos recursos disponibilizados à pesquisa. Ao Ex-Comandante do CINDACTA II, Cel Alvaro Wolnei Guimarães, por permitir a execução do estudo.

Ao Maj. Tomaz Lopes de Araujo por conduzir, de maneira excepcional, nossos testes em vôo com a aeronave Caravan.

À equipe do ACC-CW, pelas coordenações, disponibilização de recursos humanos e trabalho árduo durante as locuções, testes e análises subjetivas necessárias à esta pesquisa, em especial para os Maj. Alexsandro Soares de Araujo, Cap Roberto Vieira Filho, Cap Fernando Nunes, Cap Wanderley Antonio Faustino, Ten Elias da Silva, Sgt Claudio Goncalves da Fonseca, Sgt Raquel Lopes Grando, Sgt Sandeywison Leal Amosim Silva, Sgt Karolinne Rocha Pereira, Sgt Caroline Viane da Silva, Sgt Luiza Liz Alves, Sgt Rafael Scarante Cordeiro, Sgt Antonio Jose de Melo Orphao, Sgt Weslley Scarpini Miranda, Sgt Franciele Z. R. Guimarães, Sgt Camila da Silva Cardoso, Sgt Isabela da S. Oliveira, Sgt Shirley de F. dos Anjos, Sgt Vinicius de O. Foletto, Sgt Érico de Rosa Fagundes, Sgt. Carolina Calçada Pinheiro, Sgt. Camilla de Abreu Cantelmo, Sgt. Breno W. Paz da Silva, Sgt. Jessica L. Rodrigues da Silva, Sgt Teofilo J. dos Santos Maia, Sgt Alexandre M. Lima dos Santos, Sgt Yuri Wies Trauer, Sgt Samila M. Veras Campos, Sgt Danilo de B. Mendes, Sgt Dayane R. da Silva Kuss, Sgt Camila dos Santos de Almeida, Sgt Raíssa R. Modesto, Sgt Raquele Cruz Marinho, Sgt Ana Caroline P. Antião, Sgt Wellington F. de Figueiredo, Sgt Aline Corrêa Maciel, Sgt Suellen P. Pires de Souza, Sgt Tathyane M. Oliveira Silva, Sgt Igor S. R. de Moraes, Sgt Thaís Sá Ribas da Silva, Sgt Davi F. da Silva Machado, Sgt Carlos da Silva Cardoso Neto, Sgt Amanda M. Hoffmann Pinto, Sgt Angie Alvarez Porto, e todos os controladores de vôo e equipe técnica que trabalharam durante os testes.

Aos queridos amigos da KM/TNEL do CINDACTA II pelo apoio na montagem de interfaces e adaptadores necessários aos testes de aeronaves, em especial aos Sgt Luiz Carlos (Zé) Oliveira Silva, Sgt Inacio Ferrarini, Sgt Ronaldo Augusto Costa Lopes, Cb Joelson Gans Pereira, Sgt Thalles Rangel Pirani, Cb Luciano Alves Dalasuana, SO Marcelo Rocha de Oliveira, Sgt Onairam dos Santos Costa.

Á equipe do CMV, nas pessoas do Cap Eduardo Buhler e Sgt Monique Silva Do Nascimento, por reunir as meteorológicas dos testes em vôo.

À sempre solícita e operacional equipe da Sala Técnica e Subdivisão de Telecomunicações, por disponibilizar recursos materiais e humanos para a realização e acompanhamento de todos os testes. Em especial aos: Cap Thiago Martins dos Santos, SO Evandro Lyra Vieira, SO Sergio Costa Matute, Maj Denniel Sancho Zorzal Rossi e Bruno Serrano. 
Aos Exmos. chefes, Ten Cel Ivantuir Leal Coelho, pelas essenciais coordenações junto ao Comando do CINDACTA II e Maj Danilo dos Santos Telechi pelo suporte e incentivo para a pesquisa.

Aos meus caríssimos colegas de trabalho, que me apoiaram nas minhas ausências e acompanharam de perto todo o percurso: Cap Ramon Bulhões e Silva, Ten Anderson Alex dos Santos Ribeiro, Ten Delcio Waculicz, Ten Rosiane Bonatti Ribeiro, Ten Mariana Moreira, Sgt Josivaldo de Souza Dias, Artur Pereira Melges, Ten Carla Cristina Tanner Gomes, Julio Cesar Frez e Sgt Paulo Cesar Castro. 
"Science is about knowing, engineering is about doing." Henry Petroski 


\section{RESUMO}

FRIGOTTO, Rodrigo. ANÁLISE DA QUALIDADE DE ÁUDIO NO SERVIÇO MÓVEL AERONÁUTICO. 160 f. Dissertação - Programa de Pós-graduação em Engenharia Elétrica e Informática Industrial, Universidade Tecnológica Federal do Paraná. Curitiba, 2018.

Até chegar ao controlador de tráfego aéreo os sinais transmitidos que carregam informações de áudio podem sofrer diferentes degradações, seja por interferências, atenuações por problemas de cobertura, problemas de canalização, uso de algoritmos de compressão ou escolha de melhor sinal, entre outros. Neste trabalho é realizado um estudo de qualidade de voz nas telecomunicações aeronáuticas, utilizando o método de análise subjetiva aplicado a sinais provenientes de diferentes meios utilizados comumente no Sistema de Controle de Espaço Aéreo Brasileiro (SISCEAB). Para tal, foi estabelecida uma base de sinais de áudio de voz de referência gravadas em estúdio, e estes sinais submetidos a diferentes degradações presentes nos meios de comunicações utilizados nas atividades de controle de espaço aéreo. Em seguida os sinais foram analisados conforme normatizado pela norma ITU-T P.800, por seres humanos de maneira a encontrar o índice de qualidade de voz, denominado Mean Opinion Score ou MOS. Com estes dados foram testados métodos de análise objetivos do PESQ (Perceptual Evaluation of Speech Quality) e SESQ (Single-Ended Speech Quality Assessment) e verificados os seus desempenhos na determinação do MOS previsto em frente aos problemas de qualidade de áudio peculiares dos meios de comunicação do SISCEAB. Os resultados mostram ampla variação do MOS dependendo do meio utilizado, com degradação mais acentuada nas comunicações que empregaram rádio-frequência. Também foi observado que o PESQ apresentou bom desempenho na previsão do MOS de sistemas de telecomunicações empregados no SISCEAB.

Palavras-chave: Serviço Móvel Aeronáutico, Qualidade de Voz, Análise subjetiva de áudio, Controle de Tráfego Aéreo 


\begin{abstract}
FRIGOTTO, Rodrigo. ANALYSIS OF SPEECH QUALITY IN THE AERONAUTICAL MOBILE SERVICE. 160 f. Dissertação - Programa de Pós-graduação em Engenharia Elétrica e Informática Industrial, Universidade Tecnológica Federal do Paraná. Curitiba, 2018.

From the airplane until reaching air-traffic controllers, transmitted signals that carry audio information may suffer different kinds of degradation. Radio interference, range or canalization issues and the use of compression are among the most common sources of audio degradation in aeronautical communications. In this work it is studied the speech quality in aeronautical communications, using standardized subjective tests applied over signal degradations of normally used aeronautical telecommunication systems of the SISCEAB (Brazilian System of Airspace Control). For this purpose, an audio database was prepared, with reference speech signals being recorded in a professional audio studio. These signals were latter submitted to different degradations of the common means of communication used in airspace control and, next, were evaluated, as standardized in the ITU-T P.800 standard, by human subjects in order to express the MOS, an audio quality index. Latter, these indexes were used to test the performance of two objective analysis algorithms, the PESQ (ITU-T P.862) and the SESQ (ITU-T P.563), in order to verify if they could predict the MOS of signals degraded by the means used in air-traffic control communications. The results show wide variations in the MOS depending on the media used, with marked variation in communications that used radiofrequency. It was also observed that the PESQ showed good performance predicting the MOS of telecommunication systems used in the SISCEAB.
\end{abstract}

Keywords: Aeronautical Mobile Service, Speech Quality Assessment, Subjective Audio Analysis 


\section{LISTA DE FIGURAS}

FIGURA $1 \quad$ - Estrutura de órgãos agentes do SMA . . . . . . . . . . . . . . . . . 19

FIGURA 2 - Área de controle de tráfego aéreo no Brasil e regiões de responsabilidade

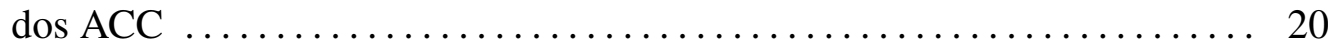

FIGURA 3 - Diagrama de blocos simplificado de solução tecnológica do SMA . . . . 21

FIGURA 4 - Diagrama de irradiação teórico de estações de telecomunicações ...... 22

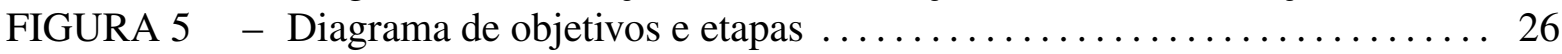

FIGURA 6 - Disposição de fonte e captação do ensaio de reverberação - S1: P1,P2 e

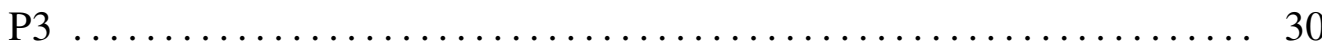

FIGURA 7 - Disposição de fonte e captação do ensaio de reverberação - S1: P4,P5 e

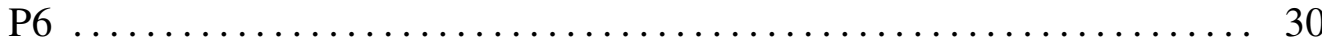

FIGURA 8 - Disposição de fonte e captação do ensaio de reverberação - S2: P1,P2 e

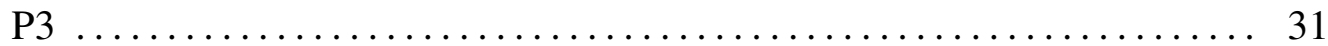

FIGURA 9 - Disposição de fonte e captação do ensaio de reverberação - S2: P4,P5 e

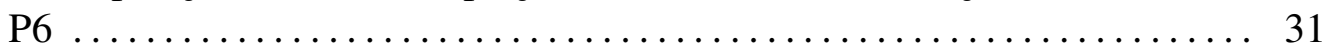

FIGURA 10 - Exemplo de Sinal de áudio do ensaio de reverberação - Estúdio principal 35

FIGURA 11 - Exemplo de Sinal de áudio do ensaio de reverberação - Sala de Con-

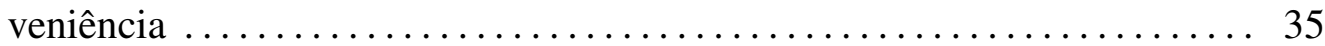

FIGURA 12 - Decaimento e polinômio ajustado - Salas $\ldots \ldots \ldots \ldots \ldots \ldots \ldots \ldots \ldots$

FIGURA 13 - Espectro de potência de ruído ambiente - Salas $\ldots \ldots \ldots \ldots \ldots \ldots \ldots . \ldots \ldots$

FIGURA 14 - Modelo de nome de arquivo de gravação . .................. 41

FIGURA 15 - Exemplo de sinal de voz com parâmetros de tempo ............. 43

FIGURA 16 - Diagrama esquemático da unidade MNRU . . . . . . . . . . . . . 49

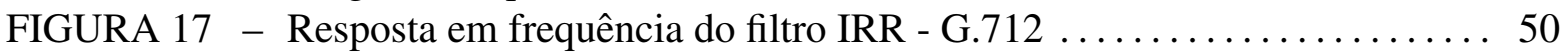

FIGURA 18 - Limiares de audição e de mascaramento, sinal $1 \mathrm{kHz} \ldots \ldots \ldots \ldots \ldots . . \ldots 1$

FIGURA 19 - Diagrama de blocos do codificador G.726 .................. 52

FIGURA 20 - Diagrama de reprodução/gravação de áudios $\ldots \ldots \ldots \ldots \ldots \ldots \ldots \ldots 7$

FIGURA 21 - Diagrama de sistema - Condições de teste G11 e G1A . . ......... 58

FIGURA 22 - Diagrama de sistema - Condições de teste G12 e G2A ........... 59

FIGURA 23 - Diagrama de sistema - Condições de teste G13 e G3A . . . . . . . . . . . 59

FIGURA 24 - Mapa de de vôo, condições de teste G16, G17, G18, G5A e G6A .... 60

FIGURA 25 - Diagrama de sistema - Condições de teste G14, G15 e G4A ........ 61

FIGURA 26 - Diagrama de sistema - Condições de teste G17 ............... 62

FIGURA 27 - Diagrama de sistema - Condições de teste G18 e G5A . .......... 63

FIGURA 28 - Mapa de de vôo, condições de teste G19, G20, G21, G22, G23, G24,

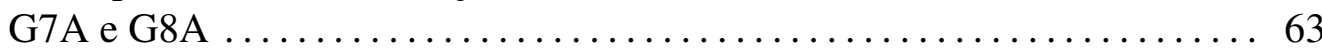

FIGURA 29 - Diagrama de sistema - Condição de teste G19 . . . . . . . . . . . . . . 64

FIGURA 30 - Diagrama de sistema - Condições de teste G20 e G7A ........... 65

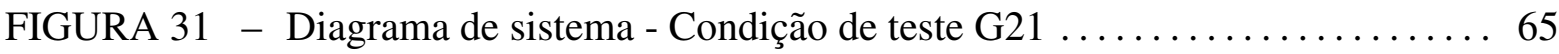

FIGURA 32 - Diagrama de sistema - Condição de teste G22 ............... 66

FIGURA 33 - Diagrama de sistema - Condições de teste G23 e G8A . ........... 67

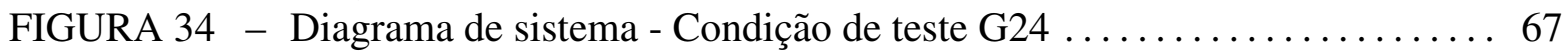

FIGURA 35 - Valores de MOS por grupo conforme obtido no experimento subjetivo . 78 
FIGURA 36 - Valores de MOS por grupo conforme obtido no experimento subjetivo . 79

FIGURA 37 - Valores de MOS por grupo conforme obtido no experimento subjetivo . 80

FIGURA 38 - Valores de MOS por grupo conforme obtido no experimento subjetivo . 81

FIGURA 39 - Comparação do MOS entre grupos de frases ATC e ITU . . . . . . . . . 81

FIGURA 40 - Rotina de sincronização utilizada pelo PESQ $\ldots \ldots \ldots \ldots \ldots \ldots \ldots . \ldots 4$

FIGURA 41 - Resposta em frequência do filtro IRS $\ldots \ldots \ldots \ldots \ldots \ldots \ldots \ldots \ldots . \ldots \ldots$

FIGURA 42 - Diagrama de blocos de processamento de voz definido pela ITU-TP563 89

FIGURA 43 - Distribuição dos resultados de aplicação do PESQ e SESQ - grupos G1

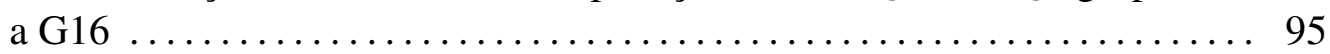

FIGURA 44 - Distribuição dos resultados de aplicação do PESQ e SESQ - grupos G17

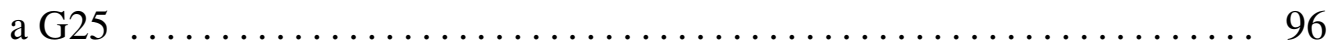

FIGURA 45 - Distribuição dos resultados de aplicação do PESQ e SESQ - grupos G1A

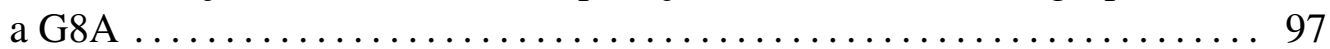

FIGURA 46 - Comparação do PESQ com MOS obtido nos Experimentos Subjetivos . 98

FIGURA 47 - Comparação do SESQ com MOS obtido nos Experimentos Subjetivos . 98

FIGURA 48 - Representação gráfica do PESQ e SESQ em relação ao MOS, para todos

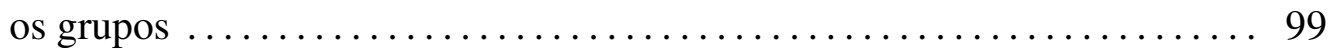

FIGURA 49 - Representação gráfica do PESQ e SESQ em relação ao MOS, para todos os grupos com comunicações ATC ...................... 99

FIGURA 50 - Representação gráfica do PESQ e SESQ em relação ao MOS, para todos

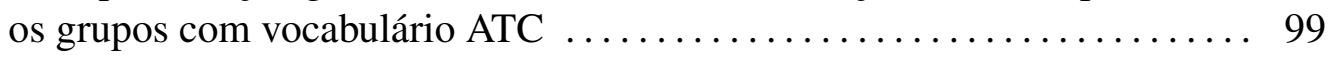

FIGURA 51 - Avião utilizado para transmissão e recepção de sinais de áudio em teto

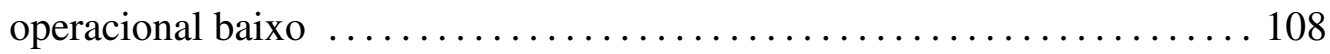

FIGURA 52 - Avião utilizado para transmissão e recepção de sinais de áudio em teto

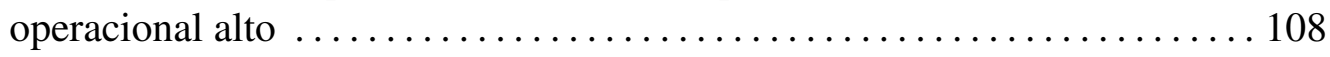

FIGURA 53 - Interface de áudio para computador 16 bits $44,4 \mathrm{kHz}$ utilizado na aplicação das condições de teste .............................. 109

FIGURA 54 - Acessórios de alimentação e inversor de frequência utilizados em testes

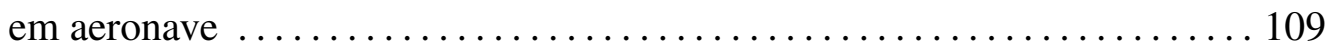

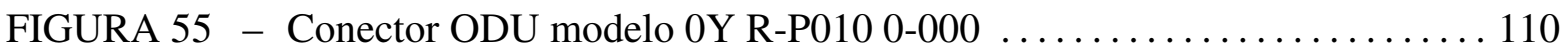

FIGURA 56 - Diagrama da interface tipo "SITTI" " ................... 111

FIGURA 57 - Plug de aviação tipo PJ-068 de 0,206"utilizado para conexão do micro-

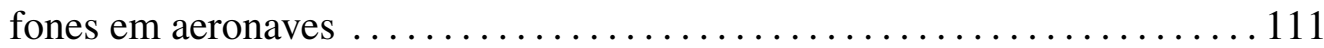

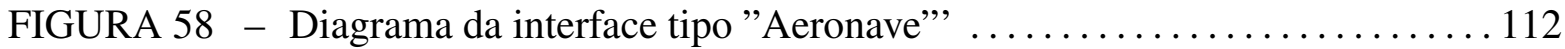

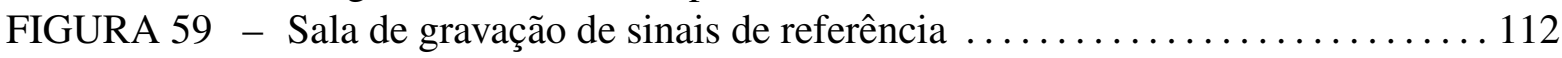

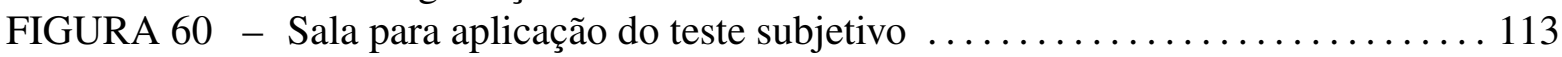

FIGURA 61 - Microfone utilizado na gravação de sinais de referências . . . . . . . . 114

FIGURA 62 - Pre-amplificador de microfone utilizado na gravação . . . . . . . . . 114

FIGURA 63 - Mesa de áudio utilizada na gravação de áudio de referência . ........ 115

FIGURA 64 - Conversor analógico-digital e digital-analógico utilizado na gravação . 115

FIGURA 65 - Conversor analógico-digital e digital-analógico utilizado na gravação . . 116

FIGURA 66 - Pré-amplificador linear de microfone AVid HD Omni utilizado em ses-

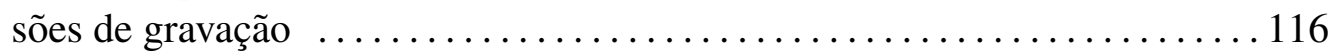

FIGURA 67 - Monitor de áudio de referência utilizado nos ensaios $\ldots \ldots \ldots \ldots \ldots 117$ 


\section{LISTA DE TABELAS}

TABELA 1 - Posições da fonte de áudio e da captação para cada arquivo gravado -

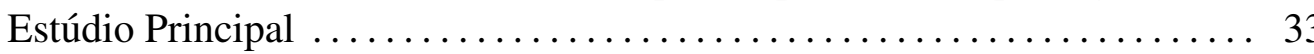

TABELA 2 - Posições da fonte de áudio e da captação para cada arquivo gravado -

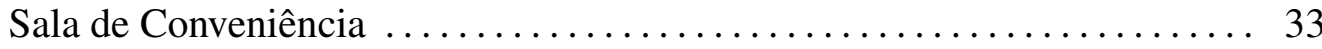

TABELA 3 - Valores estimados de RT60 para as salas utilizadas no estudo subjetivo . 35

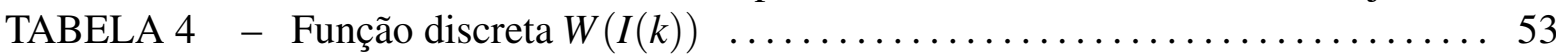

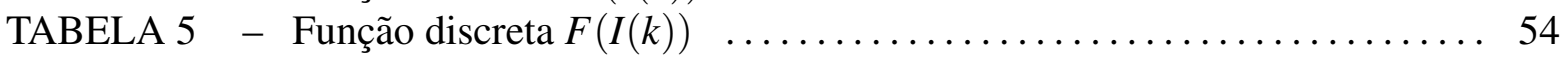

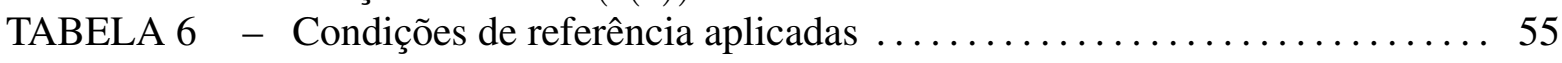

TABELA 7 - Condições de teste aplicadas, grupo ITU $\ldots \ldots \ldots \ldots \ldots \ldots \ldots \ldots \ldots \ldots$

TABELA 8 - Condições de teste aplicadas, grupo ATC $\ldots \ldots \ldots \ldots \ldots \ldots \ldots \ldots$

TABELA 9 - Valores de MOS obtidos no experimento subjetivo por condição ...... 77

TABELA 10 - Valores médios de MOS em diferentes situações usando meios de ATC 79

TABELA 11 - Valores de MOS previstos para os métodos objetivos empregado ..... 92

TABELA 12 - Correlação entre MOS e valores previstos do PESQ e SESQ - Todos os

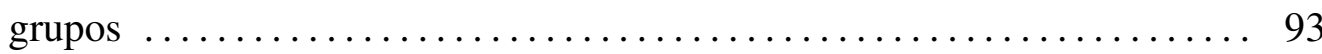

TABELA 13 - Correlação entre MOS e valores previstos do PESQ e SESQ - Somente Grupos de Testes ................................. 94 


\section{LISTA DE SIGLAS}

\begin{tabular}{|c|c|}
\hline SMA & Serviço Móvel Aeronáutico \\
\hline ICAO & Organização Internacional de Aviação Civil \\
\hline AM & Amplitude Modulada \\
\hline ITU & International Telecommunications Union \\
\hline ATC & Air Traffic Control ou Controle de Tráfego Aéreo \\
\hline MOS & Mean Opinion Score \\
\hline SESQ & Single-Ended Speech Quality Assessment \\
\hline PESQ & Perceptual Evaluation of Speech Quality \\
\hline DECEA & Departamento de Controle do Espaço Aéreo \\
\hline ATCO & Air Traffic Controller, ou Controlador de Tráfego Aéreo \\
\hline TWR & Tower - Aerodrome Control \\
\hline APP & Approach Control, Centro de Controle de Aproximação \\
\hline $\mathrm{ACC}$ & $\begin{array}{l}\text { Area Control Centre, Centro de Controle de Área de AZ (Manaus), A0 (Atlântico), } \\
\text { BS (Brasília), CW(Curitiba), RF(Recife) }\end{array}$ \\
\hline FIR & Flight Information Region ou Região de Informação de Vôo \\
\hline ICA & Órgao: Instituto de Cartografia da Aeronáutica \\
\hline VHF & Very High Frequency \\
\hline PTT & Push to talk, comando de liberação de portadora \\
\hline DG & Distribuidor Geral de Telecomunicações \\
\hline VOIP & Voice Over IP \\
\hline ATIS & $\begin{array}{l}\text { Automatic Terminal Information Service, frequência de serviço de mensagens gra- } \\
\text { vadas do terminal }\end{array}$ \\
\hline GNDC & Ground Control, frequência de controle de solo \\
\hline WAV & Waveform Audio File Format \\
\hline MLS & Maximum Lenght Sequence, ou Sequência de Comprimentos Máximos \\
\hline PCM & Pulse Code Modulation \\
\hline CEP & Comitê de Ética da UTFPR \\
\hline TCLE & Termo de Consentimento Livre e Esclarecido \\
\hline TCUISV & Termo de Consentimento para Uso de Imagem e Som de Voz \\
\hline MNRU & Modulated Noise Reference Unit \\
\hline ADPCM & Adaptative diferential pulse code modulation \\
\hline IIR & Infinite Impulse Response, ou resposta infinita ao impulso \\
\hline DTCEA & $\begin{array}{l}\text { Destacamento de Controle do Espaço Aéreo de CT (Catanduvas), MDI (Morro da } \\
\text { Igreja) }\end{array}$ \\
\hline$I C A$ & Documento, Instrução do Comando da Aeronáutica \\
\hline PDH & Plesiochronous digital hierarchy, ou hierarquia digital plesiócrona \\
\hline KT-VHF & Casa de transmissão de VHF \\
\hline GEIV & Grupamento de Ensaios em Vôo do DECEA \\
\hline $\mathrm{PCO}$ & Estação Terrena de VHF de Pico do Couto - RJ \\
\hline CAM & Estação Terrena de VHF de Campos-RJ \\
\hline PIE & Estação Terrena de VHF de Piedade-MG \\
\hline
\end{tabular}


VARG Estação Terrena de VHF de Varginha-MG

ACR Absolute category rating

DSIS Double-stimulus impairment scale

DSCQS Double-stimulus continuous quality scale

VOIP Voice Over IP

IRS Intermediate Reference System

FFT Fast Fourier Transform, ou transformada rápida de Fourier

LPC Coeficiente de predição linear

THD Distorção harmônica total 


\section{SUMÁRIO}

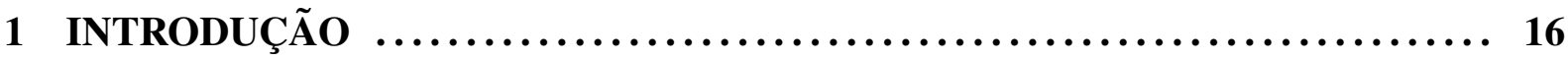

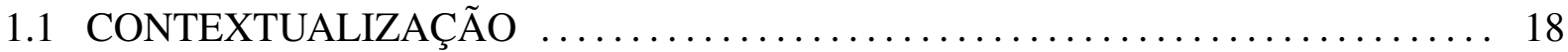

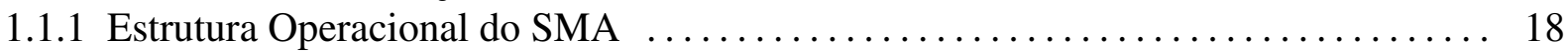

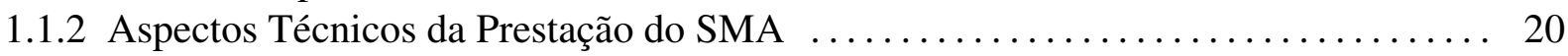

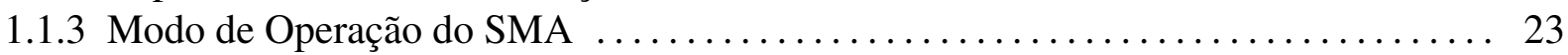

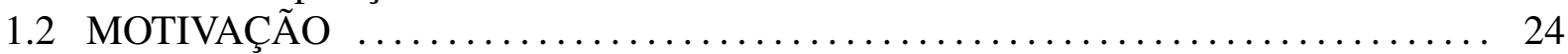

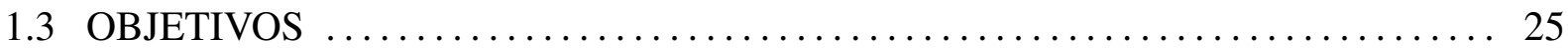

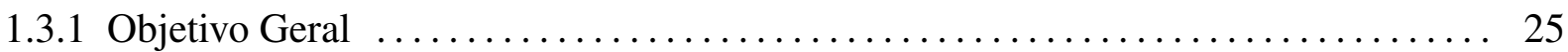

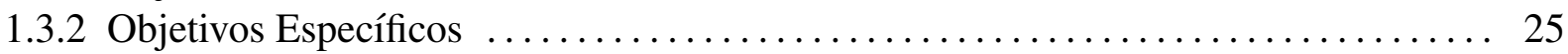

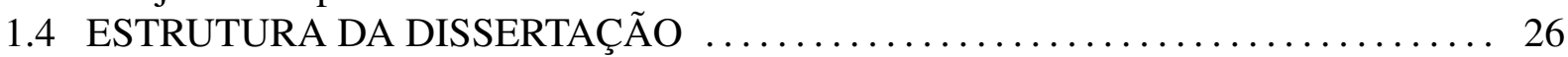

2 GERAÇÃO DE ESTÍMULOS - GRAVAÇÃO DOS SINAIS DE VOZ $\ldots \ldots \ldots \ldots 28$

2.1 NECESSIDADES DE EQUIPAMENTOS E RECURSOS $\ldots \ldots \ldots \ldots \ldots \ldots \ldots 28$

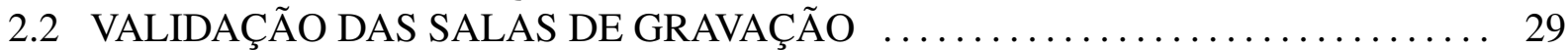

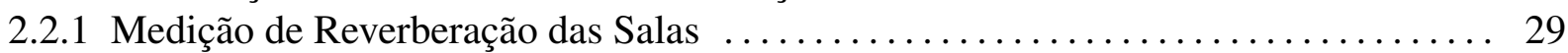

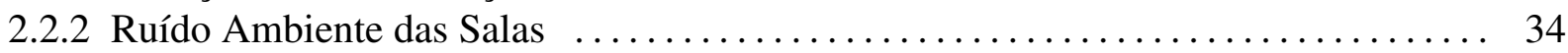

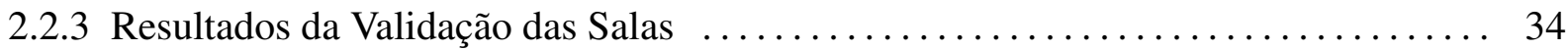

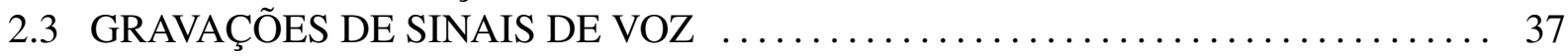

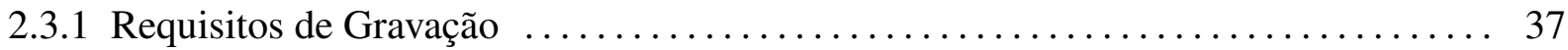

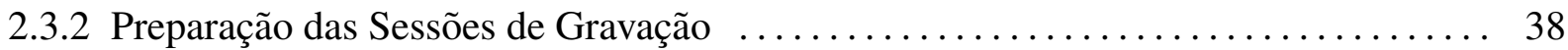

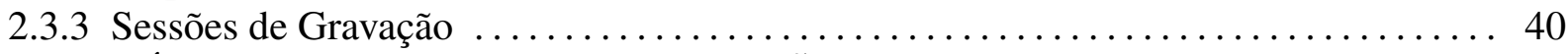

2.4 PRÉ-PROCESSAMENTO E PREPARAÇÃO DOS SINAIS DE VOZ $\ldots \ldots \ldots \ldots 41$

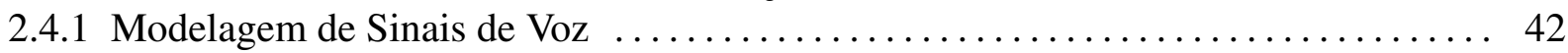

2.4.2 Algoritmo de Normalização de Sinais de $\operatorname{Voz} \ldots \ldots \ldots \ldots \ldots \ldots \ldots \ldots \ldots \ldots . \ldots \ldots$

2.4.3 Pré-processamento, Tom de Calibração ............................ 45

3 GERAÇÃO DE DEGRADAÇÕES - TESTES E SITUAÇÕES DE CONTROLE • 48

3.1 PROCESSAMENTOS ADICIONAIS: DEGRADAÇÕES CONTROLADAS $\ldots \ldots .48$

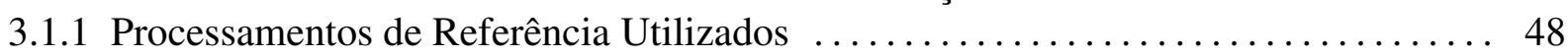

3.1.2 Aplicação das degradações/tratamentos controlados $\ldots \ldots \ldots \ldots \ldots \ldots \ldots \ldots \ldots 54$

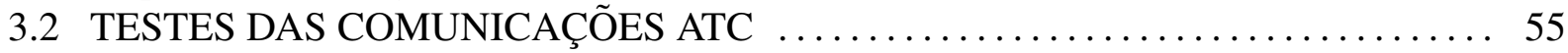

3.2.1 Equipamentos para aplicação das condições de teste $\ldots \ldots \ldots \ldots \ldots \ldots \ldots \ldots \ldots$

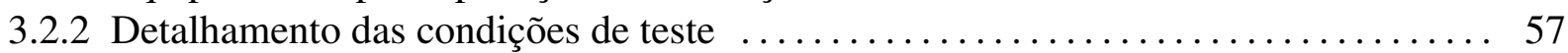

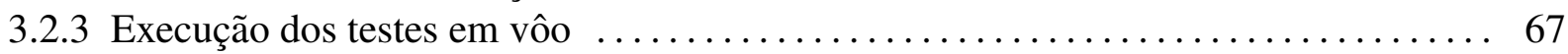

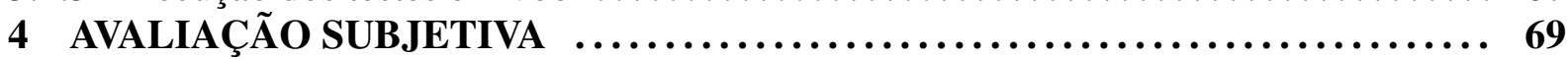

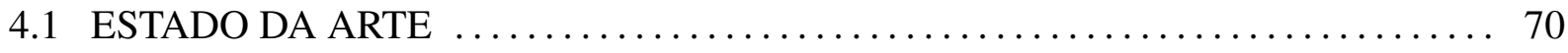

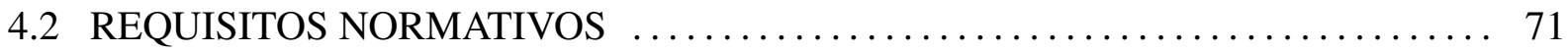

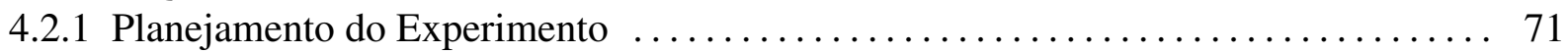

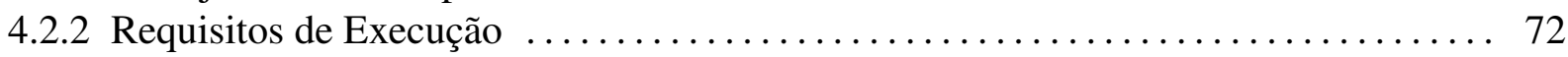

4.3 PREPARAÇÃO DO EXPERIMENTO SUBJETIVO .................... 73

4.3.1 Delineamento do Experimento Subjetivo e Intervenções nos Participantes ........ 74

4.4 RESULTADOS DO EXPERIMENTO SUBJETIVO $\ldots \ldots \ldots \ldots \ldots \ldots \ldots \ldots \ldots \ldots$

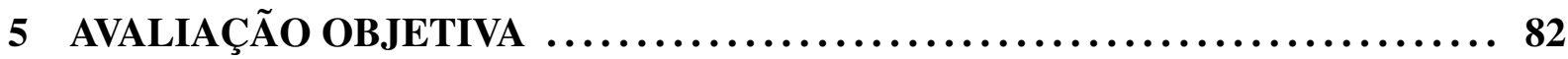


5.1 MÉTODOS OBJETIVOS COM REFERÊNCIA $\ldots \ldots \ldots \ldots \ldots \ldots \ldots \ldots \ldots \ldots$

5.2 MÉTODOS OBJETIVOS SEM REFERÊNCIA $\ldots \ldots \ldots \ldots \ldots \ldots \ldots \ldots \ldots \ldots \ldots$

5.3 APLICAÇÃO DE MÉTODOS DE ANÁLISE OBJETIVA $\ldots \ldots \ldots \ldots \ldots \ldots \ldots \ldots$

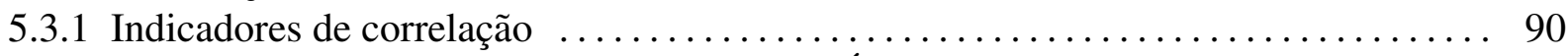

5.4 RESULTADOS DE DESEMPENHO DOS MÉTODOS OBJETIVOS $\ldots \ldots \ldots \ldots . . . . .91$

6 CONCLUSÃO E TRABALHOS FUTUROS $\ldots \ldots \ldots \ldots \ldots \ldots \ldots \ldots \ldots \ldots \ldots \ldots \ldots$

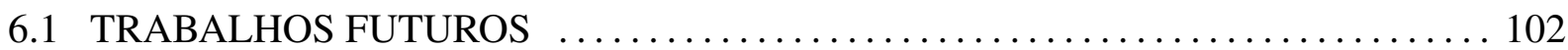

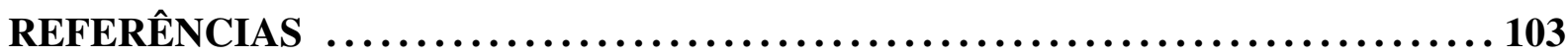

Anexo A - RECURSOS, EQUIPAMENTOS E INFRAESTRUTURA $\ldots \ldots \ldots \ldots \ldots 107$

A.1 MATERIAIS E RECURSOS PARA TESTES COM AERONAVES $\ldots \ldots \ldots \ldots \ldots 107$

A.2 MATERIAIS E RECURSOS PARA GRAVAÇÃO E TESTE SUBJETIVO $\ldots \ldots \ldots 11$

Anexo B - ROTEIRO DO LOCUTOR E LISTA DE FRASES ................ 118

Anexo C - MODELO DE QUESTIONÁRIOS: LOCUTOR E AVALIADOR ...... 126

Anexo D - TLCE E TCUISV UTILIZADOS NA PESQUISA .............. 129

Anexo E - FORMULÁRIOS DE ACOMPANHAMENTO DE GRAVAÇÃ̃o ....... 138

Anexo F - RESULTADOS DE PRÉ-PROCESSAMENTO DOS ÁUDIOS $\ldots \ldots \ldots \ldots 141$

Anexo G - DIVISÃO DE FRASES EM GRUPOS DE TRATAMENTO $\ldots \ldots \ldots \ldots \ldots 148$

Anexo H - CONDIÇÕES METEOROLÓGICAS - TESTES EM Vôo $\ldots \ldots \ldots \ldots \ldots 1$

Anexo I - MODELO DE QUESTIONÁRIOS DE AVALIAÇÃO $\ldots \ldots \ldots \ldots \ldots \ldots \ldots 154$

Anexo J - LISTAS DE REPRODUÇÃO DAS SESSÕES SUBJETIVAS $\ldots \ldots \ldots \ldots 158$ 


\section{INTRODUÇÃO}

As telecomunicações aeronáuticas para fins de controle de tráfego aéreo são realizadas entre as aeronaves e os centros de controle, torres e estações de aeroportos localizados no solo. Dentre as comunicações utilizadas no Serviço Móvel Aeronáutico (SMA) padronizadas pela Organização Internacional de Aviação Civil (ICAO), a de maior importância para a segurança da aviação é a comunicação por voz, por onde são fornecidos procedimentos e informações importantes e realizadas as coordenações necessárias para organizar o espaço aéreo. Através do SMA são passadas instruções de navegação, como nível de vôo (altitude), emitidos alertas e informações de tráfegos conflitantes.

As comunicações por voz ocorrem por meio de transmissão e recepção analógica, na faixa de 117 a 137 MHz, em AM, em haf-duplex através de estações de comunicações que podem distar a mais de $1000 \mathrm{~km}$ do Centro de Controle. Os sinais precisam ser encaminhados ao Centro de Controle onde as equipes de controle de tráfego aéreo fazem as coordenações necessárias, passando por diferentes equipamentos e mídias de comunicação e sofrendo alterações ao longo do percurso.

Nessas comunicações, podem ser observadas diferentes formas de degradação, pois os sinais ficam sujeitos à diferentes degradações relacionados à propagação de rádio-frequência, interferências com outros transmissores locais, interferências por descargas atmosféricas, entre outros. Na estação de comunicação remota podem ocorrer problemas relacionados aos equipamentos de recepção tais como a saturação de receptores, atenuações de sinal por mal contato elétrico, entre outros. Além disso, ao serem transmitidos ao Centro de Controle, dependendo da mídia que transportará o sinal, este passará por conversões analógico-digital e digital-analógico podendo passar por compressões e outros tratamentos que possivelmente podem causar degradações ou adicionar artefatos indesejados.

Os requisitos de comunicação para os serviços de controle de tráfego aéreo são definidos num documento, o Anexo 10 da ICAO, em seus 5 volumes (ICAO, 1996). Este documento determina que, para a avaliação de qualidade de áudio das comunicações aeronáuticas, devem 
ser atendidos aos requisitos da International Telecommunications Union (ITU). Considerando que a inteligibilidade dos diálogos pode impactar a segurança da aviação e devido ao grande número de fatores degradantes que os sinais de voz em telecomunicações aeronáuticas podem sofrer, e ao aumento do tráfego aéreo registrado nos últimos anos, a avaliação da qualidade de sinais de voz nas telecomunicações aeronáuticas ganhou relevância.

A identificação da qualidade de sinais de áudio e voz é um assunto importante na área de telecomunicações e é considerada uma análise subjetiva, pois depende do julgamento de indivíduos (usuários) de um determinado serviço. Os testes de análise subjetiva utilizados para levantamento de qualidade de voz consistem na aplicação de um trecho de áudio de referência a um grupo de pessoas que avaliam a qualidade do sinal em termos de inteligibilidade. Outra possibilidade é o uso de métodos objetivos de análise, que utilizam modelos matemáticos para avaliar a qualidade de voz. Essa técnica apresenta baixo custo, por não necessitar das pesquisas de opinião e quando automatizada pode ser utilizada para o monitoramento em tempo real da qualidade do serviço prestado.

Neste trabalho, foi realizado um experimento subjetivo de qualidade de áudio levando em consideração os requisitos da ITU-T P.800 - Methods for Subjective Determination of Transmission Quality (ITU, 1996b), norma considerada referência na execução deste tipo de teste. Nesta etapa, os sinais foram gravados por um grupo de locutores em um estúdio, tratados e organizados de maneira a serem utilizados nos experimentos. Os sinais foram então degradados de diferentes maneiras, representando situações comuns de comunicação de controle de tráfego aéreo (ATC), e posteriormente avaliados por um grupo de pessoas, a fim de se determinar o Mean Opinion Score (MOS), um índice de 1 a 5 que representa a qualidade percebida de um determinado trecho de áudio.

Em seguida, os dados obtidos no experimento subjetivo são utilizados para a avaliação de métodos objetivos existentes, entre eles o método objetivo sem referência denominado Single-Ended Speech Quality Assessment (SESQ), definido na norma ITU-T P.563 (Single-ended meth-od for objective speech quality assessment in narrow-band telephony applications) e o método com referência denominado Perceptual Evaluation of Speech Quality (PESQ), definido na norma ITU-T P.862 (Perceptual evaluation of speech quality (PESQ): An objective method for end-to-end speech quality assessment of narrow-band telephone networks and speech codecs). Foi realizada então uma análise de desempenho destes métodos de análise objetiva aplicados à sinais degradados pelos meios utilizados nas comunicações aeronáuticas. 


\subsection{CONTEXTUALIZAÇÃO}

A determinação de qualidade de voz percebida pelos usuários das telecomunicações aeronáuticas necessita do conhecimento do modo de operação do Sistema de Controle de Espaço Aéreo Brasileiro (SISCEAB), dos agentes responsáveis e das atribuições de cada um. Esta seção é dedicada à contextualização do problema.

Em um esforço para padronizar os procedimentos da aviação civil foi estabelecida em 1944 a Convenção Internacional da Aviação Civil de Chicago. Nesta Convenção foi estipulada uma legislação internacional com objetivo de promover a regulamentação da atividade aérea, com enfoque na segurança operacional. Um dos resultados deste encontro foi a criação da ICAO, órgão internacional permanente responsável pela criação e atualização de padrões e normas internacionais da aviação civil.

A Convenção de Chicago foi promulgada no Brasil em 1946 (BRASIL, 1946) para aplicação em âmbito nacional, e, conforme o Código Brasileiro de Aeronáutica (BRASIL, 1986), ficou a cargo do Comando da Aeronáutica, através do Departamento de Controle do Espaço Aéreo (DECEA), o gerenciamento e prestação dos serviços de controle de tráfego aéreo. No âmbito do Comando da Aeronáutica, foi instituído o SISCEAB, composto por diferentes órgãos e agentes cuja responsabilidade é prestar, regular e fiscalizar os serviços de tráfego aéreo no Brasil além de promover o cumprimento das normas da ICAO em âmbito nacional.

Dentre os serviços de tráfego aéreo prestados pelo SISCEAB, o que possui maior importância é o SMA. Este serviço consiste em prover um meio de comunicação entre as aeronaves que trafegam em determinado espaço aéreo e um controlador de tráfego aéreo (ATCO) situado em um órgão de controle de tráfego aéreo. As informações consistem em instruções de navegação para organização do tráfego aéreo, e conforme a normatização vigente devem ser utilizados recursos de comunicação de maneira a garantir maior probabilidade de sucesso nas tentativas de comunicação. Nas seções seguintes serão apresentadas a estrutura operacional do SMA e as soluções técnicas utilizadas para a prestação deste serviço.

\subsubsection{ESTRUTURA OPERACIONAL DO SMA}

Os agentes do SMA, conforme definido pela ICAO e suas respectivas funções são: Torre (TWR), que presta serviços de navegação de aeronaves em processos de pouso e decolagem, em trânsito nos pátios e pistas dos aeródromos; Centro de Controle de Aproximação (APP), responsável pela prestação de serviços de navegação em instantes posteriores à decolagem e que precedem o pouso, com área de cobertura de aproximadamente 40 milhas náuticas de 
distância do aeródromo; Centro de Controle de Área (ACC), que presta serviços de navegação para aeronaves em rota, entre as áreas de atuação dos APP. A Figura 1 apresenta a disposição dos agentes do SMA e suas regiões de responsabilidade, conforme definição da ICAO.

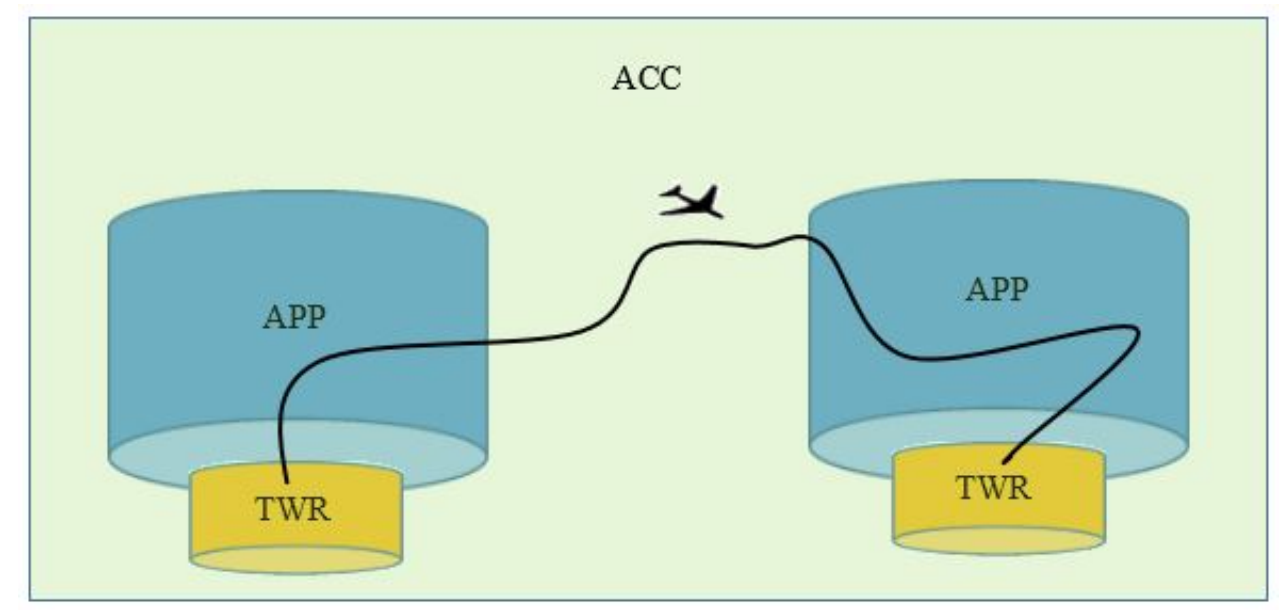

Figura 1: Representação dos agentes do SMA

Conforme pode ser observado na Figura 1, TWR e APP operam no espaço aéreo imediatamente próximo aos aeródromos, onde normalmente são localizadas os equipamentos de telecomunicações responsáveis pelos serviços de voz destes agentes. Em contrapartida, as áreas de atuação dos ACC englobam todo o espaço aéreo sob sua responsabilidade. Levando em consideração que a extensão do território nacional é superior a 8,5 milhões de quilômetros quadrados, que a área de controle supera 22 milhões de quilômetros quadrados, e a concentração de tráfego aéreo nos principais centros urbanos do país, foram constituídos dezenas de órgãos de controle de tráfego aéreo, entre TWR, APP e ACC. A Figura 2 apresenta a área de controle de espaço aéreo sob jurisdição do SISCEAB, bem como sua divisão em regiões de informação de vôo (FIR sob a responsabilidade de cada um dos 5 ACC que o compõem.

O Centro de Controle de Área de Brasília (ACC-BS), localizado na cidade de Brasília tem responsabilidade sobre a FIR Brasília, o Centro de Controle de Área de Brasília (ACC$\mathrm{CW}$ ), sediado em Curitiba atua sobre a área da FIR Curitiba. Já o Centro de Controle de Área de Recife (ACC-RF) e o Centro de Controle de Área do Atlântico (ACC-A0) são sediados em Recife e atuam sobre as áreas da FIR Recife e FIR Atlântico. O Centro de Controle de Área de Manaus (ACC-AZ), localizado em Manaus tem responsabilidade sobre a FIR Amazônica, conforme identificado na Figura 2. As áreas de atuação podem ser eventualmente modificadas, e por esta razão, são disponibilizadas pelo Instituto de Cartografia da Aeronáutica (ICA) aos aeronavegantes através de cartas de navegação aérea.

Ainda, de maneira a possibilitar a distribuição de tráfego aéreo entre os operadores 


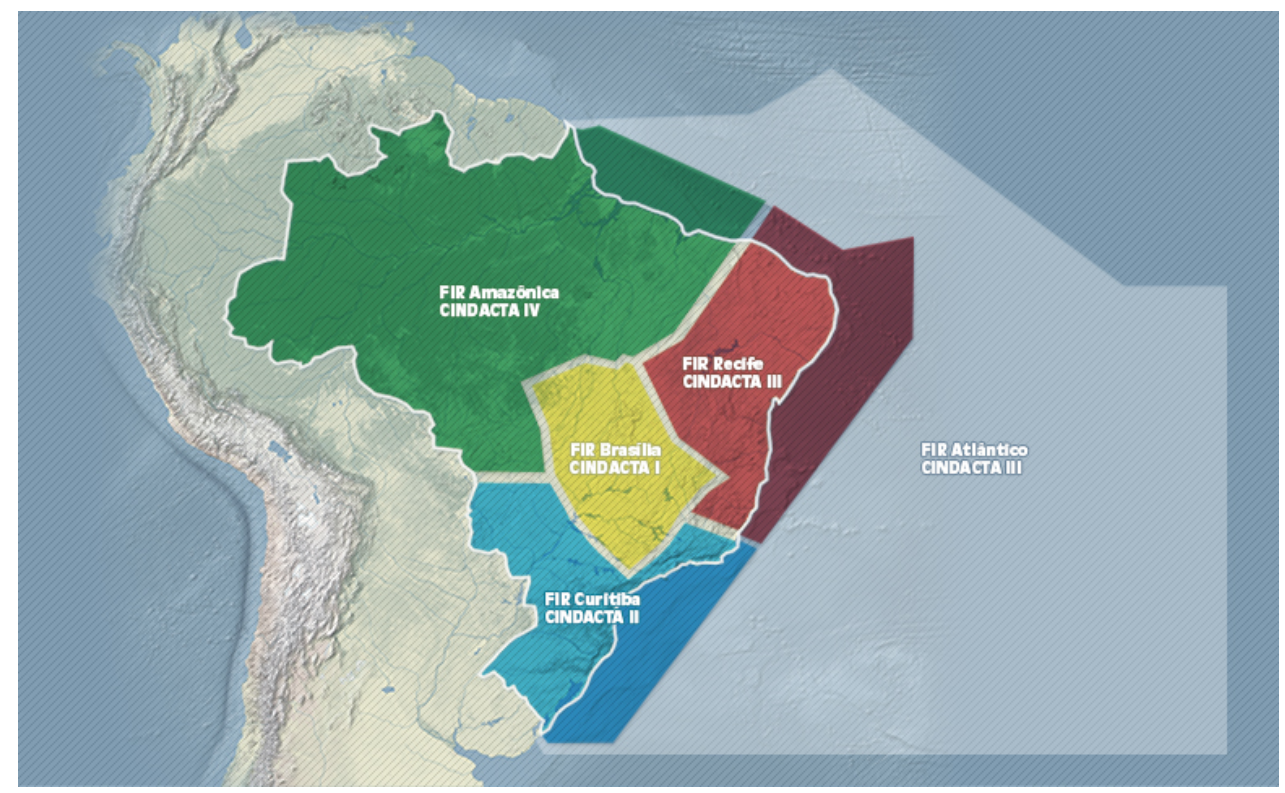

Figura 2: Área de controle de tráfego aéreo no Brasil e regiões de responsabilidade dos ACC Fonte: (DECEA, 2016)

e de maneira a otimizar os recursos de telecomunicações, as áreas de abrangência dos ACC são subdivididas em setores. Para o caso do ACC-CW, objeto de estudo desta Dissertação, o espaço aéreo foi subdividido em 12 setores, abrangendo as regiões Sul, Sudeste e Centro-Oeste do Brasil.

\subsubsection{ASPECTOS TÉCNICOS DA PRESTAÇÃO DO SMA}

Os requisitos técnicos para prestação do SMA são definidos na parte II do Anexo 10 da ICAO (ICAO, 1996), incluindo a especificação de que todas as comunicações por voz deverão ser realizadas em amplitude modulada (AM), com portadora e banda lateral dupla (DSB), em half-duplex, na faixa de espectro de VHF entre 117 e 137 MHz e que a potência radiada dos transmissores em solo deverá ser tal a alcançar um campo elétrico mínimo de 75 microvolts por metro $\left(-109 \mathrm{~dB} / \mathrm{m}^{2}\right)$ em toda a área de cobertura. A comunicação deverá ser bilateral (nos sentidos controlador-aeronave e aeronave-controlador). Este documento define ainda as separações de canal, fatores de modulação, especificações de receptores de solo, transceptores de aeronaves, características de imunidades a interferências, entre outros.

A ICAO determina ainda que para cada setor de controle de tráfego aéreo (seja em TWR, APP ou ACC) sejam atribuídos dois valores de frequência, sendo uma frequência primária (ou principal) e uma secundária (ou de reserva). Tal especificação se deve à criticidade de aplicação de maneira que, em caso de indisponibilidade de uma frequência, a comunicação 
possa ser realizada através de outra.

Sendo assim, quando uma aeronave necessita entrar em contato com um controlador, o piloto sintoniza uma das frequências atribuídas ao setor em que se encontra, aciona o comando de liberação da portadora (PTT) e inicia a fala. O sinal é transmitido em VHF pelo transceptor de bordo e recebido através de uma estação em terra, que será sensibilizada quando o nível de potência de sinal superar -110 dBW, e encaminhará a transmissão ao operador responsável. No caminho inverso, caso um ATCO tente comunicação com uma aeronave, o mesmo aciona o PTT e o sinal é transmitido em VHF através de uma das estações em terra. Convém registrar que as estações de VHF em terra possuem transmissores e receptores sintonizados em ambas as frequências designadas para cada setor, de maneira que a comunicação controlador-aeronave poderá ser realizada independente do canal sintonizado pelo piloto.

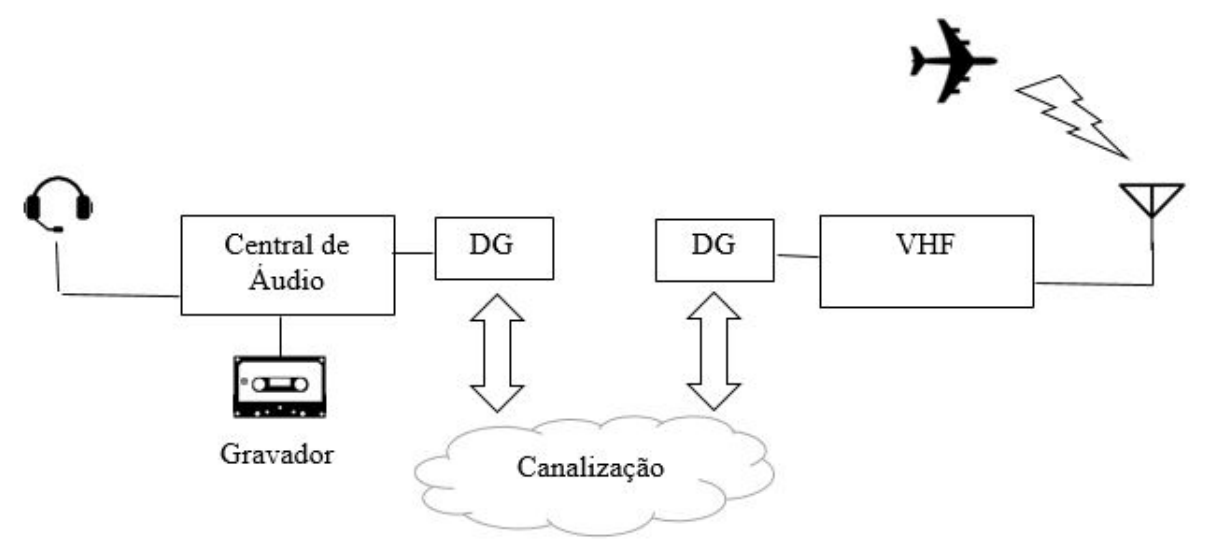

Figura 3: Diagrama de blocos simplificado da solução tecnológica utilizada para prestação do SMA. O sinal de voz percorre diversos equipamentos desde o avião até a console de controle do ATCO.

A Figura 3 apresenta um diagrama de blocos simplificado da solução técnica para prestação do SMA, mostrando os principais equipamentos envolvidos na comunicação, entre eles: sistemas de irradiação, receptores/demoduladores de VHF, distribuidores gerais (DG), equipamentos pertencentes às operadoras de telecomunicações, central de áudio, gravadores, entre outros. Os sinais recebidos são todos encaminhados aos centros de controle, através de diferentes canalizações disponíveis, entre estas: satélite, radio-enlaces, comunicações contratadas, em banda base (sinais analógicos), Voice Over IP (VOIP) (ainda em teste), etc.

Para o caso de TWR e APP, que possuem abrangência operacional em área próxima aos aeródromos, geralmente é utilizada apenas uma estação de transmissão/recepção em solo para a prestação do SMA. Porém, conforme foi verificado na Seção 1.1.1, os setores do ACC abrangem um extenso volume de espaço aéreo controlado. Por este motivo e devido às limitações 
tecnológicas e físicas das radio-comunicações, para o caso dos setores do ACC, normalmente são necessárias duas ou mais estações de radiodifusão em solo para garantir a cobertura necessária à prestação do SMA.

Como exemplo, a figura 4 mostra as estações de comunicação que prestam o SMA no setor 7 do ACC-CW. São utilizadas 5 estações para abranger a cobertura deste setor, cujos diagramas teóricos de irradiação se interceptam em diferentes pontos. A transmissão é realizada utilizando-se um pequeno desvio da frequência da portadora (offset) diferente em cada uma das estações próximas, possibilitando reduzir os efeitos de interferências entre as mesmas. Entretanto, a recepção pode ocorrer simultaneamente em todas as estações.

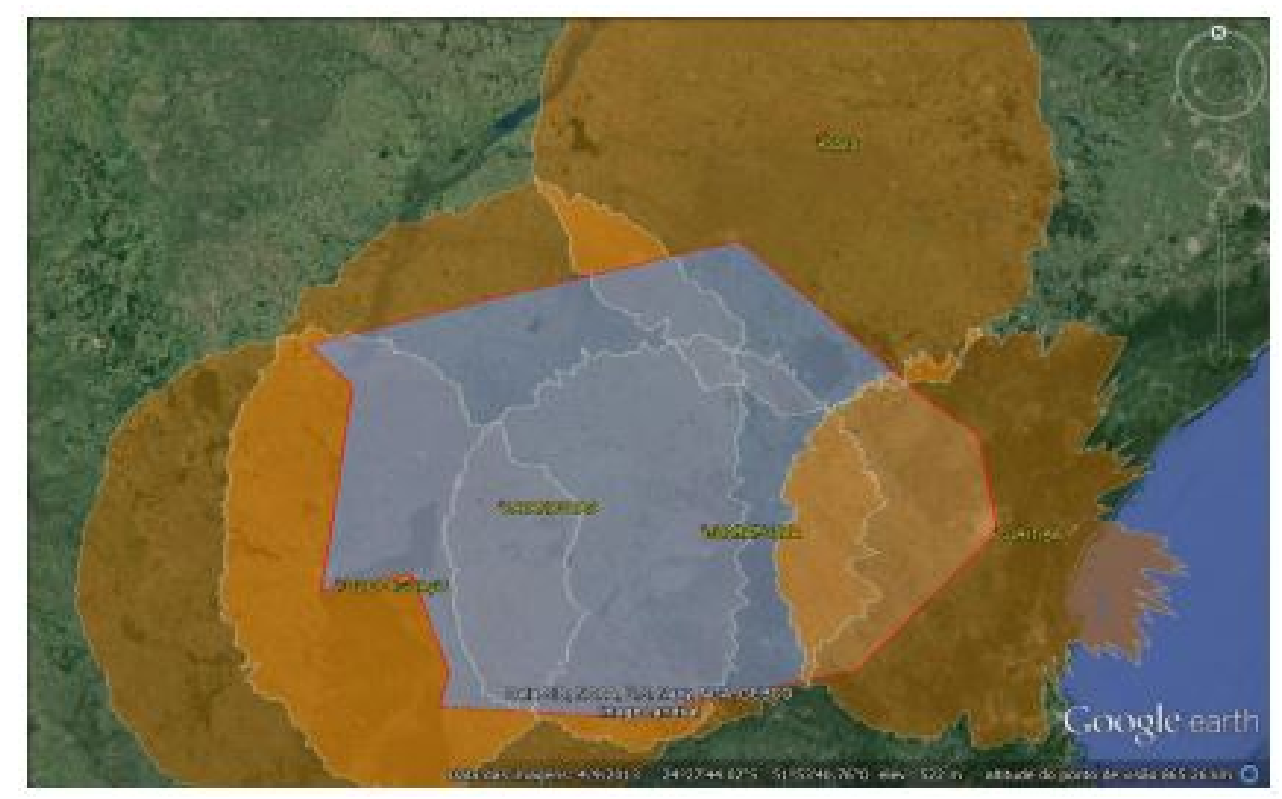

Figura 4: Diagrama de irradiação teórico de estações de telecomunicações do SMA, evidenciando intersecção das coberturas (ACC-CW, setor 7)

Observam-se situações em que os sinais provenientes de uma aeronave são recebidos simultaneamente por até 4 estações de telecomunicações. No ACC deve ser selecionado o melhor sinal e este encaminhado ao controlador responsável, atividade esta, que é realizada por um equipamento denominado Central de Áudio, por meio de um hardware proprietário, ou manualmente pelo ATCO.

Ainda sobre os requisitos técnicos do SMA, a ICAO em seu Anexo XXI (ITU, 2001a) recomenda o registro e o armazenamento de todas as mensagens de coordenação realizadas entre as aeronaves e os ATCO. Tal prática se deve à necessidade de rastrear possíveis causas de eventuais acidentes ou incidentes. Cabe ressaltar, no entanto que, no sentido de comunicação piloto - ATCO, o sinal de referência, ou seja a gravação da voz captada antes de ser transmitida pelo piloto, embora normalmente gravado na aeronave, só é disponibilizado aos órgãos compe- 
tentes em caso de incidentes ou acidentes aéreos. No sentido inverso de comunicação (ATCO piloto), o sinal de referência é gravado nos ACC, porém o sinal distorcido dificilmente pode ser obtido pois, novamente, será armazenado pelas aeronaves. Dessa maneira, somente são disponibilizados nos ACC os sinais de referência (gravados antes de serem transmitidos) no sentido ATCO - aeronaves e os sinais distorcidos captados no sentido piloto - ATCO.

Dada esta dificuldade de obtenção dos sinais de referência das aeronaves, este estudo também buscou analisar o desempenho de métodos sem referência, cuja aplicação no SMA seria facilitada.

\subsubsection{MODO DE OPERAÇÃO DO SMA}

Antes de iniciar a viagem, os aeronavegantes devem apresentar um plano de vôo ao DECEA. Neste plano de vôo devem ser fornecidos, dentre outras informações importantes, os aeródromos de partida, destino, e a rota a ser utilizada. Com base na aprovação do plano proposto, o aeronavegante deve consultar as cartas de navegação pertinentes a cada etapa do vôo, desde a decolagem, vôo em rota, aproximação para pouso e pouso.

Numa carta de vôo de determinado aeródromo, verifica-se que, junto às primeiras informações fornecidas estão as frequências de Automatic Terminal Information Service ou de serviço de mensagens gravadas do terminal (ATIS), APP, TWR e GNDC.

Assim no caso de vôo que parte, por exemplo, do Aeroporto Afonso Pena, em $\mathrm{Cu}$ ritiba - PR, o piloto sintonizará uma das frequências indicadas da TWR-CW e realizará as comunicações necessárias com este órgão operacional. Assim que a aeronave deixa o espaço aéreo controlado pela TWR e entra no espaço aéreo de controle do APP, o ATCO da TWR transfere o tráfego ao controlador do APP, e fornece ao piloto a frequência de APP a ser utilizada a partir daquele ponto. O APP assume então o controle do tráfego e passa a monitorar e a coordenar os procedimentos da aeronave. De maneira análoga, ao deixar o espaço aéreo do APP e adentrar a área de controle do ACC, quando a aeronave se encontrar em rota, o ATCO desse órgão coordena o tráfego com o controlador do respectivo setor do ACC e passa a frequência a ser sintonizada pelo piloto para o próximo estágio do seu vôo.

Na medida em que a aeronave evolui nos setores do ACC, o tráfego vai sendo transferido e novas frequências são fornecidas aos aeronavegantes, passando pelo APP de destino e, finalmente, a TWR de destino.

Quanto à utilização das comunicações VHF no SMA, convém ainda identificar alguns procedimentos adotados: 
1. Pelas Aeronaves: Caso exista algum problema de comunicação, a aeronave pode adotar o uso de outro canal atribuído ao setor (conforme definido nas cartas de navegação). A comunicação será possível tendo em vista a existência de receptores em terra sintonizados em todas as frequências do setor, conforme tratado na seção 1.1.2. Vale ressaltar que independente da frequência escolhida, a transmissão e recepção da aeronave ocorre através de um único canal;

2. Pelos ATCO: Como as estações em terra possuem transmissores sintonizados em todas as frequências de determinado setor, os ATCO podem transmitir simultaneamente as instruções através dos dois canais designado para o setor. Dessa maneira, os sinais transmitidos pelos ATCO são captados pelas aeronaves de determinado setor, independentemente do canal em uso pelas mesmas. No entanto, os ATCO priorizam manter todas as aeronaves de determinado setor em um mesmo canal VHF, tendo em vista que este procedimento favorece a segurança operacional e permite que todas fiquem cientes do tráfego existente.

\subsection{MOTIVAÇÃO}

Diante do exposto e considerando que as degradações dos sinais de áudio prejudicam a inteligibilidade do diálogo entre os controladores e os pilotos das aeronaves, pode-se afirmar que a qualidade de voz é essencial para a segurança de operação do SMA. Atualmente a identificação de problemas de qualidade de áudio baseia-se em reclamações realizadas diretamente pelos controladores ao setor responsável pelas canalizações, que deve prontamente identificar e corrigir os problemas. No entanto, não há indicadores quantitativos do nível de qualidade percebida pelos usuários (seja piloto ou ATCO), o que motivou a realização de um experimento subjetivo, embasado em normatização atual da ITU, para avaliar a percepção dos usuários sobre o serviço.

Além disso, essa metodologia exige resposta reativa da equipe técnica aos problemas apresentados, dificultando uma análise mais apurada de degradações recorrentes e a percepção de tendências de longo prazo. Nesse contexto, foi avaliado o desempenho de métodos de análise objetiva na avaliação de sinais degradados pelos meios de comunicação de ATC. O uso de um método objetivo eficaz poderia auxiliar na identificação de tendências de degradação de um determinado canal antes de que o mesmo se torne inutilizável e na realização de um levantamento estatístico a fim de se classificar os canais de áudio conforme a qualidade de áudio obtida.

Devido às características técnicas de implantação do SMA, há dificuldade em se obter 
os sinais de referência transmitidos pelas aeronaves para realização de análises comparativas. Por este motivo, além do PESQ, considerada uma técnica consagrada de análise com referência, serão estudadas técnicas de análise de sinais sem referência, também denominados de métodos não invasivos.

\subsection{OBJETIVOS}

\subsubsection{OBJETIVO GERAL}

Avaliar o desempenho dos sistemas de comunicações aeronáuticas, quanto à qualidade de voz percebida pelos usuários, através da realização de ensaio subjetivo, e métodos de análise objetiva (PESQ e SESQ), envolvendo pelo menos as seguintes situações: comunicação terraterra, entre órgãos de controle de tráfego aéreo, comunicações terra-ar e ar-terra entre aeronaves e os órgãos de controle de tráfego aéreo.

\subsubsection{OBJETIVOS ESPECÍFICOS}

- Planejar um experimento de análise subjetiva de qualidade de áudio em telecomunicações aeronáuticas com base na norma ITU-T P.800 e aprová-lo junto ao Comitê de Ética da UTFPR (CEP);

- Gravar uma lista de sinais de referência para uso no experimento subjetivo;

- Realizar o processamento dos sinais de referência conforme definições normatizadas;

- Realizar experimentos de campo, submetendo os sinais de referência às situações de comunicação do SMA e realizando gravações nos trajetos aeronave-solo e solo-aeronave;

- Aplicar os sinais gravados e de referência a um grupo de pessoas para realizar a avaliação subjetiva;

- Calcular resultados do experimento subjetivo e consolidar base de dados do experimento para uso em atividades futuras;

- Submeter os sinais degradados aos métodos com referência e sem referência definidos, respectivamente, pelas normas ITU-T P.862 (PESQ) e ITU-T P.563 (SESQ);

- Avaliar o desempenho dos métodos objetivos utilizando como referência, a base de dados de MOS obtidos do experimento subjetivo; 
Para melhor entendimento dos objetivos e métodos do estudo, foi elaborado o diagrama da Figura 5 incluindo as principais atividades desempenhadas.

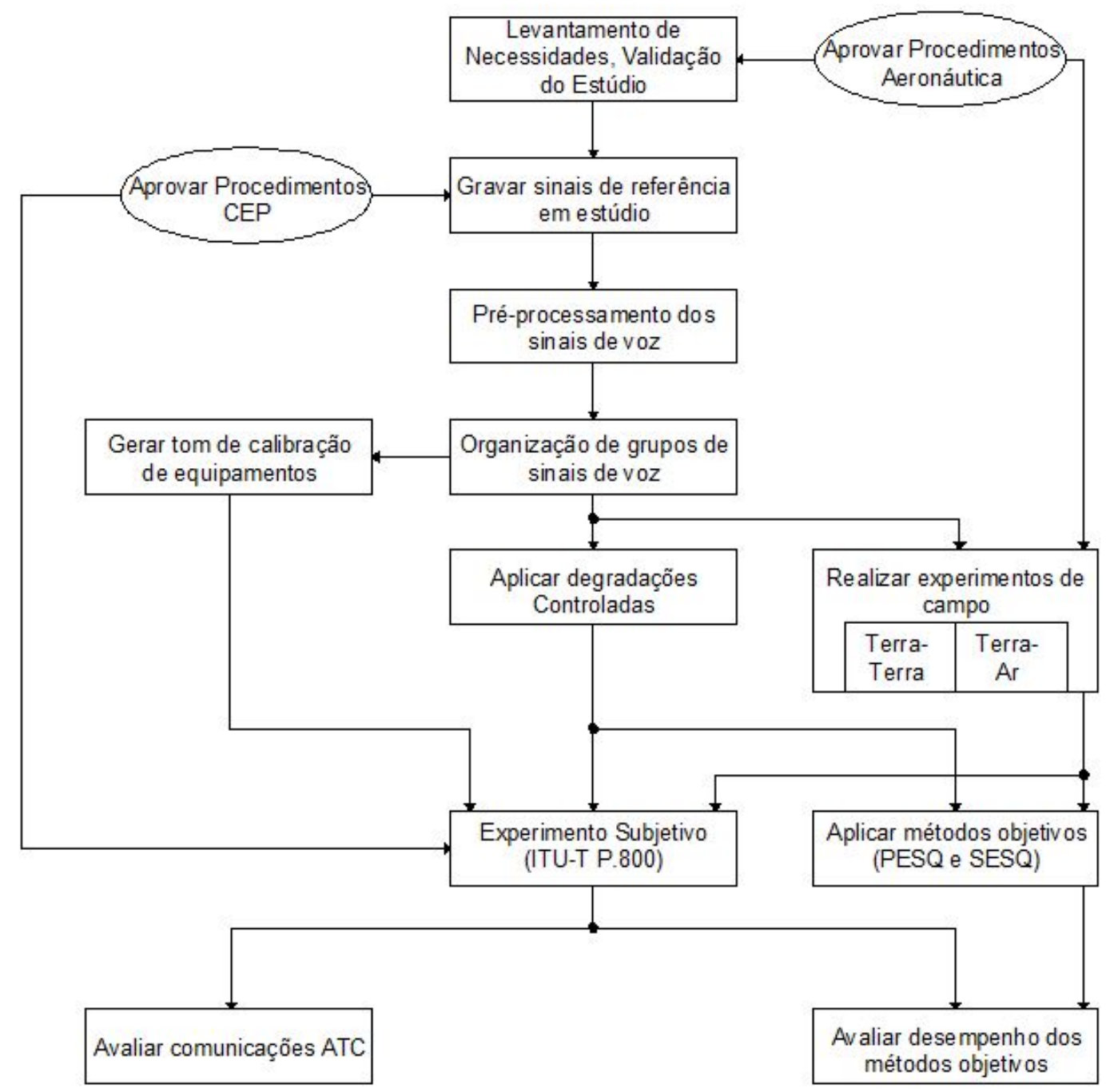

Figura 5: Diagrama de objetivos e etapas do estudo

\subsection{ESTRUTURA DA DISSERTAÇÃO}

Esta Dissertação possui outros 5 capítulos. Os cápítulos 2, 3, 4 e 5 apresentam as etapas desempenhadas neste estudo, cada um contendo, quando aplicável, a sua revisão de literatura pertinente, metodologia utilizada e resultados.

O capítulo 2 apresenta os ensaios preliminares realizados na validação das salas de gravação utilizadas, gravações dos sinais de voz de referência, pré-processamentos exigidos pelas normas aplicadas. O capítulo 3 detalha a realização dos testes nos meios de telecomunicações aeronáuticas, incluindo ensaios com aeronaves e as degradações controladas aplicadas aos sinais gravados. Já o capítulo 4 se dedica à análise subjetiva da qualidade dos áudios obtidos nos 
testes e apresentação dos resultados.

O cápítulo 5 apresenta a análise objetiva através do PESQ e do SESQ dos sinais de áudio de voz e faz uma avaliação de desempenho destes métodos na previsão da qualidade de áudio percebida pelos usuários. Finalmente, o capítulo 6 apresenta as conclusões e trabalhos futuros sugeridos a partir deste estudo. 


\section{GERAÇÃO DE ESTÍMULOS - GRAVAÇÃO DOS SINAIS DE VOZ}

Este Capítulo apresenta a metodologia utilizada na obtenção das gravações de áudio e pré-processamentos de sinais, necessários aos testes dos sistemas de telecomunicações aeronáuticas e à realização dos ensaios subjetivos. São mostrados os componentes de aquisição bem como explicando o funcionamento dos métodos desenvolvidos para os testes e apresentados os resultados iniciais dos processamentos.

Nesta pesquisa foi necessária a realização de um experimento subjetivo de qualidade de áudio a fim de avaliar o desempenho dos meios de telecomunicações de ATC. Este experimento envolveu a gravação de sinais de áudio de voz em estúdio, o processamento destes sinais por métodos de referência e por outros métodos sob avaliação. Para tal, foram adotados os requisitos e procedimentos estabelecidos na ITU-T P.800 (ITU, 1996b), descrita com maior detalhamento no capítulo 4 desta dissertação.

De maneira a verificar a viabilidade de execução deste experimento, precisou ser realizado primeiramente um levantamento de equipamentos, materiais e recursos necessários. Estes levantamentos são apresentados na seção 2.1 .

Já a seção 2.2 traz os procedimentos, métodos utilizados e resultados obtidos da validação das salas de gravação, enquanto a seção 2.3 detalha os procedimentos de gravação empregados e a seção 2.4 dedica-se aos procedimentos de pré-processamento e escolha de áudios empregados neste trabalho.

\subsection{NECESSIDADES DE EQUIPAMENTOS E RECURSOS}

Primeiramente, foi necessária a avaliação dos recursos necessários à execução da avaliação subjetiva. Foram avaliados os requisitos de materiais, recursos, equipamentos e infraestrutura necessários para a condução do experimento, conforme recomendações da ITU-T P.800 (ITU, 1996b), e/ou das solicitações realizadas pelo CEP. O estúdio utilizado possui infraestrutura e equipamentos bastante superiores às exigências normatizadas. O Anexo A traz as 
informações de todos os equipamentos e principais recursos utilizados na avaliação subjetiva, suas principais especificações, marca, modelo e motivo de utilização.

\subsection{VALIDAÇÃO DAS SALAS DE GRAVAÇÃO}

Foi verificada a necessidade de verificar se as salas do estúdio utilizado atendiam às condições recomendadas pela norma ITU-T P.800 utilizada na elaboração dos testes subjetivos. O primeiro requisito diz respeito à reverberação das salas, normatizado em no máximo 500 ms, e o segundo quanto ao ruído ambiente, que deve ser inferior a $30 \mathrm{dBA}$. Os dois requisitos foram analisados através de medições descritas nesta seção.

\subsubsection{MEDIÇÃO DE REVERBERAÇÃO DAS SALAS}

O estúdio possui duas salas que foram utilizadas para a realização dos testes subjetivos. A sala principal (Sala de gravação) possui volume de $91 \mathrm{~m}^{3}$ e possui reverberação estimada pelo projetista na faixa de 300 a 400 ms. Estúdios de gravação precisam de certa quantidade de reverberação / reflexão de áudio para que seja possível uma maior flexibilidade de gravação com possibilidade de captações em posições diferentes.

Outra sala disponível é a Sala de Conveniência do estúdio, com volume de 75,3 $\mathrm{m}^{3}$ que foi projetada levando em consideração requisitos de salas de cinema, que possuem maior absorção de som. Foi projetada para obter níveis de 200 a 300 ms de reverberação.

De maneira a atestar as informações estimadas pelo projetista, foi elaborado um ensaio de reverberação levando em consideração os principais requisitos na norma ISO 3382 (Acoustics - Measurement of room acoustic parameters - Part 2: Reverberation time in ordinary rooms) (ISO, 2008). Foi utilizado o método de resposta ao impulso, que depende do uso de uma fonte de áudio na forma de um delta de Dirac. Embora impossível obtê-lo na prática, existem aproximações adequadas do impulso para a aplicação, como o uso de armas de fogo, ou outras fontes de som abruptas.

O seguinte procedimento foi utilizado:

1. Foram enchidos 14 balões de plástico $n^{\circ} 9$, para cada ensaio. O estouro dos balões foi utilizado como fonte de sinal de impulso para o ensaio;

2. Foram distribuídas aleatoriamente 6 posições para a locação da fonte de sinal na sala. As posições da fonte de sinal se localizam há mais de um metro das paredes da sala e 
foram devidamente registradas, conforme as Figuras 6 e 7, para a Sala de Conveniência e as Figuras 8 e 9 para o Estúdio Principal. A posição vertical das fontes de sinal foi estabelecida em $1,20 \mathrm{~m}$;

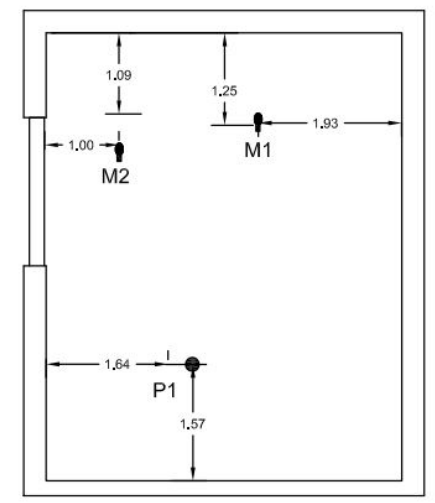

PONTO 1

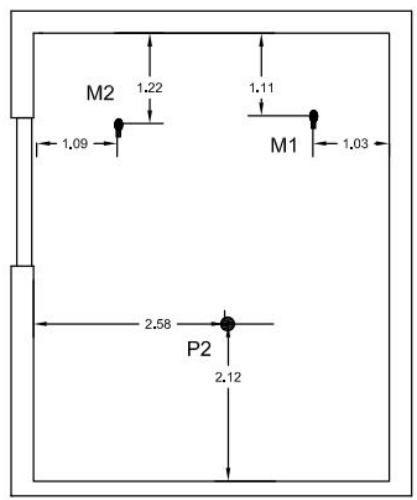

PONTO 2

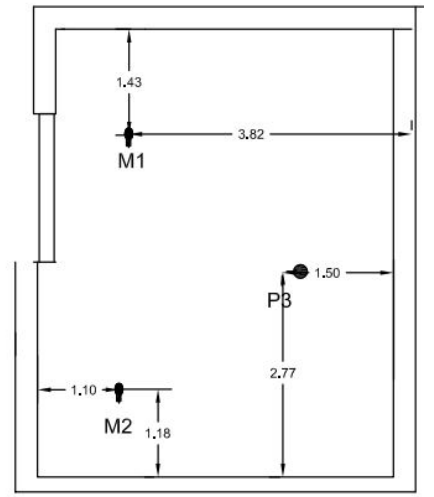

PONTO 3

Figura 6: Disposição de fonte de impulso e captação do ensaio de reverberação, posições 1,2 e 3 na Sala de Conveniência. P1, P2, P3 correspondem aos pontos de aplicação do impulso e M1, M2 os locais de instalação dos microfones de captação

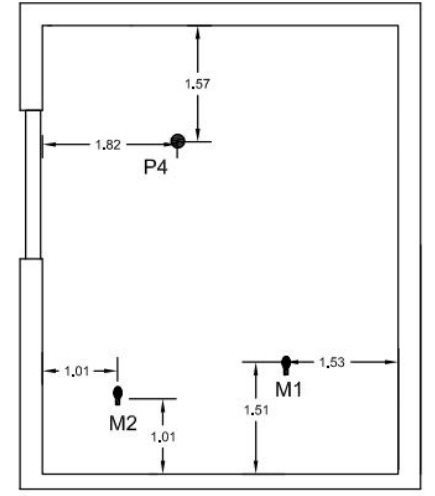

PONTO 4

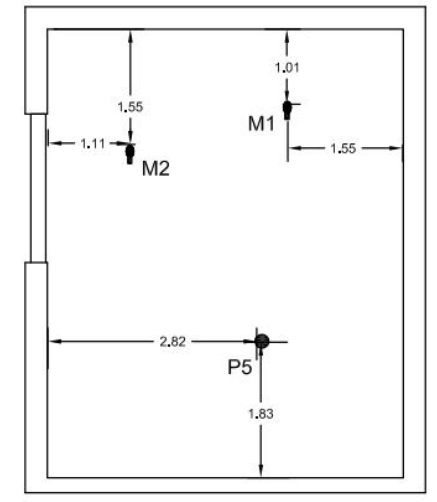

PONTO 5

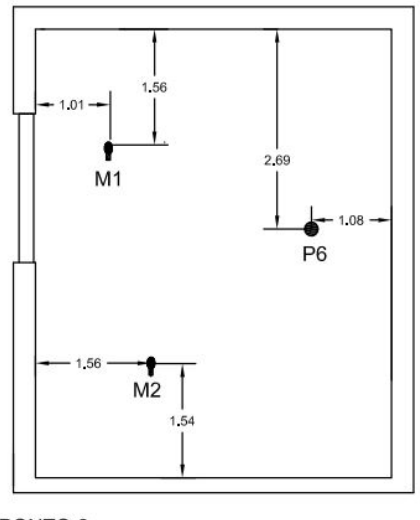

PONTO 6

Figura 7: Disposição de fonte de impulso e captação do ensaio de reverberação, posições 4,5 e 6 na Sala de Conveniência. P4, P5, P6 correspondem aos pontos de aplicação do impulso e M1, M2 os locais de instalação dos microfones de captação

3. Para cada uma das posições de fonte de sinal, foram atribuídas duas posições de captação (locação do microfone). A distância mínima do microfone foi calculada usando a expressão 12 em que $V$ é o volume da sala em $m^{3}, c$ a velocidade do som em $m / s$ e $T$ a reverberação estimada para a sala, em segundos. Utilizando $\mathrm{V}=91 \mathrm{~m}^{2}$, c é $340 \mathrm{~m} / \mathrm{s}$ e T é estimado em $0,2 \mathrm{~s}$. Foi encontrado o valor mínimo de $2,2 \mathrm{~m}$. Foi utilizado então a distância de 3 metros. A posição vertical do captador foi estipulada em 1,2 metro;

$$
\operatorname{dmin}=2 \cdot \sqrt{\frac{V}{c . T}}
$$




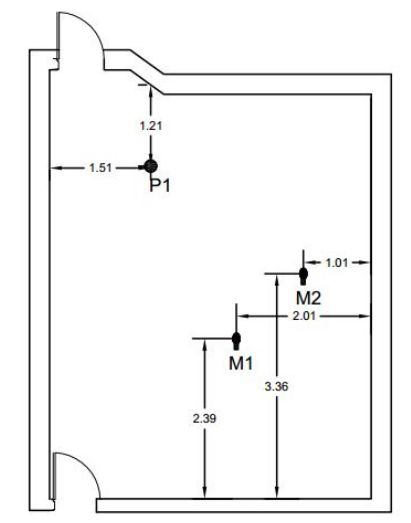

PONTO 1

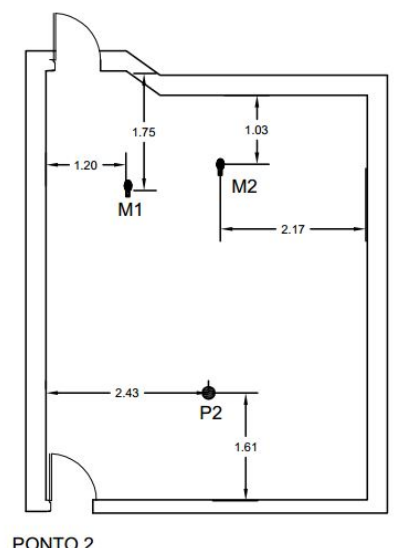

PONTO 2

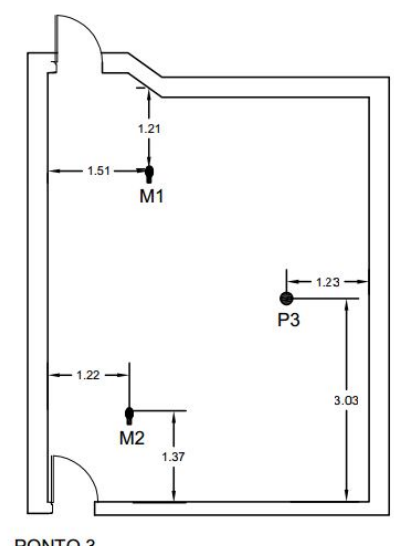

PONTO 3

Figura 8: Disposição de fonte de impulso e captação do ensaio de reverberação, posições 1,2 e 3 no Estúdio Principal. P1, P2, P3 correspondem aos pontos de aplicação do impulso e M1, M2 os locais de instalação dos microfones de captação

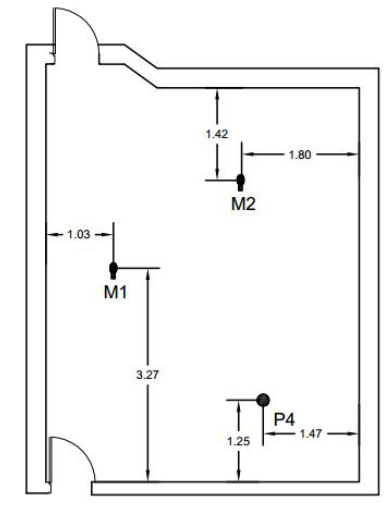

PONTO 4

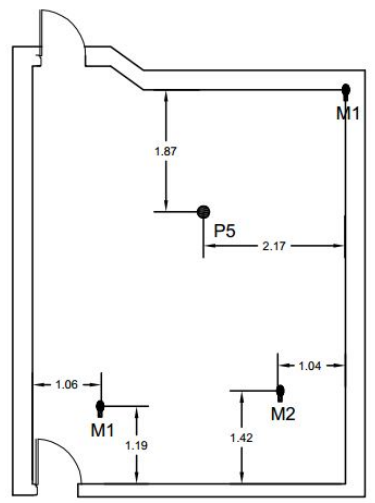

PONTO 5

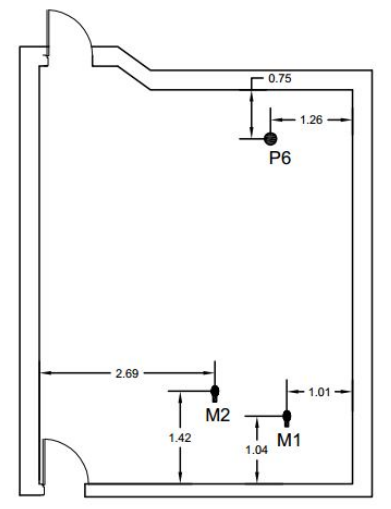

PONTO 6

Figura 9: Disposição de fonte de impulso e captação do ensaio de reverberação, posições 4,5 e 6 no Estúdio Principal. P4, P5, P6 correspondem aos pontos de aplicação do impulso e M1, M2 os locais de instalação dos microfones de captação

4. Foi utilizado sistema de captação formado por um microfone Neumann U87. Para o ensaio na sala principal, foi utilizado sistema de tratamento composto por pré-amplificador de microfone linear Universal Audio LA-610 MKII, enquanto na Sala de Conveniência foi utilizado o pré-amplificador de microfone linear AVid HD Omni. Foi utilizado sistema de gravação composto por conversor analógico-digital Lynx Studio Aurora 16, ajustados para precisão de 16 bits e taxa de amostragem de 44,1 kHz. As especificações completas dos equipamentos utilizados podem ser encontradas no Anexo A.

5. O microfone e demais componentes foram conectados e os sistemas de captação e gravação foram colocados em funcionamento por pelo menos 15 minutos antes do início das gravações;

6. O microfone foi posicionado em pedestal na altura requerida e foi realizado estouro de um 
balão, a distância de três metros da captação, em altura de 1,20 m e com o bico do balão virado na direção oposta ao microfone. O balão foi estourado por meio de dispositivo perfurante para realização da calibração de ajuste de nível, de maneira a evitar a saturação dos sistemas de captação, tratamento e gravação;

7. Para cada conjunto de posições P-M indicadas nas Figuras 6, 7, 8 e 9 foi realizado estouro de balão e gravação do sinal captado;

8. Foram registrados os seguintes móveis e objetos no Estúdio Principal: 5 caixas de som posicionadas na parede, tapete com dimensões aproximadas de 2,2 $\mathrm{m}$ de largura e 3,6 m de comprimento. Uma pessoa ocupou a sala durante os ensaios.

9. Foram registrados os seguintes móveis e objetos na Sala de Conveniência: sofá de 3 lugares, duas poltronas simples, móvel de televisão, mesa de centro, tapete. Os móveis mencionados pertencem à sala e não foram removidos nas sessões posteriores de gravação/ reprodução de áudio.

10. Foi registrado no estúdio principal temperatura de $23,5^{\circ} \mathrm{C}$ e umidade relativa de $56 \% U R$. $\mathrm{Na}$ Sala de Conveniência foi registrada temperatura de $25,7^{\circ} \mathrm{C}$ e umidade relativa de 67 $\%$ UR.

11. Realizada a calibração de ganho do microfone, os testes foram iniciados. Para cada conjunto de posição de fonte de sinal - captador, o gravador foi habilitado, o operador do sistema de gravação informava sinalizava indicando que o sistema estava pronto. Um balão era estourado em posição horizontal, com o seu fecho virado em direção oposta ao do microfone. O registro de som foi interrompido cerca de três segundos após as explosões.

Dessa maneira, foram obtidos 24 sinais de áudio, sendo 12 oriundos da Sala Principal e outros 12 da Sala de Conveniência. A Tabela 1 mostra a posição da fonte de áudio e a posição da captação para cada arquivo de áudio gravado, para o Estúdio Principal, enquanto a Tabela 2 mostra estas informações para a Sala de Conveniência, conforme as Figuras 6 a 9. Os sinais foram alinhados no domínio do tempo utilizando a ferramenta PROTOOLS e todos os áudios foram editados para que ficassem com duração de $1 \mathrm{~s}$ (44.100 amostras). Os sinais foram armazenados em formato Waveform Audio File Format (WAV) para processamento posterior utilizando a ferramenta MATLAB.

Para processamento foi utilizado o método de medida direta de tempo de decaimento (ISO, 2008), calculando-se o envelope de cada sinal de áudio sincronizado no tempo, e anali- 
Tabela 1: Posições da fonte de áudio e da captação para cada arquivo gravado - Estúdio Principal Nome do arquivo Posição da Fonte de Sinal Posição do Microfone

$\begin{array}{lll}\text { POS 1.wav } & \text { P1 } & \text { M1 } \\ \text { POS 2.wav } & \text { P1 } & \text { M2 } \\ \text { POS 3.wav } & \text { P2 } & \text { M1 } \\ \text { POS 4.wav } & \text { P2 } & \text { M2 } \\ \text { POS 5.wav } & \text { P3 } & \text { M1 } \\ \text { POS 6.wav } & \text { P3 } & \text { M2 } \\ \text { POS 7.wav } & \text { P4 } & \text { M1 } \\ \text { POS 8.wav } & \text { P4 } & \text { M2 } \\ \text { POS 9.wav } & \text { P5 } & \text { M1 } \\ \text { POS 10.wav } & \text { P5 } & \text { M2 } \\ \text { POS 11.wav } & \text { P6 } & \text { M1 } \\ \text { POS 12.wav } & \text { P6 } & \text { M2 }\end{array}$

Tabela 2: Posições da fonte de áudio e da captação para cada arquivo gravado - Sala de Conveniência

\begin{tabular}{ccc}
\hline Nome do arquivo & Posição da Fonte de Sinal & Posição do Microfone \\
POSA 1.wav & P1 & M1 \\
POSA 2.wav & P1 & M2 \\
POSA 3.wav & P2 & M1 \\
POSA 4.wav & P2 & M2 \\
POSA 5.wav & P3 & M1 \\
POSA 6.wav & P3 & M2 \\
POSA 7.wav & P4 & M1 \\
POSA 8.wav & P4 & M2 \\
POSA 9.wav & P5 & M1 \\
POSA 10.wav & P5 & M2 \\
POSA 11.wav & P6 & M1 \\
POSA 12.wav & P6 & M2 \\
\hline
\end{tabular}

sando o tempo para que o distúrbio seja absorvido pelas superfícies da sala. É então calculada a média dos envelopes, resultando no sinal médio de decaimento. Esse sinal é então convertido para a escala logarítmica, passando a ser representado em decibéis.

Foram ajustados dois polinômios de terceiro grau que apresentam menor erro quadrático médio em relação aos sinais medidos. O sinal foi então filtrado com filtro em oitavas de 125 $\mathrm{Hz}, 250 \mathrm{~Hz}, 500 \mathrm{~Hz}, 1 \mathrm{kHz}, 2 \mathrm{kHz}$ e $4 \mathrm{kHz}$ e, para cada uma das respostas filtradas foi estimado o tempo de decaimento entre $-5 \mathrm{~dB}$ e $-25 \mathrm{~dB}$, determinando o indicador normatizado RT20, definido como tempo necessário para que o sinal de impulso decaia 20 dB. O RT60 é obtido por extrapolação, multiplicando-se por três o RT20, e é definido como o tempo necessário para que o sinal de impulso decaia $60 \mathrm{~dB}$. Foi utilizado, para o processamento dos sinais adquiridos, um algoritmo elaborado em ambiente do software MATLAB. 
Foi utilizado o método de medição direta de tempo de reverberação, que é recomendado pela ISO 3382 (ISO, 2008) apenas para ensaios de menor precisão. Embora a explosão de balões não possa considerada um sinal de impulso omnidirecional, conforme verificado em (PATYNEN; LOKKI, 2011), esta representa uma boa aproximação dentro de determinadas circunstâncias. Uma medição mais rigorosa poderia ser obtida, por exemplo, utilizando fontes de som específicas para a aplicação e aplicando uma sequência de pulsos pseudo-aleatórios do tipo "Sequência de Comprimentos Máximos"(MLS), calculando-se, em seguida, a correlação cruzada para se obter a resposta ao impulso (BURT, 1998). Entretanto, como o objetivo deste ensaio foi apenas validar a informação de reverberação calculada pelo projetista das salas, a metodologia utilizada pode ser considerada adequada para a aplicação.

\subsubsection{RUÍDO AMBIENTE DAS SALAS}

Aproveitando-se a configuração dos microfones nas salas, foi realizada gravação de 30 segundos de ruído ambiente do estúdio principal e da sala de conveniência, registrandose, respectivamente, os arquivos "RUIDO.wav" e "RUIDOS.wav". Desses arquivos, foi extraída a estimativa de densidade espectral de potência do ruído ambiente das salas, utilizando transformada rápida de Fourier e uma janela de Hanning.

\subsubsection{RESULTADOS DA VALIDAÇÃO DAS SALAS}

Conforme descrito na seção 2.2, o ensaio de reverberação foi realizado com a aplicação de sinais impulsivos de áudio e registro da resposta da sala através de microfone e um gravador. Exemplos de sinais de resposta, no domínio do tempo, para as duas salas utilizadas neste estudo, são apresentados nas Figuras 10 e 11. Observando estas figuras, mesmo sem realizar os cálculos e tratamentos normatizados previstos, já é possível perceber que o Estúdio Principal possui tendência de menor amortecimento ao sinal reverberado do que a Sala de Conveniência.

Foi calculada a média dos 12 sinais obtidos para as duas salas a fim de se obter o decaimento médio do impulso para os ambientes. Foram então ajustados polinômios de terceiro grau para cada sala para cada uma das seguintes bandas de frequência: $125 \mathrm{~Hz}, 250 \mathrm{~Hz}, 500$ $\mathrm{Hz}, 1 \mathrm{kHz}, 2 \mathrm{kHz}$ e 4 kHz. Os gráficos de decaimentos médios são exibidos na Figura 12. Os polinômios de terceiro grau ajustados para cada um dos gráficos foram então utilizados para encontrar o RT20. O RT60, encontrado multiplicando o RT20 por três, para cada banda de frequência e para cada sala é apresentado na Tabela 3. Conforme pode ser verificado, o RT60 em nenhuma das condições analisadas, alcançou $500 \mathrm{~ms}$ e, portanto, as salas foram consideradas adequadas para a realização das gravações e sessões de avaliação. 


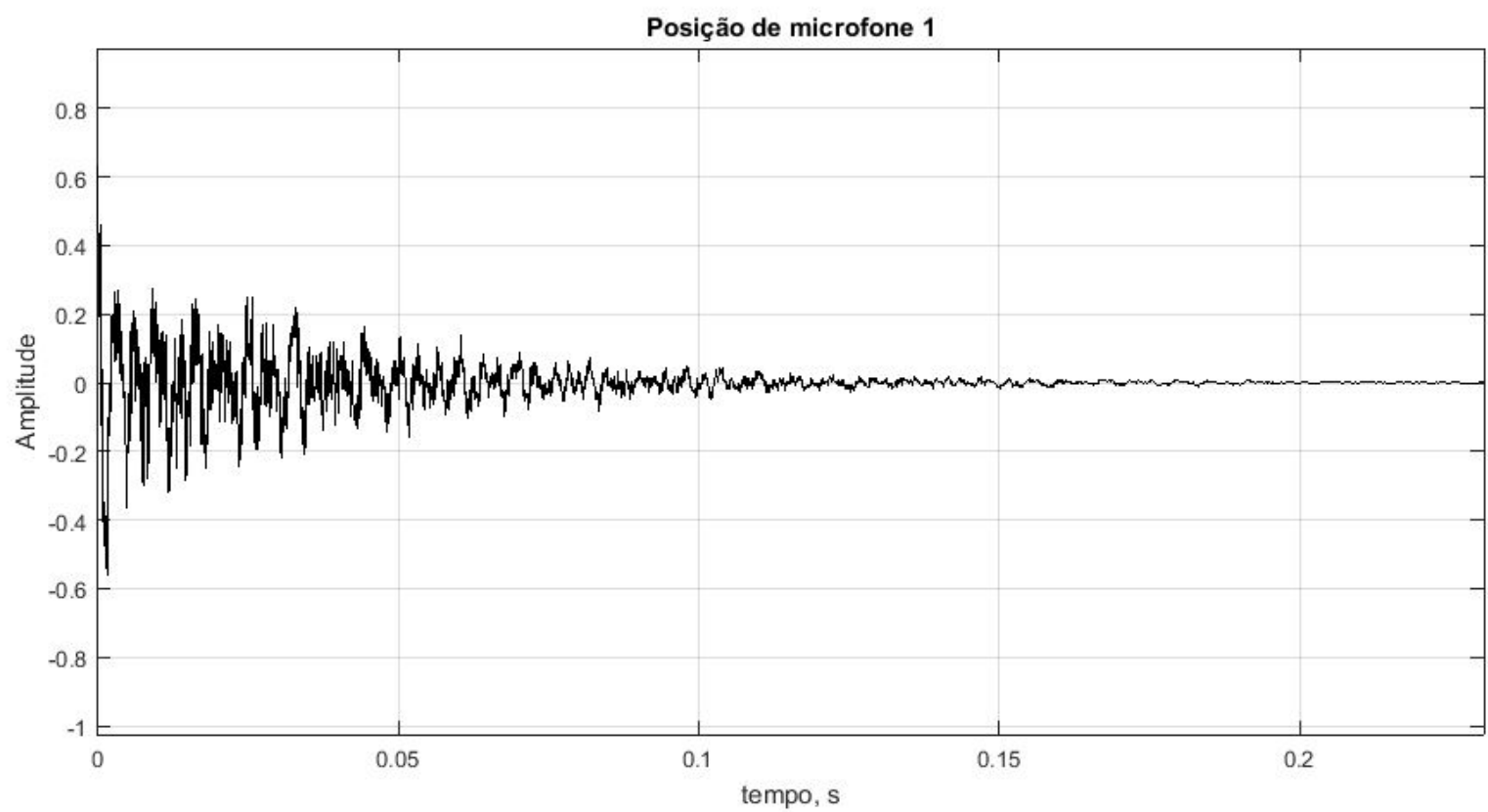

Figura 10: Exemplo de Sinal de áudio do ensaio de reverberação - Estúdio principal

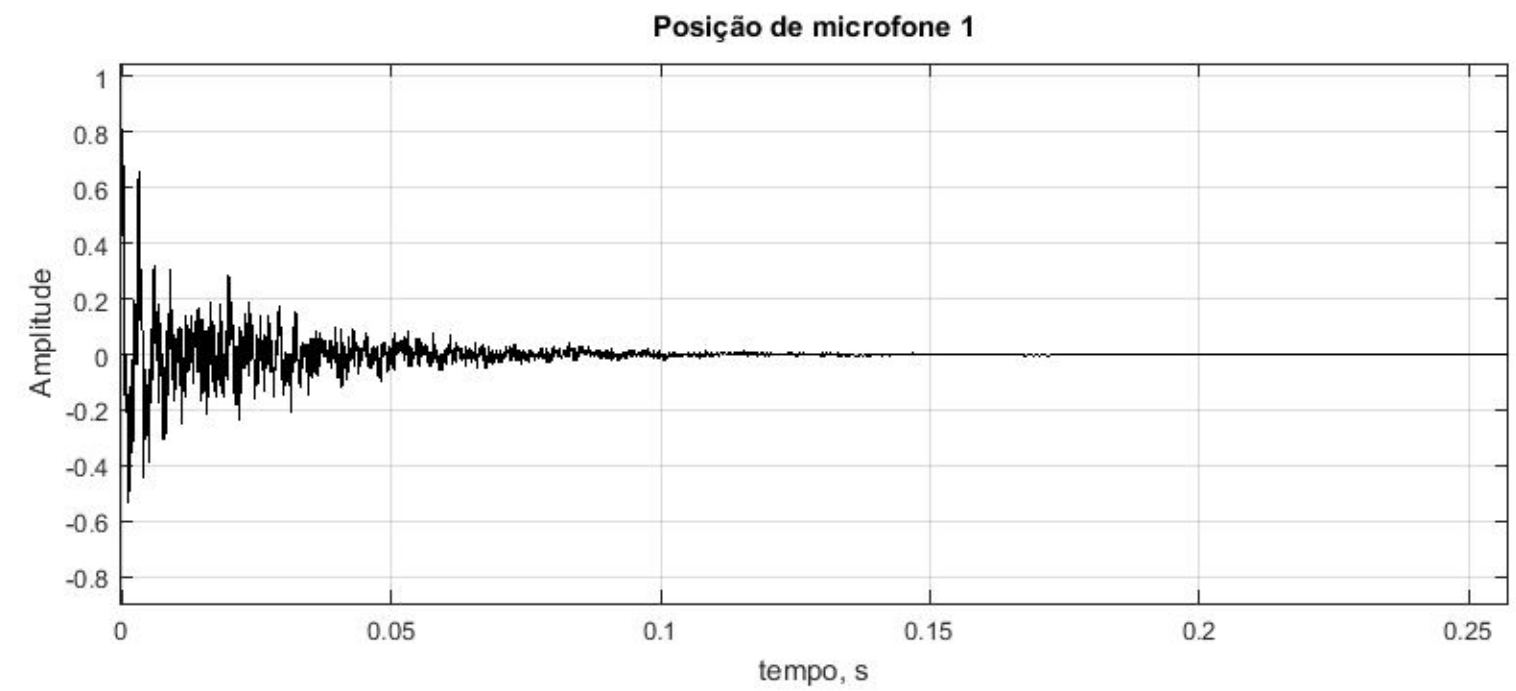

Figura 11: Exemplo de Sinal de áudio do ensaio de reverberação - Sala de Conveniência

Tabela 3: Valores estimados de RT60, por banda de frequência, para as salas utilizadas no estudo subjetivo

\begin{tabular}{ccc}
\hline Banda de frequência & RT60 Estúdio & RT60 Sala de Conveniência \\
\hline $125 \mathrm{~Hz}$ & $302 \mathrm{~ms}$ & $241 \mathrm{~ms}$ \\
$250 \mathrm{~Hz}$ & $410 \mathrm{~ms}$ & $260 \mathrm{~ms}$ \\
$500 \mathrm{~Hz}$ & $338 \mathrm{~ms}$ & $240 \mathrm{~ms}$ \\
$1 \mathrm{kHz}$ & $277 \mathrm{~ms}$ & $235 \mathrm{~ms}$ \\
$2 \mathrm{kHz}$ & $298 \mathrm{~ms}$ & $308 \mathrm{~ms}$ \\
$4 \mathrm{kHz}$ & $233 \mathrm{~ms}$ & $272 \mathrm{~ms}$ \\
\hline
\end{tabular}



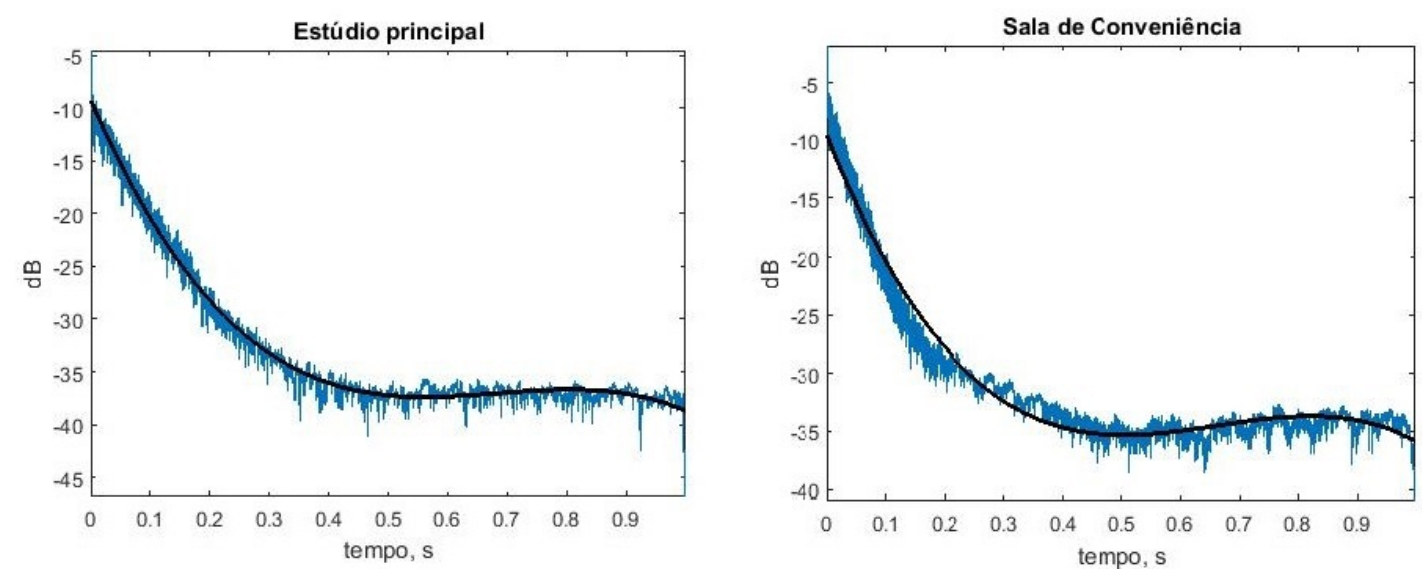

Figura 12: Decaimento médio obtido e polinômio de terceiro grau ajustado - Sala Principal e Sala de Conveniência

Quanto aos ruídos ambientes do Estúdio Principal e da Sala de Conveniência, foi realizada medição de ruído na sala com decibelímetro, registrando níveis de 28 dBA no Estúdio Principal e 29 dBA na Sala de Conveniência. De maneira a obter, de forma qualitativa, as densidades espectrais de potência dos ruídos ambientes das salas, foram utilizadas as gravações de ruído realizadas durante o ensaio de reverberação. A Figura 13 apresenta os espectros de potência de ruído ambiente do Estúdio Principal e da Sala de Conveniência.
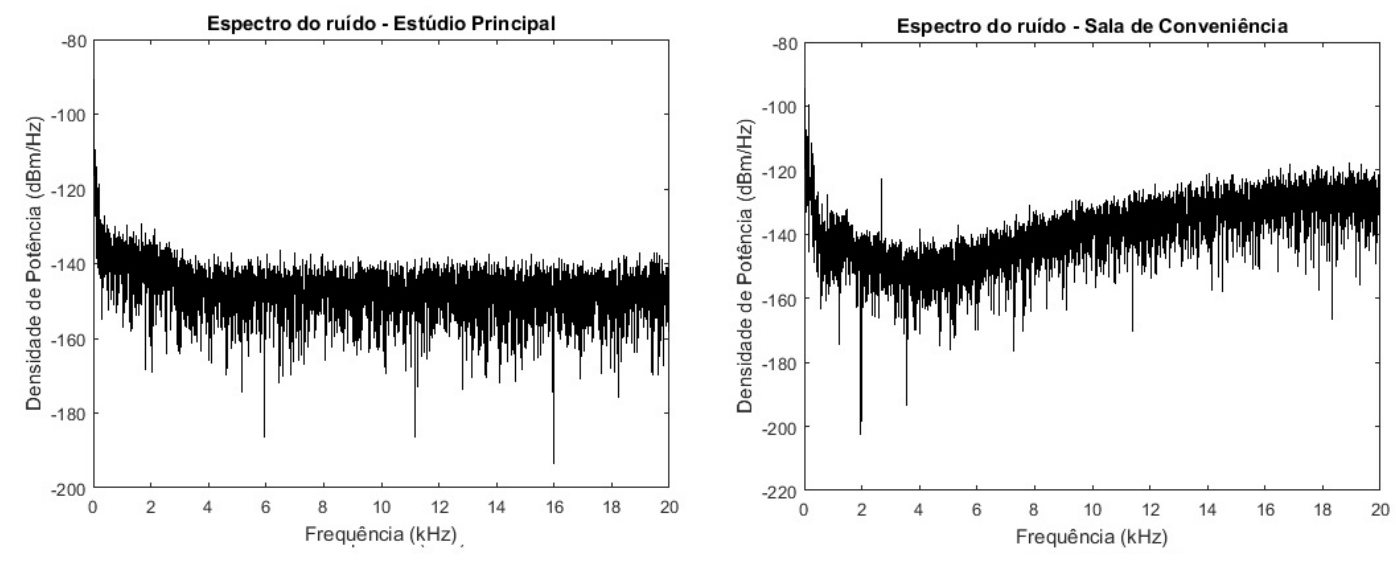

Figura 13: Espectro de potência de ruído ambiente - Estúdio Principal e Sala de Conveniência

Verifica-se que o espectro de ruído do estúdio principal apresenta valores na faixa de $-110 \mathrm{~dB}$, para bandas de frequência próximas a $100 \mathrm{~Hz}$ a $-145 \mathrm{~dB}$ na faixa de $2 \mathrm{kHz}$ a 20 kHz. Já para o caso da Sala de Conveniência, percebe-se que o comportamento do espectro de ruído tem maior dependência em relação à frequência, além de apresentar maior amplitude. Apresenta valores de cerca de $-105 \mathrm{~dB}$ em frequências próximas a $100 \mathrm{~Hz}$, decrescendo para um mínimo local de cerca de $-155 \mathrm{~dB}$ a cerca de $5 \mathrm{kHz}$ e atingindo aproximadamente $-130 \mathrm{~dB}$ em frequências próximas a $20 \mathrm{kHz}$. Entretanto, não foi evidenciado ruído pronunciado em banda específica de frequência, de maneira que ambas as salas podem ser consideradas adequadas para 
a realização das sessões de gravação e do experimento subjetivo.

\subsection{GRAVAÇÕES DE SINAIS DE VOZ}

A metodologia descrita na ITU-T P.800 foi escolhida para a realização do experimento subjetivo necessário a esta pesquisa. O procedimento definido nesta norma consiste na gravação de frases aleatórias de curta duração em ambiente e em situações controladas. Em seguida esses áudios devem ser organizados em listas, formando grupos de frases, e cada lista submetida a um tipo de tratamento, sendo algumas listas tratadas com métodos de referência e outras submetidas ao sistema sob estudo, que no caso, são os meios de telecomunicações ATC.

Nesta seção serão descritos os procedimentos de gravação de sinais de áudio de referência realizados neste estudo. Primeiramente, na seção 2.3.1 serão apresentados os requisitos normatizados de gravação de sinais de áudio. Em seguida, na seção 2.3.2 os procedimentos de preparação adotados para as sessões de gravação e no item 2.3.3 o detalhamento das sessões de gravação.

\subsubsection{REQUISITOS DE GRAVAÇÃO}

A norma ITU-T P.800 define requisitos e recomendações de gravação, apresentando as características do ambiente de gravação, sistema a ser utilizado, material a ser gravado e procedimento geral a ser adotado; requisitos de preparação, apresentando os tratamentos aos quais os áudios deverão ser sujeitos, as condições de referência a serem adotadas, a definição das condições de teste e o projeto do experimento; e as condições de execução, apresentando os requisitos de ambiente, sistema de reprodução, requisitos pessoais e o tipo de instruções a serem fornecidas aos participantes.

Os requisitos de gravação incluem requisitos da sala de gravação, do sistema de recepção e gravação, do material a ser gravado e do procedimento a ser adotado. O documento recomenda que a sala de gravação possua volume na faixa de 30 a $120 \mathrm{~m}^{3}$, ruído inferior a 30 dBA e tempo de reverberação RT60 (definido pela ISO 3382-2) inferior a 500 ms.

Quanto ao sistema de gravação, recomenda-se a utilização de gravador digital, com gravação em Pulse Code Modulation (PCM) linear, com resolução e amostragem compatíveis com a aplicação. Tendo em vista que a ITU-T P.800 não traz dados de resolução específicos para aplicações de banda estreita, foram utilizados como balizadores os mínimos definidos no padrão ITU-T P.830 - Subjective Performance Assessment of Telephone-band and Wideband Digital Codecs (ITU, 1996d), que define requisitos mínimos de resolução e amostragem para 
análise de codificadores. Para o caso de sinais de áudio de banda larga (largura de espectro de $8 \mathrm{kHz}$ ), esta norma define resolução mínima de 16 bits, e frequência de amostragem de, pelo menos, $16 \mathrm{kHz}$.

Quanto à captação, a norma ITU-T P.800 define que deve ser utilizado um microfone com característica linear na banda de interesse, e que as gravações deverão ser realizadas com o locutor à uma distância na faixa de 140 a 200 mm do microfone. Define ainda que a sensibilidade do sistema de gravação deverá ser medida no início e no fim das locuções e comparado. Caso seja verificada alteração de sensibilidade do sistema, as gravações deverão ser descartadas e refeitas.

Já em relação ao material a ser gravado, é definido que deverão ser utilizadas pelo menos 4 (quatro) locutores, sendo 2 (dois) masculinos e 2 (dois) femininos, utilizando tom e volume de voz naturais. As frases a serem gravadas deverão ter duração entre dois a três segundos, serem simples, aleatórias e deverão possuir significado. Deverão ser formados grupos com 2 (duas) a 5 (cinco) frases e listas compostas por 5 (cinco) a 10 (dez) grupos. Cada lista formada deverá, posteriormente, ser submetida a um tipo de tratamento, de maneira que não existam listas nem frases repetidas para cada tratamento.

Quanto ao procedimento de gravação, deverá ser assegurada relação sinal-ruído superior a $40 \mathrm{~dB}$, e a gravação deverá ser realizada na faixa de 20 a $30 \mathrm{~dB}$ abaixo do nível de saturação do sistema de gravação. Deverá ser registrado 30 segundos de ruído da sala, para análise posterior.

\subsubsection{PREPARAÇÃO DAS SESSÕES DE GRAVAÇÃO}

Por se tratar de um experimento que envolve seres humanos, uma série de precauções foram necessárias, incluindo a submissão da pesquisa para avaliação do CEP, preparação de termos de aceitação, formulários, procedimentos, entre outros. Nesta subseção serão detalhados os procedimentos adotados na preparação e planejamento necessários à realização das gravações de áudio, em atendimento às referências normatizadas utilizadas e também conforme recomendações do Comitê de Ética da UTFPR.

Primeiramente foi elaborada uma lista de 402 frases que foram narradas pelos locutores a fim de se estabelecer a base de sinais de áudio de referência utilizada nesta pesquisa. Procurouse utilizar vocabulário e construções simples, comumente utilizadas em situações de diálogos. A lista de frases totalizando de 5 a 12 sílabas, de maneira que, ao serem reproduzidas de forma natural, gerassem áudios de voz com duração na faixa de 2 a 3 segundos. A lista de frases é 
composta por:

1. Conjunto de frases em português: 153 frases;

2. Conjunto de frases em inglês: 153 frases;

3. Conjunto de frases de controle de tráfego aéreo em português: 48 frases; e

4. Conjunto de frases de controle de tráfego aéreo em inglês: 48 frases;

As listas de frases foram organizadas em ordem aleatória em grupos de três frases. A cada um destes grupos de frases foi atribuído um número de identificação de grupo, e os grupos distribuídos para os 8 locutores que realizaram a reprodução das frases.

Levando em consideração o alto custo de disponibilização do estúdio de gravação e técnicos especializados para a operação dos equipamentos e de maneira a otimizar o tempo dos locutores, foi elaborado um roteiro do locutor. Este documento tem como objetivos: a) apresentar a lista de frases para cada locutor, de maneira que esse possa tomar ciência e reproduzir com antecedência as frases; b) conhecer os procedimentos adotados durante as atividades de locução; c) apresentar o ambiente de realização da locução com antecedência e permitir que esse possa se ambientar com os procedimentos adotados. Um modelo de roteiro utilizado, juntamente com uma das lista de frases empregadas pode ser encontrado no Anexo B.

Todos os procedimentos e recursos necessários foram levantados, e foram elaborados outros documentos adicionais, conforme solicitação do CEP: os Termo de Consentimento Livre e Esclarecido (TCLE), Termo de Consentimento para Uso de Imagem e Som de Voz (TCUISV) e Questionário do Locutor. Nestes documentos constam informações como: apresentação e objetivo da pesquisa, condições de confidencialidade, riscos e benefícios da pesquisa, critérios de inclusão e exclusão utilizados, direitos do participante e consentimento quanto ao uso das gravações de voz obtidas na pesquisa. Os termos podem ser encontrados no Anexo D, enquanto o modelo do questionário utilizado pode ser encontrado no Anexo C. O projeto foi então submetido à análise no CEP, obtendo aprovação através do Parecer 2.163.376 de 07 de julho de 2017.

Foi então solicitado ao ACC do CINDACTA II a coordenação necessária para disponibilizar colaboradores com proficiência em português e inglês para a realização das locuções. Foram recomendadas 8 pessoas, sendo 4 do sexo masculino e 4 do sexo feminino, na faixa etária de 22 a 36 anos para as atividades. 
Aos indivíduos selecionados foi realizada a entrega dos TCLE e TCUISV e Roteiros de Locução, apresentando um procedimento detalhado das atividades de locução a serem desenvolvidas, incluindo lista individual de 48 frases curtas (com duração entre 2 a 3 segundos quando reproduzidas em voz alta), procedimentos de treinamento e execução do teste;

Foram esclarecidas as eventuais dúvidas e os TLCE e TCUISV foram assinados pelos sujeitos interessados em participar da pesquisa. Nesta data, foi agendada a sessão de gravação de áudios junto ao participante, conforme a disponibilidades destes, do Estúdio BOOM Sound Design e dos técnicos especializados. Foi considerada antecedência de 3 dias da data de entrega do Roteiro de Locução, de maneira que os participantes puderam tomar conhecimento das frases utilizadas;

O arranjo de equipamentos de gravação foi montado com um dia de antecedência e os equipamentos testados de maneira a minimizar o risco de ocorrência de falhas ou imprevistos.

\subsubsection{SESSÕES DE GRAVAÇÃO}

No dia agendado, antes do início das sessões de gravação, os participantes entregaram as documentações necessárias, incluindo: a) Questionário do Locutor, preenchi na hora, a fim de constatar eventuais condições de exclusão (como o consumo de bebidas alcoólicas); b) Termos de Consentimento, TCLE e TCUISV, conforme recomendações do Comitê de Ética da UTFPR. Os candidatos selecionados que: concordaram com os termos da avaliação, confirmaram fluência nos idiomas português e inglês; confirmarem que não realizaram consumo de substâncias que prejudiquem a atenção/dicção, incluindo álcool; foram liberados a participar da sessão de locução.

O participante foi então levado ao estúdio e reproduziu a lista de frases identificadas como "treinamento", composto por 12 frases. Este procedimento teve o propósito tanto de ambientar o locutor ao procedimento de locução quanto ajustar os equipamentos de gravação para possibilitar a melhor captação possível dentro das condições normatizadas.

As gravações foram então realizadas em conformidade com os procedimentos aprovados pelo CEP da UTFPR, utilizando-se a resolução máxima possível de 24 bits e taxa de amostragem de $192 \mathrm{kHz}$. Foi utilizado o microfone Neumann e pré-amplificador Avalon. O pré-amplificador foi ajustado com ganho $40 \mathrm{~dB}$, impedância configurada em $850 \mathrm{ohm}$ e selecionado filtro passa alta de $60 \mathrm{~Hz}$ (6 dB por oitava).

Cada participante fez a locução de 48 frases. Foi elaborado um formulário de acompanhamento de gravações (modelo no Anexo E) e todas as sessões de gravação foram assistidas, 
de maneira que falhas de pronúncia puderam ser corrigidas na própria sessão. A gravação foi realizada de forma contínua e os trechos de áudios das frases foram editados utilizando a ferramenta de uso profissional PROTOOLS, retirando os trechos de áudio substituídos.

Os arquivos foram editados foram salvos em formato de áudio WAV, utilizando o modelo indicado na Figura 14, em que $\mathbf{X}$ identifica o sexo do locutor (F para feminino e $\mathbf{M}$ para masculino), Y é a identificação do locutor (algarismo de 1 a 4), $\mathbf{Z Z}$ é a sessão de gravação e $\mathbf{R} \mathbf{R}$ é a identificação da frase (de 1 a 60).

Após a realização da locução, a participação destes sujeitos no experimento é finalizada, e os sinais obtidos submetidos aos tratamentos, processamentos de referência, condições de teste descritas nos itens subsequentes.

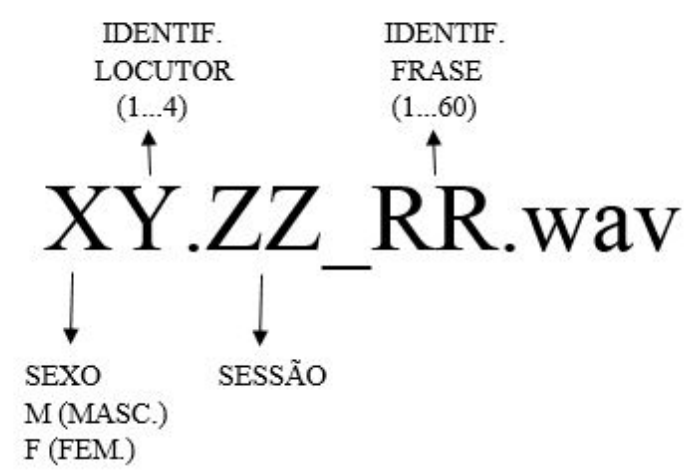

Figura 14: Modelo de nome de arquivo de gravação

\subsection{PRÉ-PROCESSAMENTO E PREPARAÇÃO DOS SINAIS DE VOZ}

Nesta etapa, os sinais gravados pelos sujeitos precisaram ser analisados e processados a fim de verificar se atendiam aos critérios estabelecidos na norma ITU-T P.800. Entre estes, se o nível médio de gravação estava na faixa de -30 a -20 dB em relação ao nível de saturação e se possuíam duração entre 2 a 3 segundos.

Para os sinais que não foram descartados, a norma ITU-T P.800 recomenda que os áudios devem ter as amplitudes normalizadas de maneira que o nível de áudio do sinal de voz (descontados os trechos de silêncios, impulsos, ecos e ruídos) fique situado a -26 dB do nível de saturação. Para tal, é disponibilizado na recomendação ITU-T P.56 (ITU, 1993b) em seu Método "B", um procedimento iterativo de medição do sinal de voz que realiza o cômputo do nível de sinal de fala de um sinal de áudio. O método em questão varre o sinal de áudio, calculando o envelope de potência de cada amostra do sinal levando em consideração um de- 
terminado limiar pré-estabelecido. Os envelopes são calculados na medida em que o algoritmo avança nas amostras de áudio até o fim da execução. Ao término o algoritmo realiza uma interpolação entre os limiares encontrados em cada amostra a fim de determinar o nível médio de fala no sinal de áudio.

A norma utilizada então recomenda que esta técnica seja utilizada para medir o nível do sinal após a realização da normalização, tomando-se os devidos cuidados para que não ocorra saturação do sinal em nenhum amostra para evitar distorções. A Seção 2.4.2 apresenta a fundamentação teórica para compreensão do algoritmo definido na ITU-T P.56, utilizado para a normalização dos sinais de áudio.

Realizada a normalização dos sinais, o nível de sinal em cada um dos trechos gravados deve ser calculado e armazenado, e a média dos valores deve ser calculada. Este valor médio deverá ser utilizado para gravar um tom de calibração, que deverá ser utilizado na fase de execução da avaliação, para calibrar o sistema de reprodução e possibilitar que cada pessoa ou grupo de pessoas responsável pela avaliação seja submetida à mesma pressão sonora.

O próximo passo é a organização dos sinais em listas para aplicação das condições de referência e teste. Deverão ser elaboradas nesta fase o número de listas necessário a atender pelo menos três condições de referência, além das condições sob estudo. As condições de referência consistem em degradações controladas do sinal de áudio, e têm como objetivo criar uma situação de controle para ser utilizada como comparação aos outros tratamentos e para garantir que o ensaio possa ser repetido em diferentes laboratórios. As condições de referência recomendadas são: adição de ruídos controlados, variação de nível de sinal, alteração da relação sinal-ruído ou outras situações de referência, como codificações padronizadas. A base de dados contida na ITU-T P.23 (ITU, 1998), por exemplo, utiliza como processamentos de referência o sinal PCM em 64 kbits/s, sinal "direto"ou sem processamento, Adaptative diferential pulse code modulation (ADPCM) em 32 kbits/s e o Modulated Noise Reference Unit (MNRU) definido na ITU-T P.81 (ITU, 1996c).

Para o melhor entendimento do funcionamento dos algoritmos utilizados na preparação dos sinais é necessária uma breve exposição sobre modelagem de sinais de voz e fala, conforme apresentado na Seção 2.4.1.

\subsubsection{MODELAGEM DE SINAIS DE VOZ}

Uma abordagem utilizada na modelagem de sinais de voz é a representação de situações de conversações utilizando máquinas de estados ou cadeias de Markov. Brady, ao estudar 
métodos de detecção de conversações em linhas telefônicas (circuitos full-duplex) introduziu técnicas de análise dos estados de uma conversação com base em medidas objetivas de tempos (BRADY, 1965). Definiu então o "throw-away time", como tempo de um sinal a ser descartado, por representar espúrias ou ruídos. Definiu ainda o tempo de ligação entre consoantes de uma palavra, como "fill-in time", que deverá ser maior do que o "throw-away time" e precedido e sucedido por trechos de conversação. Já o "hangover time” define o tempo a ser considerado para término do diálogo. A Figura 15 mostra um exemplo de sinal de voz, identificando os tempos mencionados no estudo de Brady.

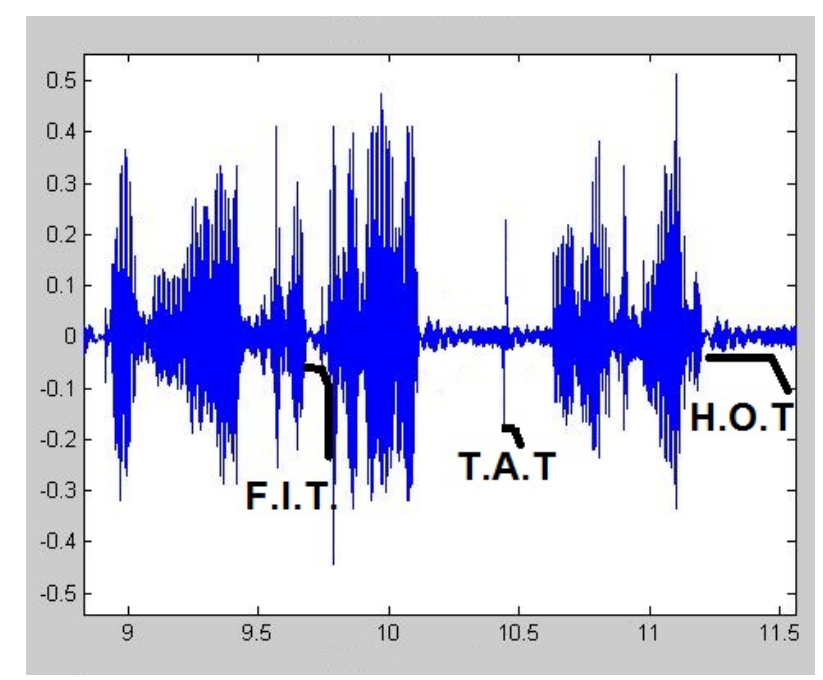

Figura 15: Parâmetros de tempo de uma conversa, segundo Brady. H.O.T indica o hangover time, T.A.T o throw-away time e F.I.T o fill-in time

Ao especificar esses parâmetros objetivos, pode-se descartar trechos do áudio que não são considerados sinais de fala. De acordo com o estudo de Brady, o throw-away time de $10 \mathrm{~ms}$ é suficiente para a remoção de espúrios de áudio, embora outros trabalhos como de Aschenbruck (ASCHENBRUCK N.; MARTINI, 2007) configuram o parâmetro acima de 300 ms. Conforme verificado por Rossi, no entanto, para o caso do SMA, a configuração em $300 \mathrm{~ms}$ acarretaria descarte de trechos de áudio importantes entre pausas intersilábicas (ROSSI, 2015).

Já para o caso do fill-in time, caracterizado como tempo entre rajadas de voz entre as sílabas, um valor de $200 \mathrm{~ms}$ é considerado adequado pelos estudos de Brady e Gruber, e o mesmo se aplicando para o hang-over time (BRADY, 1965; GRUBER, 1982).

\subsubsection{ALGORITMO DE NORMALIZAÇÃO DE SINAIS DE VOZ}

Conforme verificado na seção 2.4, foi necessário empregar um algoritmo para medir o nível médio dos sinais de voz gravados e encontrar um parâmetro multiplicador a fim de normalizar as amostras de áudio gravadas. O método recomendado pela norma ITU-T P.800 
é o definido pela recomendação ITU-T P.56. De forma sucinta, o algoritmo da ITU-T P.56, utilizado para a medição de nível de sinais e normalização dos mesmos funciona da seguinte maneira:

- Seja $x_{i}$ as amostras sucessivas do trecho de áudio, em que i=1,2,3,...n, e $n$ é o número de amostras;

- Submeter as amostras ao Processo 1, acumulando o número total de amostras $n_{i}$, soma dos sinais $s_{i}$ e soma quadrática $s q_{i}$, conforme a Equação 13;

$$
\left\{\begin{aligned}
n_{i} & =n_{i-1}+1 \\
s_{i} & =s_{i-1}+x_{i} \\
s q_{i} & =s q_{i-1}+x_{i}^{2}
\end{aligned}\right.
$$

- Submeter as amostras ao Processo 2, calculando a média exponencial retificada do sinal (envelope), conforme a Equação 14, em que $t$ é o período da amostra (inverso da frequência de amostragem), $T$ é o coeficiente de alisamento, definido em 0,03 s, $p$ é um valor intermediário de cálculo e $q$ é definido como envelope do sinal;

$$
\left\{\begin{array}{l}
p_{i}=e^{(-t / T)} \cdot p_{i-1}+\left(1-e^{(-t / T)}\right) \cdot\left|x_{i}\right| \\
q_{i}=e^{(-t / T)} \cdot q_{i-1}+\left(1-e^{(-t / T)}\right) \cdot\left|p_{i}\right|
\end{array}, p_{o}=q_{o}=0\right.
$$

- Seja c uma série de valores de limiares de intensidade espaçados em progressão geométrica em intervalos de 2:1 (6,02 dB), do máximo valor quantizado ao menor, sendo $j$ o número de elementos desta lista. Seja também $a$ uma lista representando uma contagem de atividade do sinal de áudio e $h$ uma lista de contagem de hang-over;

- Para cada valor de j, fazer:

$$
\left\{\begin{array}{c}
\text { Se }_{i}>c_{j} \text { ou } q_{i}=c_{j} \Rightarrow a_{j}=a_{j-1}+1, h_{j}=0 \\
\text { Se } q_{i}<c_{j} \text { e } h_{j}<I \Rightarrow a_{j}=a_{j-1}+1, h_{j}=h_{j-1}+1 \\
\text { Se } q_{i}<c_{j} \text { e } h_{j}=I \Rightarrow n / a
\end{array}\right.
$$

Observa-se que no primeiro caso o envelope apresenta potência maior do que o limiar testado, então o sinal de fala é considerado ativo para aquele limiar. No segundo caso, o envelope está abaixo do limiar porém o sinal de fala ainda é considerado ativo porque o tempo de hang-over ainda não expirou. No terceiro caso, o sinal de fala é considerado inativo para este nível de limiar sob teste. No instante inicial, considera-se a(0) nulo e 
$\mathrm{h}(0)$ assume o valor de $I$, que é o valor arredondado inteiro correspondente à razão entre o limiar de hang-over time (definido em $0,2 \mathrm{~s}$ ) e o período de amostragem do sinal.

- Após a finalização dos processos acima, para cada valor de $j$, são realizados os cálculos a fim de determinar o nível global $L$, o valor de nível de sinal ativo de fala $A(j)$, e o limiar $C(j)$, todos em decibéis, em relação ao valor de tensão de referência $r$. As expressões deste cálculo são apresentadas na Equação 16, em que $r$ é o valor de tensão de referência e $v$ o fator de escala do conversor analógico-digital, em V/unidade.

$$
\left\{\begin{array}{c}
L=10 \cdot \log \left(s q \cdot v^{2} / n\right)-20 \cdot \log (r) \\
A_{j}=10 \cdot \log \left(s q \cdot v^{2} / a_{j}\right)-20 \cdot \log (r) \\
C_{j}=10 \cdot \log \left(c_{j} \cdot v\right)-20 \cdot \log (r)
\end{array}\right.
$$

- Então, para cada valor de $j$, calcula-se a diferença $A_{j}-C_{j}$ e compara-se com o valor de margem $M$, definido em 15,9 dB. É então encontrado, por interpolação, caso não exista, um par de $\mathrm{A}(\mathrm{j})$ e $\mathrm{C}(\mathrm{j})$ que satisfaça a igualdade $A_{j}-C_{j}=M$. Este nível $\mathrm{A}(\mathrm{j})$ encontrado será o nível de áudio de fala ativo, resultado do algoritmo, e seu par C(j), o limiar considerado para aquela amostra de áudio.

Compreendido o funcionamento do algoritmo, o que merece ser destacado é que ele pode ser utilizado para encontrar o nível de sinal médio de fala ativa de uma amostra de áudio. Com base nos valores encontrados, este método foi utilizado para encontrar um valor multiplicador a fim de normalizar uma amostra de áudio.

\subsubsection{PRÉ-PROCESSAMENTO, TOM DE CALIBRAÇÃO}

Os sinais gravados e editados foram exportados pelo software PROTOOLS utilizando duas resoluções, 24 bits $192 \mathrm{kHz}$, para utilização futura para estudos que necessitem de áudio em altíssima fidelidade e 16 bits $44,1 \mathrm{kHz}$, para as aplicações tratadas neste trabalho. Os arquivos exportados em 16 bits $44,1 \mathrm{kHz}$ foram então convertidos em arquivo do tipo .RAW, através da retirada do cabeçalho. Os mesmos foram então tratados utilizando o método da ITU-T P.56, conforme definido na seção 2.3.1, através de rotina implementada no MATLAB. Este método normaliza os sinais de áudio de maneira que o conteúdo de voz fique com um nível médio de -26 dB do nível de saturação do sinal, tomando-se o cuidado de que não haja saturação em nenhum instante de tempo. Realizado este pré-processamento, os sinais são regravados num arquivo que apresenta a mesma nomenclatura indicada na Figura 14, adicionando-se o sufixo norm depois de $\mathbf{R} \mathbf{R}$. 
Foram então obtidos através do algoritmo descrito no item 2.4.2 os parâmetros dos áudios originais e dos pré-processados (com sufixo norm), incluindo tempo de duração do sinal de fala, nível original do sinal e nível após a normalização, bem como o ganho que foi aplicado no sinal original para obtenção do arquivo normalizado. Os dados foram compilados no Anexo F que apresenta também os arquivos que foram descartados do teste. Os atributos que levaram à decisão de descarte de cada arquivo foram destacados, incluindo tempo de duração (insuficiente ou superior ao limite especificado na ITU-T P.800), e nível médio do sinal original (abaixo ou acima da faixa de -30 a $-20 \mathrm{~dB}$ normatizado). As frases identificadas como tipo $\mathbf{P}$ são em português, $\mathbf{E}$ são em inglês, $\mathbf{A E}$ são frases de controle de tráfego aéreo em inglês e $\mathbf{A P}$ frases de controle de tráfego aéreo em português. Verifica-se que foram descartadas 42 frases gravadas.

As gravações normalizadas que tiveram seus indicadores aprovados foram então distribuídas em grupos balanceados com duas frases de cada narrador montados da seguinte maneira:

1. Grupos de frases definidos na norma ITU-T P.800

- Contendo duas frases femininas em inglês de mesmo narrador (tipo E);

- Contendo duas frases femininas em português de mesmo narrador (tipo $\mathbf{P}$ );

- Contendo duas frases masculinas em português de mesmo narrador (tipo P);

- Contendo duas frases masculinas em inglês de mesmo narrador (tipo E);

2. Grupos de frases de controle de tráfego aéreo (ATC)

- Contendo duas frases de controle de tráfego aéreo femininas em inglês de mesmo narrador (tipo AE);

- Contendo duas frases de controle de tráfego aéreo femininas em português de mesmo narrador (tipo AP);

- Contendo duas frases de controle de tráfego aéreo masculinas em português de mesmo narrador (tipo AP);

- Contendo duas frases de controle de tráfego aéreo masculinas em inglês de mesmo narrador (tipo AE);

As Tabelas do Anexo $\mathrm{G}$ apresentam as listas de reprodução criadas com base na metodologia da ITU-T P.800 e as listas de reprodução com frases típicas utilizadas no controle de tráfego aéreo. 
Em seguida, os arquivos foram novamente exportados para o formato "WAV" de maneira que pudessem ser reproduzidos nas interfaces de áudio. Também foi calculado o nível médio dos sinais não descartados, obtendo-se o valor de $-26,0 \mathrm{~dB}$ abaixo do nível de saturação. Este valor foi utilizado para a criação do tom de calibração de $1 \mathrm{kHz}$, com duração de 30 segundos, para ser utilizado no ajuste de ganho dos equipamentos de reprodução utilizados no teste subjetivo. O tom de calibração foi criado através de rotina no MATLAB, com resolução de 16 bits e taxa de amostragem de 44,1 kHz. O seu nível foi validado através do método definido na ITU-T P.56, obtendo-se o valor de nível de -26,0 dB. Este sinal também foi exportado em formato "WAV". 


\section{GERAÇÃO DE DEGRADAÇÕES - TESTES E SITUAÇÕES DE CONTROLE}

Neste capítulo são descritos os procedimentos aplicados aos sinais obtidos no Capítulo 2 a fim de degradá-los, para que, então possam ser avaliados pelos métodos subjetivos e objetivos previstos. Conforme normatizado na ITU-T P.800, alguns grupos de sinais foram aplicados a situações de controle, com degradações controladas, conforme descrito na Seção 3.1. Outros grupos de sinais foram aplicados às condições testadas dos meios comumente utilizados nas comunicações ATC, conforme será verificado na Seção 3.2.

\subsection{PROCESSAMENTOS ADICIONAIS: DEGRADAÇÕES CONTROLADAS}

Após o pré-processamento dos sinais e organização dos áudios de fala em grupos de frases, cada um dos grupos foi submetido à uma condição de degradação diferente. Alguns dos grupos foram submetidos a degradações controladas, conforme recomendação da norma ITU-T P.800 utilizada e outros grupos foram utilizados nos testes dos meios de telecomunicações ATC, objeto deste estudo. As degradações controladas foram implementadas através de algoritmos, e serão discutidas nesta seção.

\subsubsection{PROCESSAMENTOS DE REFERÊNCIA UTILIZADOS}

Neste estudo foram escolhidos três métodos de referência. A MNRU, definida pela ITU-T P.81 (ITU, 1996c), a codificação PCM definida na ITU-T G.711 (ITU, 1993a) e a codificação ADPCM definida na ITU-T G.726 (ITU, 1996a).

A MNRU, ou unidade de referência modulada de ruído, consiste num sistema capaz de realizar adição de certa quantidade de ruído de maneira controlada num sinal de áudio. Um diagrama esquemático deste sistema descrito na ITU-T P.81 é ilustrado na figura 16. Pode-se verificar que o sinal, primeiramente, é desacoplado de seu componente de corrente contínua, trazendo seu valor médio para zero. Em seguida, o sinal é dividido em dois caminhos: um caminho de sinal e outro de ruído. No caminho do sinal, o sinal de entrada é atenuado ou am- 
plificado (conforme a necessidade), enquanto no caminho do ruído, o sinal original é utilizado para modular uma "portadora"de ruído gerado por meio de um gerador gaussiano que possui amplitude controlável.

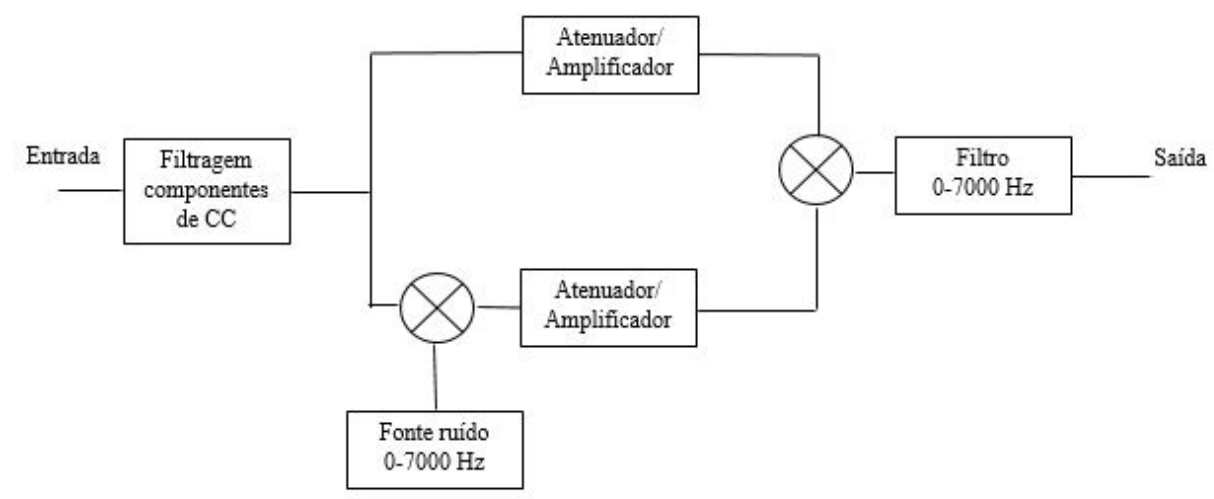

Figura 16: Diagrama esquemático da unidade MNRU para sinais digitais de banda larga

Para o caso de sinais digitais e de banda larga , que trataremos neste trabalho, o ruído produzido pela fonte deverá ser gaussiano, na faixa de 0 a $7.000 \mathrm{~Hz}$. A norma define também que o espectro do ruído deverá ser plano na faixa mínima de $50 \mathrm{~Hz}$ a $7.000 \mathrm{~Hz}$. Neste caso, também deverá ser implementado um ceifador de picos parametrizado a pelo menos $12 \mathrm{~dB}$ acima do nível RMS do ruído gerado. O ruído deverá ser gerado por meio de gerador de números aleatórios gaussianos que deverá possuir um período de pelo menos $2^{20}$ amostras.

Em seguida o sinal proveniente do caminho de sinal (atenuado ou amplificado) é juntado ao sinal proveniente do caminho de ruído (atenuado ou amplificado) para gerar um sinal distorcido. Para a implementação digital da MNRU, considerando ganho unitário para o sinal de entrada, o sinal de saída do sistema pode ser escrito conforme definido na Equação 18, em que $y(i)$ é o sinal de saída, $Q$ é a razão, em dB, entre o sinal de fala e o valor modulado de ruído pretendida, $x(i)$ o sinal de entrada e $N(i)$ o sinal de ruído.

$$
y(i)=x(i)\left[1+10^{-Q / 20} N(i)\right]
$$

Outra condição de referência utilizada foi a aplicação da codificação PCM definida no padrão ITU-T G.711 (ITU, 1993a). Esta norma define um conjunto codificador/decodificador de áudio amplamente utilizado em sistemas de telecomunicações, em que um sinal é filtrado na faixa de $300 \mathrm{~Hz}$ a $3.400 \mathrm{~Hz}$, amostrado com precisão de 8 bits a uma taxa de amostragem de 8 KHz. Assim, é obtida uma taxa de transmissão de dados de 64 kbits/s. 
A filtragem é realizada por um filtro passa-faixa cujas características são definidas no padrão ITU-T G.712 (ITU, 2001b). Este filtro é implementado com propriedades IIR, de maneira a atingir a janela de resposta em frequência exibida na Figura 17. Seguida da filtragem, é realizada a compressão e expansão do sinal.

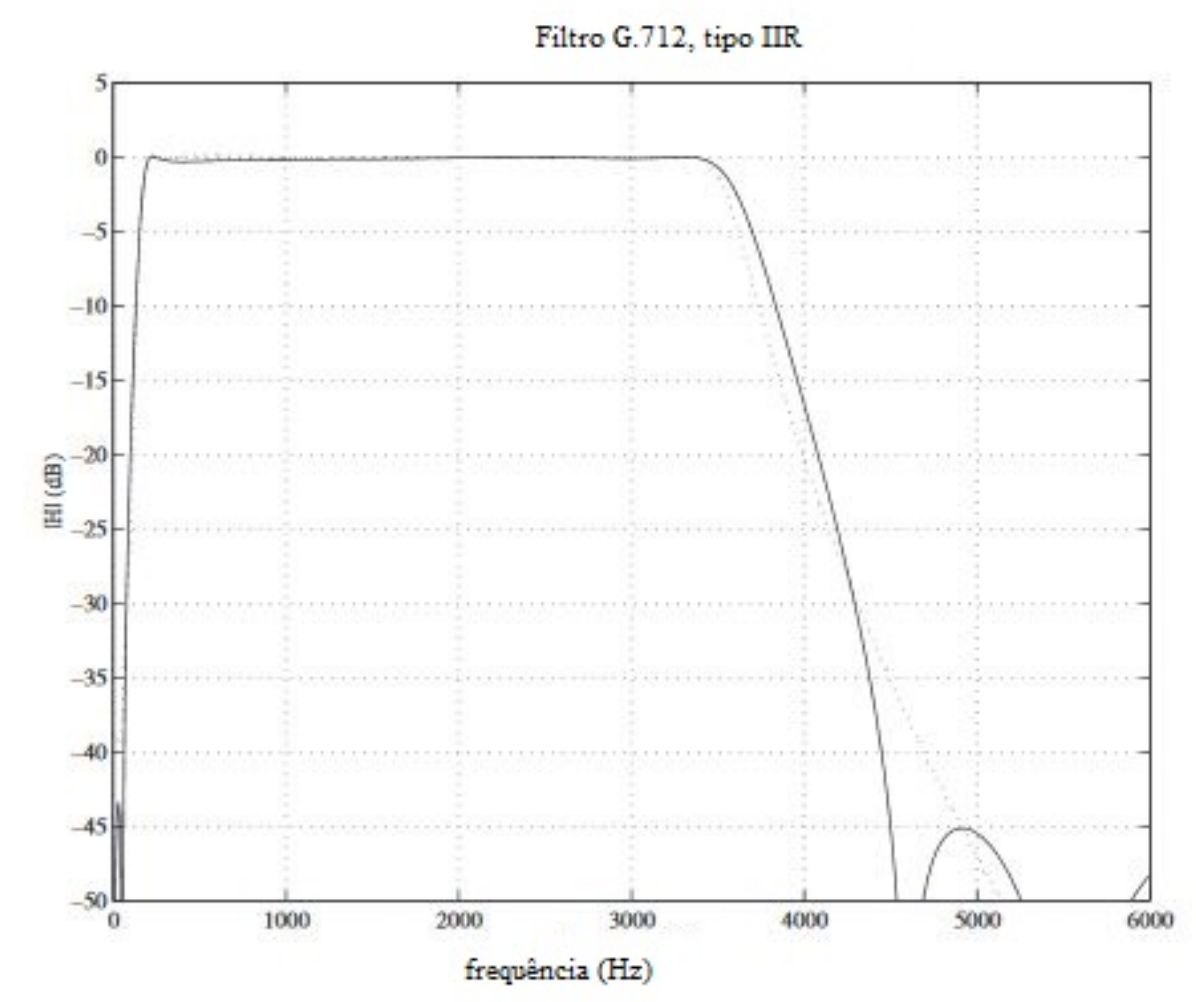

Figura 17: Resposta em frequência do filtro IRR definido na ITU-T G.712

Fonte: Adaptado de (RAAKE, 2007)

De maneira a atenuar as limitações de faixa dinâmica dos canais de telecomunicações, o procedimento utilizado na ITU-T G.711 pode utilizar duas técnicas de compansão (compressão - expansão), a lei de compressão " $\mu$ "ou a lei de compressão "A". Ambas as técnicas levam em consideração o efeito não linear do mascaramento, característica do sistema auditivo humano em que a percepção de um som é afetada pela presença de outro som. A Figura 18 apresenta o limiar de audição e as curvas de mascaramento produzidas por um tom de $1 \mathrm{kHz}$ a diferentes pressões sonoras, conforme verificado por Veldhuis et al. (VELDHUIS R N. J.; WML, 1989). Percebe-se que que as curvas de mascaramento de sons são mais abrangentes (possuem maior banda) quanto maior o nível de pressão sonora. Assim, as técnicas de compressão podem se beneficiar desta característica tendo em vista que para a representação de sons de maiores amplitudes pode-se optar por uma resolução mais baixa do que para sinais de menores amplitudes no processo de digitalização. Dessa maneira, os eventuais ruídos de 
quantização serão menos perceptíveis em amplitudes elevadas.

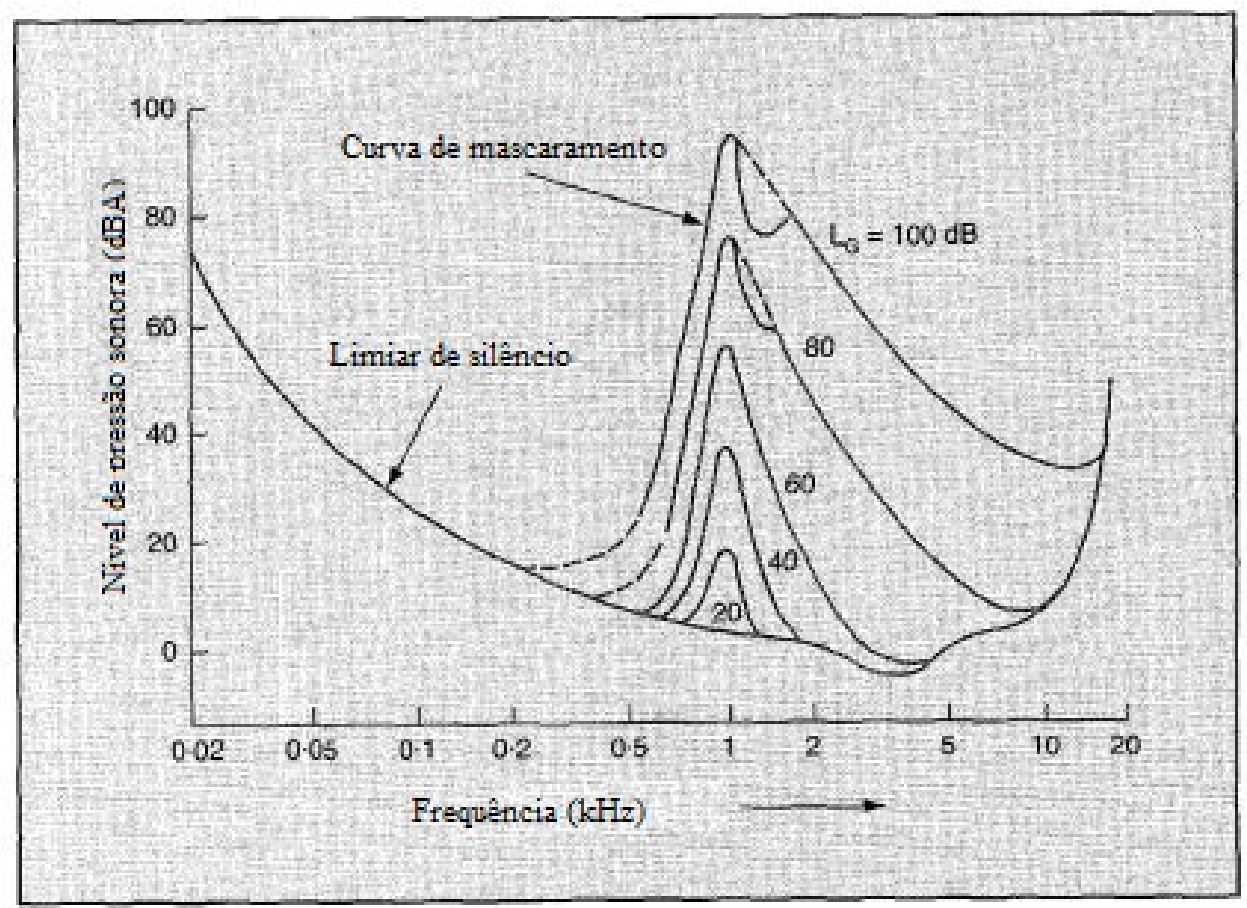

Figura 18: Limiares de audição e de mascaramento, sinal 1 kHz, a diferentes pressões sonoras Fonte: Adaptado de (VELDHUIS R N. J.; WML, 1989)

As leis de compressão compressão " $\mu$ "e "A"utilizam uma escala de quantização logarítmica em que sinais de menor amplitude são representados com maior precisão (maior número de bits) do que os sinais de maior amplitude. Como resultado, pode-se obter uma taxa de compressão aproximada de 2:1 mantendo-se a inteligibilidade do sinal de áudio. A curva da lei de compressão "A"pode ser encontrada através equação 19 (FREEMAN, 2005), em que A $=87,6, F_{A}(x)$ o sinal comprimido e $x$ o sinal de entrada.

$$
\left\{\begin{array}{l}
F_{A}(x)=\frac{A|x|}{1+\ln (A)}, \quad 0 \leqslant|x| \leqslant \frac{1}{A} \\
F_{A(x)}=\frac{1+\ln |A \cdot x|}{1+\ln (A)}, \quad \frac{1}{A} \leqslant|x| \leqslant 1
\end{array}\right.
$$

Já a curva da lei de compressão " $\mu$ "pode ser encontrada através equação 20 (FREEMAN, 2005), em que $\mu=255, F_{\mu}(x)$ o sinal comprimido e $x$ o sinal de entrada.

$$
F_{\mu}(x)=\frac{\ln (1+\mu|x|)}{\ln (1+\mu)}
$$

Para a reprodução, os sinais são novamente convertidos em PCM linear através das 
relações complementares às equações 19 e 20. A implementação destas equações, conforme normatizado ITU-T G.711 é realizada por meio de tabelas de conversão, que aproximam a curva logarítmica a segmentos de retas.

Outro processamento de referência utilizado é o definido na ITU-T G.726 (ITU, 1996a), em que são obtidas taxas de compressão ainda superiores às obtidas por meio da ITU-T G.711. Nesta técnica padronizada, é utilizado o ADPCM, ou modulação diferencial adaptativa por códigos de pulsos. Esta técnica procura estimar o sinal de saída com base na diferença entre o sinal de entrada e um sinal gerado por um modelo de referência. Este sinal de diferença é utilizado na reconstrução do sinal original e pode ser amostrado com uma precisão de 5, 4, 3 ou 2 bits, obtendo-se assim taxas de até $16 \mathrm{kbit} / \mathrm{s}$, ou compressões de até 4:1 em relação ao padrão ITU-T G.711.

O diagrama de blocos simplificado do codificador ADCPM é exibido na Figura 19. Observa-se que a entrada do codificador é um sinal já comprimido pelo padrão ITU-T G.711. O sinal é decodificado e transformado em PCM linear, e calcula-se o sinal de diferença $d(k)$ entre a entrada em PCM linear si $(k)$ e um sinal estimado se $(k)$. Este sinal diferença é armazenado com precisão de 5,4,3 ou 2 bits, dependendo do parâmetro utilizado e corresponde ao sinal codificado. Em seguida, um quantizador reverso reproduz o sinal de diferença a partir desse parâmetro de 5,4,3 ou 2 bits, gerando o sinal $d q(k)$ e este valor é somado ao sinal estimado $s e(k)$ a fim de gerar um sinal reconstruído $s r(k)$. O quantizador reverso utilizado leva em consideração a velocidade de transição do sinal aplicando comportamentos de conversão distintos para sinais de voz (que possuem transições alternadas do sinal diferença) e para sinais de dados / tons (que possuem sinais diferença com menores flutuações), multiplicando o valor do sinal por um fator de escala $y(k)$.

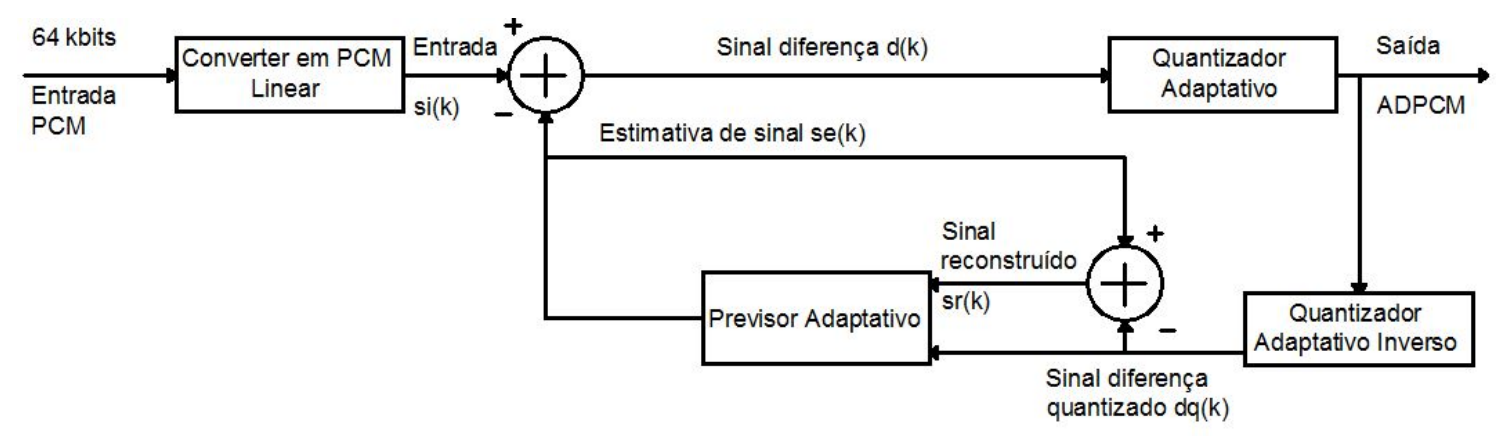

Figura 19: Diagrama de blocos simplificado do codificador G.726

Fonte: Adaptado de (ITU, 1996a)

Para o caso de sinais rápidos (sinais de fala, por exemplo), o fator de escala é compu- 
tado pela Equação 21, em que $y_{u}$ é o fator de escala calculado, $W[I(k)]$ é uma função discreta definida pela Tabela 4 para o caso da taxa de transmissão de $32 \mathrm{kbits} / \mathrm{s}$ ( 3 bits de resolução e 1 bit de sinal, e $y(k)$ o fator de escala global calculado na iteração anterior.

$$
\begin{gathered}
y_{u}(k)=\left(1-2^{-5}\right) \cdot y(k)+2^{-5} W[I(k)], \\
1,06 \leqslant y_{u}(k) \leqslant 10,00
\end{gathered}
$$

Tabela 4: Função discreta $W(I(k))$

\begin{tabular}{ccccccccc}
\hline$|I(k)|$ & 7 & 6 & 5 & 4 & 3 & 2 & 1 & 0 \\
$W[I(k)]$ & 70,13 & 22,19 & 12,38 & 7,00 & 4,00 & 2,56 & 1,13 & $-0,75$ \\
\hline \multicolumn{7}{c}{ Fonte: (ITU, 1996a) }
\end{tabular}

Já para sinais com transições lentas (dados ou tons por exemplo), o fator de escala é calculado a partir de uma adaptação da Equação 21, conforme descrito na Equação 22, em que $y_{l}(k)$ é o fator de escala lento calculado, $y_{u}(k)$ o fator de escala obtido a partir da equação 21.

$$
y_{l}(k)=\left(1-2^{-6}\right) \cdot y_{l}(k-1)+2^{-6} \cdot y_{u}(k)
$$

O fator de escala global $y(k)$ é então obtido por meio da equação 23 , em que $a_{l}(k)$ é o parâmetro de velocidade do sinal.

$$
\begin{gathered}
y(k)=a_{l}(k) \cdot y_{u}(k-1)+\left[1-a_{l}(k)\right] y_{l}(k-1) \\
0 \leqslant a_{l}(k) \leqslant 1
\end{gathered}
$$

O parâmetro de velocidade $a_{l}(k)$ tende para unidade em sinais de voz e tende a ser nulo para sinais de dados transmitidos em banda estreita. $\mathrm{O}$ valor é derivado da medida da taxa de variação do sinal diferença $d(k)$. São calculados dois valores de média de $I(k), d m s$ e $d m l$ conforme definido na Equação 24, em que $F[I(k)]$ é uma função discreta, definida na Tabela 5

$$
\left\{\begin{array}{l}
d_{m s}=\left(1-2^{-5}\right) d_{m s}(k-1)+2^{-5} F[I(k)] \\
d_{m l}=\left(1-2^{-7}\right) d_{m l}(k-1)+2^{-7} F[I(k)]
\end{array}\right.
$$

Os sinais $d m s$ e $d m l$ são então combinados a fim de estimar o parâmetro de velocidade $a_{l}(k)$, conforme a equação 25 , em que 


\begin{tabular}{ccccccccc} 
Tabela 5: Função discreta & $F(I(k))$ \\
\hline$|I(k)|$ & 7 & 6 & 5 & 4 & 3 & 2 & 1 & 0 \\
$F[I(k)]$ & 7 & 3 & 1 & 1 & 1 & 0 & 0 & 0
\end{tabular}

Fonte: (ITU, 1996a)

$$
\left\{\begin{array}{cc}
\text { se }\left|d_{m s}(k)-d_{m l}(k)\right| \geq 2^{-3} d_{m l}(k) \\
\left(1-2^{-4}\right) a_{p}(k-1)+2^{-3}, & \text { ou se } y(k)<3 \\
1, & {\text { ou se } t_{d}(k)=1} \\
& \text { se t } t_{r}(k)=1 \\
\left(1-2^{-4}\right) a_{p}(k-1) & \text { demais casos }
\end{array}\right.
$$

Os sinais diferença $d q(k)$ e reconstruído $\operatorname{sr}(k)$ são operados num previsor adaptativo que gera um novo sinal estimado se $(k)$.

\subsubsection{APLICAÇÃO DAS DEGRADAÇÕES/TRATAMENTOS CONTROLADOS}

Foram utilizadas 10 condições de degradação de referência, aplicadas às primeiras 10 listas de reprodução, conforme resumido na Tabela 6 . Os grupos submetidos à técnica indicada como "MNRU" correspondem ao método definido na ITU-T P.81, variando-se o parâmetro "'Q"'(equação 18), conforme descrito na coluna "Parâmetro Utilizado"”. O grupo submetido à técnica identificada como "G.711" corresponde ao sinal PCM, codificado com método definido na ITU-T G.711. Já o submetido à técnica identificada como "G.726”" corresponde à codificação ADPCM definida na ITU G.726. A aplicação das codificações e da MNRU foi realizada através de rotinas do MATLAB, utilizando o código padronizado em linguagem $\mathrm{C}$ fornecido pela ITU e compilado através da ferramenta Microsoft Visual Studio 2015. A descrição teórica dos métodos utilizados pode ser encontrada na Seção 3.1.1.

O grupo 25 não recebeu nenhum tipo de tratamento após o pré-processamento, e também foi reservado para uso nas avaliações subjetivas e objetivas descritas, respectivamente, nos Capítulos 4 e 5. 
Tabela 6: Condições de referência aplicadas

\begin{tabular}{ccc}
\hline Identificação & Técnica & Parâmetro Utilizado \\
Grupo 1 & MNRU (ITU-T P.810) & 5 \\
Grupo 2 & MNRU (ITU-T P.810) & 10 \\
Grupo 3 & MNRU (ITU-T P.810) & 15 \\
Grupo 4 & MNRU (ITU-T P.810) & 20 \\
Grupo 5 & MNRU (ITU-T P.810) & 25 \\
Grupo 6 & MNRU (ITU-T P.810) & 30 \\
Grupo 7 & MNRU (ITU-T P.810) & 35 \\
Grupo 8 & MNRU (ITU-T P.810) & 50 \\
Grupo 9 & PCM (ITU-T G.711) & $64 \mathrm{kbits} / \mathrm{s}$ \\
Grupo 10 & ADPCM (ITU-T G.726) & $32 \mathrm{kbits} / \mathrm{s}$ \\
Grupo 25 & Áudio puro & $192 \mathrm{kHz}, 24 \mathrm{bits}$ \\
\hline
\end{tabular}

\subsection{TESTES DAS COMUNICAÇÕES ATC}

Além dos tratamentos de referência, foram previstas as condições de teste conforme a necessidade do estudo, incluindo os meios utilizados nas telecomunicações ATC. Os testes envolveram os principais equipamentos comumente utilizados nas comunicações de controle de tráfego aéreo, incluindo central de áudio, equipamentos de comunicação satelital, equipamentos de VHF, entre outros e foram elaborados com base em estatísticas de reclamações dos usuários do SMA, que apontaram problemas de qualidade de áudio. Os testes consistiram em reproduzir os grupos de frases a partir de consoles do ACC-CW e captados em aeronaves, outros órgãos ou posições operacionais e, também, reproduzir os sinais de áudio a partir das aeronaves e captar no ACC-CW, em diferentes posições.

A tabela 7 apresenta as condições de teste aplicadas aos grupo de frases elaborados em conformidade com o estabelecido na norma ITU-T P.800, apresentando na coluna "Fonte"o local em que foi aplicado o sinal, na coluna "Destino"o local em que o sinal foi gravado e na coluna "Observações"outras informações pertinentes. De maneira análoga, a tabela 8 apresenta as mesmas informações para os grupos que contém frases padronizadas de controle de tráfego aéreo.

A seguir, no item 3.2.1 serão apresentados os materiais e meios utilizados para a realização destes testes. Já no item 3.2.2 serão detalhadas as condições de teste a que os áudios gravados foram submetidos. 
Tabela 7: Condições de teste aplicadas, grupo ITU

\begin{tabular}{cccc}
\hline Identificação & Fonte & Destino & Observações \\
\hline Grupo 11 & ACC-CW & APP-CW & Terra-terra, sistema TF1 \\
Grupo 12 & ACC-CW & ACC-CW & Terra-terra, entre posições operacionais \\
Grupo 13 & ACC-CW & Aeronave CAV & Tx DTCEA-CT, 127,5 MHz \\
Grupo 14 & Aeronave CAV & ACC-CW & Rx DTCEA-CT, 127,5 MHz \\
Grupo 15 & Aeronave CAV & ACC-CW & Tx DTCEA-CT, 127,5 MHz \\
Grupo 16 & ACC-CW & Aeronave FL & Tx DTCEA-CT, 127,5 MHz \\
Grupo 17 & ACC-CW & Aeronave FL & Tx MDI + CT, 127,5 MHz \\
Grupo 18 & Aeronave FL & ACC-CW & Rx MDI, 127,5 MHz \\
Grupo 19 & ACC-CW & Aeronave GEIV & Tx PCO + CAM, 133,6 MHz \\
Grupo 20 & ACC-CW & Aeronave GEIV & Tx PCO + CAM + PIE, 133,6 MHz \\
Grupo 21 & ACC-CW & Aeronave GEIV & Tx PCO + PIE, 133,6 MHz \\
Grupo 22 & ACC-CW & Aeronave GEIV & Tx PCO+VARG, 125,35 MHz \\
Grupo 23 & ACC-CW & Aeronave GEIV & Tx PCO+VARG+PIE, 125,35 MHz \\
Grupo 24 & ACC-CW & Aeronave GEIV & Tx PCO+PIE, 125,35 MHz \\
\hline
\end{tabular}

Tabela 8: Condições de teste aplicadas, grupo ATC

\begin{tabular}{cccc}
\hline Identificação & Fonte & Destino & Observações \\
\hline Grupo 1A & ACC-CW & APP-CW & Terra-terra, sistema TF1 \\
Grupo 2A & ACC-CW & ACC-CW & Terra-terra, entre posições operacionais \\
Grupo 3A & ACC-CW & Aeronave CAV & Tx DTCEA-CT, 127,5 MHz \\
Grupo 4A & Aeronave CAV & ACC-CW & Rx DTCEA-CT, 127,5 MHz \\
Grupo 5A & Aeronave CAV & ACC-CW & Tx FL+ MDI + CT, 127,5 MHz \\
Grupo 6A & ACC-CW & Aeronave FL & Tx DTCEA-CT, 127,5 MHz \\
Grupo 7A & ACC-CW & Aeronave GEIV & Tx PCO + CAM + PIE, 125,35MHz \\
Grupo 8A & ACC-CW & Aeronave GEIV & Tx PCO+VARG+PIE, 125,35 MHz \\
\hline
\end{tabular}

\subsubsection{EQUIPAMENTOS PARA APLICAÇÃO DAS CONDIÇÕES DE TESTE}

A reprodução de áudios, para todos os testes, foi realizada a partir de dois computadores pessoais portáteis, conectados à interfaces de áudio Behringer UCA222. Para os testes que envolveram aeronaves, que não dispunham de tomadas de força de $127 \mathrm{~V}$, foi necessário também a realização de alimentação elétrica dos equipamentos. Para tal, foi adquirido um conjunto de inversor de frequência e elaborados cabos adaptadores de alimentação de maneira a possibilitar a alimentação do computador através de tomadas de $12 \mathrm{~V}$ em corrente contínua, disponíveis no avião. As características dos componentes e equipamentos utilizados podem ser encontrados no Anexo A. A Figura 20 apresenta o diagrama simplificado do sistema utilizado para gravações e reproduções durante as situações de teste.

As gravações, para os testes que envolveram o avião do GEIV (Embraer Legacy) foram realizadas utilizando-se o gravador de bordo que compõe a instrumentação daquele aviãolaboratório. 


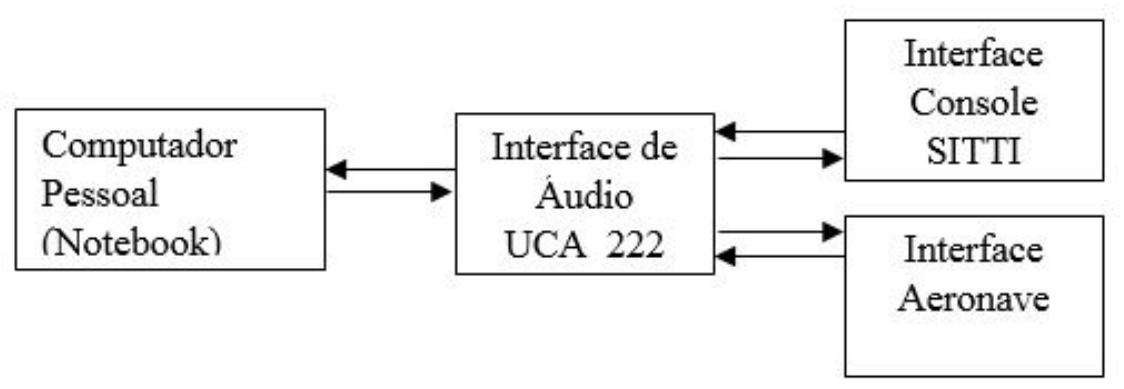

\section{Figura 20: Diagrama simplificado de reprodução/gravação de áudio utilizado nos testes}

Verificando-se a Figura 20, observa-se que as interfaces de áudio UCA 222 foram conectadas às interfaces adaptadoras de maneira a injetar o sinal de áudio de referência ao sistema em estudo, através da console de operação do ACC ou através da aeronave, dependendo da condição de teste. Para testes cuja origem do sinal foi a console do ACC, o sinal foi injetado através de interfaces do tipo "Console SITTI"'. Para testes cuja origem do sinal foi a aeronave, os sinais foram injetados a partir da Interface do tipo "Aeronave", conectada à entrada de microfone da aeronave.

Já no caminho da recepção, nos testes cujo destino foi a aeronave, a chegada dos sinais ocorreu através de interface tipo "Aeronave", que foi ligada no conector da aeronave destinado ao uso de fones de ouvido. Já nas recepções realizadas nos órgãos operacionais, a chegada dos sinais foi realizada através de interfaces do tipo "SITTI", conectadas à saída de fone de ouvido da posição de operação.

As interfaces do tipo "Aeronave"” e "SITTI"” foram construídas especificamente para esta aplicação, e contam com componentes a fim de adequar os sinais de entrada e saída da interface UCA 222, respectivamente, para o uso nas conexões disponíveis nas aeronaves e nos postos de operação de controle de tráfego aéreo. Maiores detalhes sobre a construção dos adaptadores, com os circuitos implementados podem ser encontrados no Anexo A.

\subsubsection{DETALHAMENTO DAS CONDIÇÕES DE TESTE}

Conforme pode ser verificado nas tabelas 7 e 8 , foram realizados 14 testes utilizando grupos de frases elaborados conforme as prescrições da ITU-T P.800 e 8 testes utilizando grupos de frases padronizadas de controle de tráfego aéreo. A seguir, serão detalhadas as condições de teste empregadas neste estudo. As condições climáticas encontradas durante os testes em vôo, descritas em maiores detalhes no Anexo $\mathrm{H}$, eram boas, com baixa nebulosidade. 
Grupos 11 e 1A: a comunicação foi realizada entre uma console do ACC-CW, localizada no CINDACTA II e uma console do APP-CW, localizada no DTCEA, no Aeroporto Afonso Pena, Curitiba-PR. A comunicação foi realizada através do sistema de telefonia operacional denominado TF1, cujas especificações são definidas na ICA102-14. A Figura 21 apresenta um diagrama simplificado dos equipamentos e meios utilizados neste teste. O sinal de referência gravado em estúdio e pré-processado é reproduzido através da interface de áudio, injetado na console do operador através da interface tipo SITTI, localizada no ACC. No interior da console de operação é digitalizado e trafega internamente até a central, localizada na Sala Técnica de comunicações, em padrão Plesiochronous digital hierarchy (PDH), hierarquia E1. Na central, é novamente convertido em banda base analógico no padrão E\&M, vai até o distribuidor geral (DG) e depois ao multiplexador, em que é novamente digitalizado no padrão E1. Em seguida, acessa equipamentos da operadora contratada, que utiliza um enlace de fibra ótica de capacidade de 2 Mbps. Ao chegar no bastidor da operadora no DTCEA-CT, passa pelo de-multiplexador, pelo DG e entra na central de áudio SITTI em padrão E\&M. É novamente digitalizado e segue para a console do operador em padrão E1, é novamente convertido em banda base e enviado à interface de reprodução, onde é captado e gravado pelo sistema de gravação. Neste teste serão analisados os efeitos de degradações de áudio ocasionados pelas sucessivas conversões de sinal, da canalização empregada e dos equipamentos utilizados.

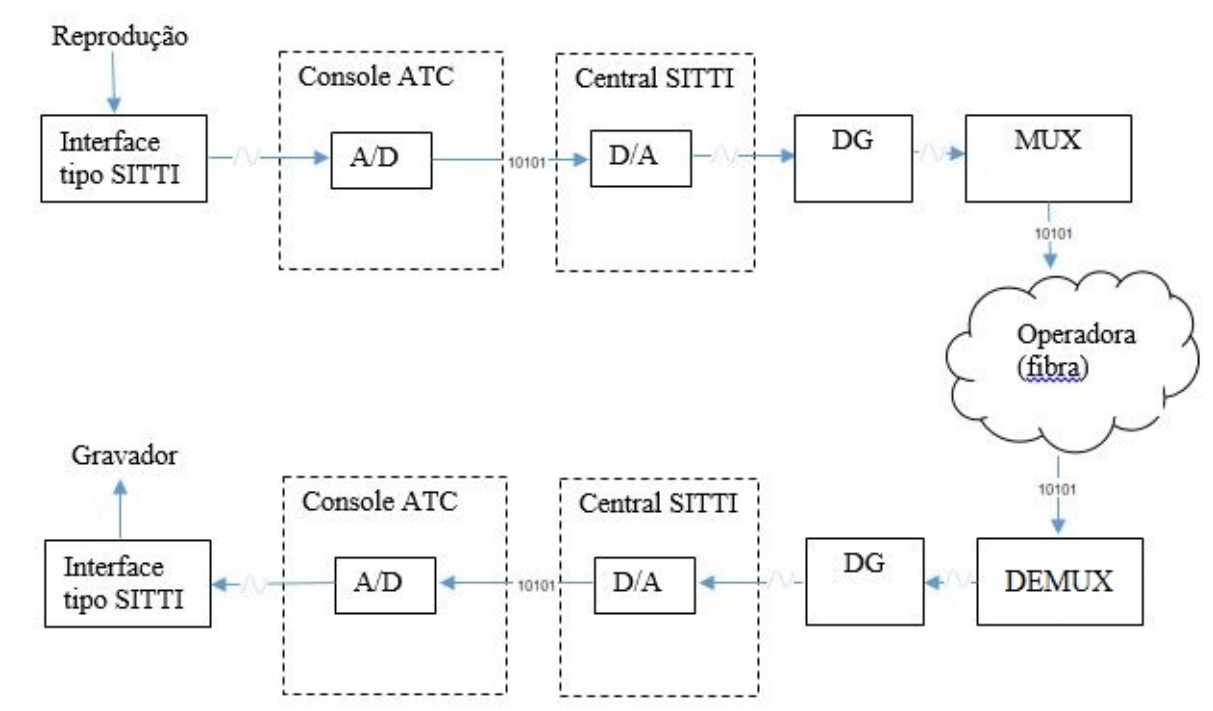

Figura 21: Diagrama simplificado de sistema sob teste, grupos G11 e G1A, entre ACC-CW e APPCW

Grupos 12 e 2A: a comunicação foi realizada entre duas consoles do ACC-CW. O diagrama de blocos simplificado do roteamento do sinal é apresentado na Figura 22. Verifica-se que o sinal é injetado na console do operador, em que é digitalizado. Trafega até a central em padrão E1, e é roteado à console de destino. Nesta console, é novamente convertido em sinal 
analógico e enviado para reprodução, que é captada por meio da interface de áudio tipo SITTI e encaminhada para o gravador. Neste teste, o número de conversões de sinal é mínimo sendo que o mesmo é digitalizado apenas uma vez.

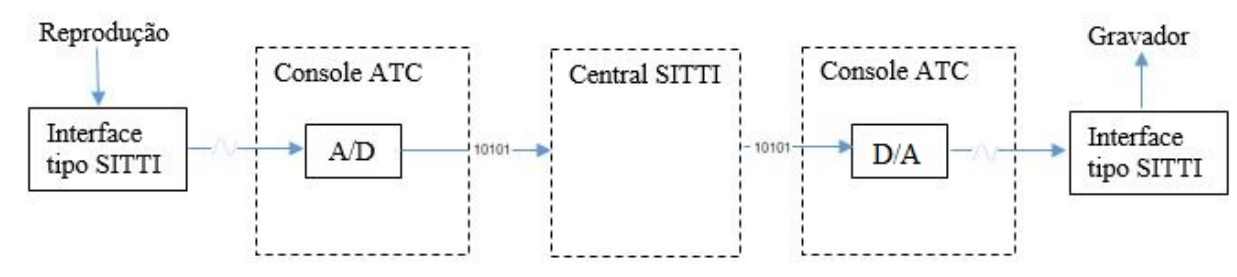

Figura 22: Diagrama simplificado de sistema sob teste, grupos G12 e G2A, entre duas consoles do ACC-CW

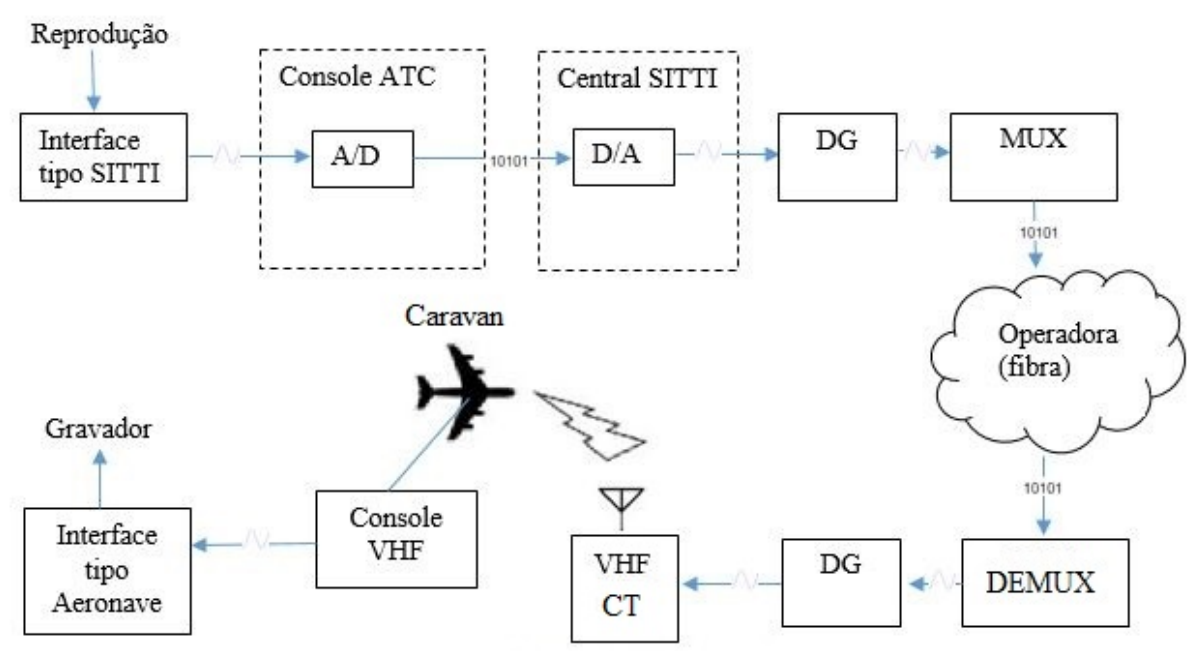

Figura 23: Diagrama simplificado de sistema sob teste, grupos G13 e G3A, entre console do ACCCW e Aeronave CARAVAN, na frequência $127,5 \mathrm{MHz}$, transmissão através do DTCEA-CT

Grupos 13 e 3A: a comunicação foi realizada entre uma console do ACC-CW e o avião Caravan, quando este se localizava nas coordenadas $25^{\circ} 24^{\prime} 02,4^{\prime \prime} \mathrm{S} 49^{\circ} 14^{\prime} 10,2^{\prime \prime} \mathrm{W}$, em solo, na parte externa do hangar do CINDACTA II. O diagrama de blocos simplificado do roteamento do sinal é apresentado na Figura 23. Verifica-se que o sinal é injetado na console do operador, em que é digitalizado. Trafega até a central em padrão E1, é convertido para analógico e segue em padrão E\&M ao DG. Entra no multiplexador, passa pelos equipamentos da operadora e segue ao DTCEA-CT através de enlace de fibra ótica contratado de capacidade de 2 Mbps. No DTCEACT é transformado em padrão analógico E\&M, segue para o DG e trafega em banda base até a Casa de transmissão de VHF (KT-VHF), onde é modulado na frequência de $127,5 \mathrm{MHz}$ e transmitido. O sinal é captado no transceptor da aeronave Caravan sintonizado na frequência mencionada. Conectado ao transceptor está a interface do tipo Aeronave, que encaminha o sinal 
para gravação na interface de áudio. Nesta condição foram incluídos elementos de comunicação em radiofrequência que terão seu desempenho avaliado nos testes subjetivos.

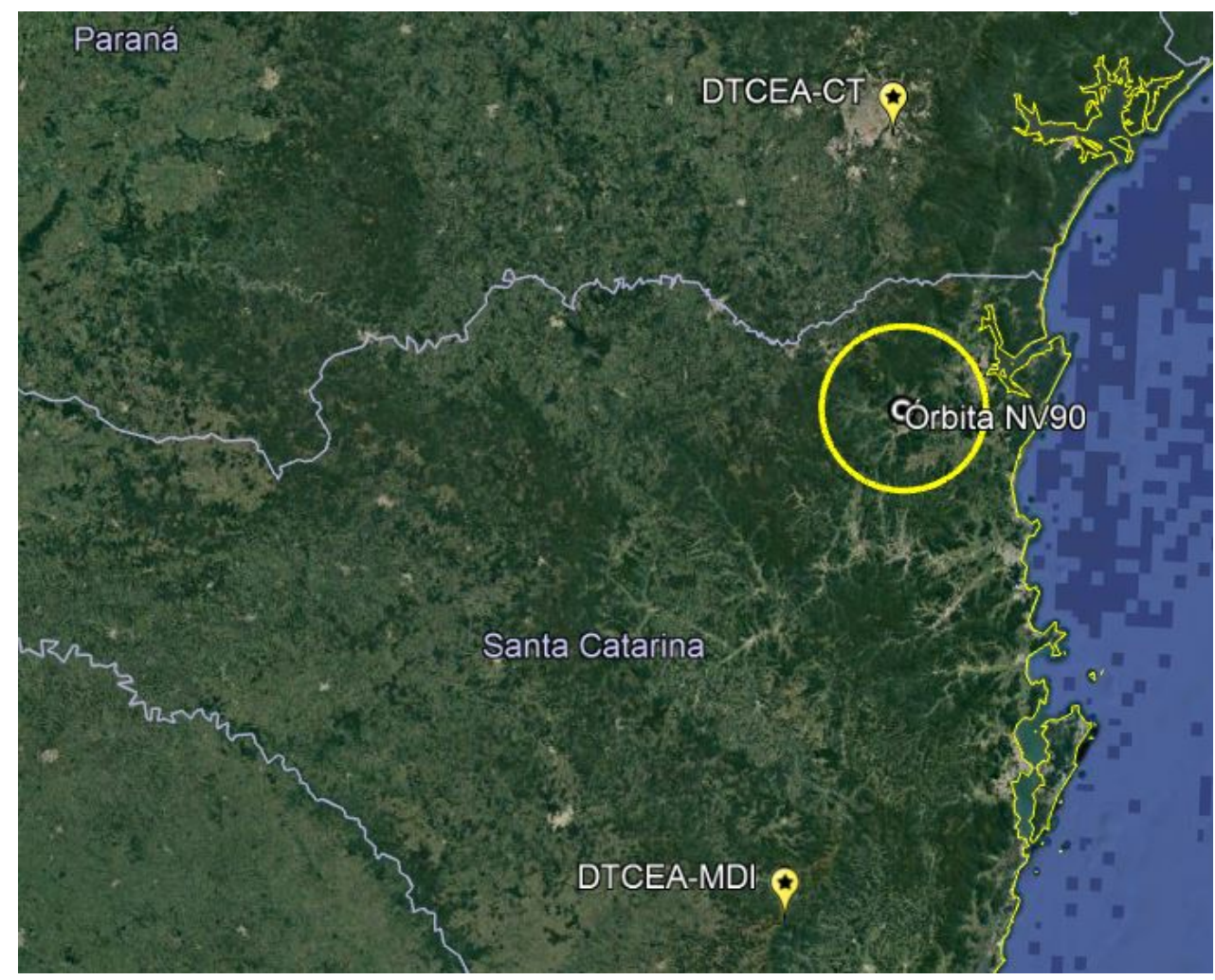

Figura 24: Mapa de vôo, condições de teste G16, G17, G18, G5A e G6A, identificando órbita e estações terrenas de VHF do DTCEA-CT e DTCEA-MDI

\section{Fonte: Google Earth}

Grupos 14, 15 e 4A: a comunicação foi realizada entre o avião Caravan, quando este se localizava nas coordenadas $25^{\circ} 24^{\prime} 02,4^{\prime \prime} \mathrm{S} 49^{\circ} 14^{\prime} 10,2^{\prime \prime} \mathrm{W}$, em solo, na parte externa do hangar do CINDACTA II, e uma console do ACC-CW. O diagrama de blocos simplificado do roteamento do sinal é apresentado na Figura 25. Verifica-se que o sinal é injetado na console do avião, e é transmitido em AM na frequência 127,5 MHz. O sinal é captado pela estação terrena do DTCEA-CT, localizada no Aeroporto Afonso Pena, em Curitiba - PR e é demodulado. É transmitido em banda base até o DG, é digitalizado e enviado ao CINDACTA II através de enlace de fibra ótica contratado. Na sede do CINDACTA II é convertido em sinal analógico novamente em formato $E \& M$, entra no DG e é distribuído à central de áudio, onde é novamente digitalizado. É roteado até a console do ACC digitalmente por meio de padrão E1, onde então é novamente convertido em banda base para reprodução, sendo captado pela interface do tipo SITTI e enviado ao gravador.

Grupos 16 e 6A: Da mesma maneira que nos grupos 13 e 3A, a comunicação foi 


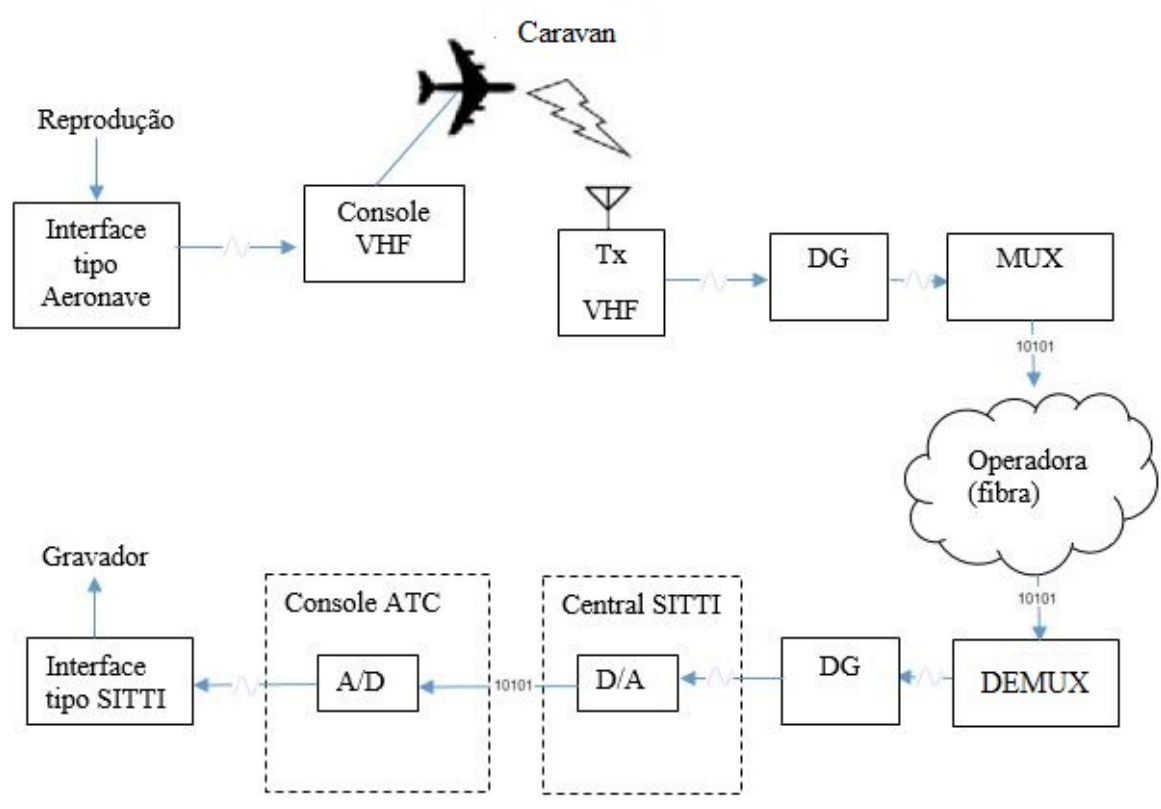

Figura 25: Diagrama simplificado de sistema sob teste, grupos G14, G15 e G4A, entre Aeronave CARAVAN e console do ACC, na frequência 127,5 MHz, transmissão através do DTCEA-CT

realizada entre uma console do ACC-CW e o avião Caravan. O diagrama de blocos simplificado do roteamento do sinal é o mesmo já apresentado na Figura 23, os sinais seguem o mesmo caminho e foi utilizada a mesma frequência de comunicação VHF. A diferença é que a aeronave Caravan estava orbitando uma área de raio aproximado de $30 \mathrm{~km}$ sobre as coordenadas $26^{\circ} 25^{\prime}$ 31,88” S, 49 06' 00,25” W, em nível 90 (9.000 pés, ou cerca de 2.700 m) enquanto recebia as transmissões do DTCEA-CT. A Figura 24 apresenta o mapa de vôo e posicionamento da estação transmissora do DTCEA-CT.

Grupo 17: Da mesma maneira que nos grupos 13 e 3A, a comunicação foi realizada entre uma console do ACC-CW e o avião Caravan. O diagrama de blocos simplificado do roteamento do sinal para este teste é apresentado na Figura 26, os sinais seguem o mesmo caminho mencionado no teste dos grupos 13 e $3 \mathrm{~A}$ até o DTCEA-CT e foi utilizada a mesma frequência de comunicação VHF. Paralelamente, o sinal foi repetido, digitalizado e transmitido ao DTCEAMDI (Morro da Igreja, Urubici - SC) por meio de canalização satelital Telesat, administrada pelo DECEA, operando em banda C (faixa de 4 a $8 \mathrm{GHz}$ ). Nesta localidade, o sinal é convertido para banda analógica no padrão E\&M e levado à KT-VHF para transmissão. Também de maneira semelhante ao teste dos grupos 16 e 6A, a aeronave Caravan estava orbitando uma área próxima à Florianópolis enquanto recebia, simultaneamente, as transmissões do DTCEA-CT e DTCEA-MDI. A Figura 24 apresenta o mapa de vôo e posicionamento da estação transmissora do DTCEA-CT e DTCEA-MDI. 


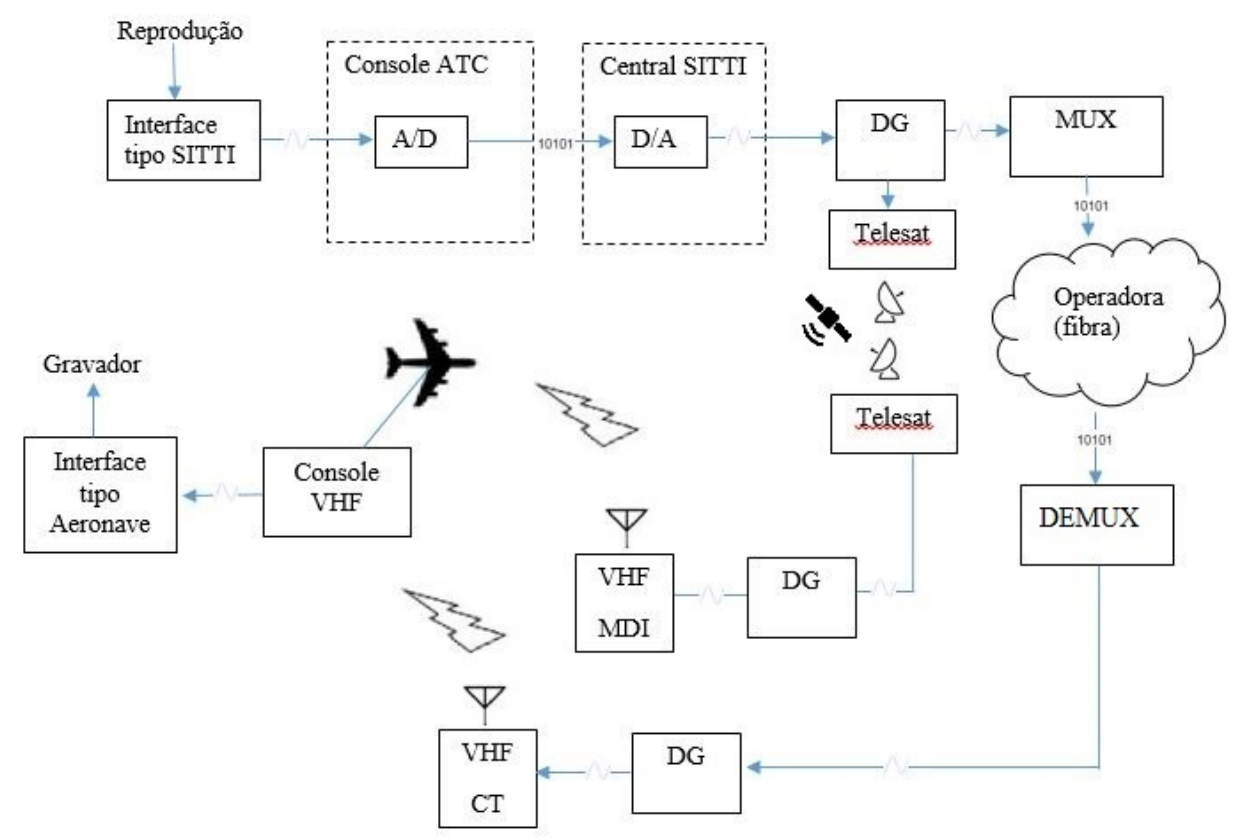

Figura 26: Diagrama simplificado de sistema sob teste, grupo G17, entre ACC-CW e aeronave Caravan

Grupos 18 e 5A: Neste teste, a comunicação foi realizada no sentido da aeronave para uma console do ACC. A aeronave sobrevoava a área indicada na Figura 24 enquanto transmitia os sinais referentes aos grupos de frases G18 e G5A, modulando na frequência 127,5 MHz. Conforme diagrama simplificado da Figura 27, o sinal foi recebido pela estação terrena de VHF do DTCEA-MDI, digitalizado no sistema Telesat, transmitido até o CINDACTA II por enlace satelital. Na sala técnica do CINDACTA II foi novamente convertido em sinal analógico E\&M e encaminhado, através do DG, para a central de áudio SITTI. Na central o sinal é novamente digitalizado, convertido no padrão $\mathrm{E} 1$ e roteado à respectiva console, onde é convertido novamente para banda base e captado pela interface do tipo SITTI para envio ao gravador.

Para os demais testes (G19, G20, G21, G22, G23, G24, G7A e G8A) foi utilizada aeronave do Grupamento de Ensaios em Vôo do DECEA (GEIV), com teto operacional mais elevado para atingir níveis de vôo superiores a 100 (10.000 pés, ou $3.048 \mathrm{~m}$ ). A aeronave escolhida voou o caminho ABC identificado na Figura 28, em que o segmento AB mede $220 \mathrm{~km}$, o segmento BC $165 \mathrm{~km}$ e CA $100 \mathrm{~km}$. Foi utilizada uma órbita maior do que nos testes realizados pela aeronave Caravan tendo em vista que o avião do GEIV possui possui velocidade de cruzeiro bem superior a do outro avião, de aproximadamente $800 \mathrm{~km} / \mathrm{h}$. O nível de vôo escolhido foi o 250 (25.000 pés, ou $7.620 \mathrm{~m}$ ) e os pontos A, B e C possuem, respectivamente, as seguintes

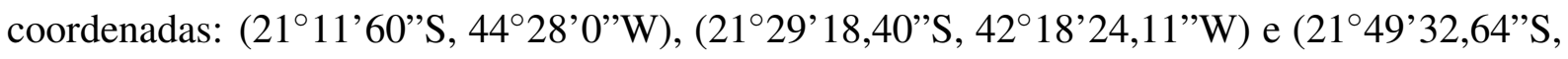
4350'41,19'”'). 


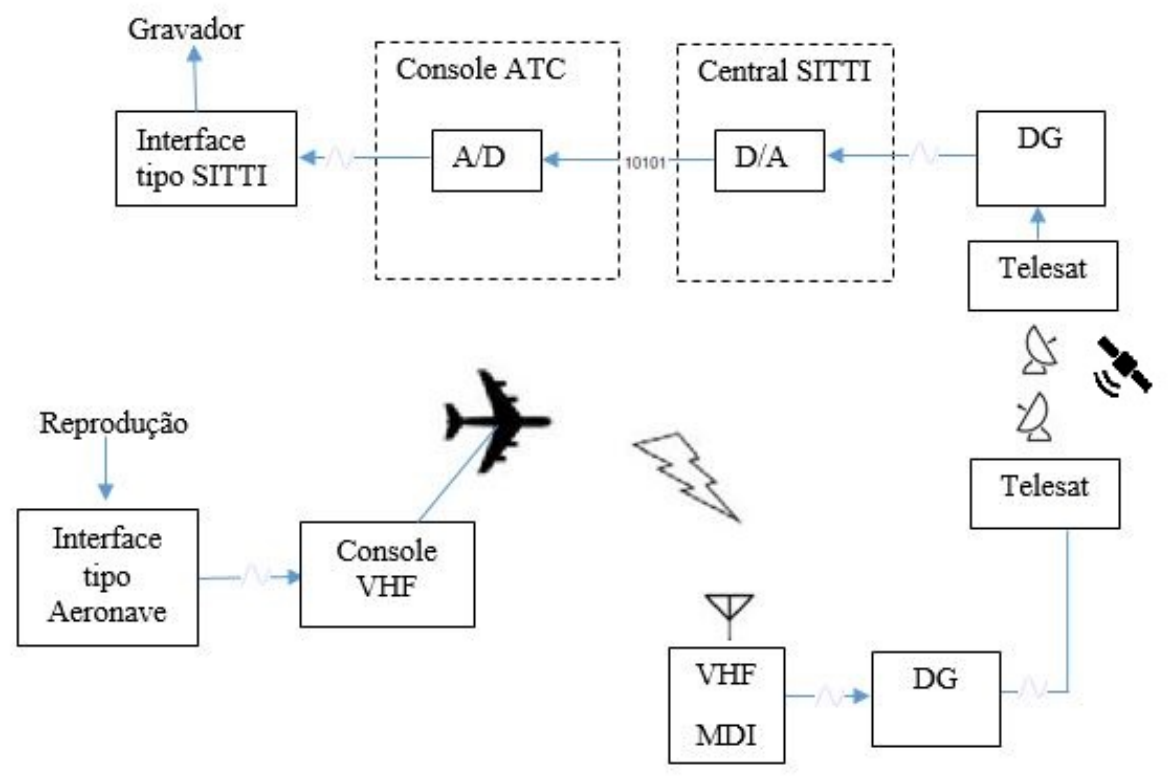

Figura 27: Diagrama simplificado de sistema sob teste, grupos G18 e G5A, entre aeronave Caravan e console do ACC-CW. Recepção através da estação VHF do DTCEA-MDI. Frequência 127,5 MHz

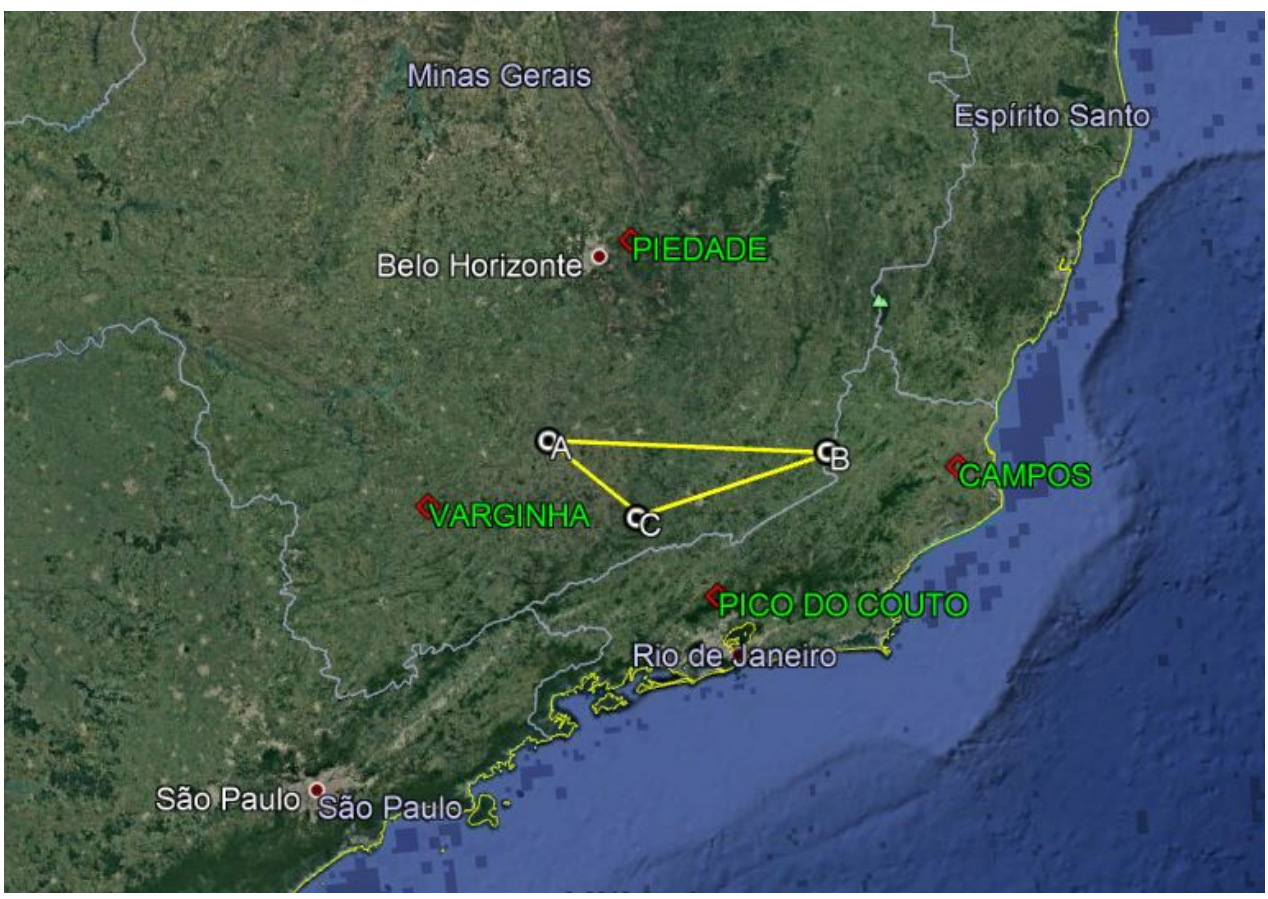

Figura 28: Mapa de vôo, condições de teste G19, G20, G21, G22, G23, G24, G7A e G8A identificando órbita e estações terrenas de VHF de Campos, Piedade, Pico do Couto e Varginha

\section{Fonte: Google Earth}

Grupo 19: Conforme pode ser verificado na Figura 29, os sinais do grupo 19 foram inseridos na console do ACC através de uma interface do tipo SITTI, digitalizados, roteados através da central de áudio, convertidos para banda base no padrão E\&M, duplicados e encami- 
nhados até o sistema Telesat em dois transponders distintos. Nas estações terrenas de Pico do Couto - RJ (PCO) e Campos-RJ (CAM) os sinais foram recebidos, transformados novamente em banda base e encaminhados através do DG para as KT-VHF para serem transmitidos. Os sinais foram captados simultaneamente pelo transceptor da aeronave do GEIV e gravados.

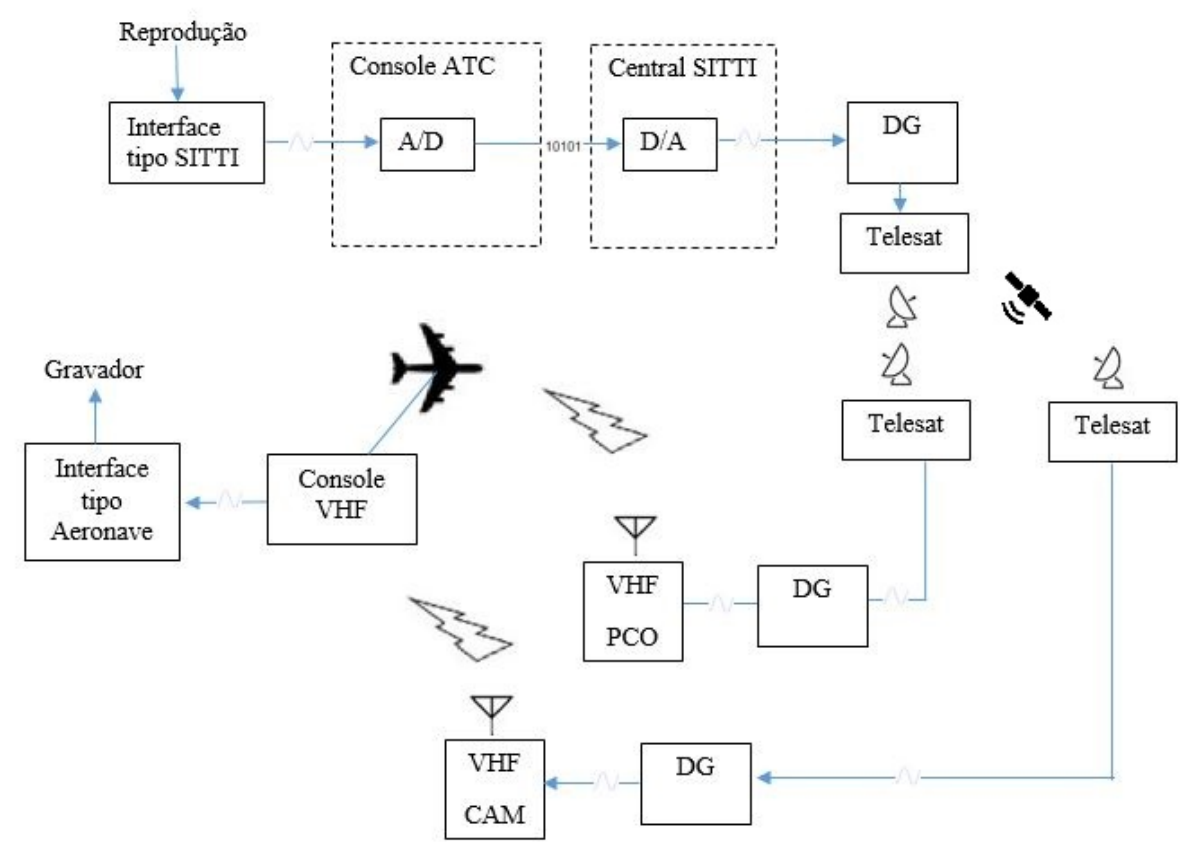

Figura 29: Diagrama simplificado de sistema sob teste, grupo G19, entre console do ACC e aeronave do GEIV. Transmissão através das estações VHF de Pico do Couto e Campos, frequência $133,6 \mathrm{MHz}$

Grupos 20 e 7A: O diagrama simplificado de sistema deste teste é mostrado na Figura 30. De maneira geral, é muito semelhante ao utilizado no teste do G19, com a diferença que o sinal é replicado para uma terceira estação, localizada em Piedade - MG (PIE). A comunicação também foi realizada na frequência 133,6 MHz utilizando canalização satelital administrada pelo DECEA. Neste teste buscou-se verificar os eventuais efeitos de degradação de qualidade de áudio no processo de clímax (sobreposição). Buscou-se, de maneira proposital, o sobrevôo da aeronave numa área com intercepção das áreas de influência das estações de PCO, PIE e CAM.

Grupo 21: O teste foi realizado conforme diagrama simplificado mostrado na Figura 31, muito semelhante aos testes com os grupos 19, 20 e 7A. A diferença em relação aos experimentos conduzidos nos outros experimentos é que a transmissão ocorreu apenas pelas estações terrenas de PCO e PIE.

Grupo 22: De maneira análoga aos testes anteriores, a transmissão foi realizada entre 


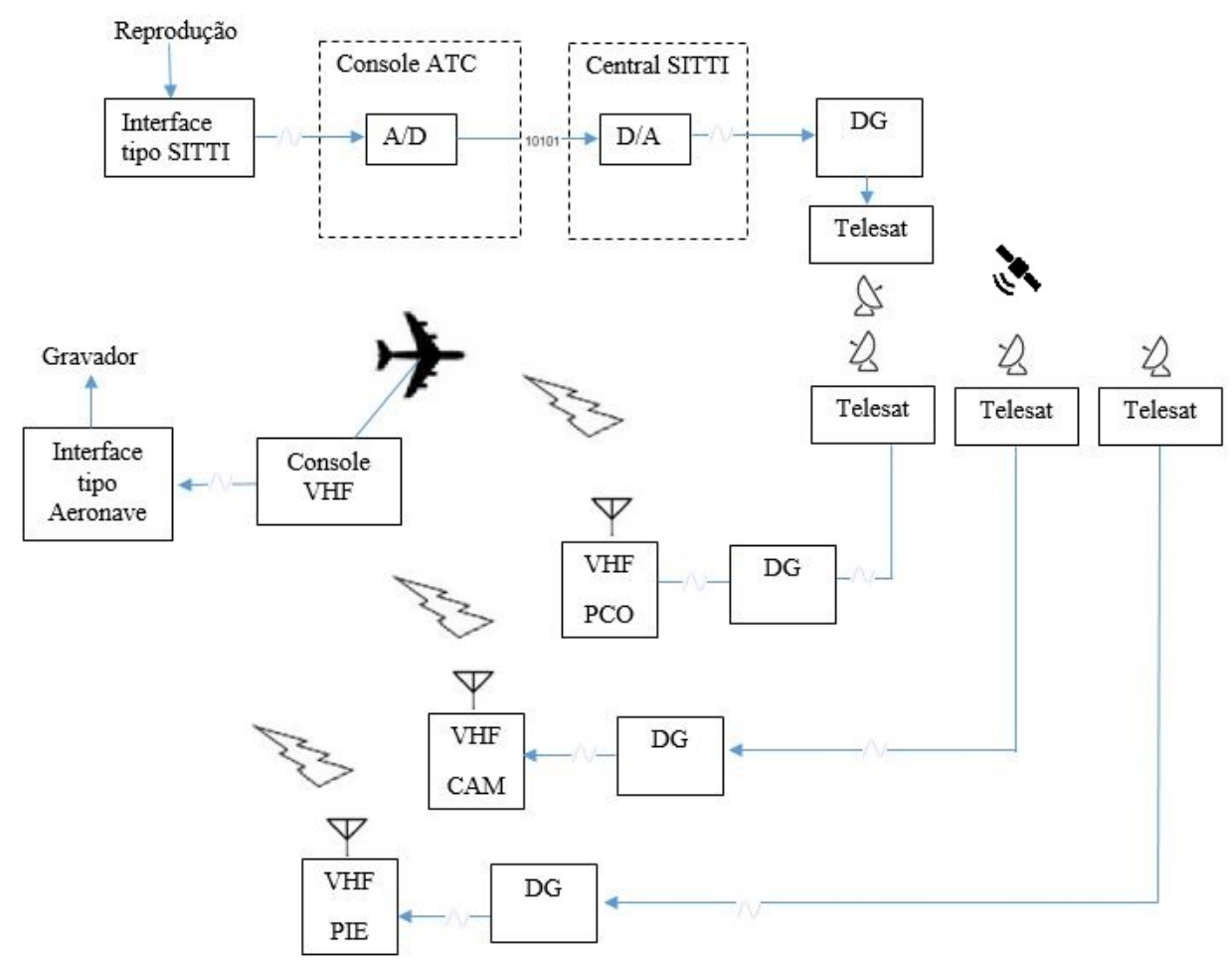

Figura 30: Diagrama simplificado de sistema sob teste, grupos G20 e G5A, entre console do ACC e aeronave do GEIV. Transmissão através das estações VHF de Pico do Couto, Campos e Piedade, frequência 133,6 MHz

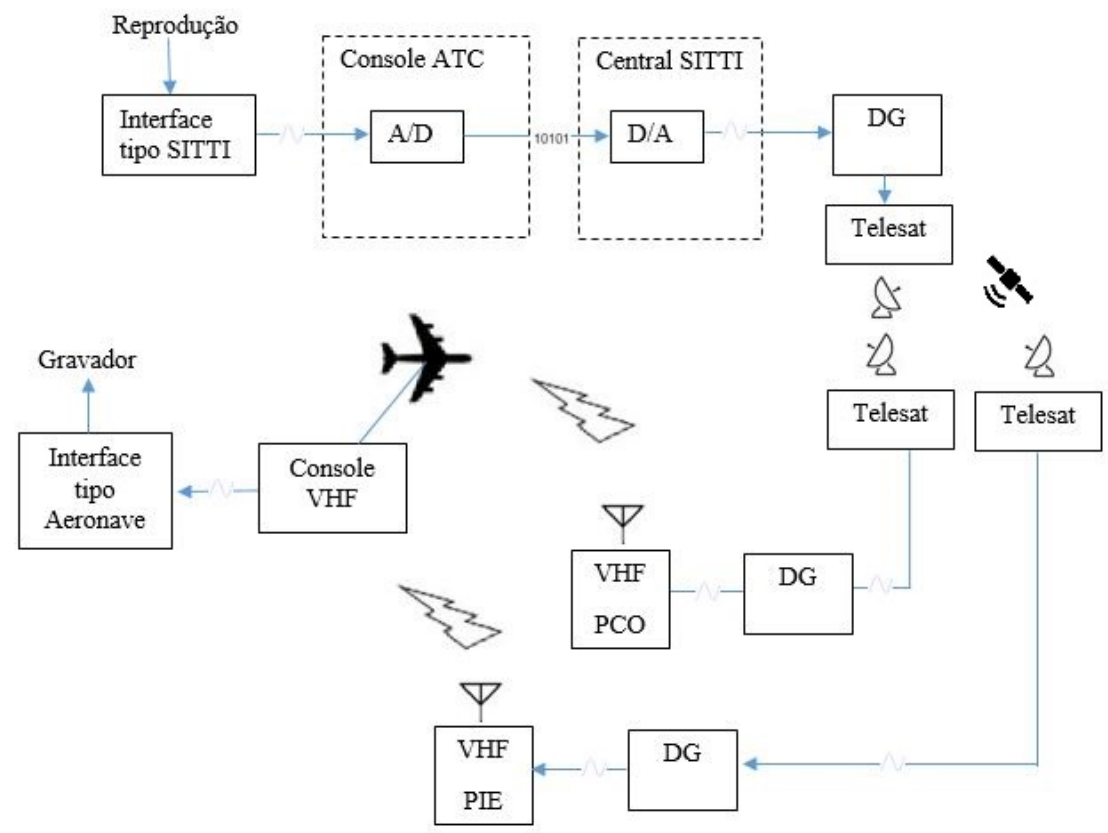

Figura 31: Diagrama simplificado de sistema sob teste, grupo G21, entre console do ACC e aeronave do GEIV. Transmissão através das estações VHF de Pico do Couto e Piedade, frequência $133,6 \mathrm{MHz}$ 
o console do ACC e a aeronave do GEIV. Este teste seguiu o diagrama simplificado mostrado na Figura 32. A diferença em relação aos testes conduzidos nos outros experimentos é que a transmissão ocorreu apenas pelas estações terrenas de PCO e VARG, e foi utilizada a frequência $125,35 \mathrm{MHz}$.

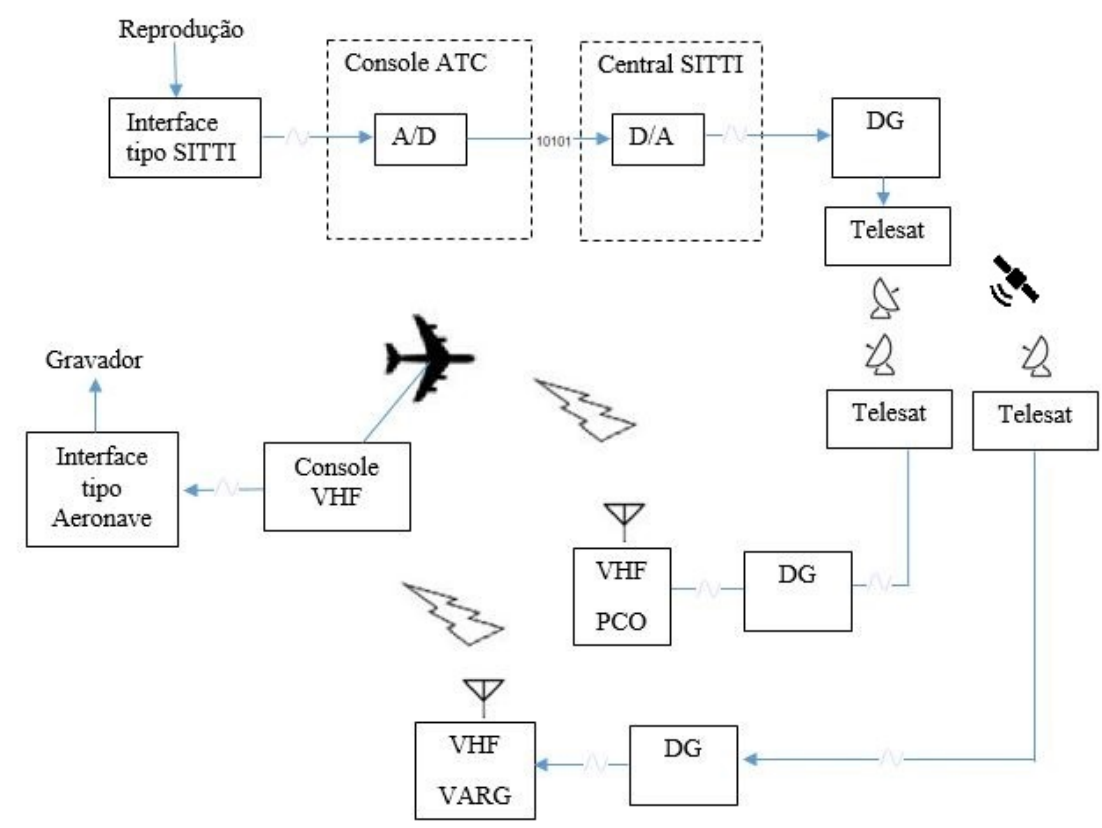

Figura 32: Diagrama simplificado de sistema sob teste, grupo G22, entre console do ACC e aeronave do GEIV. Transmissão através das estações VHF de Pico do Couto e Varginha, frequência $125,35 \mathrm{MHz}$

Grupos 23 e 8A: Também para estes testes, a transmissão foi realizada entre o console do ACC e a aeronave do GEIV. Para a execução, seguiu-se o diagrama simplificado mostrado na Figura 33. Foi utilizada a frequência 125,35 MHz. As diferenças em relação aos testes conduzidos nos outros experimentos é que a transmissão ocorreu pelas estações terrenas de PCO, VARG e PIE. No caso desta frequência, para a estação terrena de Piedade, a ligação de dados é realizada por meio de operadora contratada, que tem a flexibilidade de utilizar o meio que desejar, desde que atenda às especificações mínimas contratados.

Grupo 24: A transmissão foi realizada entre o console do ACC e a aeronave do GEIV conforme o diagrama simplificado mostrado na Figura 34. Foi utilizada a frequência 125,35 MHz. As diferenças em relação aos testes conduzidos nos outros experimentos é que a transmissão ocorreu pelas estações terrenas de PCO e PIE. 


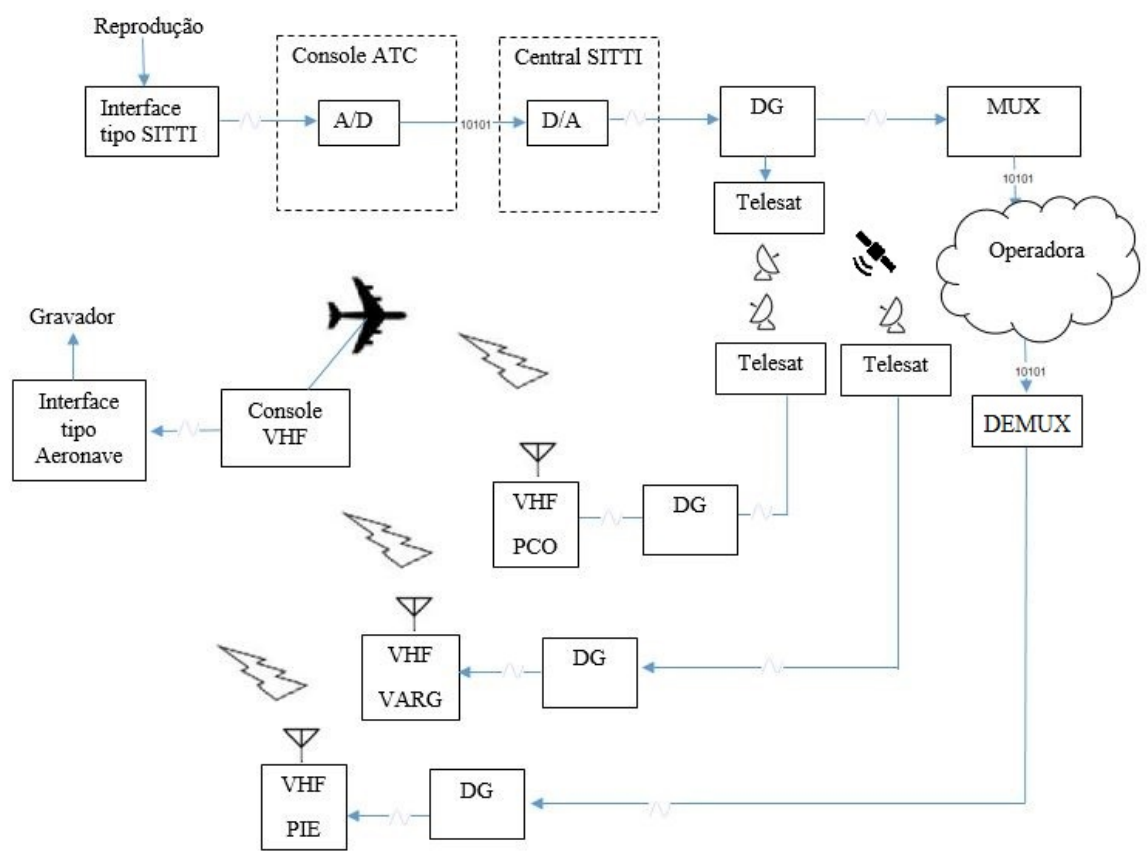

Figura 33: Diagrama simplificado de sistema sob teste, grupos G23 e G8A, entre console do ACC e aeronave do GEIV. Transmissão através das estações VHF de Pico do Couto, Varginha e Piedade, frequência 125,35 MHz

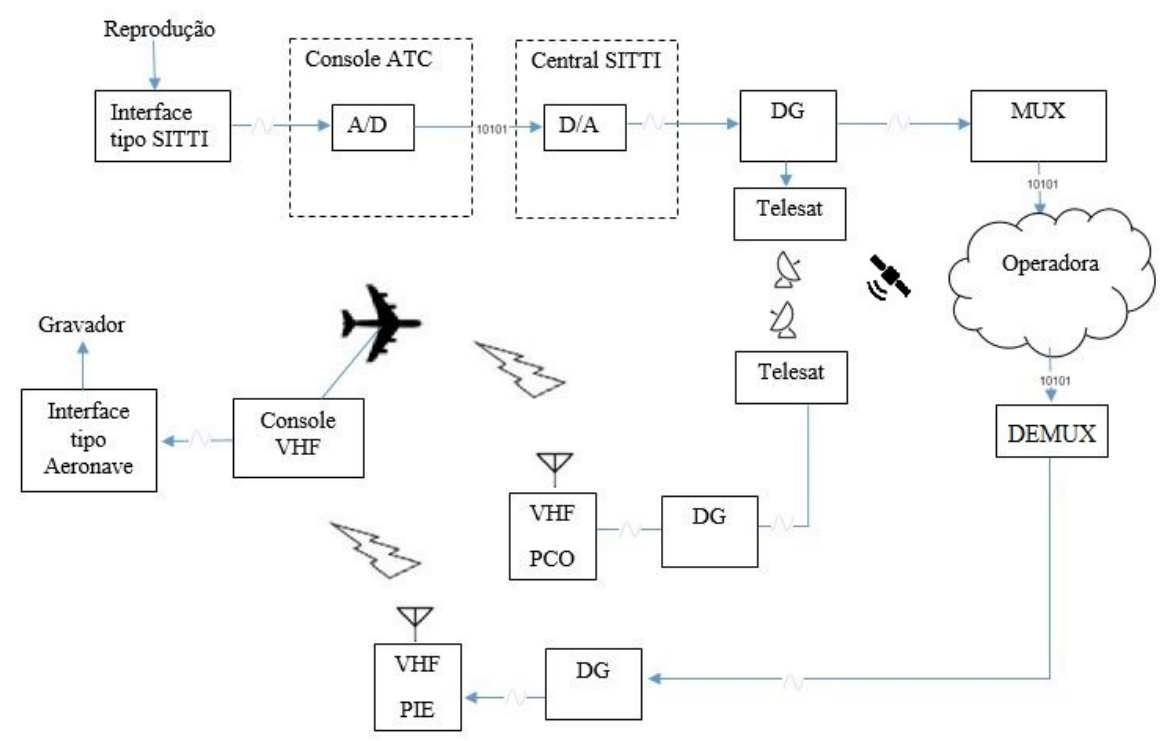

Figura 34: Diagrama simplificado de sistema sob teste, grupo G24, entre console do ACC e aeronave do GEIV. Transmissão através das estações VHF de Pico do Couto e Piedade, frequência $125,35 \mathrm{MHz}$

\subsubsection{EXECUÇÃO DOS TESTES EM VÔO}

Cabe destacar que, embora não sejam procedimentos detalhados nesta dissertação por não serem relacionados ao tema, a realização dos testes com aeronaves consumiu recursos con- 
sideráveis e teve essencial apoio de uma equipe grande de profissionais especializados da Aeronáutica. A realização dos ensaios de vôo necessitou, resumidamente, das seguintes atividades:

1. Aprovação de necessidade e agendamento de aeronave junto ao GEIV, oficializado através do Comando do CINDACTA II àquele órgão, para os testes que envolveram nível de vôo superior ao 100 ;

2. Elaboração de planejamento do experimento: com identificação dos pontos de interesse para teste, frequências a serem testadas, equipamentos a serem utilizados, reserva de horas de vôo, escala de tripulação. Essas atividades foram realizadas em conjunto com a equipe do GEIV para os vôos de nível elevados (acima do 100) e com a equipe da CAV do CINDACTA II para os vôos executados com a aronave Caravan;

3. Elaboração de plano de vôo pelos pilotos do CINDACTA II e GEIV e submissão à aprovação, respectivamente, dos Comandantes do CINDACTA II e do GEIV;

4. Disponibilização, em tempo integral, de técnicos para operação dos equipamentos de telecomunicações do CINDACTA II e de controladores de vôo para acompanhamento e coordenações junto aos pilotos das aeronaves;

5. Elaboração de metodologia e disponibilização de infraestrutura de telecomunicações para propiciar comunicação constante com a aeronave em teste;

6. Coordenação prévia do tráfego aéreo local pela equipe de controladores de tráfego aéreo do ACC-CW, para possibilitar a execução dos testes. As seguintes operações necessitaram ser realizadas: desvio do tráfego existente dos caminhos em que eram realizadas as órbitas, com coordenações constantes junto aos pilotos e alterações dos planos de vôo em curso, desocupação das frequências que foram testadas, coordenando junto às aeronaves o uso de frequências alternativas para cada setor; 


\section{AVALIAÇÃO SUBJETIVA}

A identificação da qualidade de sinais de voz é considerada uma análise subjetiva, pois depende do julgamento de indivíduos (usuários) de um determinado serviço. Um indicador muito popular utilizado para indicar a qualidade de mídias de áudio e vídeo é o MOS, que consiste na média de índices de opinião de diferentes pessoas sobre um determinado estímulo de áudio e/ou vídeo.

O MOS mostra-se um método adequado para o monitoramento da qualidade de sistemas de telecomunicações e para levantamento de dados para treinamento e validação de métricas objetivas (STREIJL et al., 2016) sendo amplamente utilizado por operadores de telecomunicações, emissoras, entre outros. Entretanto, apresenta limitações que devem ser consideradas tanto no planejamento dos experimentos, quanto na interpretação dos resultados.

Primeiramente, pode-se citar que o MOS é, em sua essência, um valor estatístico, que consiste na média de uma distribuição de um número finito de avaliações individuais e que, por isso, não é um indicador preciso. Outros indicadores que também descrevem características desta distribuição (como desvio padrão, intervalo de confiança, curtose, etc.) também podem, portanto, ser considerados na análise dos resultados. Outra crítica ao MOS é que ele assume homogeneidade dos participantes do experimento, tendo em vista que o seu resultado é fornecido pela média aritmética entre as avaliações (XU et al., 2011). Outras limitações incluem o fato da opinião dos participantes poder ser afetada pelas expectativas iniciais do usuário, pela faixa de degradações apresentadas durante as sessões, e por fatores humanos, como humor, diferenças de julgamento, entre outros (STREIJL et al., 2016). Além disso, apresenta pouca informação sobre a causa do problema, tornando a detecção de possíveis falhas difícil.

Quanto aos métodos de teste, podem ser empregados diferentes possibilidades como o Absolute category rating (ACR), Double-stimulus impairment scale (DSIS), Double-stimulus continuous quality scale (DSCQS), entre outros (STREIJL et al., 2016). No ACR, por exemplo, a avaliação pelos participantes é realizada numa escala discreta de 1 a 5 , após uma única exposição do sinal de teste. Já nos DSIS e DSCQS, são apresentados aos avaliadores os sinais 
degradados e o não degradados e a avaliação é realizada numa escala contínua de 1 a 5 para o DSCQS e numa escala de degradações para o DSIS.

A escolha dos métodos de teste depende dos objetivos do experimento, das limitações de tempo disponível, entre outros. Estudos como o de Tominaga et al. mostram altos índices de correlação (linear e de postos) entre ensaios realizados utilizando estes métodos de teste citados, apresentando resultados entre 0,96 e 0,99 (TOMINAGA et al., 2010). Este estudo também mostra que o tempo de avaliação é geralmente menor quando o ACR é utilizado.

Neste capítulo será realizada uma breve descrição do estado da arte da avaliação subjetiva, uma descrição do método escolhido neste trabalho, sua aplicação e os resultados obtidos.

\subsection{ESTADO DA ARTE}

Os testes de análise subjetiva utilizados para levantamento de qualidade de voz consistem na aplicação de trechos de áudio submetidos a determinado tratamento a um grupo de pessoas que avaliam a qualidade do sinal em termos de qualidade ou inteligibilidade.

Os métodos de análise subjetiva, embora dispendiosos em termos de tempo e custo, continuam sendo a maneira mais confiável de encontrar o MOS. Os estudos recentes pesquisados como (MöLLER, 2016), (JASSIM;; ZILANY, 2015) , (SALEHI, 2016), (ANDERSON AVILA; BENJAMIN, 2016) e outros, que incluem pesquisas de métodos de análise objetiva de qualidade de áudio, utilizam os resultados de testes subjetivos tanto para treinamento quanto para validação dos resultados obtidos por meio de análises objetivas. Os próprios métodos de análise objetiva normalizados pela ITU-T, como o P.563 (ITU, 2004), são validados utilizando bases de dados provenientes de análise subjetiva.

Dentre as metodologias utilizadas para a realização destes experimentos, um método há bastante tempo consolidado e que é amplamente empregado nos estudos atuais é o MOS, definido na norma ITU-T P.800 (ITU, 1996b), cuja principal desvantagem é o elevado custo das pesquisas de opinião (SUN; IFEACHOR, 2002). Este método, desenvolvido inicialmente para testar o desempenho de sistemas telefônicos (que opera em banda estreita) balizou os experimentos realizados nos estudos citados no parágrafo anterior e foi estendido, inclusive, a outros tipos de uso, como avaliação de sistemas que operam com áudio de alta fidelidade, em aplicações de multimídia em dispositivos eletrônicos móveis, comunicações analógicas ou digitais e até em equipamentos de auxiliares de audição (FALK et al., 2015), por apresentar método de avaliação que independe do tipo de problema sofrido pelo áudio e ampla repetitividade. Desde a sua criação, em 1996, este padrão mostrou capacidade de avaliar sinais sujeitos 
a diferentes problemas como perdas, erros de transmissão, ruídos, eco, incorreções de tempo de propagação, entre outros.

\subsection{REQUISITOS NORMATIVOS}

Pelos motivos apontados, a metodologia descrita na ITU-T P.800 foi escolhida para a realização do experimento subjetivo necessário a esta pesquisa. O procedimento definido nesta norma consiste na gravação de frases aleatórias de curta duração em ambiente e em situações controladas. Em seguida esses áudios devem ser organizados em listas, formando grupos de frases, e cada lista submetida a um tipo de tratamento, sendo algumas listas tratadas com métodos de referência e outras submetidas ao sistema sob estudo. Todos estes procedimentos foram realizados e estão detalhados nos Capítulos 2 e 3.

Os sinais são então gravados e submetidos à avaliação de pessoas não treinadas que deverão realizar a classificação dos áudios de voz segundo um parâmetro de qualidade. Foi escolhido o método de ensaio do ACR por apresentar o menor tempo de execução, em que os participantes são expostos uma única vez somente aos sinais degradados, e avaliam numa escala discreta de 1 a 5 , em que 5 representa qualidade "excelente"e 1 qualidade "péssima". Esta seção apresenta os requisitos de preparação e execução do experimento subjetivo, conforme normatizado na ITU-T P.800.

\subsubsection{PLANEJAMENTO DO EXPERIMENTO}

Após a realização das gravações dos áudios em estúdio, pré-processamentos, degradações controladas e testes, deve ser elaborado um planejamento do experimento. Este planejamento deverá levar em consideração as seguintes premissas:

- o tempo de avaliação dos sinais de áudio deverá preferencialmente ser inferior a 20 minutos, e nunca superior a 40 minutos, a fim de se evitar a fadiga do sujeito humano;

- deverá ser previsto o número de sessões de avaliação e o número de pessoas de maneira que o tempo de avaliação máximo não seja desrespeitado;

- deverá ser levado em consideração efeitos de cansaço dos participantes; e

- deverá ser levado em consideração efeito de sugestão da ordem de apresentação.

A limitação do tempo de avaliação deve ser utilizado para calcular o número de frases que poderão ser analisadas numa determinada sessão bem como estimar o número de 
sessões previstas. Embora a norma ITU-T P.800 cite que deverá haver tempo de silêncio "adequado"entre cada frase e o período de avaliação, nenhum parâmetro objetivo é citado. Entretanto, durante a pesquisa bibliográfica foi encontrada a recomendação ITU-T P.807 (ITU, 2016), norma recente (2016) que trata de avaliação subjetiva de inteligibilidade de sinais de voz, que recomenda que o tempo de teste e de pausas seja aproximadamente igual. Tendo em vista a similaridade das normatizações, este parâmetro pode ser considerado adequado para aplicações de análise subjetiva de qualidade de áudio.

\subsubsection{REQUISITOS DE EXECUÇÃO}

Neste item são apresentados os requisitos da norma ITU-T P.800 com relação o processo de execução dos testes. Quanto aos requisitos físicos do ambiente de reprodução dos áudios, a norma define as mesmas características do ambiente de gravação, verificados no item 2.2, ou seja: possuir volume na faixa de 30 a $120 \mathrm{~m}^{3}$, ruído inferior a $30 \mathrm{dBA}$ e tempo de reverberação RT60 (definido pela ISO 3382-2) inferior a 500 ms.

Quanto ao sistema de reprodução, a norma define que o mesmo deverá possuir resposta em frequência e sensibilidade compatível com a aplicação, e o nível de reprodução deve ser ajustado por meio do tom de calibração gerado na etapa de preparação (conforme item 2.4.3). A referida norma não cita um nível de reprodução considerado adequado, entretanto, utilizandose como parâmetro a base de dados contida na ITU-T P.23 (ITU, 1998), foi utilizado 79 dB de pressão sonora para a execução dos testes. Este nível equivalente a uma conversa em voz alta em ambiente comercial ruidoso.

Quanto aos requisitos pessoais, são definidas as seguintes restrições:

- os participantes não podem ter participado de testes subjetivos de áudio no período mínimo de 6 meses;

- não podem conhecer a lista de frases; e

- não podem trabalhar em área de pesquisa relacionada a qualidade de áudio.

Quanto às instruções fornecidas aos participantes, deverão ser fornecidas por escrito e verbalmente, se necessário. Quaisquer informações específicas somente poderão ser fornecidas após o término da avaliação. 


\subsection{PREPARAÇÃO DO EXPERIMENTO SUBJETIVO}

Após todas as etapas das sessões de gravação, pré-processamentos e aplicação das condições de referência e de teste, foi necessária a preparação do experimento subjetivo, realizado em conformidade com o item 4.2.1. A organização do experimento levou em consideração, primeiramente, as limitações de tempo das sessões. Foi considerado um tempo médio de 2,5 segundos por frase, com pausa de 2 segundos entre cada frase e um tempo de avaliação de 7 segundos. Considerando que são 31 grupos para análise, e que cada grupo é composto por 2 frases, chegou-se num tempo de teste de 7 minutos e 14 segundos. Considerando o tempo para leitura de instruções de 5 minutos e a realização da sessão de treinamento, com cerca de 2 minutos, chegou-se ao tempo de experimento de aproximadamente 15 minutos, abaixo, portanto, da recomendação máxima recomendável de 20 minutos.

O experimento foi planejado de maneira que:

- Cada grupo, representando um tipo de degradação/tratamento apareceu uma vez em cada sessão (arranjo de quadrados latinos);

- De maneira a considerar o efeito de ordem de apresentação/cansaço, cada tipo de degradação/ tratamento foi apresentado numa ordem aleatória diferente em cada sessão;

- Foram distribuídas o mesmo número de frases em português e em inglês em cada sessão;

- Foram distribuídas igualmente nas sessões as vozes femininas e masculinas.

As listas de reprodução das sessões subjetivas, com o nome dos arquivos, tipos de tratamentos, identificações dos locutores e tratamentos podem ser encontradas no Anexo J. Foram incluídos trechos de treinamento correspondentes aos 4 primeiros grupos de reprodução de outra lista, de maneira que dentro de cada sessão não houve repetição das frases. Assim, a lista de reprodução 1 utilizou os quatro primeiros grupos sequenciais da lista 2 como treinamento. A lista de reprodução 2 utilizou os 4 primeiros da lista 3; a lista 3 os 4 primeiros da lista 4; e a lista 4 os 4 primeiros da lista 1 .

Foi então utilizado o software de edição proprietário PROTOOLS para consolidar os arquivos das listas de reprodução, sendo introduzidos após a reprodução de cada frase de mesma identificação sequencial a pausa de 2 segundos, e uma pausa de 7 segundos ao término, para a realização da avaliação e anotação nos formulários.

Os arquivos consolidados, LISTA01.wav, LISTA 02.wav, LISTA 03.wav e LISTA 
04.wav possuem, respectivamente, as durações de: 10 min 15 segundos, 10 min 02 segundos, 10 min 01 segundos e 10 min 09 segundos.

\subsubsection{DELINEAMENTO DO EXPERIMENTO SUBJETIVO E INTERVENÇÕES NOS PAR- TICIPANTES}

A pesquisa consistiu na análise subjetiva de qualidade de sinais de áudio de voz por meio de avaliadores humanos. Foi utilizada uma amostra com 32 avaliadores. Estes componentes pertencem ao assim denominado "Grupo 2 - Avaliação"que realizou a classificação dos sinais de áudio em termos de qualidade, numa escala de 1 a 5 , em que 5 indica alta qualidade e 1, qualidade ruim. Os sinais de referência foram obtidos a partir de gravações de frases simples com 4 vozes masculinas e 4 femininas, em português e em inglês (pessoas pertencentes ao "Grupo 1 - Locução"). Os avaliadores, pertencentes ao Grupo 2 foram divididos em 4 subgrupos, e cada subgrupo analisou uma sessão de áudio diferente, de maneira a balancear os efeitos de atenção/ordem de apresentação. Os resultados obtidos são as avaliações emitidas por cada participante, que compiladas forneceram o MOS dos sinais de áudio.

Da mesma maneira que na gravação dos áudios, cuja metodologia adotada é descrita na seção 2.3.2, os procedimentos do experimento subjetivo também foram avaliados pelo CEP, que registrou aprovação no Parecer 2.163.376 de 07 de julho de 2017. Também foram elaborados os TCLE e TCUISV para o grupo de participantes do ensaio subjetivo, apresentando a pesquisa, indicando os objetivos, riscos, benefícios, critérios de inclusão e exclusão, direitos dos participantes, entre outras informações relevantes.

A seguir será apresentada a maneira com que foram coletados os dados do experimento para o grupo de indivíduos que participou da avaliação subjetiva:

1. Entrega dos TLCE e TCUISV a 40 sujeitos selecionados ${ }^{1}$, conforme apresentando um roteiro das atividades de avaliação que seriam desenvolvidas, tempos de sessão, riscos envolvidos, apresentação da pesquisa, entre outras informações;

2. Esclarecimento de eventuais dúvidas e assinatura do TLCE/TCUISV por parte dos sujeitos interessados em participar da pesquisa. Não foram fornecidas informações detalhadas sobre o procedimento, conforme exigência da norma ITU P.800 utilizada como referência para esta avaliação. É importante observar, entretanto, que os esclarecimentos, quando demandados pelos participantes, foram fornecidos ao término do experimento. Nesta data, foi agendada a sessão de avaliação de áudios junto a cada participante;

\footnotetext{
${ }^{1}$ Foram pré-selecionadas 40 pessoas, embora a avaliação tenha sido realizada por apenas 32.
} 
3. Realização de questionário de participação em 32 sujeitos selecionados, em papel, na mesma data da realização da sessão de avaliação, conforme modelo (Anexo -Documento 6b) apresentando: a) as condições de realização da avaliação subjetiva; b) solicitando a concordância dos mesmos em participar da avaliação; c) Solicitando ao sujeito informar se possui fluência nos idiomas português e inglês; d) solicitando se o sujeito fez o consumo de bebidas alcoólicas ou outras substâncias que podem prejudicar a atenção; e) solicitado se a pessoa selecionada não foi afastada do serviço de controle de tráfego aéreo na data da realização da sessão.

Os candidatos selecionados que: concordaram com os termos da avaliação; confirmaram fluência nos idiomas português e inglês; confirmaram que não realizaram consumo de substâncias que prejudiquem a atenção, incluindo álcool; não estavam afastados da atividade de controle de tráfego aéreo, foram liberados para a participação na avaliação.

4. Os sujeitos que atenderam às condições mencionadas no item acima realizaram o preenchimento de questionário de avaliação de qualidade de áudio, conforme modelo. Este questionário foi preenchido por 32 militares, sendo 13 homens e 19 mulheres de faixa etária entre 20 e 41 anos. Cada pessoa avaliou a qualidade de áudio na medida em que os áudios foram reproduzidos.

No total foram realizadas 4 sessões, cada uma com 8 pessoas, totalizando 32 pessoas, sendo 19 mulheres e 13 homens, de idades entre 21 e 38 anos. Cada sessão contou com um conjunto de duas frases representantes de cada tipo de degradação. As frases foram dispostas de maneira aleatória. Foram balanceados de maneira a possuírem o mesmo número de frases em português e em inglês e o mesmo número de vozes femininas e masculinas. Conforme recomendações da ITU-T P.800, antes de cada sessão de reprodução foi aplicado o tom de calibração gravado previamente, obtendo, no decibilímetro, medida de 75 dBA SPL. Foi realizada prévia do experimento, em que foi monitorado o nível sonoro durante o teste. Em nenhuma ocasião o decibelímetro registrou valor superior a 85 dBA.

\subsection{RESULTADOS DO EXPERIMENTO SUBJETIVO}

Após a realização dos experimentos, as avaliações indicadas por cada um dos entrevistados foram compiladas, sendo organizadas nos grupos que representavam cada uma das condições de teste. Dessa maneira, cada conjunto de duas frases de cada grupo recebeu 8 avaliações, e, como cada grupo possuía 4 conjuntos de frases, um total de 32 avaliações para cada tratamento. Foi calculado também o desvio padrão entre as notas dentro de cada grupo 
e a distribuição em quartis para cada teste. Os resultados do experimento, apresentados nesta seção, foram utilizados como referência para avaliação dos métodos de análise objetiva aplicados, conforme descrito no item 5.3.

Conforme detalhado no item 4.3, as listas de reprodução de cada sessão foram reproduzidas após a acomodação dos participantes, leituras das instruções e treinamento. Foi registrado o tempo de duração das sessões de reprodução, obtendo tempo inferior a 16 minutos nas 4 sessões.

Os valores registrados na avaliação foram transcritos para uma planilha e organizados de acordo com a identificação de cada uma das frases. Foram então calculados a média das avaliações de cada grupo, o desvio padrão e o intervalo de confiança da dos valores levantados, considerando uma distribuição tipo T de Student e nível de confiança de $95 \%$. Os indicadores do MOS obtidos a partir da realização do experimento subjetivo são mostrados na Tabela 9. Pode-se perceber que os maiores valores de 4,969 foram obtidos em duas condições: no MNRU com parâmetro Q de 50 (Grupo 8) e no caso de áudio puro (Grupo 25), muito próximo do valor máximo de 5. Em ambas as situações foram obtidas 31 avaliações 5 (que corresponde à "Excelente", a nota máxima) e uma avaliação 4 (que corresponde a "Bom").

Verifica-se que o pior valor de MOS obtido, de 1,531, foi o do grupo 20, que representa a situação de transmissão simultânea das estações PCO, CAM e PIE na frequência 133,6 MHz, através do sistema Telesat, conforme condições definidas no item 3.2.2. A condição do grupo 23 também atingiu um valor de MOS baixo, de 1,563, e refere-se à situação de transmissão simultânea através das estações de PIE, VARG e PCO na frequência 125,35 MHz, com transmissões através do Telesat para as localidades de PCO e VARG e de operadora contratada para o sítio de PIE. Esses valores correspondem a qualidade de áudio entre "péssimo"e "ruim".

A Figura 38 apresenta um gráfico ilustrando os valores de MOS para cada grupo/ condição apresentado na Tabela 9. As barras de erros indicam o intervalo de confiança da medida, considerando uma distribuição T de Student e nível de confiança de $95 \%$, limitado aos extremos da escala que vai de 1 a 5 . Verifica-se uma tendência crescente do MOS para os grupos submetidos ao tratamento pela MNRU, na medida em que o parâmetro Q aumenta de 5 para 50. Os grupos submetidos às codificações G.711 e G.726 também apresentam valor de MOS elevado, superior a 4. Para os sinais submetidos aos meios de comunicação de ATC, somente as comunicações entre órgãos operacionais e entre consoles (grupos 11, 12, 1A e 2A) apresentam MOS superior a 4, que equivale à qualidade boa.

Para as condições de teste que utilizaram transmissão de radio-frequência, e desconsiderando os grupos de frases ATC, foi obtida uma média de MOS de 2,267, o que corresponde a 
Tabela 9: Valores de MOS obtidos no experimento subjetivo por condição. Houve falha de comunicação durante os testes dos grupos 15 e 6A e os áudios foram descartados.

\begin{tabular}{|c|c|c|c|c|}
\hline Identificação & Condição & $\begin{array}{l}\text { Valor } \\
\text { MOS }\end{array}$ & $\begin{array}{l}\text { Desvio } \\
\text { Padrão }\end{array}$ & $\begin{array}{l}\text { Intervalo de } \\
\text { Confiança }\end{array}$ \\
\hline Grupo 25 & Áudio puro $192 \mathrm{kHz} 24$ bits & 4,969 & 0,177 & 0,064 \\
\hline Grupo 8 & MNRU Q=50 & 4,969 & 0,177 & 0,064 \\
\hline Grupo 7 & MNRU Q=35 & 4,938 & 0,246 & 0,089 \\
\hline Grupo 6 & MNRU Q=30 & 4,875 & 0,336 & 0,121 \\
\hline Grupo 10 & G.726 $32 \mathrm{kbit} / \mathrm{s}$ & 4,813 & 0,397 & 0,143 \\
\hline Grupo 9 & G.711 $64 \mathrm{kbit} / \mathrm{s}$ & 4,500 & 0,672 & 0,242 \\
\hline Grupo 5 & MNRU Q=25 & 4,469 & 0,718 & 0,259 \\
\hline Grupo 2A & ACC_ACC & 4,438 & 0,669 & 0,241 \\
\hline Grupo 1A & ACC_APP_TF1 & 4,375 & 0,554 & 0,200 \\
\hline Grupo 4 & MNRU Q $=20$ & 4,375 & 0,707 & 0,255 \\
\hline Grupo 12 & ACC_ACC & 4,281 & 0,634 & 0,229 \\
\hline Grupo 11 & ACC_APP_TF1 & 4,031 & 0,595 & 0,214 \\
\hline Grupo 3 & MNRU Q=15 & 3,625 & 0,793 & 0,286 \\
\hline Grupo 2 & MNRU Q=10 & 3,094 & 0,777 & 0,280 \\
\hline Grupo 8A & PCO_VARG_PIE_12535 & 2,969 & 0,740 & 0,267 \\
\hline Grupo 5A & ACC_FL_CT_MDI & 2,938 & 0,619 & 0,223 \\
\hline Grupo 19 & ACC_PCO_CAM_1336 & 2,906 & 0,641 & 0,231 \\
\hline Grupo 3A & ACC_CAV_1275 & 2,844 & 0,847 & 0,305 \\
\hline Grupo 18 & FL_ACC_CT_MDI & 2,844 & 0,723 & 0,261 \\
\hline Grupo 22 & PCO_VARG_12535 & 2,656 & 0,602 & 0,217 \\
\hline Grupo 17 & ACC_FL_MDI_CT & 2,594 & 1,132 & 0,408 \\
\hline Grupo 1 & MNRU Q=5 & 2,438 & 0,801 & 0,289 \\
\hline Grupo 24 & PCO_PIE_12535 & 2,406 & 0,911 & 0,328 \\
\hline Grupo 4A & CAV_ACC_1275 & 2,344 & 0,602 & 0,217 \\
\hline Grupo 16 & ACC_FL_CT & 2,344 & 0,787 & 0,284 \\
\hline Grupo 13 & ACC_CAV_1275 & 2,125 & 0,707 & 0,255 \\
\hline Grupo 21 & PCO_PIE_1336 & 2,031 & 0,967 & 0,349 \\
\hline Grupo 14 & CAV_ACC_1275 & 1,938 & 0,759 & 0,274 \\
\hline Grupo 7A & PCO_CAM_PIE_1336 & 1,844 & 0,767 & 0,276 \\
\hline Grupo 23 & PCO_VARG_PIE_12535 & 1,563 & 0,564 & 0,203 \\
\hline Grupo 20 & PCO_CAM_PIE_1336 & 1,531 & 0,718 & 0,259 \\
\hline
\end{tabular}

qualidade de áudio entre ruim e regular. Para condições de clímax (transmissão simultânea) entre duas estações foi obtida média de MOS de 2,469, enquanto que, para três estações percebese sensível degradação da qualidade, com o MOS atingindo 1,896, valor este considerado entre ruim e péssimo. Os valores de MOS, agrupados em diferentes condições de utilização dos meios técnicos de ATC e por tipo de frases utilizadas (padrão da ITU-T P.800 ou frases típicas de ATC) são apresentados na Tabela 10.

A análise desta tabela também permite visualizar que, de maneira geral, o MOS percebido pelos avaliadores é superior quando são utilizadas frases típicas de ATC. Esta característica 
G1 (MNRU, Q=5)
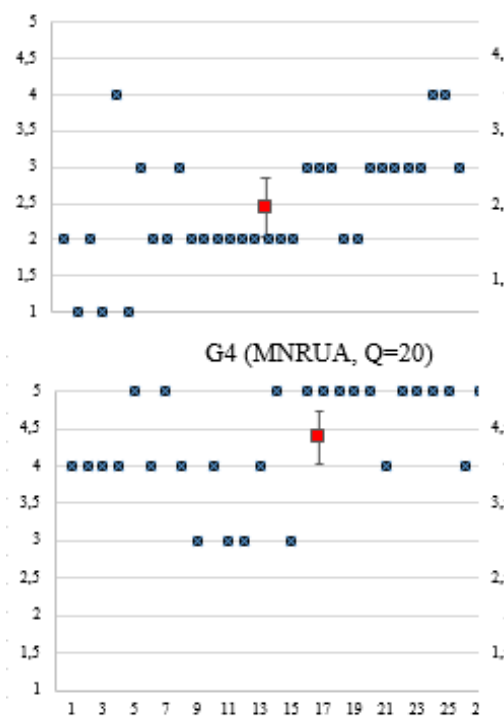

G7 (MNRU, Q=35)

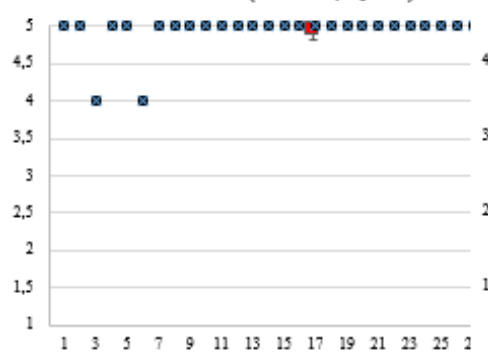

G10 (ADPCM, 32 kbits/s)

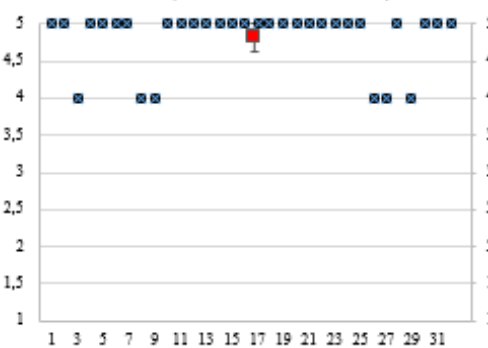

G13 (ACC_CAV_1275)

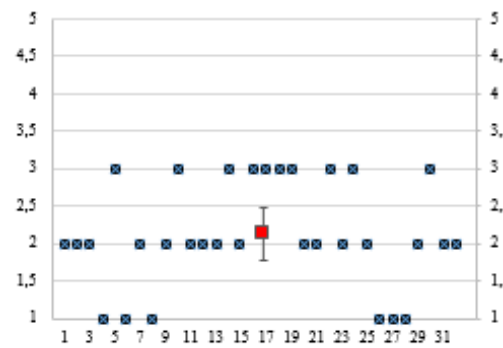

G2 (MNRU, Q=10)

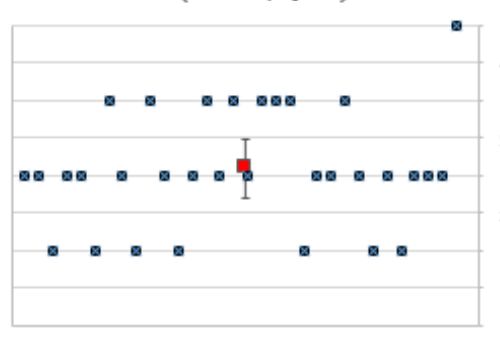

G5 (MNRU, Q=25)

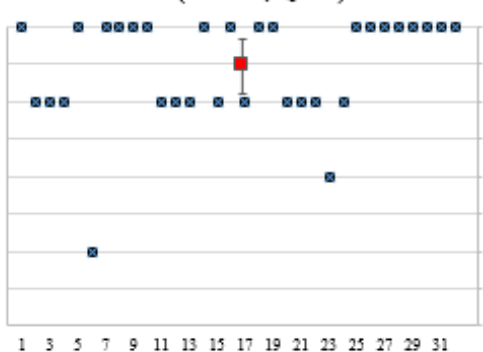

G8 (MNRU, $Q=50$ )

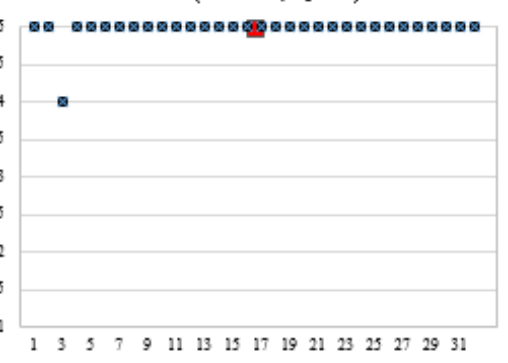

G11 (ACC_APP_TF1)

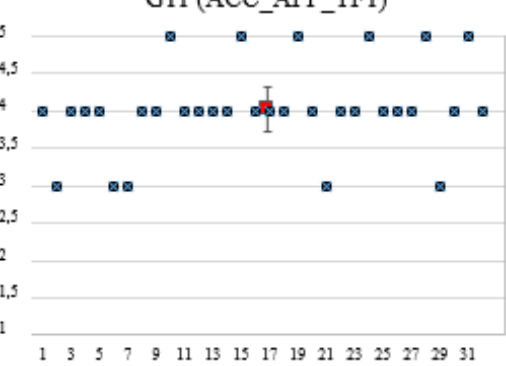

G14 (CAV_ACC_1275)

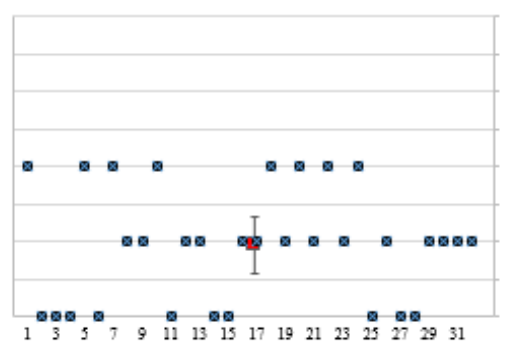

G3 (MNRU, Q=15)

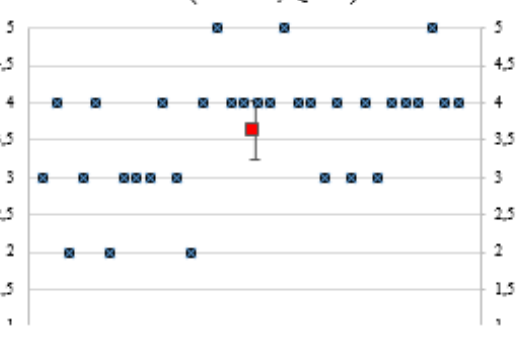

G6 (MNRU, Q=30)

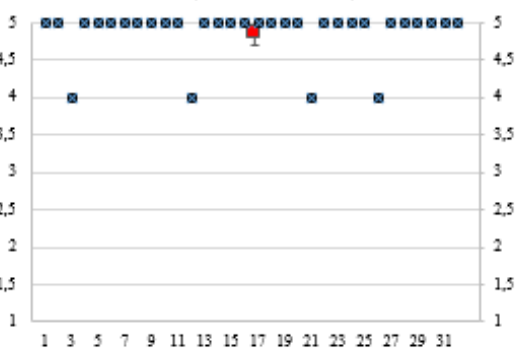

G9 (PCM, $64 \mathrm{kbits} / \mathrm{s})$

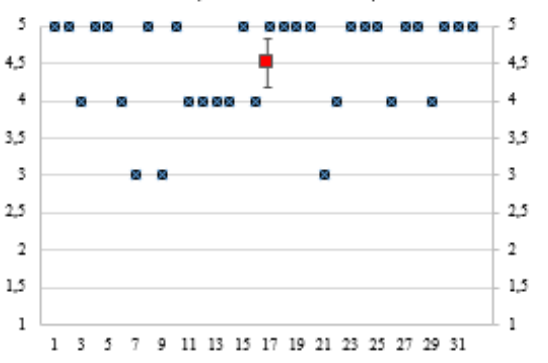

G12 (ACC_ACC)

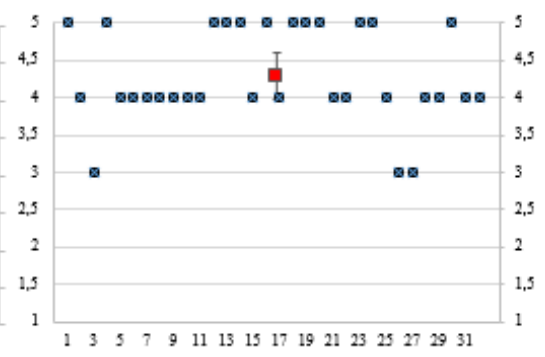

G16 (ACC_FL_CT)

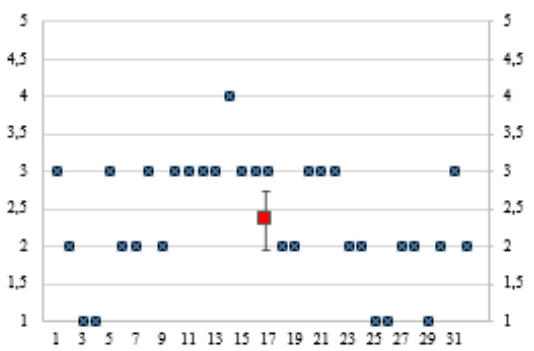

Figura 35: Valores de MOS por grupo/condição, conforme experimento subjetivo. As barras de erro têm o comprimento do intervalo de confiança, considerando distribuição T de Student e nível de confiança de $95 \%$.

fica ainda mais evidente quando analisamos o gráfico da figura 39. Neste sentido, é possível verificar a importância do uso de vocabulários padronizados nas aplicações de ATC, quanto à 

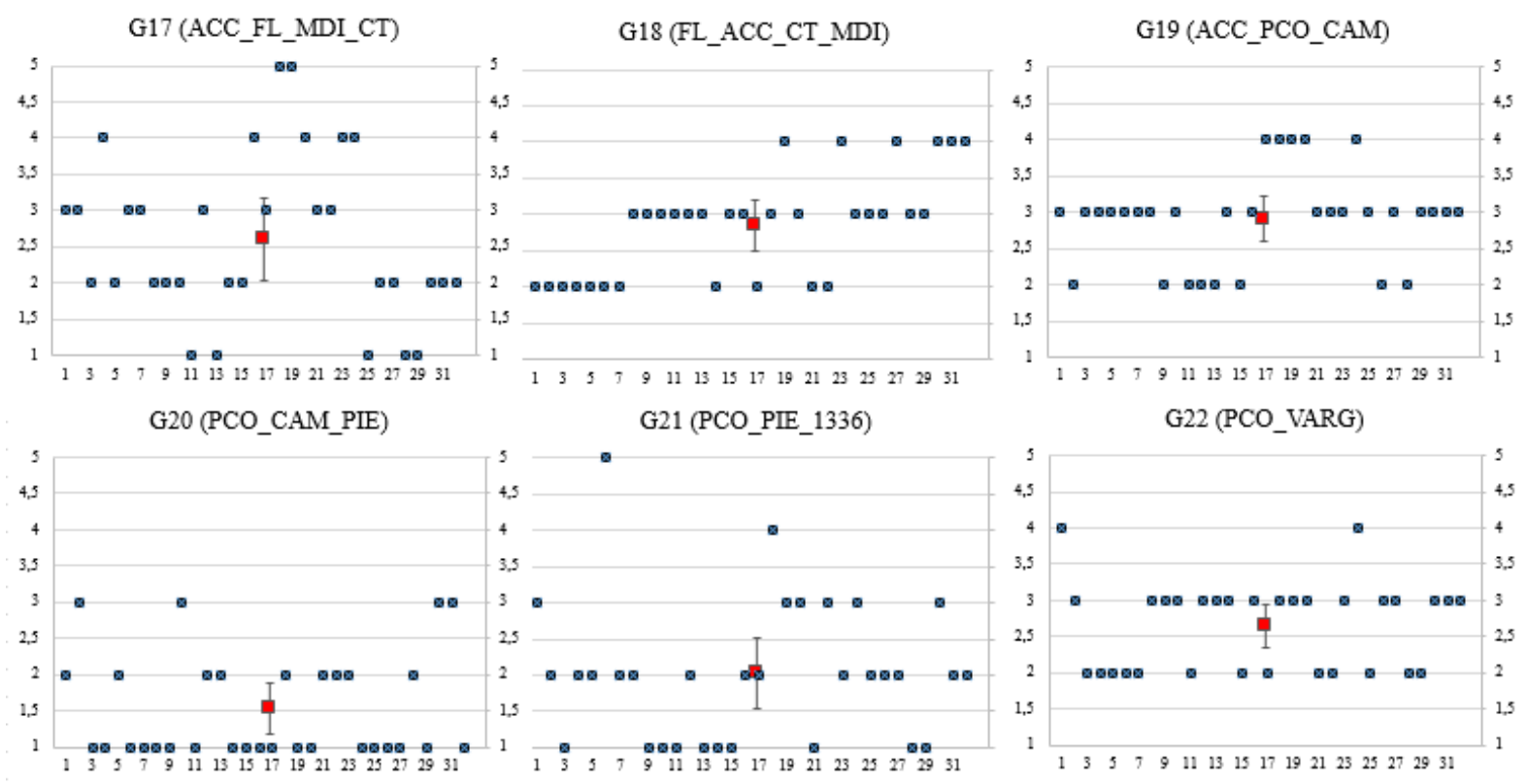

G22 (PCO_VARG)

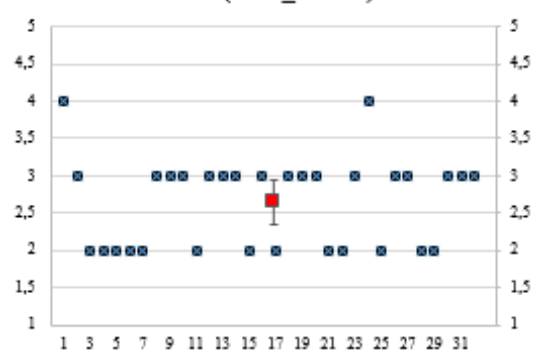

G23 (PCO_VARG_PIE)

G24 (PCO_PIE_12535)
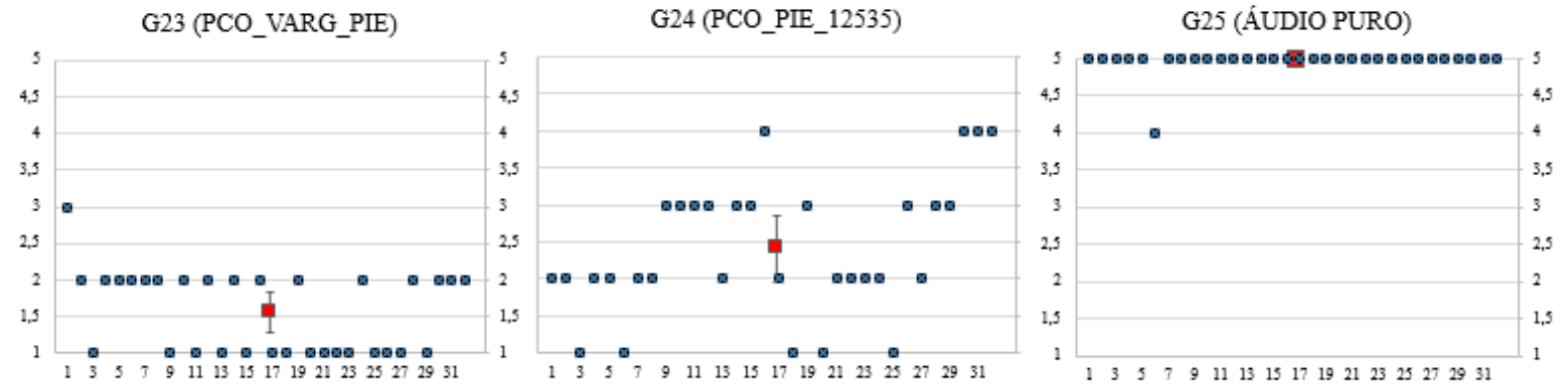

Figura 36: Valores de MOS por grupo/condição, conforme experimento subjetivo. As barras de erro têm o comprimento do intervalo de confiança, considerando distribuição $\mathbf{T}$ de Student e nível de confiança de $95 \%$.

inteligibilidade das instruções passadas e, portanto, à segurança do controle de tráfego. Nenhum teste utilizou frases tipo ATC para a transmissão através de duas estações simultâneas.

Outra observação importante se refere ao grupo de avaliadores selecionados. Embora tenha se tomado o cuidado de seguir todos os requisitos normativos da ITU-T P.800, conforme observado na pesquisa de Zaballos et al. (ZABALLOS et al., 2016), os controladores de vôo apresentam, em geral, maior habilidade de compreensão de fala em ambientes ruidosos em relação a não controladores. Este comportamento pode ter influenciado nos resultados.

Tabela 10: Valores médios de MOS em diferentes situações usando meios técnicos de ATC

\begin{tabular}{ccc}
\hline Condições & MOS (grupos ITU) & MOS (grupos ATC) \\
\hline Grupos com comunicação sem radio-frequência & 4,156 & 4,407 \\
Grupos com comunicação com radio-frequência & 2,267 & 2,588 \\
\hline Grupos com transmissão em 2 estações de VHF & 2,469 & N/D \\
Grupos com transmissão em 3 estações de VHF & 1,896 & 2,584 \\
\hline
\end{tabular}




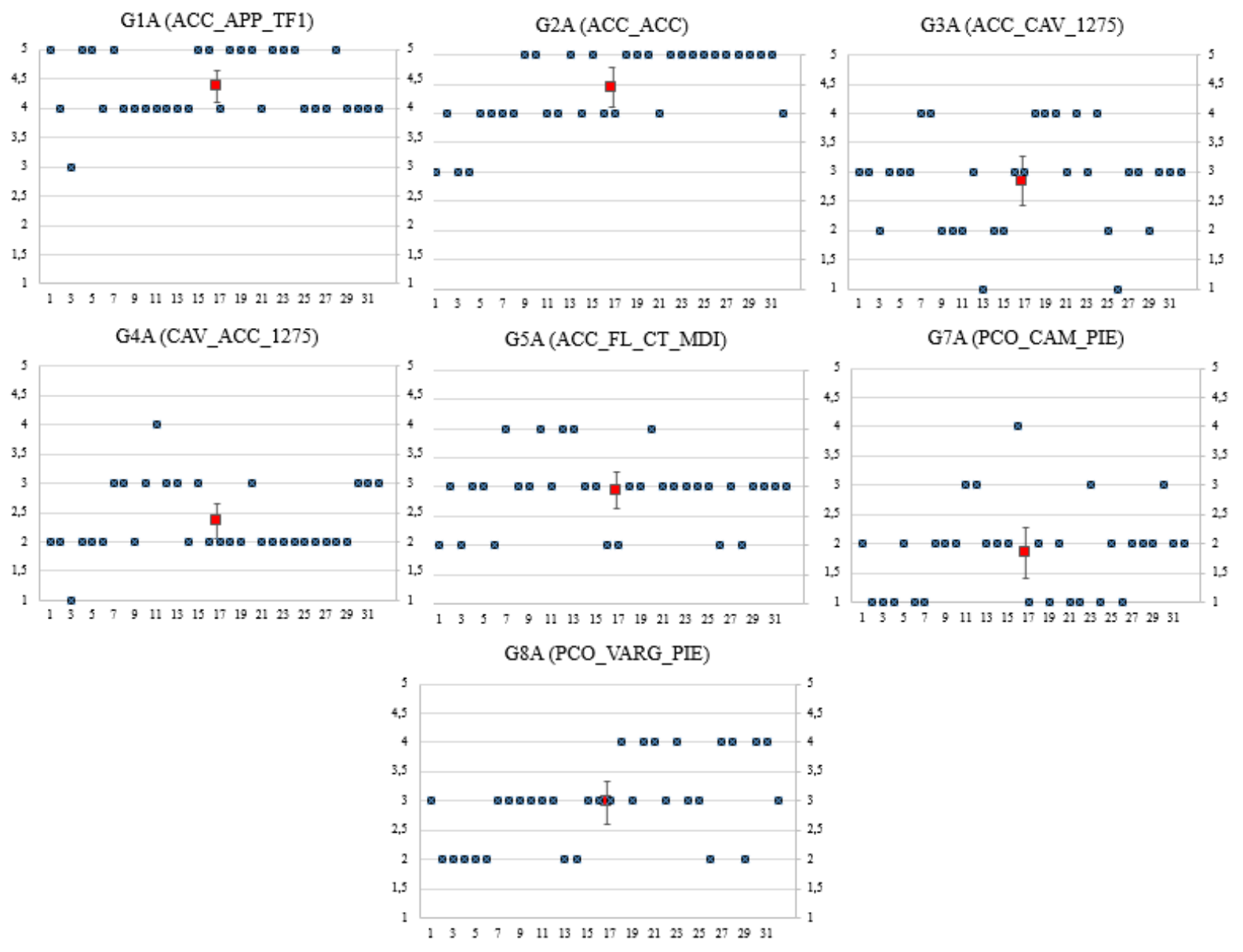

Figura 37: Valores de MOS por grupo/condição, conforme experimento subjetivo. As barras de erro têm o comprimento do intervalo de confiança, considerando distribuição T de Student e nível de confiança de $95 \%$. 


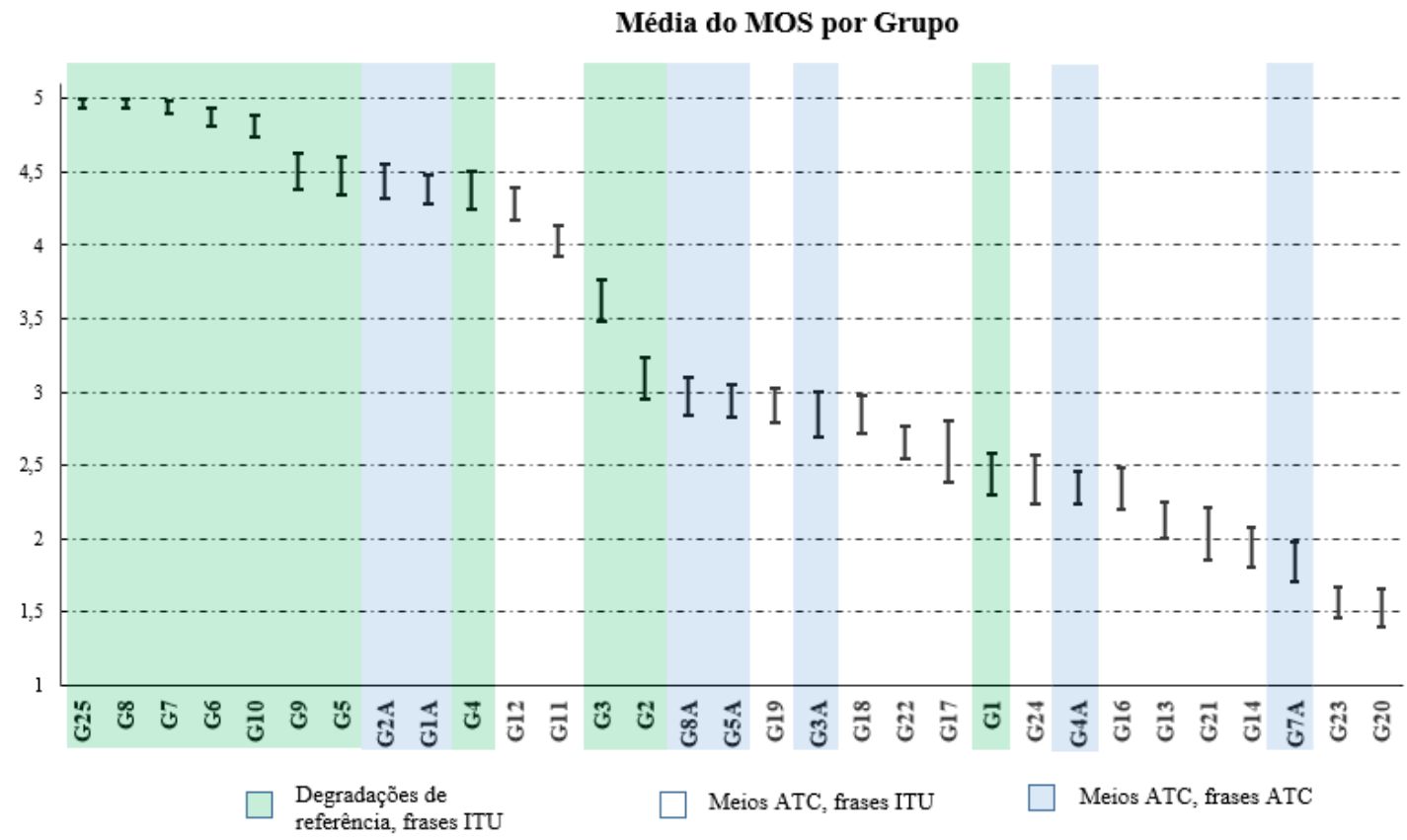

Figura 38: Valores de MOS por grupo/condição, conforme experimento subjetivo. As barras de erro têm o comprimento do intervalo de confiança, considerando distribuição $\mathbf{T}$ de Student e nível de confiança de $95 \%$.

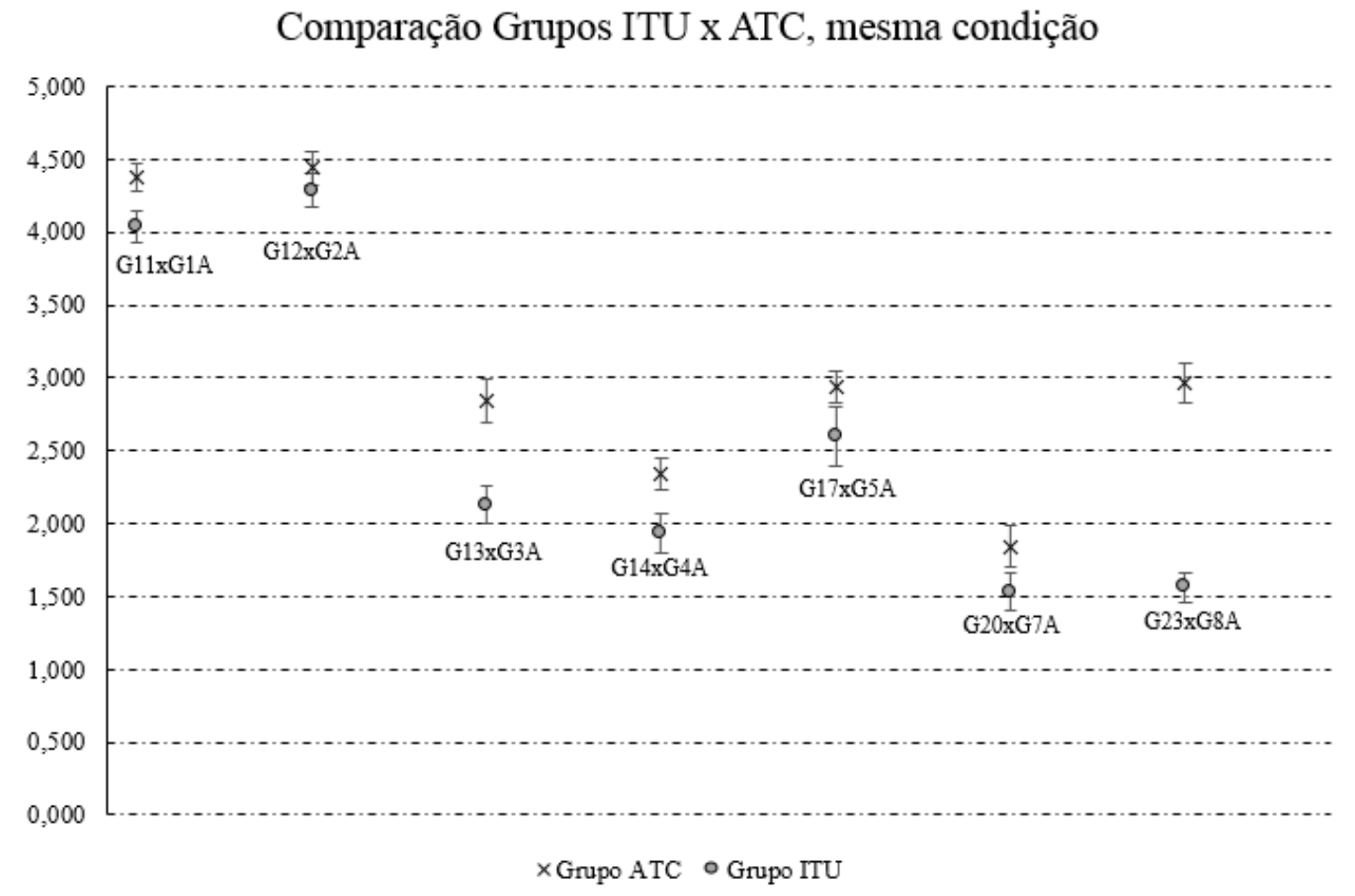

Figura 39: Comparação do MOS entre grupos de frases ATC e ITU submetidos às mesmas condições. As barras de erros representam o intervalo de confiança, considerando distribuição T de Student e nível de confiança de $95 \%$. 


\section{AVALIAÇÃO OBJETIVA}

Outra possibilidade para análise de qualidade de áudio e voz é o uso de métodos objetivos, que utilizam modelos matemáticos para buscar prever a qualidade de voz percebida por um usuário humano. Essa técnica apresenta baixo custo, por não necessitar das pesquisas de opinião e pode ser utilizada para o monitoramento da qualidade do serviço prestado sob demanda ou até mesmo em tempo real, caso a implantação tenha um tempo de processamento compatível. Dentre os métodos disponíveis, há os métodos com referência (também chamados de intrusivos), que necessitam do sinal original para comparar com o sinal degradado, e sem referência (também denominados não intrusivos), que independem do sinal original não degradado para fornecerem um valor previsto de MOS. Como em outros serviços de telecomunicações, na solução tecnológica utilizada no SMA, o sinal de referência pode ser de difícil obtenção, conforme verificamos na Seção 1.1.2, motivo pelo qual, este trabalho também buscou avaliar o desempenho de um método sem referência.

Para o caso dos métodos intrusivos, que necessitam do sinal original, antes de ser injetado nos meios de comunicação sob teste, para comparar com o sinal extraído após a aplicação no meio em estudo, o mais utilizado comercialmente é o PESQ, definido pela ITU-T P.862, que apresenta alta correlação com o MOS obtido em experimentos subjetivos (PAPASRATORN et al., 2013). Este método consolidado foi validado nas mais diferentes aplicações de telecomunicações, conseguindo prever com grande grau de acerto, o MOS de sinais de áudio originados de diferentes tipos de degradações, inclusive para problemas ocorridos em redes de comutação de pacotes (MRVOVA; POCTA, 2013). Atualmente é também utilizado na validação de métodos alternativos de análise de qualidade de áudio, como em (ROZHON et al., 2016). Este método utiliza parâmetros extraídos de indicadores de desempenho da rede aplicados numa rede neural para, então, estimar o MOS dos circuitos VOIP.

Já para os métodos sem referência, a técnica considerada padrão dos métodos de análise de qualidade de áudio para sinais de telecomunicações é o definido na norma ITU-T P.563 (ITU, 2004), conforme (SONI; PATIL, 2016) e (GRANCHAROV DAVID Y. ZHAO, 2006), e suas variantes são utilizadas nos mais modernos algoritmos para aplicações específicas 
de qualidade de voz, como na análise de qualidade de áudio de voz sintetizada eletronicamente (HINTERLEITNER, 2017). Este método se baseia na identificação de atributos de distorção no sinal de entrada através de três blocos funcionais principais, correspondentes à diferentes classes de distorções. Esses blocos são: análise/modelagem do trato vocal e voz não natural, análise de ruído / qualidade básica e análise de interrupções e cortes temporais do sinal.

Quanto às limitações das métricas objetivas, tendo em vista que estes são ajustados e validados de acordo com resultados obtidos em ensaios subjetivos, pode-se afirmar que são afetados pelos mesmos problemas e apresentam limitações semelhantes aos métodos subjetivos, conforme descrito no início do Capítulo 4.

Neste capítulo será apresentada uma revisão bibliográfica de dois métodos objetivos aplicados, sendo um com referência (PESQ) e outro sem referência (SESQ). Em seguida, os métodos objetivos serão aplicados nos mesmos sinais degradados apresentados aos avaliadores humanos do experimento subjetivo, e os resultados obtidos pelos métodos objetivos comparados com o MOS.

\subsection{MÉTODOS OBJETIVOS COM REFERÊNCIA}

Conforme exposto anteriormente, os métodos objetivos com referência são aqueles que necessitam do sinal original, a fim de realizar comparações com o sinal degradado e estimar um valor de MOS. Conforme verificamos, o método com referência adotado neste estudo foi o definido pela norma ITU-T P.862, também chamado de PESQ, que terá sua teoria de funcionamento descrita brevemente nesta seção.

O primeiro passo executado pelo algoritmo do PESQ é um preprocessamento a fim de ajustar o nível do sinal degradado $(Y(t))$ e fazer o seu alinhamento no domínio do tempo em relação ao sinal de referência $(X(t))$. Estas funções são realizadas pelo bloco de preprocessamento e alinhamento, cujo diagrama simplificado é apresentado na Figura 40.

O ganho do sistema em teste é a princípio desconhecido, o que faz com que seja necessária a realização do alinhamento de ganho do sinal degradado em relação ao sinal original. O algoritmo do PESQ assume, então, que o nível original do sinal é 79 dB SPL. As seguintes ações são tomadas:

- Os sinais original e degradado são filtrados. O filtro utilizado bloqueia componentes abaixo de $250 \mathrm{~Hz}$, apresenta resposta plana até a frequência de $2.000 \mathrm{~Hz}$. Acima de 2.000 $\mathrm{Hz}$, o filtro possui atenuação linear, passando pelos seguintes pontos: $2.500 \mathrm{~Hz},-5 \mathrm{~dB}$, 


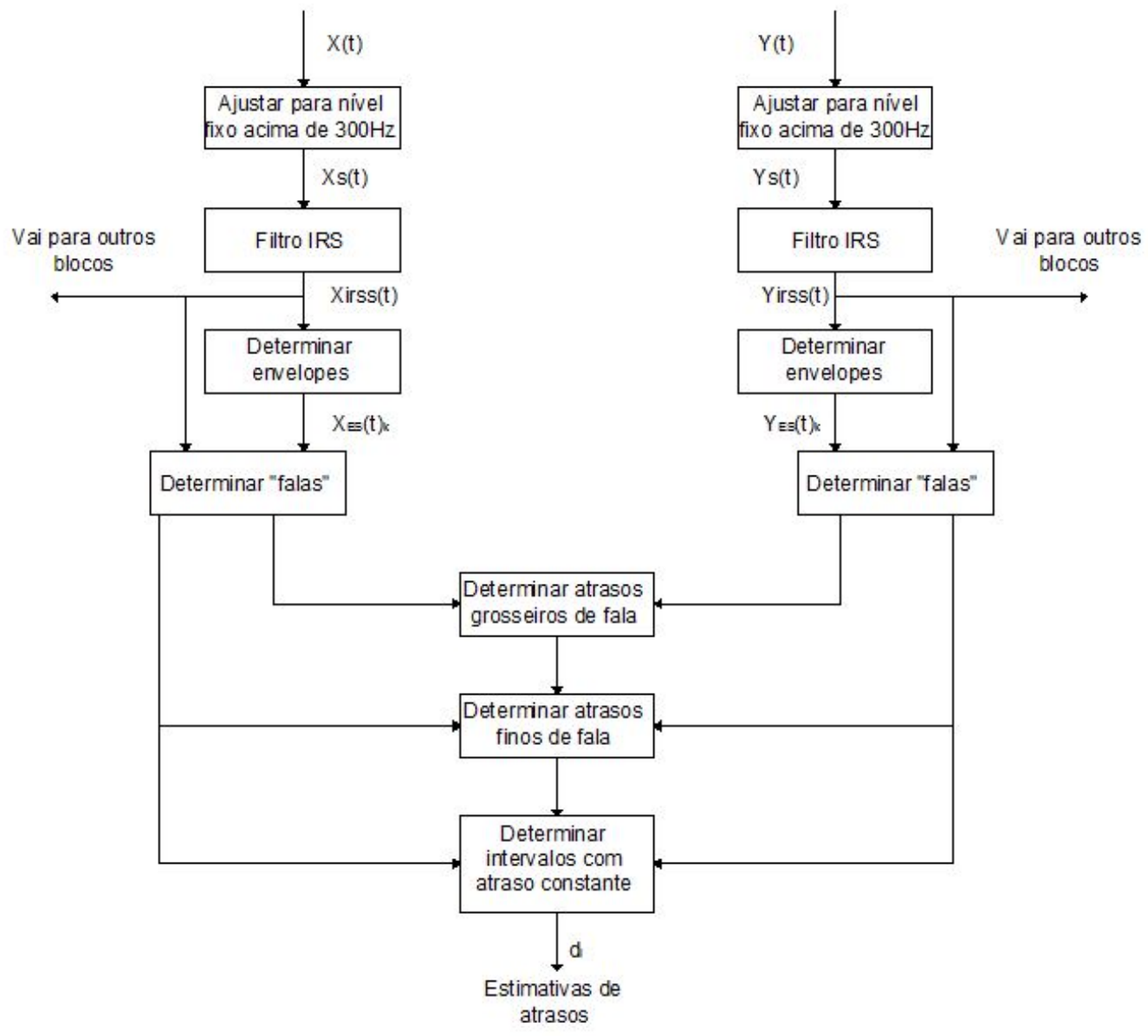

Figura 40: Rotina de sincronização utilizada pelo PESQ, identificando os principais componentes Fonte: (ITU, 2001c)

$3.000 \mathrm{~Hz},-10 \mathrm{~dB}, 3.150 \mathrm{~Hz},-20 \mathrm{~dB}, 3.500 \mathrm{~Hz},-50 \mathrm{~dB}$ e acima de $4.000 \mathrm{~Hz}$ apresenta atenuação de $50 \mathrm{~dB}$;

- São calculadas as médias quadráticas dos sinais original e degradado, filtrados de acordo com o descrito no item anterior;

- São calculados valores de ganho para os sinais original e degradado com base no resultado da operação anterior, resultando nos sinais multiplicados Xs(t) e Ys(t).

Em seguida, no bloco denominado IRS, o algoritmo aplica um modelo especificado na ITU-T P.830 que busca considerar os efeitos da resposta em frequência usual encontrada em sistemas telefônicos (ITU, 1996d). O filtro mencionado tem a sua resposta representada pela Figura 41. O algoritmo implementa o filtro através da transformada rápida de Fourier (FFT), que é aplicada tanto ao sinal original quanto ao degradado. A operação de atenuação/ganho é realizada no domínio da frequência e, então, é aplicada a transformada FFT inversa para 
retornar o sinal ao domínio do tempo. Os sinais de saída desta etapa XIRSS e YIRSS são, respectivamente, os sinais original e degradado filtrados pelo filtro IRS.

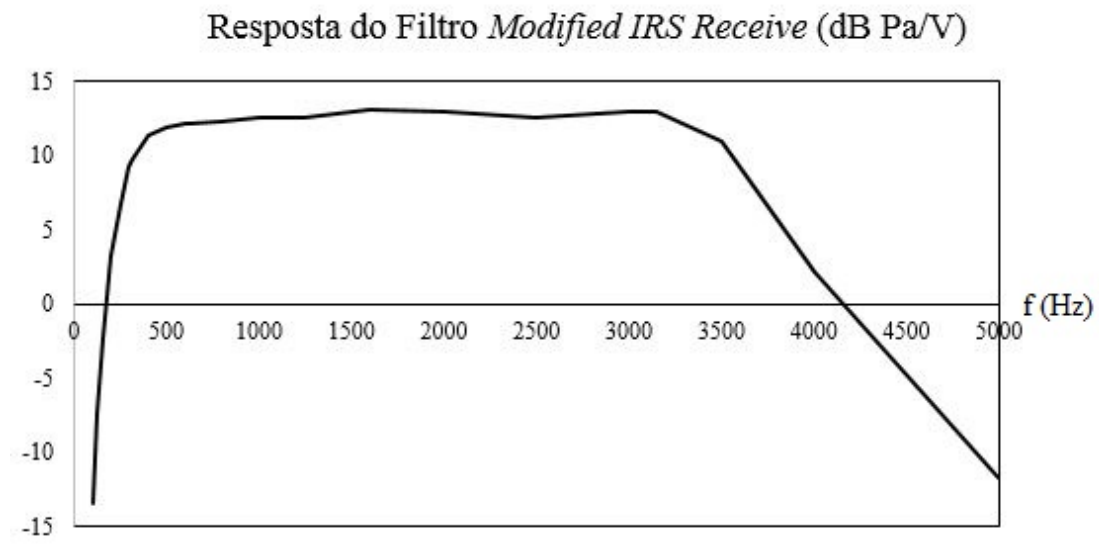

Figura 41: Resposta em frequência do filtro IRS utilizado para representar a resposta em frequência de equipamentos telefônicos, conforme padrão ITU-T P.830

A próxima etapa é a realização do cálculo de valores de atraso no sinal que são utilizados pelo modelo matemático que estima o valor do MOS. As seguintes atividades são realizadas nos blocos de detecção de alinhamento:

- estimativa de valor de atraso entre o sinal original $(X(t))$ e degradado $(Y(t))$, para cada envelope de sinal, aplicado a toda a extensão do sinal;

• divisão do sinal original em um número de seções, denominadas "expressões";

- estimativa de valor de atraso entre o sinal original e degradado, para cada envelope de sinal, aplicado à cada "expressão";

- ajuste fino baseado na análise de correlação e do histograma de valores de atraso em relação às amostras próximas;

- divisão de "expressões"e realinhamento dos intervalos de tempo para pesquisar por variações de tempos de atraso durante a fala;

Os envelopes de sinal Xes $(t)$ e Yes(t) são calculados a partir dos sinais de saída do filtro IRS e são definidos de acordo com a Equação 28, em que $E(k)$ é a energia de um quadro de duração de $4 \mathrm{~ms}, E_{\text {limiar }}$ é o limiar do sinal de fala definido por um detector de voz. Os valores de atrasos brutos, com resolução de 4 ms, são determinados com base nos valor de correlação cruzada entre o sinal original e degradado. 


$$
E n v=\log \left[\max \left(\frac{E(k)}{E_{\text {limiar }}}, 1\right)\right]
$$

Em seguida é realizado um cálculo de "ajuste fino"a fim de calcular, com precisão de uma amostra, os valores de atraso de tempo. Este ajuste fino é realizado através de uma sequência de operações estatísticas que incluem:

- cálculo, em quadros de 64 ms em janelas de Hann com $75 \%$ de sobreposição, da correlação cruzada entre o sinal degradado e original após a realização do alinhamento baseado no método de envelopes;

- o valor máximo de correlação, elevado à potência 0,125 , é utilizada como medida do nível de confiança do alinhamento de cada quadro. O índice do valor máximo indica a estimativa de atraso do quadro;

- é calculado o histograma das estimativas de atraso, ponderado pela medida de grau de confiança. A análise deste histograma, combinado com a estimativa de atraso da amostra anterior fornece o valor de atraso do quadro.

Ao término destas operações, é estimado o valor de atraso associado a cada quadro. Este valor, junto a seu intervalo de confiança, é armazenado para utilização pelo modelo perceptual. Este, por sua vez, é o responsável por fornecer o valor estimado do MOS para o modelo, através da comparação com o sinal original. Seu funcionamento, de maneira simplificada, é descrita a seguir:

- Aplicação de fatores de escala nos sinais para condicionamento / processamentos futuros;

- Identificar e descartar da análise os trechos de silêncio localizados no início e fim do intervalo de áudio sob análise;

- Mapeamento dos sinais original e degradado no domínio da frequência, através da aplicação de FFT, com sobreposição de 50\%. Esta operação busca imitar o comportamento do ouvido humano. É calculado o espectro de potência (soma quadrática da parte real e imaginária de cada componente da FFT), e os valores armazenados, tanto para o sinal de referência quanto para o degradado. Os valores de fase são descartados, pois não são utilizados na análise do PESQ;

- Aplicação de fatores de escala aos mapas de FFT a fim de considerar a característica de sensibilidade do ouvido humano (escala Bark); 
- Realização de cálculos de compensação de filtragem, através de cálculo de relações entre os espectros de potência dos sinais de referência e degradado, e compensação de variações bruscas no nível de sinal. Estas compensações buscam identificar problema de filtragem excessiva e variações bruscas de nível, que podem ser prejudiciais para a qualidade de áudio;

- Cálculo de densidades de intensidade, para cada janela de $32 \mathrm{~ms}$, através da escala de nível de Zwicker, para cada nível de frequência, conforme a Equação 29, em que $n$ é a identificação da janela, $P_{0}$ e $S_{l}$ são fatores de escala e $P(f)_{n}$ as densidades de potência com as devidas compensações mencionadas no item anterior. O fator de potência $\gamma$ é o valor de potência de Zwicker, que leva em consideração efeitos psicoacústicos;

$$
L(f)_{n}=S_{l} \cdot\left(\frac{P_{0}(f)}{0,5}\right)^{\gamma} \cdot\left[\left(0,5+0,5 \cdot \frac{P(f)_{n}}{P_{0}(f)}\right)^{\gamma}-1\right]
$$

- Realização de cálculo de densidade de perturbações do sinal de áudio $D(f)_{n}$. Para tal é realizada o cálculo do sinal diferença, entre as densidades de intensidade do sinal degradado e sinal de referência. Quando esta diferença tem valor positivo, componentes de ruído foram adicionados ao sinal original. Quando o sinal é negativo, componentes foram omitidos do sinal original. Os valores de diferença são comparados com um limiar inferior, de maneira que apenas os valores maiores são considerados na análise;

- Determinação de fatores de assimetria através da relação matemática entre as densidades de potência do sinal original e sinal degradado, elevado à potência 1,2. Em seguida é realizada multiplicação dos valores de densidade de perturbação do sinal de áudio pelo fator de assimetria (quando este for no mínimo 3 e limitado ao máximo de 12), determinando o parâmetro de densidade de perturbações de sinal de áudio com fator assimétrico $D A(f)_{n}$. Este parâmetro de densidade de perturbações busca a encontrar possíveis artefatos de áudio prevenientes do uso de CODEC, por exemplo.

- É realizada a soma das densidades de perturbações $D(f)_{n}$ e densidade de perturbações assimétricas $D A(f)_{n}$ para cada banda de frequência, com ênfase nas perturbações que ocorrem em trechos mais silenciosos do áudio, encontrando os valores de distúrbio de quadros $D_{n}$ e $D A_{n}$, limitando-se o valor a 45 . Para este cálculo são consideradas as seguintes situações: os valores de $D_{n}$ e $D A_{n}$ são zerados em quadros que apresentem grande variação negativa de atraso; quadros consecutivos com valores de $D_{n}$ ou $D A_{n}$ superiores a 45 recebem tratamento adicional, tendo em vista que em observação empírica, raramente representam perturbações e frequentemente erro de cálculo no algoritmo de detecção de 
atraso; consideração de fator de detecção de sinal de voz presente;

- Realizadas as compensações, o PESQ é computado através da combinação linear entre os valores $D(f)_{n}$ e $D A(f)_{n}$.

\subsection{MÉTODOS OBJETIVOS SEM REFERÊNCIA}

Várias técnicas de análise de qualidade de sinais de voz por métodos sem referência foram propostas, através de diferentes métodos. Vai desde a identificação de parâmetros como presença de eco, atrasos de sinal, ruído e nível de som, como em (ITU, 1993c). (AU, 1998) utilizou estudos prévios para definir espectrogramas de sinais de voz classificando-os em espectrogramas de boa qualidade ou má qualidade. Para tal, propôs método que divide o sinal em blocos de $30 \mathrm{~ms}$, calcula o espectrograma e correlaciona a qualidade do sinal à faixa dinâmica e variância do espectro nos blocos, atingindo correlação de até 0.65 com o MOS. Outros métodos, como em (GRAY M P HOLLIER, 2000) baseiam-se na modelagem do trato vocal humano e na identificação de blocos em que há violação do modelo matemático. Outras alternativas se baseiam na construção de uma sinal de referência artificial com base no sinal distorcido de origem e então utilizar um método comparativo de análise com sinal de referência, como em (FALK QINGFENG XU, 2005).

Vários desses métodos foram e são incorporados no método da ITU T-P.563, também conhecido como SESQ, na medida em que são desenvolvidos (ITU, 2004), recomendação essa até pouco tempo considerada o estado da arte dos métodos de análise de qualidade de voz sem referência (GRANCHAROV DAVID Y. ZHAO, 2006). A análise do padrão em tela identifica atributos de distorção no sinal de entrada através de três blocos funcionais principais, correspondentes à diferentes classes de distorções. Esses blocos são: análise/modelagem do trato vocal e voz não natural, análise de ruído / qualidade básica e análise de interrupções e cortes temporais do sinal. Para tal, o método prevê um pré-processamento do sinal que envolve a identificação dos trechos de voz do sinal, filtragem inicial, cálculo do nível médio do sinal e normalização do mesmo, cálculo de variação de nível de sinal entre sentenças, cálculo bloco a bloco da variação da potência do sinal, e extração do tom de voz através de método iterativo de auto-correlação. Os resultados deste pré-processamento são então utilizados nos respectivos blocos funcionais. A Figura 42 apresenta o diagrama de blocos simplificado do processamento de voz realizado pelo método descrito no padrão ITU-T P.563.

O bloco de análise/modelagem do trato vocal e voz não natural computa coeficientes de predição linear do sinal (LPC) e realiza a análise cepstral do mesmo. Aplica então uma série 


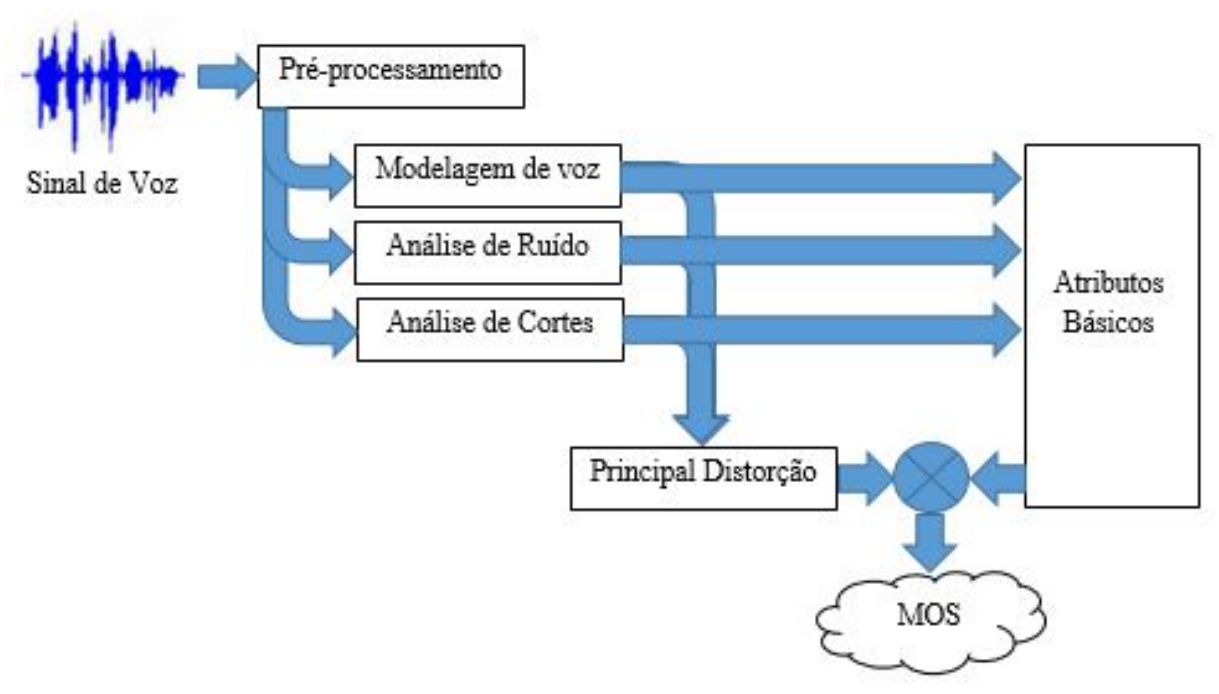

Figura 42: Diagrama de blocos de processamento de voz simplificado definido pela ITU-TP563

de estatísticas de ordem superior, incluindo estimativa de assimetria e curtose dos conjuntos de coeficientes resultantes da análise cepstral e da LPC. Esta etapa de análise atribui um indicativo de qualidade com base nestes fatores. Em seguida, o bloco modela o trato vocal humano como um conjunto de tubos de diferentes comprimentos e com secções transversais variantes no tempo. A partir do sinal de entrada, o modelo estima as áreas das secções transversais e aplica as restrições do modelo físico a fim de encontrar variações não naturais. O bloco ainda faz uma análise de sinais de periodicidades não naturais, como as presentes em problemas de voz "metalizada"calculando a correlação cruzada entre blocos adjacentes e identificando repetições do sinal de entrada. Há ainda outra etapa que identifica presença de sons / bipes não naturais, através da análise de espectro de potência.

O bloco de análise ruído / qualidade básica avalia a influência das distorções na percepção com base num modelo psicoacústico complexo que também leva em consideração as características do trato vocal humano, características como o limiar de audição, densidade de potência do tom de voz, entre outros. Este bloco também realiza o cálculo da relação sinalruído, identificação de ruído estático e ruídos de fundo, clareza espectral (em que é calculada, para cada bloco, a diferença entre a energia dos harmônicos do tom de voz e os sinais não múltiplos), identificação de ruídos multiplicativos através de análise estatística do espectro (cálculo de envelope do sinal, densidade espectral do sinal).

O bloco de análise de interrupções realiza uma análise de perfil de nível do sinal de entrada, identifica e calcula o tempo de sinal "mudo", partindo do pressuposto de que não podem ocorrer pontos de atenuação abrupta do sinal. Após a realização de todas essas análises, 
o método classifica o principal problema de qualidade do sinal dentro de uma hierarquia prédefinida. Os problemas são priorizados na seguinte ordem: baixa relação sinal/ruído, ocorrência de interrupções de voz / atenuações abruptas, distorções de sinal identificadas na análise cepstral / LPC, voz não natural ou "metalizada", outros problemas de voz não natural.

Para cada problema principal é realizada uma combinação linear diferente entre os vários fatores calculados no algoritmo, chegando-se a um coeficiente de qualidade intermediário. Este, por sua vez, é combinado linearmente com outros 11 coeficientes que representam indicadores de qualidades básicos do sinal, como ruído, nível de sinal, repetições de blocos e outros parâmetros calculados na etapa de pré-processamento. Essa última combinação retorna um valor de nota objetiva para o sinal de voz sob análise, conseguindo correlação superior à 0,80 em relação ao MOS (ITU, 2004) para determinadas situações de teste. A principal desvantagem do método, entretanto, é o seu elevado custo computacional. Simulações atestam que a análise de um trecho de áudio pode levar mais do que 50\% da duração do mesmo, utilizando implementação em linguagem $\mathrm{C}$ e hardware computacional convencional (HOLUB MICHAEL STREET, 2006; GRANCHAROV DAVID Y. ZHAO, 2006).

\subsection{APLICAÇÃO DE MÉTODOS DE ANÁLISE OBJETIVA}

Os sinais gravados e submetidos às diferentes degradações/tratamentos foram então submetidos a três métodos de análise objetiva de qualidade de áudio. Os métodos escolhidos foram o PESQ, o SESQ, cujo funcionamento e fundamentos teóricos foram descritos no início do capítulo. O PESQ, como verificado, é um método com referência, enquanto o SESQ não usa sinal de referência.

Os códigos fonte do PESQ e SESQ foram obtidos, em linguagem C, junto à ITU e compilados com o Microsoft Visual Studio 2015, gerando arquivos executável em ambiente Windows/DOS. Foi elaborada uma rotina no MATLAB para automatizar a chamada de arquivos e registrar os resultados de MOS previstos por cada um dos três métodos, e os resultados apresentados no item 5.4.

\subsubsection{INDICADORES DE CORRELAÇÃO}

O grau de proximidade entre os valores previstos pelos métodos objetivos utilizados e os dados obtidos no experimento subjetivo foi então avaliado através dos coeficientes de correlação.

As correlações foram calculadas sobre os valores médios obtidos de cada condição, 
utilizando os coeficientes de correlação de Pearson e o coeficiente de correlação de postos de Spearman. A partir da equação 30 é calculada a correlação de Pearson em que $x_{i}$ é o valor de MOS obtido no experimento subjetivo para a condição $i, \bar{x}$ é a média dos valores de MOS obtidos no experimento subjetivo para a condição (média dos valores de $x_{i}$ ), $y_{i}$ o valor previsto pelo algoritmo para cada condição $i$ e $\bar{y}$ a média dos valores previstos pelo algoritmo para a condição (média dos valores de $y_{i}$ ).

$$
r=\frac{\sum\left(x_{i}-\bar{x}\right)\left(y_{i}-\bar{y}\right)}{\sqrt{\sum\left(x_{i}-\bar{x}\right)^{2} \sum\left(y_{i}-\bar{y}\right)^{2}}}
$$

Já o coeficiente de correlação de postos de Spearman, que avalia a monotonicidade entre os conjuntos analisados, pode ser encontrado por meio da expressão 31 em que $\gamma_{i}$ e $\rho_{i}$ são, respectivamente, os postos da medida objetiva e subjetiva de uma amostra de áudio $i$. Já $\bar{\gamma}$ e $\bar{\rho}$ são as médias dos postos objetivos e subjetivos, respectivamente. Ambos os coeficientes de correlação estão confinados no intervalo [-1,1].

$$
r=\frac{\sum\left(\rho_{i}-\bar{\rho}\right)\left(\gamma_{i}-\bar{\gamma}\right)}{\sqrt{\sum\left(\rho_{i}-\bar{\rho}\right)^{2} \sum\left(\gamma_{i}-\bar{\gamma}\right)^{2}}}
$$

\subsection{RESULTADOS DE DESEMPENHO DOS MÉTODOS OBJETIVOS}

Os métodos de análise objetiva do PESQ, SESQ foram aplicados aos sinais degradados, conforme descrito no item 5.3. Os resultados da aplicação destes métodos, para cada grupo, são exibido nas Figuras 43, 44 e 45. Nas figuras os resultados do PESQ, SESQ e MOS estão representados através de quartis, e o valor médio obtido é o valor central plotado em vermelho.

Observa-se que o PESQ apresentou, em geral, resultados menos dispersos do que o MOS obtido do experimento subjetivo e valores obtidos pelo SESQ. Percebe-se que há situações em que cada um dos métodos objetivos utilizados apresentou resultados mais próximos ao MOS real.

A tabela 11 apresenta os valores médios previstos de MOS para cada situação, de acordo com cada método empregado.

A Figura 46 apresenta os resultados do PESQ e os resultados obtidos no MOS nos Experimentos Subjetivos. Pode-se verificar graficamente que há acentuada correlação entre os valores do PESQ e os obtidos pelo Experimento Subjetivo, principalmente nos grupos que envolveram os processamentos de referência. As maiores diferenças foram verificadas nos grupos 
Tabela 11: Valores de MOS previstos obtidos para cada condição para cada método objetivo utilizado

\begin{tabular}{ccccc}
\hline Identificação & Condição & MOS & PESQ & SESQ \\
\hline Grupo 25 & Áudio puro 192 kHz 24 bits & 4,969 & 4,998 & 4,598 \\
Grupo 8 & MNRU Q=50 & 4,969 & 4,884 & 3,620 \\
Grupo 7 & MNRU Q=35 & 4,938 & 4,843 & 3,088 \\
Grupo 6 & MNRU Q=30 & 4,875 & 4,722 & 3,440 \\
Grupo 10 & G.726 32 kbit/s & 4,813 & 4,620 & 3,745 \\
Grupo 9 & G.711 64 kbit/s & 4,500 & 4,725 & 3,524 \\
Grupo 5 & MNRU Q=25 & 4,469 & 4,542 & 3,114 \\
Grupo 2A & ACC_ACC & 4,438 & 3,716 & 3,941 \\
Grupo 1A & ACC_APP_TF1 & 4,375 & 3,673 & 3,694 \\
Grupo 4 & MNRU Q=20 & 4,375 & 4,0075 & 3,670 \\
Grupo 12 & ACC_ACC & 4,281 & 3,868 & 4,143 \\
Grupo 11 & ACC_APP_TF1 & 4,031 & 3,571 & 2,726 \\
Grupo 3 & MNRU Q=15 & 3,625 & 3,663 & 3,055 \\
Grupo 2 & MNRU Q=10 & 3,094 & 2,823 & 2,462 \\
Grupo 8A & PCO_VARG_PIE_12535 & 2,969 & 2,130 & 2,007 \\
Grupo 5A & ACC_FL_CT_MDI & 2,938 & 2,048 & 4,078 \\
Grupo 19 & ACC_PCO_CAM_1336 & 2,906 & 2,335 & 1,641 \\
Grupo 3A & ACC_CAV_1275 & 2,844 & 2,067 & 2,069 \\
Grupo 18 & FL_ACC_CT_MDI & 2,844 & 2,780 & 2,739 \\
Grupo 22 & PCO_VARG_12535 & 2,656 & 2,453 & 1,963 \\
Grupo 17 & ACC_FL_MDI_CT & 2,594 & 2,354 & 3,483 \\
Grupo 1 & MNRU Q=5 & 2,438 & 2,438 & 2,192 \\
Grupo 24 & PCO_PIE_12535 & 2,406 & 2,262 & 1,689 \\
Grupo 4A & CAV_ACC_1275 & 2,344 & 2,008 & 2,899 \\
Grupo 16 & ACC_FL_CT & 2,344 & 2,107 & 2,523 \\
Grupo 13 & ACC_CAV_1275 & 2,125 & 2,236 & 2,388 \\
Grupo 21 & PCO_PIE_1336 & 2,031 & 2,126 & 1,704 \\
Grupo 14 & CAV_ACC_1275 & 1,938 & 2,123 & 4,060 \\
Grupo 7A & PCO_CAM_PIE_1336 & 1,844 & 1,835 & 1,692 \\
Grupo 23 & PCO_VARG_PIE_12535 & 1,563 & 1,869 & 1,967 \\
Grupo 20 & PCO_CAM_PIE_1336 & 1,531 & 1,897 & 1,579 \\
\hline & & & & \\
& & &
\end{tabular}

de frases de controle de tráfego aéreo, que correspondem aos grupos G1A a G8A. Na maioria dos casos registrados, o valor do MOS obtido foi superior ao obtido pelo PESQ em cerca de $21 \%$.

Já em relação ao SESQ, percebe-se, através da Figura 47 que há correlação entre os valores obtidos do MOS e os valores previstos pelo SESQ. Entretanto, observa-se situações de erros superiores a 1,5 na escala MOS, como nos casos dos grupos G14 e G7. Em 4 situações de teste o valor de MOS previsto pelo SESQ foi superior aos valores encontrados no teste subjetivo, correspondendo aos grupos G14, G17, G4A e G5A. 
A Figura 48 apresenta uma representação gráfica do SESQ e do PESQ em relação ao MOS obtido nos experimentos subjetivos para todos os grupos do experimento subjetivo, com exceção dos que envolviam vocabulários próprios de ATC. Fica mais perceptível a dispersão de resultados do SESQ e a maior correlação do PESQ com o MOS.

Já na Figura 49 foram retirados os grupos com degradações de referência (MNRU e codificações) e foram isolados somente os grupos padronizados do experimento subjetivo que continham situações de comunicações ATC. Percebe-se para o PESQ, também neste caso, uma quantidade significativa de pontos plotados sobre ou próximo à reta, indicando correspondência quase exata entre o MOS e o PESQ. Estes casos são mais raros no caso do SESQ.

Na Figura 50, foram isolados somente os grupos que continham vocabulário ATC. Percebe-se, como esperado, menor correlação entre o MOS observado pelos usuários e o previsto pelos algoritmos.

Por fim, foram calculados os índices de correlação de Pearson e Speerman entre os valores de MOS obtidos para cada conjunto de frases nos experimentos subjetivos e os métodos objetivos aplicados e os valores são apresentados na Tabela 12. Verifica-se que, o PESQ atingiu correlação superior a 0,90 pelos dois índices avaliados, apresentando, portanto, alta linearidade e monotonia na predição do MOS, quando avaliado o conjunto que continha todos os grupos (Figura 48). Já o SESQ, método sem referência apresentou os dois índices ligeiramente superiores a 0,50 para as mesmas condições.

Já quando avaliado somente os grupos que continham frases padronizadas de ATC, situação que corresponde ao conjunto da Figura 50 o PESQ apresentou correlações próximas a 0,84 (Pearson) e 0,74(Spearman) em relação ao MOS e, o SESQ, os respectivos valores de 0,564 e 0,584. A menor correlação do PESQ com a percepção de MOS dos usuários, para este caso, pode ser atribuída ao fato dos usuários conhecerem o vocabulário padronizado da aviação utilizado nas frases.

Tabela 12: Correlação entre MOS e valores previstos do PESQ e SESQ - Todos os grupos

\begin{tabular}{cccc}
\hline Técnica & Tipo de Frases & Correlação de Pearson $(\rho)$ & Correlação de Spearman $\left(r_{s}\right)$ \\
\hline PESQ & ITU & 0,922 & 0,906 \\
SESQ & ITU & 0,514 & 0,522 \\
\hline PESQ & ATC & 0,841 & 0,743 \\
SESQ & ATC & 0,564 & 0,584 \\
\hline
\end{tabular}

Quando foram descartados as degradações de referência (MNRU e codificações), sendo avaliadas somente as situações de teste que simularam situações comuns de comunicação ATC (correspondentes à Figura 49), os índices de correlação de Pearson e Spearman do PESQ foram 
de, respectivamente, 0,89 e 0,84, conforme observado na Tabela 13. Já o SESQ obteve os mesmos índices de, respectivamente, 0,29 e 0,28, evidenciando baixo desempenho na previsão do MOS para as situações testadas.

Tabela 13: Correlação entre MOS e valores previstos do PESQ e SESQ - Somente grupos de Testes Técnica Método Correlação de Pearson $(\rho)$ Correlação de Spearman $\left(r_{s}\right)$

PESQ ITU $0,891 \quad 0,839$

SESQ ITU $\quad 0,288 \quad 0,285$ 


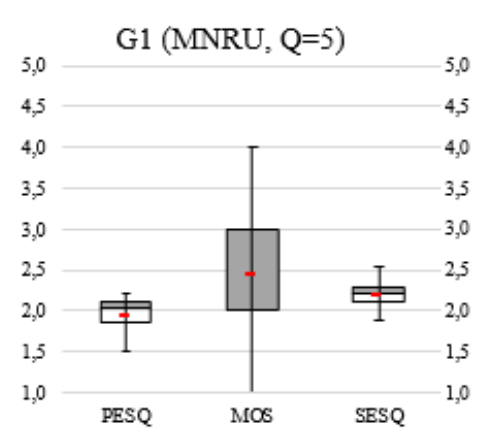

G2 (MNRU, Q=10)

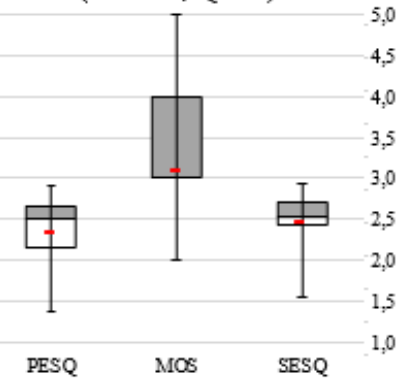

G5 (MNRU, Q=25)

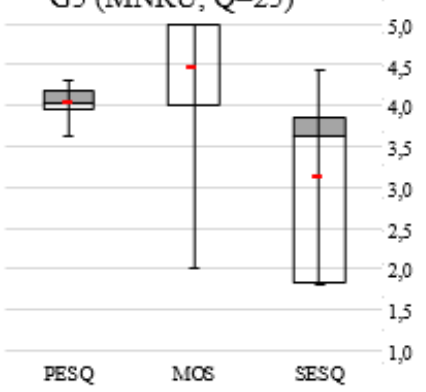

G8 (MNRU, Q=50)
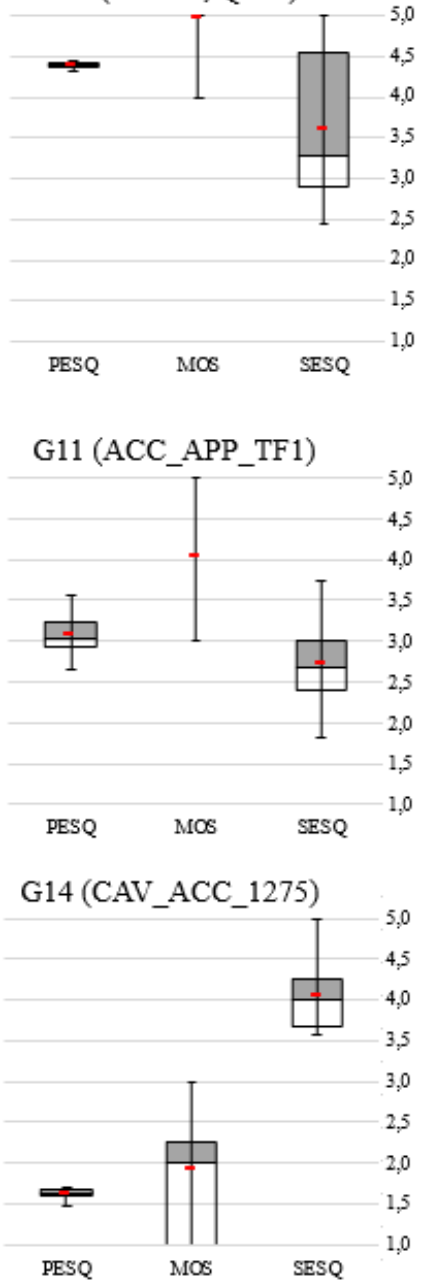

G3 (MNRU, Q=15)

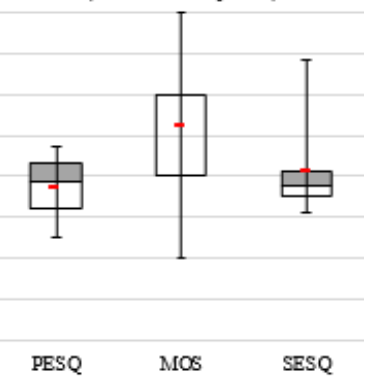

G6 (MNRU, Q=30)

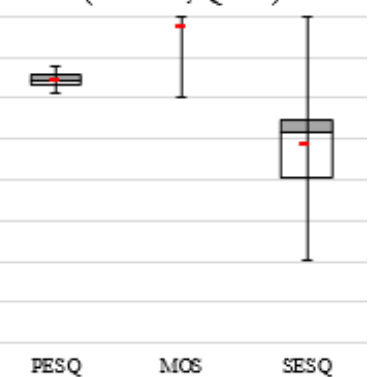

G9 (PCM, 64 kbits/s)

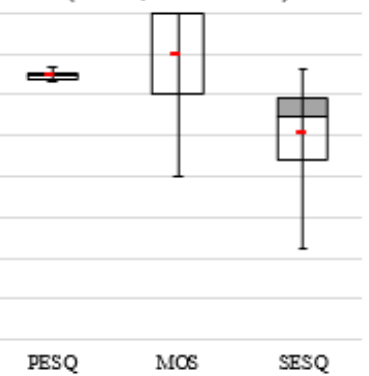

G12 (ACC_ACC)

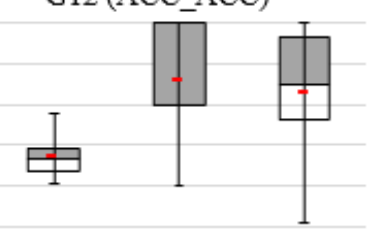

PESQ MOS SESQ

G16 (ACC_FL_CT)

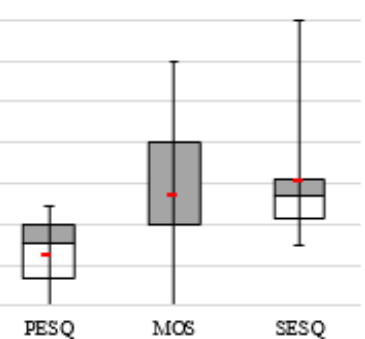

Figura 43: Distribuição, em quartis, dos resultados de aplicação do PESQ e SESQ em relação ao MOS - grupos G1 a G16 

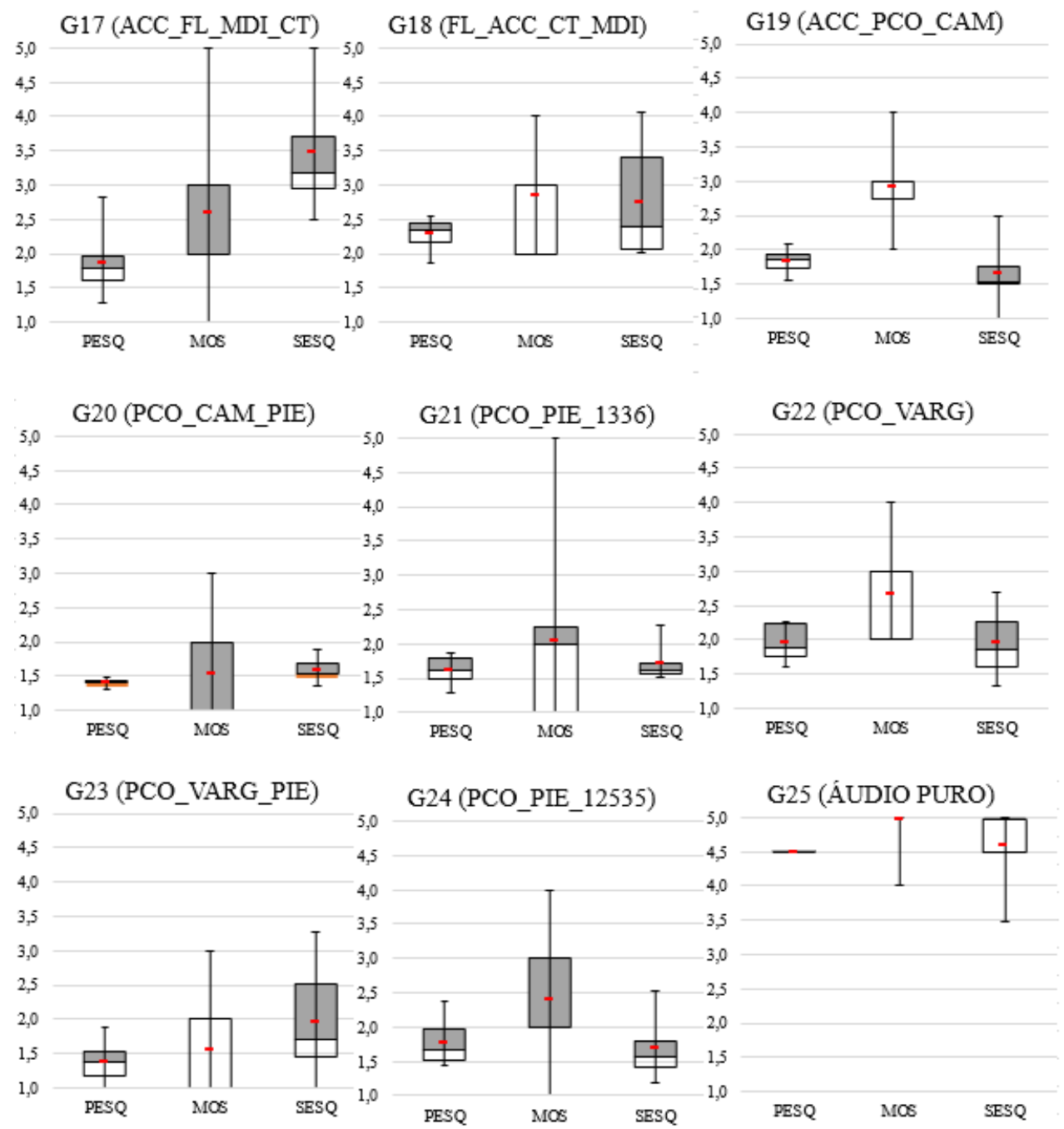

Figura 44: Distribuição, em quartis, dos resultados de aplicação do PESQ e SESQ em relação ao MOS - grupos G17 a G25 


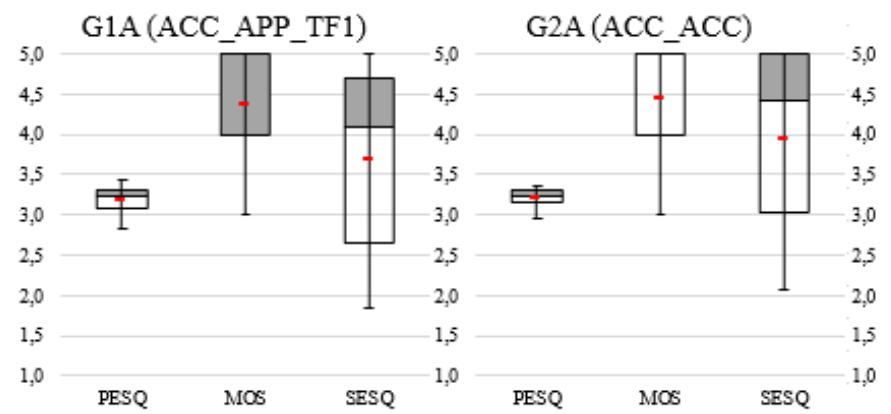

G3A (ACC_CAV_1275)
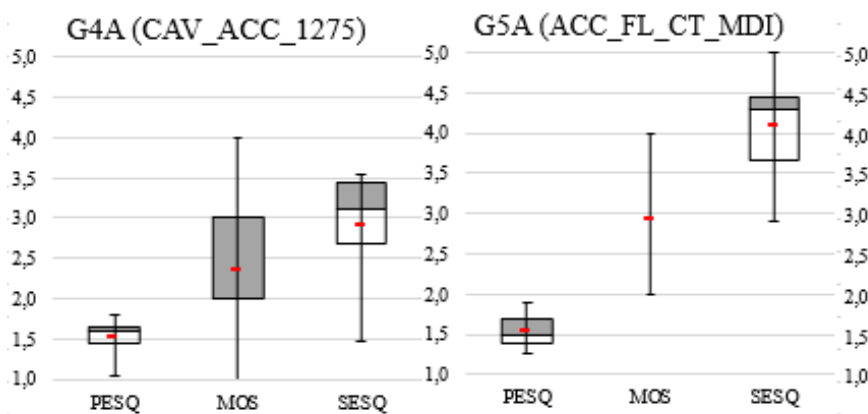

G7A (PCO_CAM_PIE)

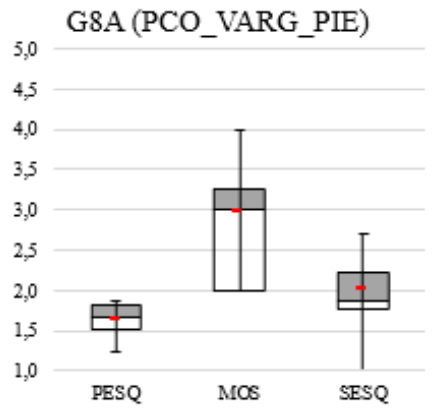

Figura 45: Distribuição, em quartis, dos resultados de aplicação do PESQ e SESQ em relação ao MOS - grupos G1A a G8A 
Média de Valores do PESQ X Média do MOS, por Grupo

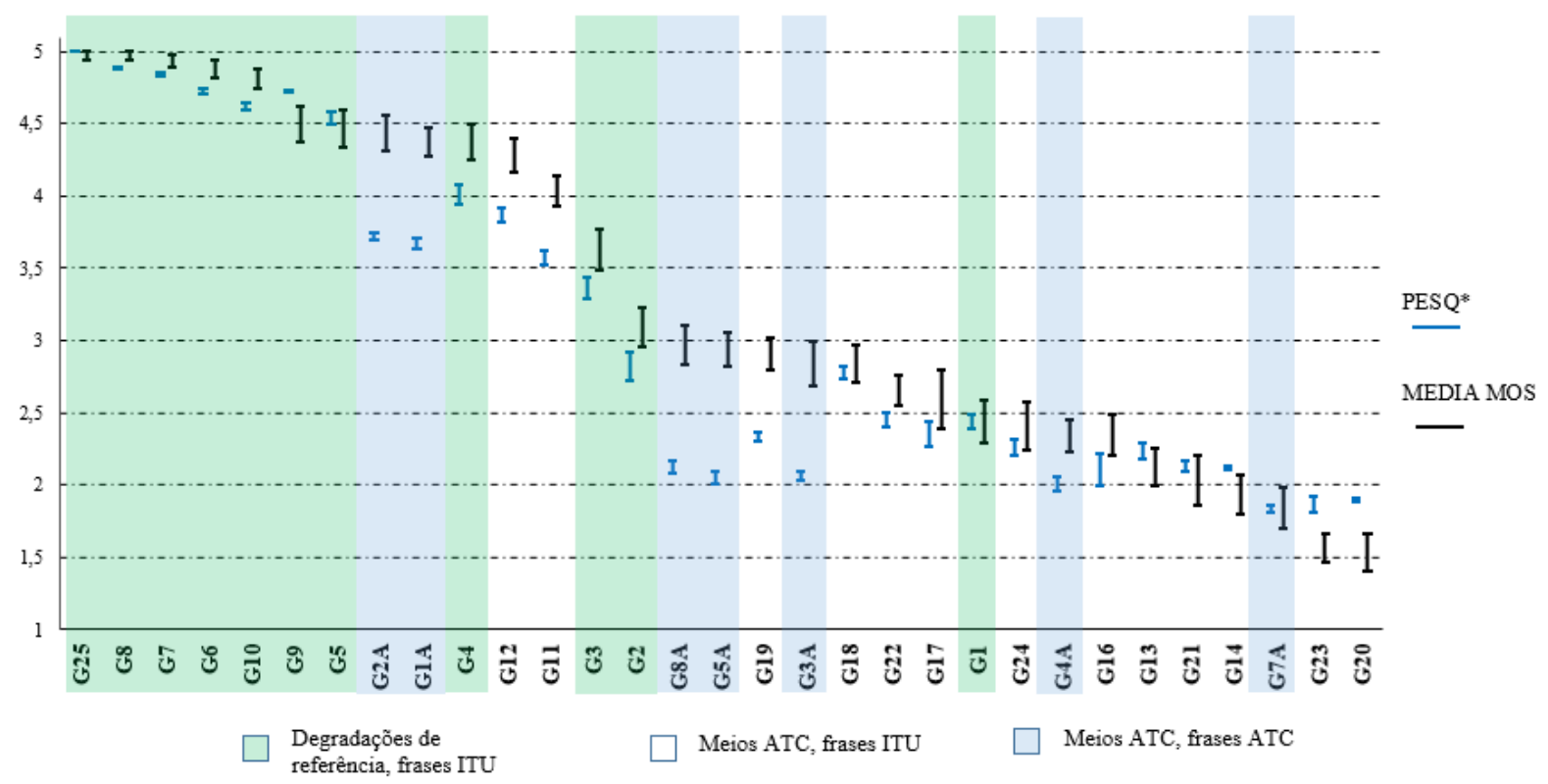

Figura 46: Comparação do PESQ com MOS obtido nos Experimentos Subjetivos. Os grupos terminados em "A"apresentam frases ATC, e não cumprem, portanto, as recomendações da ITU. As barras de erros representam o intervalo de confiança, considerando distribuição $T$ de Student e nível de confiança de $95 \%$.

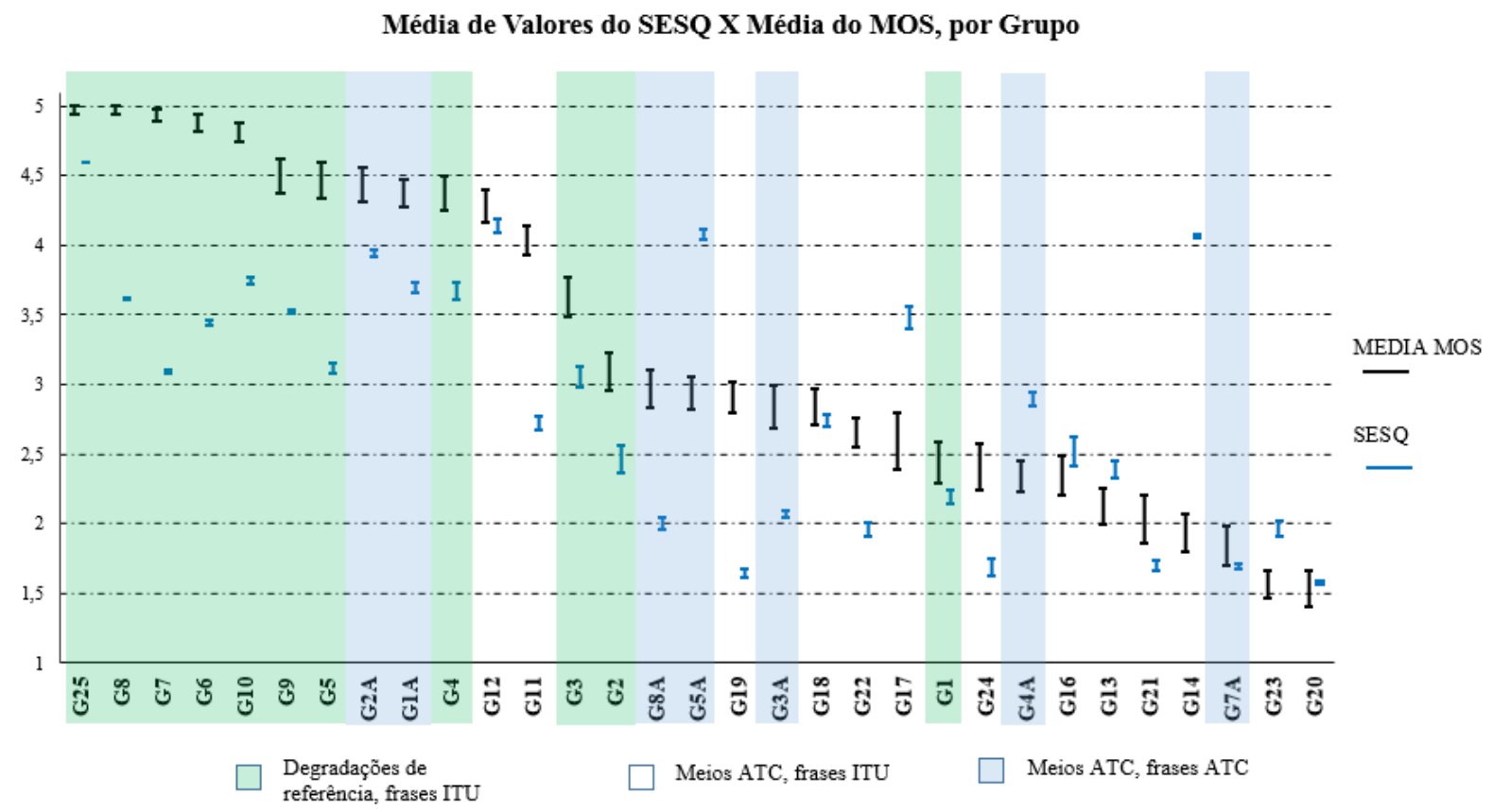

Figura 47: Comparação do SESQ com MOS obtido nos Experimentos Subjetivos. Os grupos terminados em "A"apresentam frases ATC, e não cumprem, portanto, as recomendações da ITU. As barras de erros representam o intervalo de confiança, considerando distribuição $T$ de Student e nível de confiança de $95 \%$. 

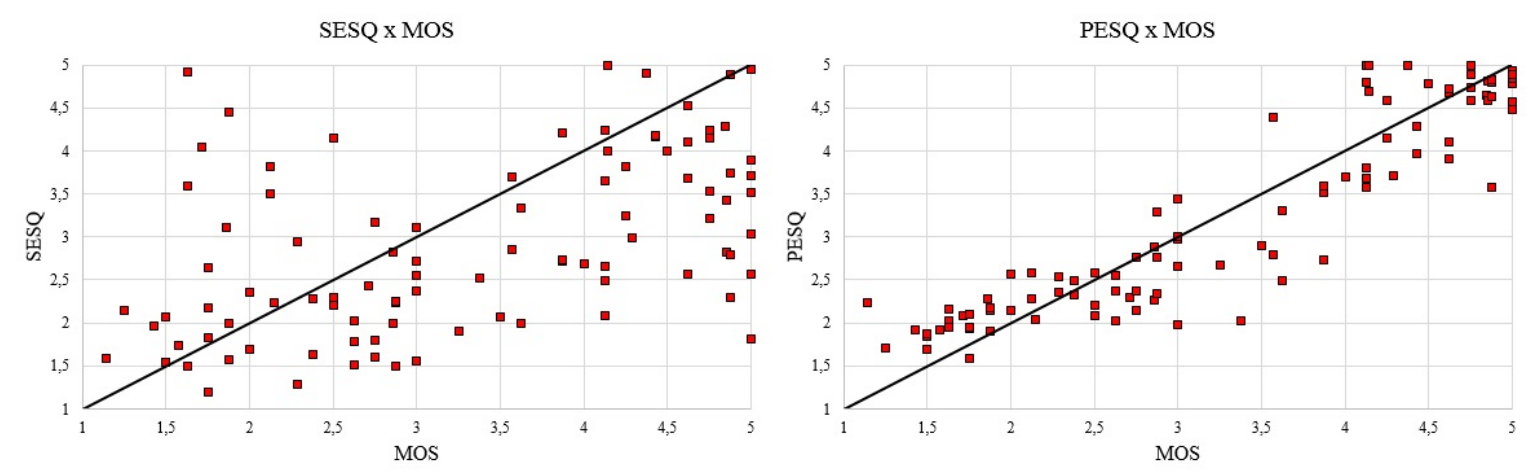

Figura 48: Representação gráfica do PESQ e SESQ em relação ao MOS, para todos os grupos padronizados (sem vocabulário ATC)
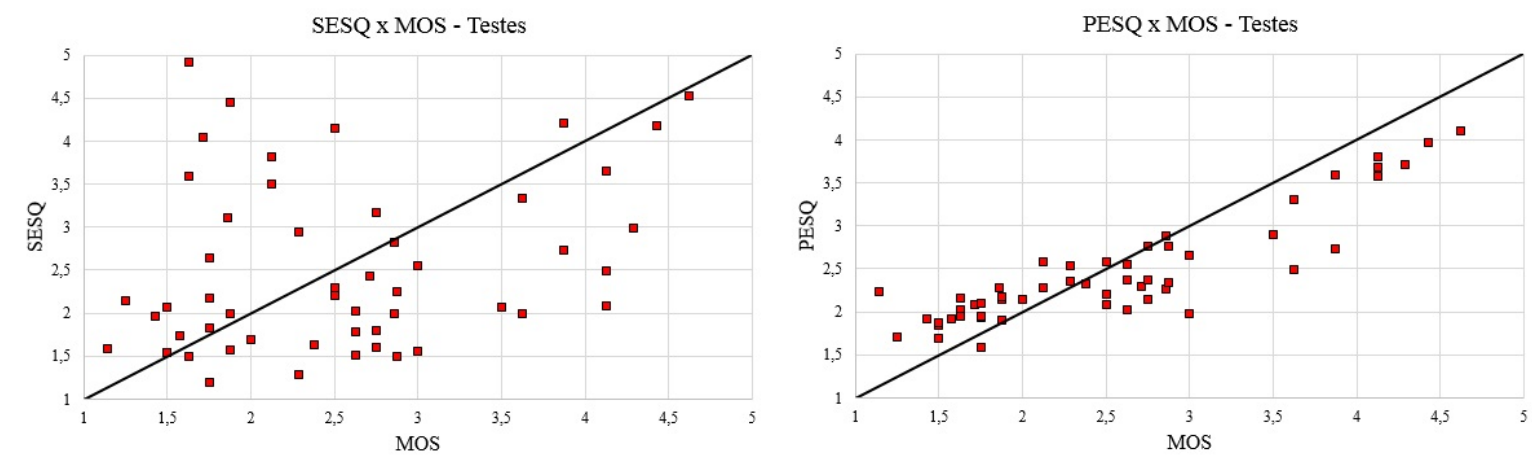

Figura 49: Representação gráfica do PESQ e SESQ em relação ao MOS, para todos os grupos com comunicações ATC (sem degradações de referência, somente frases padronizadas pela ITU
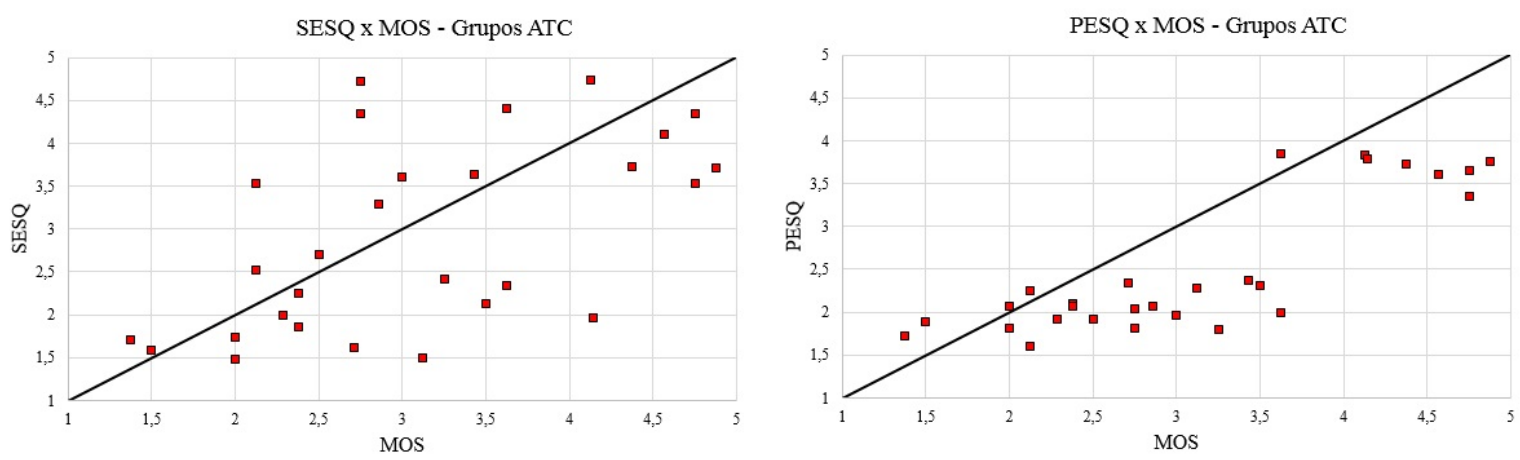

Figura 50: Representação gráfica do PESQ e SESQ em relação ao MOS, para todos os grupos com vocabulário ATC 


\section{CONCLUSÃO E TRABALHOS FUTUROS}

Sendo essencial a inteligibilidade das comunicações aeronáuticas para as atividades de controle do espaço aéreo, esta dissertação se propôs a analisar os problemas de qualidade de áudio nestes meios no âmbito do CINDACTA II. Para tal, foi realizado um estudo subjetivo de qualidade de áudio nos padrões definidos pela ITU-T P.800, que englobou desde a avaliação de salas de gravação em estúdio profissional, produção e gravação de material de áudio de referência em alta fidelidade em estúdio, nos idiomas inglês e português, por 8 pessoas, submissão de sinais a degradações controladas e aos meios de comunicação utilizados nas comunicações aeronáuticas, até a realização da avaliação, por sujeitos humanos, do MOS em cada uma das situações pesquisadas. Com a finalidade de estudos adicionais de percepção de qualidade de áudio, foram gravadas e avaliadas também frases padronizadas de controle de tráfego aéreo.

As condições testadas representaram diferentes cenários de comunicação empregados comumente no controle de tráfego aéreo, como comunicações terra-terra, terra-ar e ar-terra. Foi testada a comunicação entre consoles do ACC-CW, entre dois órgãos ATC, e realizados diferentes testes em vôo. Estes percorreram aproximadamente $3.500 \mathrm{~km}$ em áreas e níveis de vôo que apresentaram reclamações por parte dos usuários e envolveram 7 estações terrenas de VHF, diferentes canalizações e simulações de situações de clímax (transmissão simultânea) através 2 e 3 estações terrenas. A realização dos testes necessitou da montagem de adaptadores, sistemas de aquisição de dados, desenvolvimento de metodologias específicas, além de extensa coordenação dos setores operacionais do CINDACTA II e colaboração de diversas pessoas.

Foi então organizado um experimento subjetivo em que foram utilizados seres humanos para a avaliação do MOS de cada um dos sinais de áudio. O experimento, que contou com a participação de 32 pessoas, foi realizado em conformidade com a normatização de referência e contou com a orientação e aprovação tanto do CEP da UTFPR quanto do DECEA. O experimento foi realizado em estúdio profissional em 4 sessões em que sujeitos, previamente selecionados por meio de entrevista, puderam avaliar os sinais de áudio. Os dados foram compilados a fim de traduzir os parâmetros de qualidade de áudio para cada situação de teste, estabelecendo uma base de dados de valores de MOS de qualidade de áudio de problemas e interferências 
comuns nas comunicações de ATC.

A análise dos dados levantados no experimento subjetivo permitiu constatar que os principais problemas de qualidade de áudio nas telecomunicações aeronáuticas estão relacionados à transmissão em VHF, sendo que nestas situações os valores de MOS obtidos é inferior a 2,50, representando qualidade de áudio entre ruim e regular. Nenhum dos testes que envolveram comunicações por radiofrequência (condições terra-ar e ar-terra) obtiveram MOS superior a 3,0, que corresponderia à qualidade regular.

As comunicações terra-terra, tanto entre órgãos operacionais quanto entre consoles apresentou MOS superior a 4, correspondendo à qualidade entre boa e excelente. Para situações de comunicação terra-ar com clímax entre duas estações, em que o sinal foi transmitido simultaneamente por duas estações terrenas e captado da aeronave, a média do MOS foi de 2,47 e quando foram usadas três estações o índice médio foi de 1,90, valor que corresponde à qualidade entre ruim e péssima. Dentre as situações avaliadas, a que apresentou maior degradação de áudio foi no clímax entre as estações de PCO, CAM e PIE, na frequência 133,6 MHz, que registrou valor de MOS de 1,531. Os diferentes meios de canalização empregados (meios contratados ou satelitais operados pelo DECEA) tiveram pouca influência nos valores de MOS obtidos.

Outro fato interessante de ser observado foi que quanto os sujeitos entrevistados foram submetidos a frases padronizadas de controle de tráfego aéreo, os valores de MOS obtidos para as mesmas condições de teste foram, em média, 0,42 superiores ao MOS das frases aleatórias recomendadas pela ITU-T P.800. E, felizmente, para a segurança da aviação geral, a situação que apresentou maior melhora de percepção foi a de clímax com 3 estações, que passou de 1,90 para 2,58, passando de um índice entre péssimo e ruim para entre ruim e regular. Constata-se que as frases conhecidas exigem menor esforço do ouvinte para serem compreendidas. Ressalta-se, portanto, a importância do uso de vocabulários padronizados nas comunicações aeronáuticas.

Outra atividade desenvolvida neste trabalho foi a aplicação de métodos objetivos de qualidade de áudio aos sinais degradados a fim de verificar seu desempenho na identificação da qualidade percebida pelo usuário. Tendo em mãos a base de dados desenvolvida, foram testados os métodos do PESQ (ITU-T P.562) e do SESQ (ITU-T P.863), sendo o primeiro um método com referência e o segundo sem referência e ambos amplamente utilizados comercialmente.

Foi verificado que o PESQ apresentou ótimo desempenho na avaliação das degradações ensaiadas, conseguindo prever, com boa precisão, os valores de MOS percebidos pelos usuários. O PESQ obteve coeficiente de correlação de Pearson superior a 0,92 e coeficiente de correlação de postos de Spearman superior a 0,90 quando analisados todas as condições de teste e degrada- 
ções controladas. Já o SESQ, embora a literatura apresente situações bons resultados sob determinadas condições de degradação, apresentou os coeficientes de Pearson e Spearman de, respectivamente, 0,51 e 0,52, correspondendo à correlação moderada entre o MOS e o valor previsto pelo método. Porém, quando foram analisadas isoladamente as degradações dos sistemas de telecomunicações aeronáuticas, somente o PESQ obteve desempenho adequado, registrando índices de correlação de Pearson e de Spearman de, respectivamente, 0,89 e 0,84. O SESQ registrou os índices de 0,29 e 0,28, indicando correlação muito fraca.

Dessa maneira, os objetivos descritos na seção 1.3 foram atingidos, destacando-se a criação da base de dados de MOS e de sinais de referência e degradados, procedimentos demorados e custosos, que poderão ser empregados em pesquisas posteriores. Outrossim, foi encontrado um método de análise objetiva com referência normatizado, o PESQ, que traduz, com boa fidelidade, a qualidade de voz percebida pelo usuário. Este, juntamente com a base de dados levantada, pode ser utilizado para os seguintes trabalhos futuros sugeridos na seção 6.1.

\subsection{TRABALHOS FUTUROS}

São sugeridos os seguintes trabalhos futuros:

- Utilizando a base de dados de MOS elaborada nesta pesquisa: no desenvolvimento e na validação de um métodos objetivo de qualidade de áudio sem referência, que consiga prever com maior precisão o MOS de sinais submetidos às degradações dos meios de telecomunicações de ATC;

- implementar solução baseada no PESQ para avaliar periodicamente as condições de qualidade de áudio em diferentes situações de comunicação entre os ATCO e aeronaves e avaliar o histórico de degradações, principalmente as que apresentam tendência de longo prazo;

- Como verificado, embora o uso de vocabulário padronizado seja um atenuante às degradações de áudio, há boa margem de melhora da qualidade de áudio nas telecomunicações aeronáuticas. Por este motivo, sugere-se, também, como desenvolvimento futuro, o estudo de melhorias que permitam a melhora da qualidade de áudio como: avaliação de maneiras de reduzir as degradações de radio-frequência, seja pela re-divisão do espaço aéreo, por melhor aproveitamento do espectro, viabilização da redução das condições de clímax; implementação de técnicas de melhoramento de voz; e por fim, avaliação de meios técnicos alternativos de comunicação poderiam ser realizados a fim de melhorar a percepção de qualidade por parte do usuário. 


\section{REFERÊNCIAS}

ANDERSON AVILA; BENJAMIN, C. S. G. S. D. T. F. Performance comparison of intrusive and non-intrusive instrumental quality measures for enhanced speech. Acoustic Signal Enhancement (IWAENC), 2016 IEEE International Workshop on, 2016.

ASCHENBRUCK N.; MARTINI, P. G. M. Characterisation and modelling of voice traffic in first responder networks. Local Computer Networks, p. 295-302, 2007.

AU, K. L. O. A novel output-based objective speech quality measure for wireless communication. Fourth International Conference on Signal Processing Proceedings, v. 1, p. 666-669, 1998.

BOOM, E. S. D. 2017.

BRADY, P. T. A technique for investigating on-off patterns of speech. The Bell System Technical Journal, v. 44, p. 1-22, 1965.

BRASIL. Convenção sobre aviação civil internacional. Diário Oficial da União, Decreto $\mathrm{N}^{\circ}$ 21.713, de 27 de agosto de 1947, Agosto 1946.

BRASIL. Código brasileiro de aeronáutica. Diário Oficial da União, Lei 7.595 de 19 de dezembro de 1986, 1986.

BURT, P. M. S. Measuring acoustic responses with maximum-length sequences. In: Telecommunications Symposium, 1998. ITS '98 Proceedings. SBT/IEEE International. [S.1.: s.n.], 1998. p. 284-289 vol.1.

DECEA. Regiões de informação de vôo. www.decea.gov.br: [s.n.], Novembro 2016. Acesso em 12/11/2016, 19h 38min.

FALK QINGFENG XU, W. C. T. H. Non-intrusive gmm-based speech quality measurement. In: . [S.1.: s.n.], 2005. p. 125-128.

FALK, T. H. et al. Objective quality and intelligibility prediction for users of assistive listening devices. IEEE SIGNAL PROCESSING MAGAZINE, p. 114-124, 2015.

FREEMAN, R. L. Fundamentals of Telecommunications, 2nd edition. [S.1.]: John Wiley \& Sons, 2005.

GRANCHAROV DAVID Y. ZHAO, J. L. W. B. K. V. Non-intrusive speech quality assessment with low computational complexity. INTERSPEECH 2006 - ICSLP, Ninth International Conference on Spoken Language Processing, Pittsburgh, PA, USA, September, p. 17-21, 2006.

GRAY M P HOLLIER, R. E. M. P. Non-intrusive speech-quality assessment using vocal-tract models. IEE Proceedings - Vision, Image and Signal Processing, v. 147, Issue: 6, p. 493 501, 2000. 
GRUBER, J. A. A comparison of measured and calculated speech temporal parameters relevant to speech activity detection. Communications, IEEE Transactions on, v. 30, p. 728-738, 1982.

HINTERLEITNER, F. Quality of Synthetic Speech: Perceptual Dimensions, Influencing Factors, and Instrumental Assessment. Springer Singapore, 2017. (TLabs Series in Telecommunication Services). ISBN 9789811037344. Disponível em: $<$ https://books.google.com.br/books?id=sfOhDgAAQBAJ $>$.

HOLUB MICHAEL STREET, O. T. J. A novel non-intrusive voice transmission quality measurement algorithm based on wavelet transform. Wireless Telecommunications Symposium, v. 06, 2006.

ICAO. International standard and recommended practices - ANNEX 10 - Communication Systems (Part II - Voice communication systems). 1996.

ISO. ISO 3382 - Acoustics - Measurement of room acoustic parameters - Part 2: Reverberation time in ordinary rooms. 2008.

ITU. ITU-T Rec. G.711 Pulse code modulation (PCM) of voice frequencies, 1993. 1993.

ITU. ITU-T Recommendation P.56 - Objective measurement of active speech level, 1993. 1993.

ITU. ITU-T recommendation P.79: Calculation of loudness ratings for telephone sets. 1993.

ITU. ITU-T Rec. G.726 : 40, 32, 24, 16 kbit/s Adaptive Differential Pulse Code Modulation (ADPCM), 1996. 1996.

ITU. ITU-T Rec. P.800 - Methods for Subjective Determination of Transmission Quality, 1996. 1996.

ITU. ITU-T Recommendation P.81 Modulated noise reference unit (MNRU), 1996. 1996.

ITU. ITU-T RECOMMENDATION P.830 - SUBJECTIVE PERFORMANCE ASSESSMENT OF TELEPHONE-BAND AND WIDEBAND DIGITAL CODECS, 1996. 1996.

ITU. Series P Supplement 23 - ITU-T coded-speech database, 1998. 1998.

ITU. International standard and recommended practices - ANNEX 11 - Air Traffic Services (Air Traffic Control Service Flight Information Service, Alerting Service). 2001.

ITU. ITU-T Rec. G.712, Transmission performance characteristics of pulse code modulation channels. 2001.

ITU. ITU-T Rec. P.862 - Perceptual evaluation of speech quality (PESQ): An objective method for end-to-end speech quality assessment of narrow-band telephone networks and speech codecs, 2001. 2001.

ITU. ITU-T Rec. P.563 - Single-ended method for objective speech quality assessment in narrow-band telephony applications, 1996. 2004. 
ITU. ITU-T P.807 - Subjective test methodology for assessing speech intelligibility, 2016. 2016.

JASSIM;, N. M. W. A.; ZILANY, M. S. A. Prediction of speech intelligibility using a neurogram orthogonal polynomial measure (nopm). IEEE/ACM TRANSACTIONS ON AUDIO, SPEECH, AND LANGUAGE PROCESSING, v. 23 NO.4, p. 760-773, 2015.

MöLLER, F. K. V. C.-L. G. M. S. Non-intrusive estimation model for the speech-quality dimension loudness. ITG-Fachbericht 267: Speech Communication, v. 05, p. 175-179, 2016.

MRVOVA, M.; POCTA, P. Quality estimation of synthesized speech transmitted over ip channel using genetic programming approach. In: The International Conference on Digital Technologies 2013. [S.1.: s.n.], 2013. p. 39-43.

PAPASRATORN, B. et al. Advances in Information Technology: 6th International Conference, IAIT 2013, Bangkok, Thailand, December 12-13, 2013. Proceedings. Springer International Publishing, 2013. (Communications in Computer and Information Science). ISBN 9783319037837. Disponível em: $<$ https://books.google.com.br/books?id=hDy5BQAAQBAJ $>$.

PATYNEN, B. F. K. J.; LOKKI, T. Investigations on the balloon as an impulse source. J.Acoustical Society of America, v. 129, 2011.

RAAKE, A. Speech Quality of VoIP: Assessment and Prediction. [S.1.]: John Wiley \& Sons, 2007.

ROSSI, D. S. Z. Modelo de uso dos canais de comunicação do controle de tráfego aéreo. Dissertação (Mestrado) — UNIVERSIDADE TECNOLÓGICA FEDERAL DO PARANÁ PROGRAMA DE PÓS-GRADUACÃO EM ENGENHARIA ELÉTRICA E INFORMÁTICA INDUSTRIAL, 2015.

ROZHON, J. et al. Utilizing the neural networks for speech quality estimation based on the network characteristics. In: AETA 2015: Recent Advances in Electrical Engineering and Related Sciences. Cham: Springer International Publishing, 2016. p. 99-109. ISBN 9783-319-27247-4.

SALEHI, V. P. H. Nonintrusive speech quality estimation based on perceptual linear prediction. IEEE Canadian Conference on Electrical and Computer Engineering (CCECE), 2016.

SONI, M. H.; PATIL, H. A. Novel subband autoencoder features for non-intrusive quality assessment of noise suppressed speech. In: Interspeech 2016. [S.1.: s.n.], 2016. p. 3708-3712.

STREIJL, R. C.; WINKLER, S.; HANDS, D. S. Mean opinion score (mos) revisited: methods and applications, limitations and alternatives. Multimedia Systems, v. 22, n. 2, p. 213-227, Mar 2016. ISSN 1432-1882. Disponível em: <https://doi.org/10.1007/s00530-014-0446-1>.

SUN, L.; IFEACHOR, E. C. Perceived speech quality prediction for voice over ip-based networks. IEEE International Conference on, v. 4, p. 2573-2577, 2002.

TOMINAGA, T. et al. Performance comparisons of subjective quality assessment methods for mobile video. In: 2010 Second International Workshop on Quality of Multimedia Experience (QoMEX). [S.1.: s.n.], 2010. p. 82-87. 
VELDHUIS R N. J., B.-M.; WML, V. D. Subband coding of digital audio signals. Philips J. Res, v. 4, p. 329-343, 1989.

$\mathrm{XU}$, J. et al. On the properties of mean opinion scores for quality of experience management. In: 2011 IEEE International Symposium on Multimedia. [S.1.: s.n.], 2011. p. 500-505.

ZABALLOS, M. T. et al. Air traffic controllers long-term speech-in-noise training effects: A control group study. Noise \& Health, v. 18(85), p. 376-381, 2016. 


\section{ANEXO A - RECURSOS, EQUIPAMENTOS E INFRAESTRUTURA}

Neste anexo são apresentados os recursos materiais, equipamentos e infraestrutura que foram necessários para a condução do experimento subjetivo. São listadas as especificações importantes, bem como marca e modelo dos equipamentos utilizados. A seleção dos equipamentos e recursos foi realizada em conformidade com as recomendações da ITU-T P.800 (ITU, 1996b), e/ou das solicitações realizadas pelo Comitê de Ética da UTFPR. Para cada item é indicado o requisito, sua finalidade, especificação e disponibilidade, que identifica a organização ou pessoa física detentora do recurso.

\section{A.1 MATERIAIS E RECURSOS PARA TESTES COM AERONAVES}

1.Avião para realizar condições de teste - teto operacional baixo; Finalidade: acessar áreas de degradação de áudio, para aferir as condições de teste; Especificação: Cessna 208 Grand Caravan, 9 passageiros, velocidade de cruzeiro $340 \mathrm{~km} / \mathrm{h}$, teto operacional 25000 pés $(7.620 \mathrm{~m})$, carga líquida de até $1200 \mathrm{~kg}$; Disponibilidade: CINDACTA II. O avião utilizado é mostrado na Figura 51.

2.Avião para realizar condições de teste - teto operacional alto; Finalidade: acessar áreas de degradação de áudio, para aferir as condições de teste; Especificação: Embraer Legacy 500, 12 passageiros, velocidade de cruzeiro de $863 \mathrm{~km} / \mathrm{h}$, teto operacional 45.000 pés (13.716 m), carga líquida de até 1270 kg; Disponibilidade: GEIV (Grupamento de Ensaio em Vôo do DECEA).

3.Reprodutor de áudio digital 16 bits, 44,4 kHz; Finalidade: reproduzir áudios de referência nos trechos avião - ACC e ACC - avião; Especificação: Behringer UCA222 - interface de áudio. Impedância de saída 400 ohm, saída máxima de 2 dBV,THD inferior a 0,05 \%, resposta em frequência de $10 \mathrm{~Hz}$ a $20 \mathrm{kHz}( \pm 1 \mathrm{~dB}$ ); Disponibilidade: recurso próprio (duas unidades).

4.Gravador de áudio digital 16 bits, 44,4 kHz; Finalidade: gravar áudios nos trechos avião ACC e ACC - avião; Especificação: Behringer UCA222 - interface de áudio. Impedância 


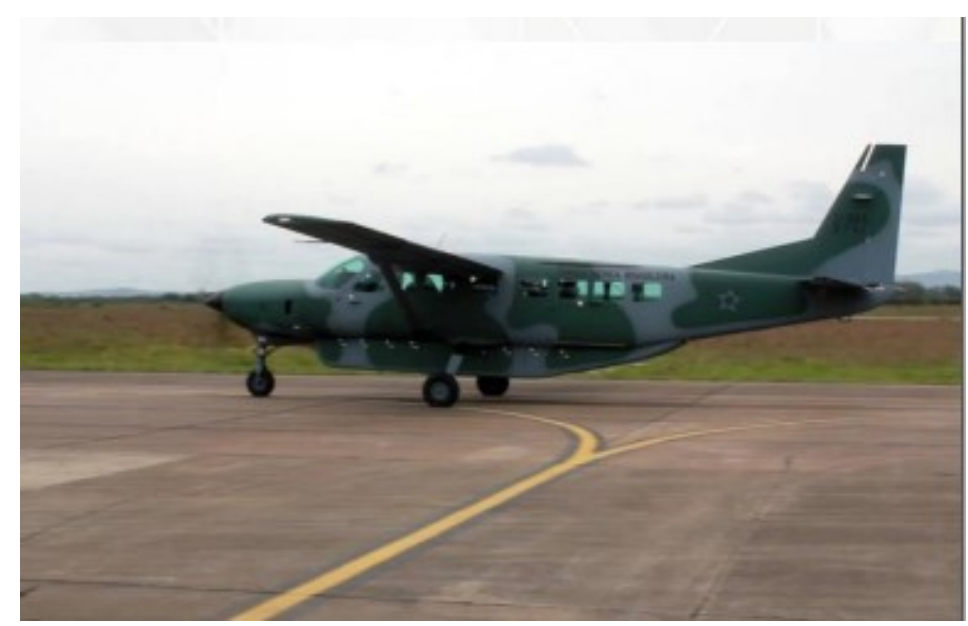

Figura 51: Avião Cessna Grand Caravan utilizado na transmissão e recepção de sinais de áudio em teto operacional baixo

Fonte: (BOOM, 2017)

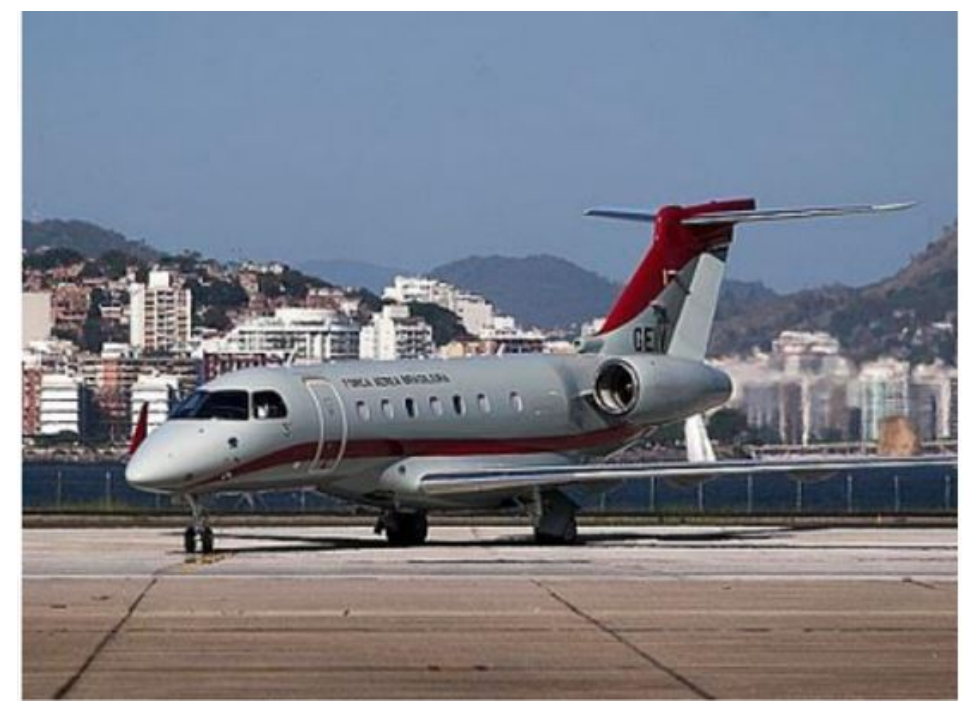

Figura 52: Avião Embraer Legacy 500 utilizado na transmissão e recepção de sinais de áudio em teto operacional alto

Fonte: (BOOM, 2017)

de saída 400 ohm, saída máxima de 2 dBV,THD inferior a $0,05 \%$, resposta em frequência de $10 \mathrm{~Hz}$ a $20 \mathrm{kHz}$ ( $\pm 1 \mathrm{~dB}$ ); Disponibilidade: recurso próprio (duas unidades).

5.Notebook para interface e armazenamento de áudio; Finalidade: interface para gravar e reproduzir áudios nos trechos avião - ACC e ACC - avião; Especificação: notebook Dell Latitude E6430s; Disponibilidade: CINDACTA II

6.Inversor de frequência 12V/127V e conjunto de cabos de alimentação; Finalidade: alimentação do sistema de gravação/reprodução no avião; Especificação: Inversor de frequência 


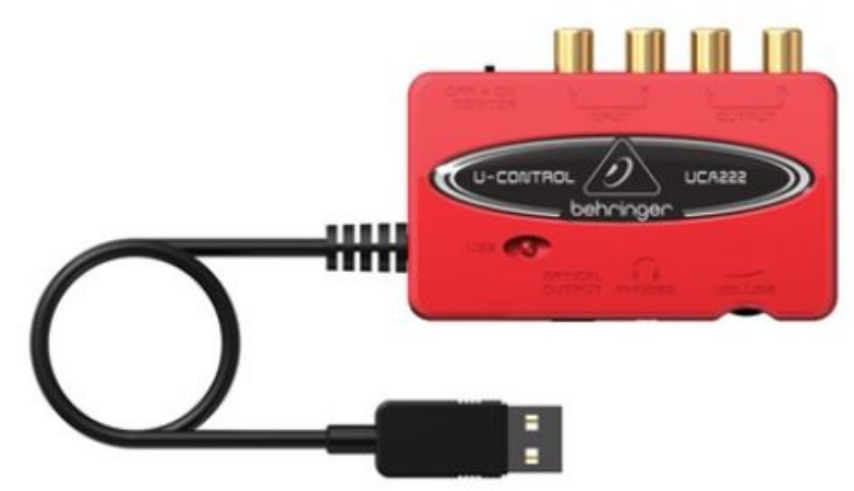

Figura 53: Interfaces de áudio Behringer UCA222 adquiridas para gravação e reprodução de áudio nas condições de teste

Fonte: Adquiridas pelo pesquisador

$12 \mathrm{~V}$ para $110 \mathrm{~V}, 150 \mathrm{~W}$, com adaptador 3 pinos, conjunto adaptador bateria de $12 \mathrm{~V} / \mathrm{plug}$ de 12V; Disponibilidade: recursos próprios.
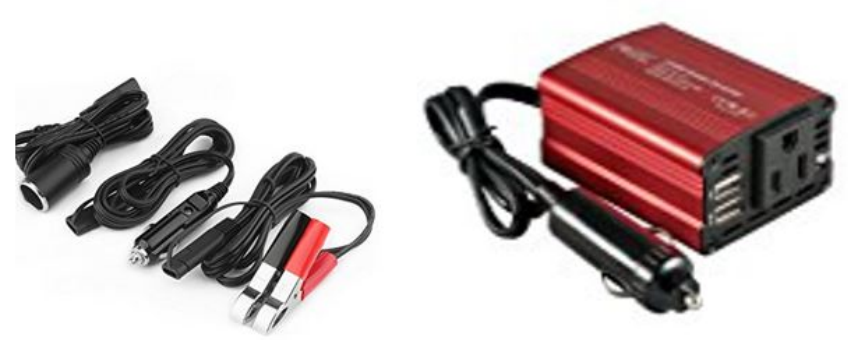

Figura 54: Inversor de frequência $12 \mathrm{~V} / 120 \mathrm{~V}$ utilizados para alimentação do sistema de gravação/reprodução na aeronave

Fonte: Adquiridas pelo pesquisador

7.Cabo de interface avião-gravador / reprodutor (interface do tipo SITTI); Finalidade: reproduzir e gravar sons a partir do avião; Especificação: Conector duplo tipo PRS, casamento de impedância, teste e validação, adaptador RCA não balanceado; Disponibilidade: Desenvolvido para a aplicação.

Observações: Esta interface foi desenvolvida para possibilitar a transferência de sinais da Central de Áudio SITTI para o sistema de gravação/reprodução. Ela possui um conector específico que se conecta à posição de operação de controle. Tendo em vista que não haviam informações disponíveis no manual do fabricante, a pinagem do conector foi levantada manualmente. A Figura 55 apresenta a pinagem do conector utilizado na interface "'SITTI", com informações dos respectivos sinais. 
Verificou-se que entre os pinos 8 e 9, que correspondem à entrada de microfone, havia uma tensão de $-24 \mathrm{~V}$, que é utilizada para alimentação do circuito de interface de microfone de eletreto. De maneira a realizar o desacoplamento do sinal de corrente contínua, foi instalado um filtro tipo RC. O resistor $\mathbf{R 1}$ foi escolhido levando em consideração que a console de operação possui um circuito que corta a entrada do microfone quando este não é detectado. Verificou-se, empiricamente, que para valores de $\mathbf{R} \mathbf{1}$ superiores a $20 \mathrm{k} \Omega$ a entrada era desabilitada, e o mesmo ocorria quando $\mathbf{R} \mathbf{1}$ era inferior a $5 \mathrm{k} \Omega$. Foi escolhido então o valor de $10 \mathrm{k} \Omega$ de maneira a "enganar" o circuito de detecção de microfone. O diagrama da interface do tipo "'SITTI"” é mostrado na Figura 56.

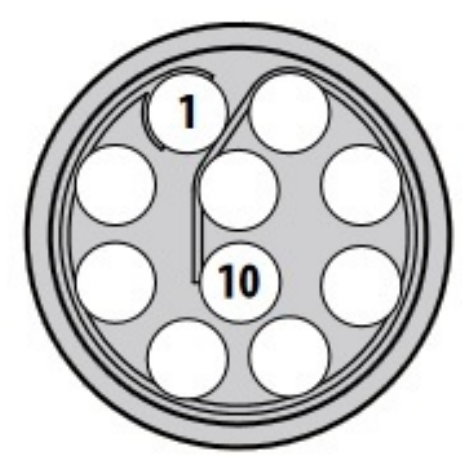

Figura 55: Conector ODU tipo 0Y R-P010 0-000 utilizado nas posições operacionais de controle. O pino 1 corresponde ao sinal Audio L+, o pino 2 a Audio L-, o pino 3 a Audio R+, pino 4 a Audio R-, pino 7 a mic+, pino 8 a mic-, pinos 8 e 10 comum e pino 6 PTT

Fonte: Catálogo ODU, conector modelo OY R-P010 0-000

8.Cabo de interface console ACC gravador / reprodutor (interface do tipo Aeronave); Finalidade: reproduzir e gravar sons a partir da console do ACC; Especificação: Conector proprietário 12 pinos, casamento de impedância, teste e validação, adaptador RCA não balanceado; Disponibilidade: Desenvolvido para a aplicação.

Observações: A interface deste tipo apresenta dois plugs que são conectados à aeronave. O conector tipo PJ-068, exibido na Figura 57 é utilizado para a conexão do microfone do headset dos tripulantes. O outro conector, do tipo PJ-055 é utilizado para alimentação do fone, e é equivalente aos utilizados em fones de ouvidos comerciais, apresentando mesma pinagem. Entre os anéis 2 e 3 do conector de microfone foi encontrada tensão de aproximadamente $+9 \mathrm{~V}$, que é utilizado pelo circuito de microfone da aeronave e também para circuitos de redução ativa de ruídos dos headsets aeronáuticos. De maneira semelhante à interface do tipo "'SITTI", foi empregado um filtro RC para realizar o desacoplamento do nível de corrente contínua. O diagrama da interface do tipo "Aeronave"” é exibida na Figura 58. 


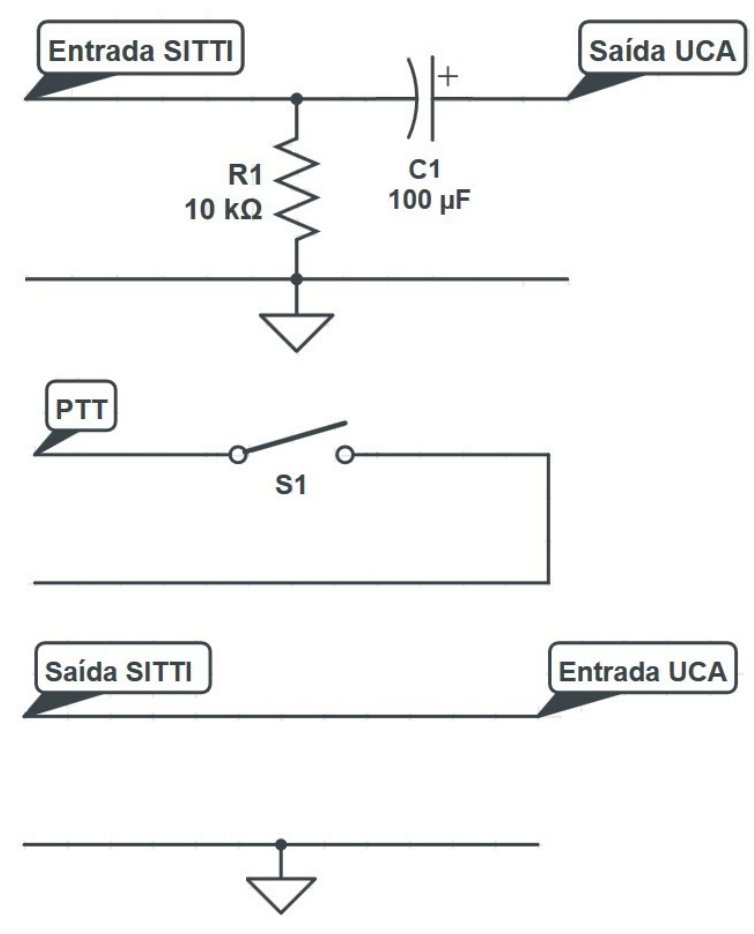

Figura 56: Diagrama da interface tipo "SITTI", evidenciando principais componentes

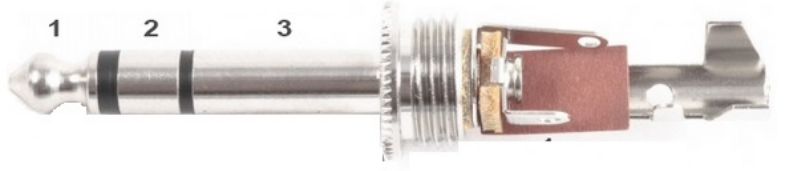

Figura 57: Plug de aviação tipo PJ-068 de 0,206”'utilizado para conexão do microfone em aeronaves. $O$ anel 1 corresponde ao sinal PTT, anel 2 ao sinal Mic+e anel 3 ao GND

Fonte: Adaptado de www.acoustic.com2015aviation-headset-information-specs

\section{A.2 MATERIAIS E RECURSOS PARA GRAVAÇÃO E TESTE SUBJETIVO}

1.Sala de Gravação: Sala de Gravação $30-120 \mathrm{~m}^{3}$, ruído inferior a $30 \mathrm{dBA}$, reverberação inferior a 500 ms. Finalidade: Gravar áudios Especificação: Sala com 31,35 m³ , ruído medido 28 dBA com ar-condicionado, medidas de $(6,4$ x 4,8) m, projeto acústico com parâmetro de reverberação inferior a 400 ms. A Figura 59 apresenta a sala de gravação utilizada pelos locutores para a gravação dos sinais de referência. Disponibilidade: Estúdio BOOM.

2.Sala de reprodução de áudio, volume na faixa de 30 a $120 \mathrm{~m}^{3}$, ruído inferior a $30 \mathrm{dBA}$, reverberação inferior a 500 ms. Finalidade: aplicação do teste subjetivo. Especificações: volume de $89 \mathrm{~m}^{3}$, ruído medido de $28 \mathrm{dBA}$, janelas de vidro duplo, acomodação para até 

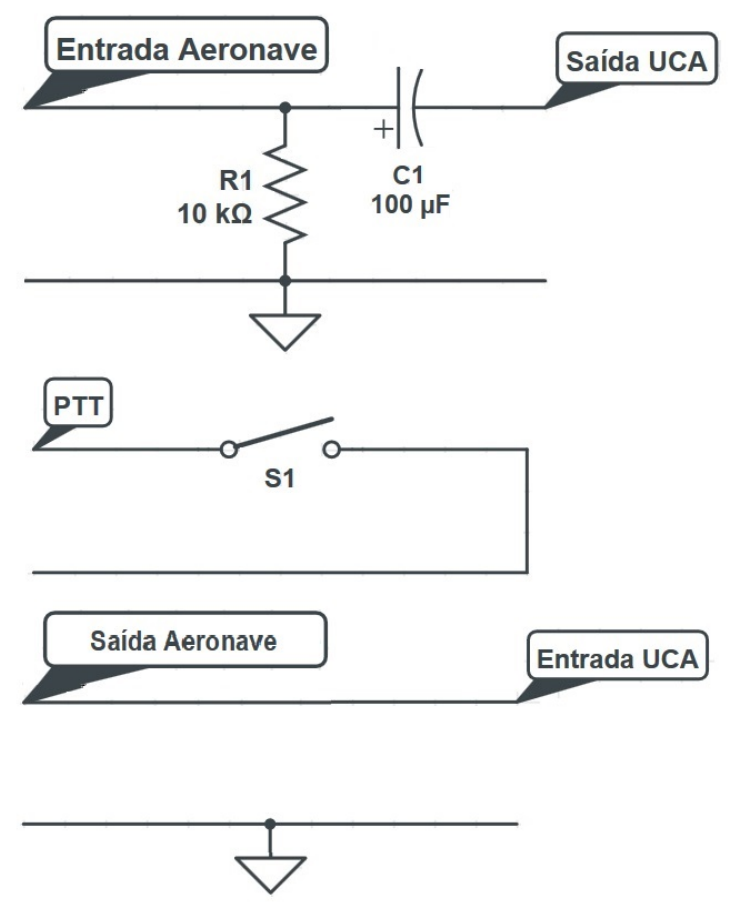

Figura 58: Diagrama da interface tipo" "Aeronave", evidenciando principais componentes

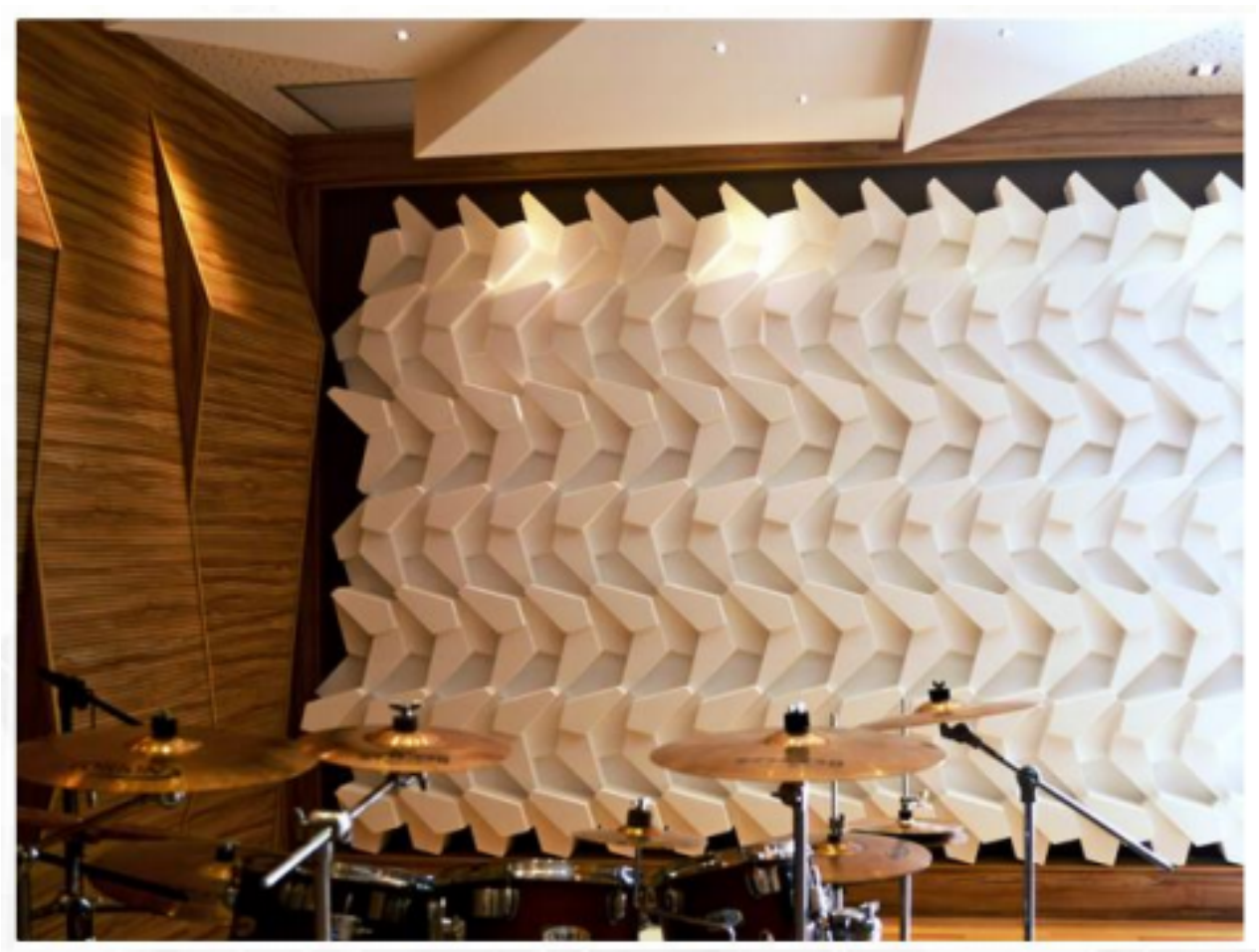

Figura 59: Sala de gravação utilizada para a gravação de sinais de referência Fonte: (BOOM, 2017) 
9 pessoas, reverberação projetada inferior a 300 ms. Disponibilidade: Estúdio BOOM.

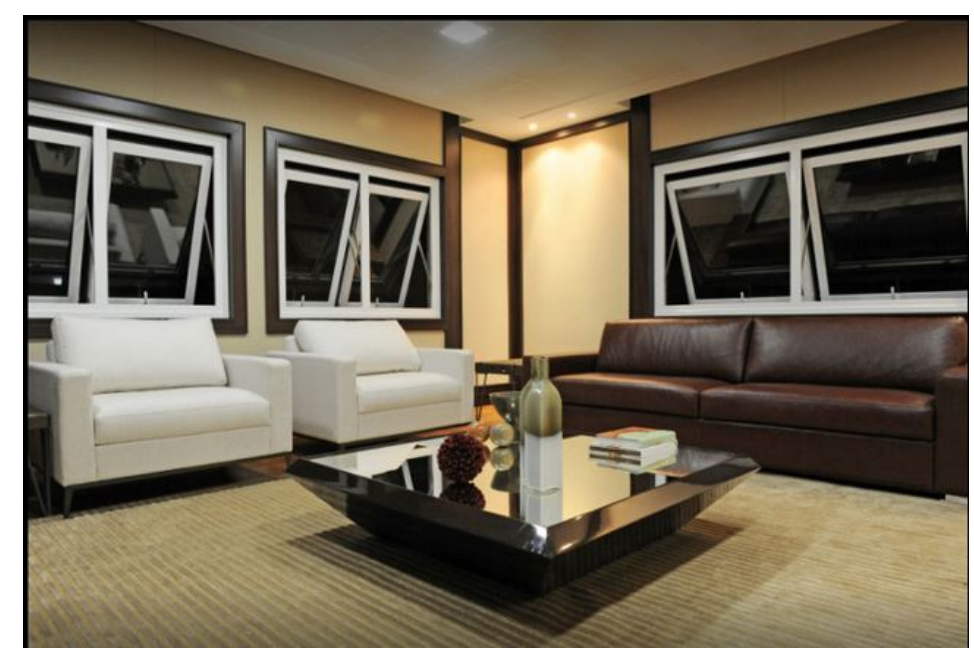

Figura 60: Sala de aplicação do teste subjetivo, com acomodação para até 9 pessoas Fonte: (BOOM, 2017)

3.Suportes de microfone: manter posição fixa do microfone em relação ao locutor; Finalidade: Gravar áudios; Especificação: Com ajuste de altura, posição do microfone, pés deslizantes; Disponibilidade: Estúdio BOOM.

4.Cadeiras / bancos de gravação: garantir condição ergonômica para o locutor; Finalidade: Gravar áudios; Especificação: Com ajuste de altura, posição, pés deslizantes; Disponibilidade: Estúdio BOOM.

5.Cabos de conexão: realizar as interligações de sinais de áudio; Finalidade: Gravar áudios Especificação: Cabos balanceados tipo XLR; Disponibilidade: Estúdio BOOM.

6.Decibilímetro digital; Finalidade: Ensaio de validação da sala de gravação e controlar os níveis de pressão sonora para a realização das avaliações; Especificação: Faixa 30120dBA, resolução 0,1dB, Testo modelo 816; Disponibilidade: CINDACTA II.

7.Trena eletrônica a laser: realizar ensaio de validação na sala de gravação; Finalidade: Ensaio de validação da sala Especificação: 100 m, precisão +-1mm, Fluke modelo 424D; Disponibilidade: CINDACTA II.

8.Microfone linear: captação de áudio; Finalidade: Gravar áudios de referência; Especificação: Neumann U87: transdutor por gradiente de pressão, $20 \mathrm{~Hz}-20 \mathrm{k} \mathrm{Hz}$, resposta linear, sensibilidade $28 \mathrm{mV} / \mathrm{Pa}$, relação sinal-ruído maior que $80 \mathrm{~dB}$, nível máximo suportado 117 dBA; Mojave Audio: transdutor por gradiente de pressão, nível máximo suportado 
120dBA, distorção inferior a $1 \%$ (a 117 dBA), 20 Hz-20 KHZ $\pm 2,5$ dB; Disponibilidade: Estúdio BOOM. O equipamento utilizado é mostrado na Figura 61.

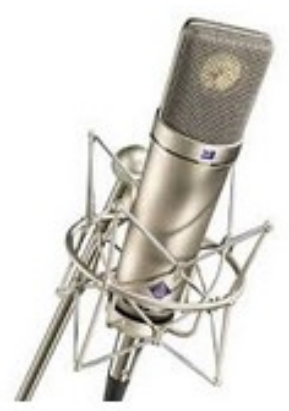

Figura 61: Microfone Neumann U87 utilizado na gravação de áudios de referência Fonte: (BOOM, 2017)

9.Pré-amplificador de microfone linear e baixa distorção Finalidade: Gravar áudios de referência Especificação: Pré-amplificador linear Classe A, valvulado, reposta em frequência de $20 \mathrm{~Hz}$ a $20 \mathrm{kHz}( \pm 0,5 \mathrm{~dB})$, ganho máximo $40 \mathrm{~dB}$, nível de ruído inferior a -72 dBu) modelo Universal Audio LA-610 MKII. Disponibilidade: Estúdio BOOM. O equipamento utilizado é mostrado na Figura 62.

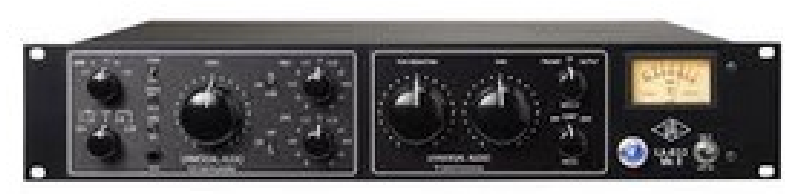

Figura 62: Pré-amplificador linear Universal Audio LA-610 MKII utilizado nas gravações de sinais de referência

Fonte: (BOOM, 2017)

10.Mesa de áudio, baixo nível de ruído; Finalidade: Gravação de áudio; Especificação: Mesa de áudio com resposta em frequência $20 \mathrm{~Hz}$ a $20 \mathrm{KHz}( \pm 0,1 \mathrm{~dB})$, nível de ruído inferior a $-89 \mathrm{dBu}$, THD inferior a 0,002 \% na faixa de frequência, Solid State Logic Matrix. A mesa utilizada é mostrada na Figura 63. Disponibilidade: Estúdio BOOM.

11.Conversor analógico-digital, 16 bits, 16 kHz; Finalidade: Gravação de áudio; Especificação: conversor Analógico-Digital e Digital-Analógico de 16 canais, 192 kHz, 24 bits, delta-sigma $\mathrm{AD}$, faixa dinâmica $117 \mathrm{~dB}$, resposta em frequência de $20 \mathrm{~Hz}$ a $20 \mathrm{kHz}$ (+0/- 


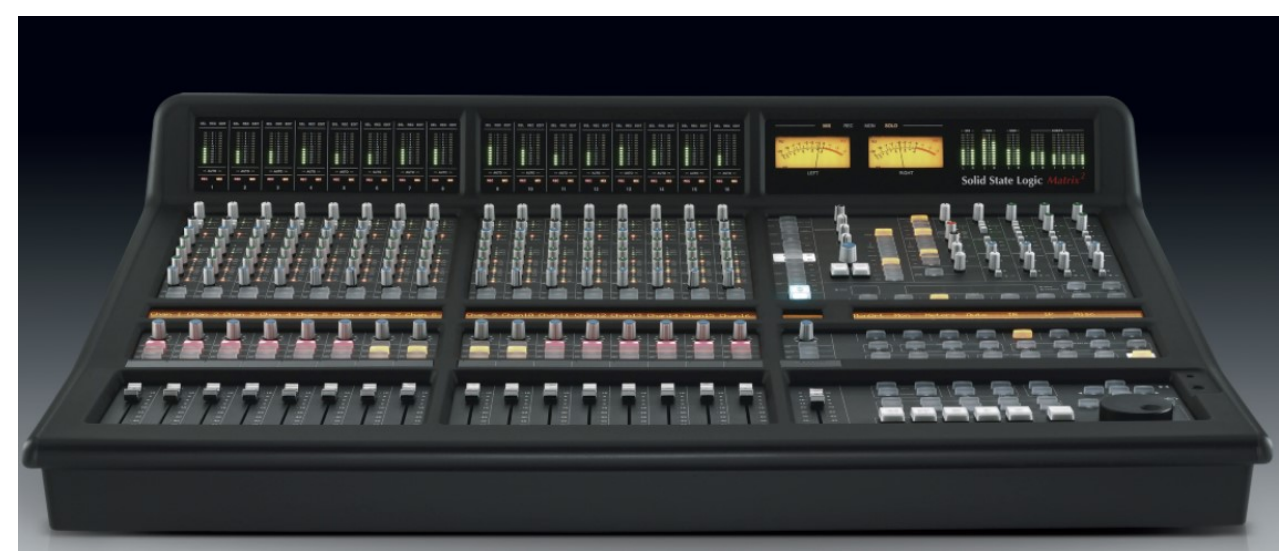

Figura 63: Mesa de áudio Solid State Logic modelo Matrix, utilizada na gravação e reprodução de áudios de referência

Fonte: (BOOM, 2017)

0,1 dB), THD inferior a 0,0004\%, Lynx Studio Aurora 16. O conversor utilizado é mostrado na Figura 64; Disponibilidade: Estúdio BOOM.

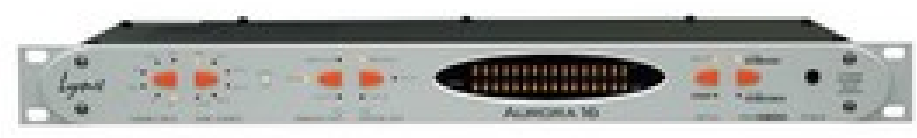

Figura 64: Conversor análógico-digital e digital-analógico Lynx Studio Aurora 16 utilizado nas gravações dos sinais de referência

Fonte: (BOOM, 2017)

12.Placa de interface com Computador tipo PC e dispositivo de armazenamento; Finalidade: Gravação de áudio; Especificação: interface digital de equipamentos e sinais, com suporte a 192 canais (Entrada/Saída) digitais AVid modelo HD Native; Disponibilidade: Estúdio BOOM. O equipamento utilizado é mostrado na Figura 65.

13.Unidade de armazenamento - 50 GB; Finalidade: Gravação de áudio; Especificação: Unidade de armazenamento de 3 TB; Disponibilidade: Estúdio BOOM.

14.Pré-amplificador de microfone linear e baixa distorção; Finalidade: Gravar áudio/ensaiar salas; Especificações: AVid HD Omni - faixa dinâmica $118 \mathrm{~dB}$, resposta em frequência de $20 \mathrm{~Hz}$ a $20 \mathrm{kHz}( \pm 0,05 \mathrm{~dB})$, THD ; 0,00045 \%, faixa de ganho $65 \mathrm{~dB}$; Disponibilidade: Estúdio BOOM. 


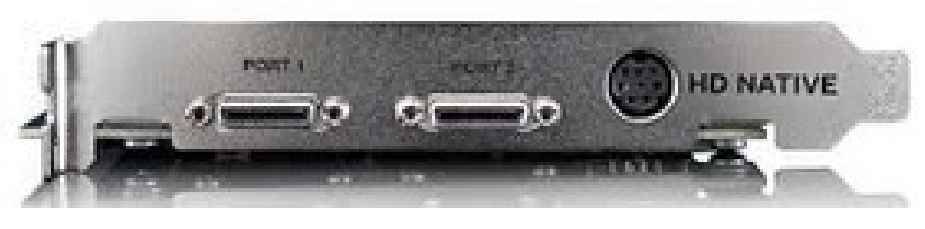

Figura 65: Conversor análógico-digital e digital-analógico Lynx Studio Aurora 16 utilizado nas gravações dos sinais de referência

Fonte: (BOOM, 2017)

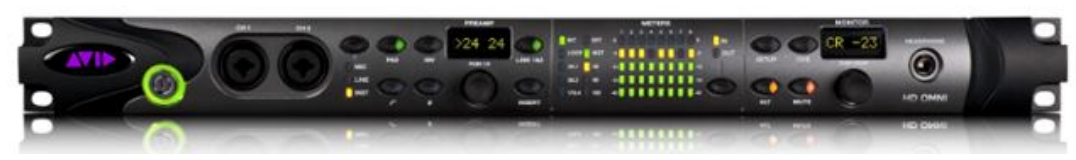

Figura 66: Pré-amplificador linear de microfone AVid HD Omni para uso nas sessões de gravação / validação das salas

Fonte: (BOOM, 2017)

15.Ferramenta de processamento de áudio que permita: medir a intensidade de áudio, gerar tons de $1 \mathrm{kHz}$, medir relação $\mathrm{S} / \mathrm{R}$, modificar nível de gravação (-26 dB), realizar edição de áudio, calcular espectro de sinais em tempo real; Finalidade: Processamento e edição de áudio; Especificação: Software Avid PRO TOOLS 11: processamento simultâneo de até 128 canais, 32 entradas de gravação simultânea de 32 bits, 192 kHz; toolbox de processamento de sinais de áudio. Matlab 2017- versão estudante: Processamentos adicionais. Microsoft Visual Studio 2015: compilação e adaptação de códigos de processamento da ITU; Disponibilidade: Estúdio BOOM, recursos próprios.

16.Material para gravação; Finalidade: gravar áudios; Especificação: Elaborar listas com 340 frases de até 3 s; Disponibilidade: providenciado.

17.Locutores para áudio de referência Finalidade: gravar áudio; Especificação: 8 pessoas que falam português e inglês com fluência, sendo 4 do sexo feminino e 4 do sexo masculino; Disponibilidade: CINDACTA II.

18.Monitores de áudio de referência; Finalidade: medir sensibilidade de microfones, execução da avaliação, ensaios Especificação: resposta em frequência faixa de $45 \mathrm{~Hz}$ a $28 \mathrm{kHz}$, nível máximo 112 dBA (a 1 metro), potência de 100 W RMS; classe AB, resposta plana; Disponibilidade: Estúdio BOOM.

19.Operadores/Técnicos de Estúdio; Finalidade: gravação de áudio, operação do sistema de aquisição e gravação; Especificação: técnicos com treinamento para utilizar os equipa- 


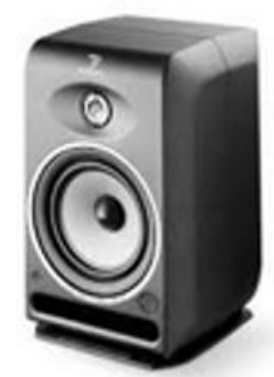

Figura 67: Monitor de áudio de referência Focal CMS 65 utilizado nos ensaios Fonte: (BOOM, 2017)

mentos de gravação e aquisição; Disponibilidade: Estúdio BOOM. 
ANEXO B - ROTEIRO DO LOCUTOR E LISTA DE FRASES 


\section{QUALIDADE DE ÁUDIO EM TELECOMUNICAÇÕES AERONÁUTICAS EXPERIMENTO SUBJETIVO - BASE DE DADOS DE REFERÊNCIA}

Prof. Alexandre Pohl

Aluno: Rodrigo L. Frigotto

\section{ROTEIRO DO LOCUTOR}

\section{Objetivo}

Este documento tem como objetivo apresentar um roteiro para os locutores que participarão da gravação de uma base de sinais de áudio de referência, em conformidade com as recomendações da norma ITU-T P.800. Este roteiro inclui: apresentação do método utilizado para gravação, um breve procedimento de treinamento dos locutores, e a lista de frases que deverá ser lida por cada locutor.

\section{Atividades dos Locutores}

As seguintes atividades deverão ser desenvolvidas pelos locutores, para a gravação dos sinais de referência:

a) Conhecer a lista de frases a serem narradas;

b) Conhecer os procedimentos a serem adotados para a gravação;

c) Realizar o treinamento de locução;

d) Reproduzir as listas de frases de gravação.

\section{Procedimentos}

Este item descreve os procedimentos para cada atividade a ser realizada pelos locutores.

a) Conhecer a lista de frases a serem narradas: o documento "Lista de Frases" deste apresenta quatro listas de frases que deverão ser lidas pelos locutores, sendo duas em português e duas em inglês. A Lista "A" apresenta frases gerais aleatórias em português, com duração de 2 a 3 segundos, retiradas de jornais ou literatura não técnica, conforme recomendação da ITU-T P.800. A Lista "B" apresenta frases em caráter geral em inglês, e representa um conjunto de frases sugeridas na norma da ITU e outras frases adicionadas utilizando os mesmos critérios da Lista "A". As Listas "C" e "D" representam frases de controle de tráfego aéreo de 2 a 3 segundos obtidas a partir de gravações reais. A "Lista de Frases" (Anexo ___ ) ainda apresenta uma Lista de "Treinamento", igual para todos os locutores, cuja finalidade é ambientar as pessoas ao procedimento de gravação.

Recomenda-se que cada locutor leia todas as frases de cada uma das listas em voz alta por pelo menos três vezes de maneira a tomar ciência das mesmas. O locutor deverá tentar reproduzi-las em voz de maneira natural, com intensidade e tom de voz habituais de um diálogo.

b) Conhecer os procedimentos a serem adotados durante a gravação: No dia e horário marcados para a gravação, o locutor deverá preencher o "Questionário do Locutor". Após 
o preenchimento, o locutor será levado ao Estúdio Principal para início das fases de treinamento e gravação.

O ambiente de gravação possui cerca de $30 \mathrm{~m}^{2}$, possui iluminação ambiente suave e será climatizado à temperatura na faixa de $22 \mathrm{a} 24^{\circ} \mathrm{C}$. Embora seja amplo e possua renovação forçada de ar, não possui janelas para o exterior, portanto é recomendável que o locutor não sofra de fobias ou restrições de permanecer em local fechado.

O locutor deverá se assentar na banqueta próximo à janela de monitoramento do estúdio e o microfone será posicionado à distância de $17,0 \mathrm{~cm}$ da boca do locutor. A "Lista de Frases" fornecida (Anexo___ será posicionada no suporte à frente do locutor, ajustado de maneira que a leitura possa ser realizada com facilidade. Os equipamentos estarão prontos e devidamente ajustados. O locutor deverá permanecer em posição ereta durante o procedimento de gravação e caso deseje descansar ou mudar de posição, a gravação será interrompida. Toda a comunicação entre a equipe de coordenação e o locutor será realizada por meio do microfone e de caixas de som instaladas no interior do Estúdio Principal. Todo o procedimento de treinamento, calibração e gravação deverá levar aproximadamente 15 minutos. A porta do estúdio será fechada e será iniciado a Calibração dos equipamentos.

Após o fechamento da sala, o Coordenador do experimento indicará o momento em que o locutor poderá iniciar a narração das frases da lista de "Treinamento". O locutor então reproduzirá em voz alta, utilizando tom de voz e intensidade habituais de diálogo, a primeira frase da Lista de Treinamento. Após sinalização do Coordenador do experimento, este deverá reproduzir a segunda frase e assim sucessivamente, até que seja sinalizado para que o locutor pare. O objetivo desta etapa é realizar a calibração dos níveis do pré-amplificador e demais componentes a fim de se obter o nível de gravação desejado. Após a calibração, será realizada a etapa de Treinamento.

c) Realizar o treinamento de locução: O treinamento consistirá em reproduzir em voz alta a lista de frases de "Treinamento", assim identificada no Anexo II, para que o locutor se acostume ao procedimento, e a gravação ocorra de maneira mais eficiente.

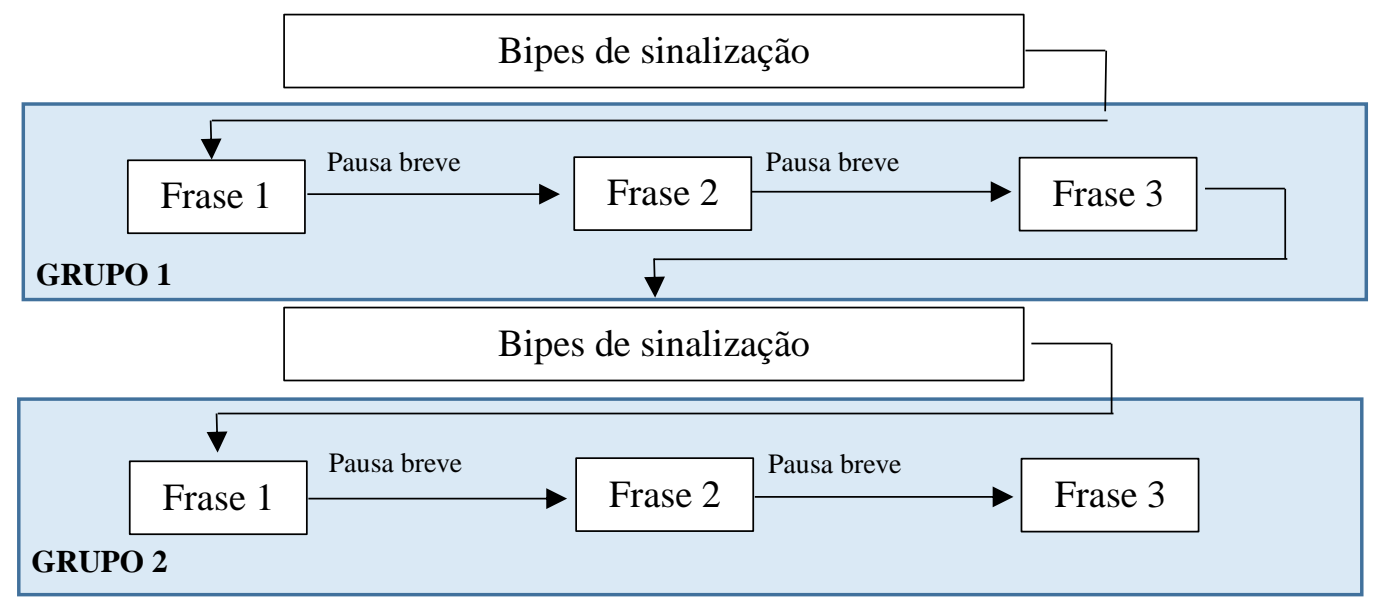

$$
\text { (...) }
$$

Figura __ _ Reprodução de grupos de frases pelo locutor 
Após sinalização do Coordenador de que o sistema está pronto para gravação, o locutor escutará três bipes seguidos, espaçados de 1 segundo. Ao término dos bipes, o locutor deverá iniciar a reprodução das frases a partir do primeiro grupo. A execução de cada um dos grupos obedecerá a ordem apresentada na Figura 1, sendo que as frases deverão ser reproduzidas de maneira natural, procurando utilizar o mesmo nível e tom de voz utilizado durante a calibração. O locutor deverá pausar brevemente entre a reprodução das frases, e terá aproximadamente 10 segundos para pronunciar as três frases de cada grupo.

Após este período, o locutor escutará novamente os três bipes cadenciados, e então deverá passar a reproduzir as frases do próximo grupo e assim sucessivamente. Conforme pode ser observado no Anexo II, a lista de treinamento possui 4 grupos de frases, e o treinamento será finalizado quando toda a lista for reproduzida. O locutor poderá, se desejar, solicitar a execução de um novo treinamento.

d) Reproduzir as listas de frases de gravação: Ao término do treinamento, e quando sinalizado pelo Coordenador, o locutor escutará novamente os três bipes. Da mesma maneira que no treinamento, o locutor deverá passar a reproduzir os grupos de frases conforme apresentado na Figura 1.

Serão reproduzidos um total de 16 grupos com 3 frases cada para cada locutor. Na medida em que as frases são narradas, o Coordenador observará a ocorrência de eventuais problemas. Serão analisados pela equipe de coordenação: se o nível de gravação permaneceu dentro dos limites exigíveis, se o locutor se movimentou durante a gravação, ultrapassando os limites permitidos. O Coordenador então anotará quaisquer problemas obtidos durante a gravação bem como o grupo de frases que apresentou problema na "Ficha de Acompanhamento de Gravação", e após o término da sessão, será coordenada com o locutor a regravação destes grupos.

******** $\mathbf{F I M} * * * * * * *$

Obs. Após o término das gravações, o locutor poderá desfrutar de um brinde 
Anexo _ do Roteiro- LISTAS DE GRUPOS DE FRASES - LOCUTOR 02 - PÁGINA 1/4

LISTA DE CALIBRAÇÃO E TREINAMENTO

Fritou a galinha na banha

\begin{tabular}{l|l} 
A comida está na mesa & G 5
\end{tabular}

Quebrou o coco com as mãos

O carneiro estava delicioso

O aparelho não funcionava G 6

Seu depoimento foi fundamental

\begin{tabular}{|l|l|}
\hline A barragem se rompeu na madrugada & \multirow{2}{*}{ G 7} \\
\cline { 1 - 1 } Seus métodos o contradiziam & \\
\hline Era relativamente pobre & \\
\hline
\end{tabular}

O acesso estava interditado

O texto foi elaborado por especialistas G 8

Era reconhecido pela gastronomia 
Anexo _ do Roteiro - LISTAS DE GRUPOS DE FRASES - LOCUTOR 02 - PÁGINA 2/4

\section{LISTA A - GRUPOS EM PORTUGUÊS}

Fritou a galinha na banha

A comida está na mesa

G 5

Quebrou o coco com as mãos

O carneiro estava delicioso

O aparelho não funcionava

G 6

Seu depoimento foi fundamental

A barragem se rompeu na madrugada

Seus métodos o contradiziam

G 7

Era relativamente pobre

$O$ acesso estava interditado

O texto foi elaborado por especialistas

G 8

Era reconhecido pela gastronomia

Era portador de boas notícias

Havia vida no novo mundo

G 35

Agia com coerência e bondade

A cortina era azul escuro.

Seu cúmplice a abandonou

G 36

As flores enchiam o jardim 
Anexo _ do Roteiro- LISTAS DE GRUPOS DE FRASES - LOCUTOR 02 - PÁGINA 3/4

\section{LISTA B - GRUPOS EM INGLÊS}

Western people eat too much meat.

He was lying when he gave the statement

The movie was amazing.

Honey is good for the skin

There was a sharp increase in crime G 57

Before sleep, she prayed

It was his first day at his new job

Try to ask your boss about your vacations

G 58

She was called late that night

He was told to stay outside of the house

She had ice-cold lemonade. G 59

There were no streets in the village

She opened the envelope and smiled

Some of these songs are sad

G 86

The criminal acted methodically

Carnival in Bahia lasts two months

The book has two-hundred pages

Depression is a sad disease 
Anexo _ do Roteiro - LISTAS DE GRUPOS DE FRASES - LOCUTOR 02 - PÁGINA 4/4

\section{LISTA C - GRUPOS ATC EM PORTUGUÊS}

Confirme proa azul cinco quatro seis zero

Mantenha proa uno nove zero

Proa três seis zero vinte milhas

Gol cinco dois três cinco

uno uno três quatro autorizado quatro uno zero $\quad$ G 106

Após nível dois nove zero usar critério

\section{LISTA D - GRUPOS ATC EM INGLÊS}

The wind is calm

Winds three-four-zero at one-zero

Climb and maintain twelve thousand

Contact ground on one-two-one decimal four

Clear to take off

join the final approach course 
ANEXO C - MODELO DE QUESTIONÁRIOS: LOCUTOR E AVALIADOR 
Identificação do Locutor

Nome Completo:

RG:

Idade:

Sexo:

É fluente em português?

$\operatorname{Sim}$

Não

É fluente em inglês?

$\operatorname{Sim}$

Não

Possui algum problema de fala?

Sim

Não

Fez uso de bebidas alcoólicas ou outras substâncias que podem prejudicar a atenção?

Sim $\square$ Não

Possui alguma fobia ou restrição quanto à permanecer em locais fechados?

Sim

Não

Declaro que as informações fornecidas acima descritas são verdadeiras. Declaro que estou ciente e que concedo autorização para que as gravações de voz sejam utilizadas em pesquisas científicas conduzidas pela UTFPR (Universidade Tecnológica Federal do Paraná) ou por outros institutos de pesquisa ou em pesquisas de qualidade de áudio realizadas pelo Departamento de Controle de Tráfego Aéreo (DECEA), não podendo serem utilizadas para fins comerciais. Cedo os direitos de minha voz para estes fins.

Data e Assinatura do Locutor 
$\underline{\text { Anexo }<>~-~ Q u e s t i o n a ́ r i o ~ d e ~ P a r t i c i p a c ̧ a ̃ o ~}$

Identificação do Avaliador:

Nome Completo:

RG:

Idade:

$\underline{\text { Sexo: }}$

É fluente em português?

$\operatorname{Sim}$

Não

É fluente em inglês?

$\operatorname{Sim}$

Não

Possui algum problema de fala?

Sim

Não

Fez uso de bebidas alcoólicas ou outras substâncias que podem prejudicar a atenção?

Sim Não

Possui alguma fobia ou restrição quanto à permanecer em locais fechados?

$\operatorname{Sim}$

Não

Declaro que as informações fornecidas acima descritas são verdadeiras. Declaro que estou ciente e que concedo autorização para que as gravações de voz sejam utilizadas em pesquisas científicas conduzidas pela UTFPR (Universidade Tecnológica Federal do Paraná) ou por outros institutos de pesquisa ou em pesquisas de qualidade de áudio realizadas pelo Departamento de Controle de Tráfego Aéreo (DECEA), não podendo serem utilizadas para fins comerciais. Cedo os direitos de minha voz para estes fins.

Data e Assinatura do Avaliador 
ANEXO D - TLCE E TCUISV UTILIZADOS NA PESQUISA 


\section{TERMO DE CONSENTIMENTO LIVRE E ESCLARECIDO (TCLE) / TERMO DE CONSENTIMENTO PARA USO DE IMAGEM E SOM DE VOZ (TCUISV) GRUPO 1 - LOCUÇÃ̃O}

Título da pesquisa: $\quad$ Estudo subjetivo de qualidade de voz em telecomunicações aeronáuticas -

Pesquisador(es/as) ou outro (a) profissional responsável pela pesquisa, com Endereços e Telefones: Rodrigo Luiz Frigotto - Eng. Eletricista, Rua Nicarágua, 1081, Ap.52, Bacacheri, Curitiba - PR, 82510170, telefone (41) 99957-7755

Alexandre de Almeida Prado Pohl - Prof. Dr, Av. Sete de Setembro, 3165 - Rebouças, Curitiba - PR, CEP 80230-901 - Curitiba - PR, telefone (41) 99236-8682

Local de realização da pesquisa: Estúdio BOOM Sound Design Endereço, telefone do local: Rua Prof. Rodolfo Belz, 913, Santa Cândida, Curitiba - PR, telefone (41) 3203-5674

\section{A) INFORMAÇÕES AO PARTICIPANTE}

\section{Apresentação da pesquisa.}

Este é um convite para você participar da pesquisa "Estudo subjetivo de qualidade de voz em telecomunicações aeronáuticas", sob a responsabilidade dos pesquisadores citados no início deste documento. Esta pesquisa pretende avaliar a influência dos meios de comunicação utilizados nas comunicações de controle de tráfego aéreo na qualidade de voz percebida pelos utilizadores. Tendo em vista que as comunicações por voz são o principal meio de intercâmbio de informações entre os controladores e tráfego aéreo e os aero-navegantes, eventuais degradações de qualidade podem prejudicar a operação e a segurança da aviação geral.

Como parte essencial desta pesquisa, serão gravados sinais de voz formados por frases comuns de 2 a 3 segundos de duração, conforme condições estabelecidas em normas técnicas reconhecidas. Estas gravações serão realizadas por indivíduos do Grupo 1 - Locução. Em seguida, os sinais de voz gravados serão submetidos aos meios técnicos utilizados nas telecomunicações aeronáuticas, simulando situações reais de comunicação entre pilotos e controladores. Estes sinais serão então avaliados por um outro grupo de pessoas denominado Grupo 2 - Avaliação.

Ao aceitar este termo, você poderá participar desta pesquisa, integrando o Grupo 1 - Locução.

2. Objetivos da pesquisa.

Avaliar a degradação dos sinais de voz quando transmitidos através dos meios técnicos utilizados em telecomunicações aeronáuticas, através da elaboração de um experimento subjetivo. Neste experimento, serão gravados sinais de voz de referência por um grupo de participantes (Grupo 1 Locução), estes serão submetidos aos meios técnicos de telecomunicações aeronáuticas. Então avaliadores humanos, pertencentes a outro grupo de participantes (Grupo 2 -Avaliação), deverão classificar os diferentes sinais em uma escala de opinião de 1 a 5 , em sessões de duração aproximada de 20 minutos.

3. Participação na pesquisa.

O método proposto consiste na montagem de uma base de áudio de referência, realização de tratamentos nesta base de áudio e submissão dos sinais tratados a um número de avaliadores para classificação dos sinais.

A gravação, realizada para os participantes do Grupo 1 - Locução, consistirá na reprodução de cerca de 400 frases por 8 pessoas, sendo 4 do sexo feminino e 4 do sexo masculino, com $50 \%$ em inglês e $50 \%$ em português. As frases consistirão de texto simples de 2 a 3 segundos de duração, e deverão ser pronunciadas com tom de voz e volume naturais, num estúdio de gravação de baixa reverberação, com ruído abaixo de $30 \mathrm{~dB}$ e temperatura controlada. Cada pessoa reproduzirá 48 frases, e é estimado o tempo de sessão de gravação em torno de 15 minutos por pessoa. Os áudios serão gravados com alta qualidade (192 kHz, 24 bits) para posteriores tratamentos. 
Sendo integrante do Grupo 1 - Locução, você receberá um roteiro denominado "Roteiro do Locutor", com a sua respectiva identificação numérica "Locutor X", em que "X" é um número de 1 a 8 . O Roteiro mencionado apresenta uma lista de frases elaboradas com instruções detalhadas. O procedimento, de maneira resumida consiste em: a) Tomar conhecimento de 16 conjuntos de 3 frases (totalizando 48 frases) curtas, pronunciando-as em voz alta pelo menos três vezes antes do início das atividades de locução; b) apresentar-se no dia agendado no Estúdio BOOM Sound Design, localizado sito à Rua Prof. Rodolfo Belz, 913, Santa Cândida, responder o "Questionário do Locutor", que solicita informações sobre a proficiências nos idiomas português e inglês, dados pessoais, entre outras informações conforme modelo; c) Realizar o treinamento de locução, no ambiente do estúdio, reproduzindo 12 frases de treinamento em tom e volumes de conversa habituais. Neste momento, serão realizadas as calibrações de nível dos equipamentos e testados os meios de comunicação entre os participantes e os responsáveis pela pesquisa; c) Realizar a gravação das 48 frases do "Roteiro do Locutor", devidamente identificadas com um código.

Ao término da gravação, sua participação no experimento se encerra. A partir deste momento, os sinais de voz gravados serão identificados apenas por sua identificação numérica, de maneira a preservar a identidade do participante.

Caso concorde com a execução da pesquisa, você poderá ser fotografado e sua imagem poderá vir a ser publicada em revista digital interna do DECEA - Departamento de Controle do Espaço Aéreo.

\section{Confidencialidade.}

Será garantido o sigilo e privacidade ao participante da pesquisa. A coleta de dados terá caráter anônimo e as identidades dos participantes da pesquisa serão preservadas. As fichas de preenchimento não serão identificadas por nomes, mas utilizando códigos. A guarda dos documentos ficará a cargo do coordenador do experimento.

\section{Riscos e Benefícios.}

5a) Riscos: Riscos ergonômicos, relacionados à posição do locutor e ao nível de exposição sonora. Convém ressaltar que serão utilizados mitigadores. No caso da posição do locutor, o experimento foi projetado de maneira que tenha duração reduzida (inferior a 30 minutos), e serão realizados em ambiente próprio (estúdio de áudio) que possui cadeiras/poltronas adequados. Quanto ao nível de exposição sonora, será utilizado decibelímetro, de maneira que, em hipótese alguma, os locutores sejam submetidos à níveis superiores a $85 \mathrm{~dB}$. (Conforme Anexo 1 da Norma Regulamentadora $\mathrm{N}^{\circ} 15$ ). Em caso de desconforto, será acionado o SAMU local.

5b) Benefícios: O experimento permitirá que seja compilada uma base de dados de sinais de áudios de referência e degradados que poderá ser utilizada em diferentes experimentos científicos. Aplicações da base de dados incluem: avaliação de qualidade de serviços de telecomunicações, avaliação de qualidade de áudio de equipamentos comerciais, sistemas de alta fidelidade, aparelhos auditivos, entre outros. Além disso, mais diretamente, possibilitará uma melhora da qualidade de áudio nas telecomunicações aeronáuticas.

\section{Critérios de inclusão e exclusão.}

6a) Inclusão: Controladores de voo ou colaboradores do CINDACTA II, ou alunos da UTFPR, com fluência em inglês e português, na faixa etária de 18 a 45 anos, sendo $50 \%$ do sexo feminino e 50\% do sexo masculino. Estas pessoas não poderão apresentar problemas de dicção ou audição.

6b) Exclusão: Pessoas que atestarem, no questionário preliminar à locução, que tenham consumido bebidas alcóolicas ou outras substâncias que possam prejudicar a fala nas últimas 12 horas ou indivíduos que tenham alguma restrição quanto à permanecer em espaços fechados.

\section{Direito de sair da pesquisa e a esclarecimentos durante o processo.}

O participante poderá deixar o estudo a qualquer momento, bem como receber esclarecimentos em qualquer etapa da pesquisa. Poderá, outrossim, evidenciar a liberdade de recusar ou retirar o seu consentimento a qualquer momento sem penalização.

Declaro que:

( ) quero receber os resultados da pesquisa 
(email para envio : )

( ) não quero receber os resultados da pesquisa

\section{Ressarcimento e indenização.}

O participante fica ciente de que para qualquer despesa decorrente da participação na pesquisa, haverá ressarcimento. De igual maneira, caso ocorra algum dano decorrente da minha participação no estudo, serei devidamente indenizado, conforme determina a Resolução 466/12.

\section{ESCLARECIMENTOS SOBRE O COMITÊ DE ÉTICA EM PESQUISA:}

O Comitê de Ética em Pesquisa envolvendo Seres Humanos (CEP) é constituído por uma equipe de profissionais com formação multidisciplinar que está trabalhando para assegurar o respeito aos seus direitos como participante de pesquisa. Ele tem por objetivo avaliar se a pesquisa foi planejada e se será executada de forma ética. Se você considerar que a pesquisa não está sendo realizada da forma como você foi informado ou que você está sendo prejudicado de alguma forma, entre em contato com o Comitê de Ética em Pesquisa envolvendo Seres Humanos da Universidade Tecnológica Federal do Paraná (CEP/UTFPR). Endereço: Av. Sete de Setembro, 3165, Bloco N, Térreo, Bairro Rebouças, CEP 80230-901, Curitiba-PR, Telefone: (41) 3310-4494, e-mail: coep@utfpr.edu.br.

\section{B) CONSENTIMENTO}

Eu declaro ter conhecimento das informações contidas neste documento e ter recebido respostas claras às minhas questões a propósito da minha participação direta (ou indireta) na pesquisa e, adicionalmente, declaro ter compreendido o objetivo, a natureza, os riscos, benefícios, ressarcimento e indenização relacionados a este estudo.

Após reflexão e um tempo razoável, eu decidi, livre e voluntariamente, participar deste estudo, permitindo que os pesquisadores relacionados neste documento obtenham fotografia, filmagem ou gravacão de voz de minha pessoa para fins de pesquisa científica/ educacional. As fotografias, vídeos e gravações ficarão sob a propriedade do grupo de pesquisadores pertinentes ao estudo e sob sua guarda.

Concordo que o material e as informações obtidas relacionadas a minha pessoa possam ser publicados em aulas, congressos, eventos científicos, palestras ou periódicos científicos. Porém, não devo ser identificado por nome ou qualquer outra forma

Estou consciente que posso deixar o projeto a qualquer momento, sem nenhum prejuízo. Após reflexão e um tempo razoável, eu decidi, livre e voluntariamente, participar deste estudo.

Nome Completo:

RG: Data de Nascimento: 1

Telefones: _ _ _ _ _ _ _

Endereço:

CEP: Cidade: Estado:

Assinatura:

Data: I

Eu declaro ter apresentado o estudo, explicado seus objetivos, natureza, riscos e benefícios e ter respondido da melhor forma possível às questões formuladas. 
Nome completo: RODRIGO LUIZ FRIGOTTO

Assinatura pesquisador (a):
Data: 1

Para todas as questões relativas ao estudo ou para se retirar do mesmo, poderão se comunicar com Rodrigo, via e-mail: rodrigorlf@ cindacta2.gov.br ou telefone: (41) 3251-5468 / (41) 99957-7755.

Contato do Comitê de Ética em Pesquisa que envolve seres humanos para denúncia, recurso ou reclamações do participante pesquisado:

Comitê de Ética em Pesquisa que envolve seres humanos da Universidade Tecnológica Federal do Paraná (CEP/UTFPR)

Endereço:Av. Sete de Setembro, 3165, Bloco N, Térreo, Rebouças, CEP 80230-901, Curitiba-PR, Telefone: 3310-4494,E-mail:coep@utfpr.edu.br

OBS: este documento deve conter 2 (duas) vias iguais, sendo uma pertencente ao pesquisador e outra ao participante da pesquisa. 


\section{TERMO DE CONSENTIMENTO LIVRE E ESCLARECIDO (TCLE) / TERMO DE CONSENTIMENTO PARA USO DE IMAGEM E SOM DE VOZ (TCUISV) GRUPO 2 - AVALIAÇÃO}

Título da pesquisa: Estudo subjetivo de qualidade de voz em telecomunicações aeronáuticas -

Pesquisador(es/as) ou outro (a) profissional responsável pela pesquisa, com Endereços e Telefones: Rodrigo Luiz Frigotto - Eng. Eletricista, Rua Nicarágua, 1081, Ap.52, Bacacheri, Curitiba - PR, 82510170 , telefone (41) 99957-7755

Alexandre de Almeida Prado Pohl - Prof. Dr, Av. Sete de Setembro, 3165 - Rebouças, Curitiba - PR, CEP 80230-901 - Curitiba - PRtelefone (41) 99236-8682

Local de realização da pesquisa: Estúdio BOOM Sound Design

Endereço, telefone do local: Rua Prof. Rodolfo Belz, 913, Santa Cândida, Curitiba - PR, telefone (41) 3203-5674

\section{A) INFORMAÇÕES AO PARTICIPANTE}

\section{Apresentação da pesquisa.}

Este é um convite para você participar da pesquisa "Estudo subjetivo de qualidade de voz em telecomunicações aeronáuticas", sob a responsabilidade dos pesquisadores citados no início deste documento. Esta pesquisa pretende avaliar a influência dos meios de comunicação utilizados nas comunicações de controle de tráfego aéreo na qualidade de voz percebida pelos utilizadores. Tendo em vista que as comunicações por voz são o principal meio de intercâmbio de informações entre os controladores e tráfego aéreo e os aero-navegantes, eventuais degradações de qualidade podem prejudicar a operação e a segurança da aviação geral.

Como parte essencial desta pesquisa, serão gravados sinais de voz formados por frases comuns de 2 a 3 segundos de duração, conforme condições estabelecidas em normas técnicas reconhecidas. Estas gravações serão realizadas por indivíduos do Grupo 1 - Locução. Em seguida, os sinais de voz gravados serão submetidos aos meios técnicos utilizados nas telecomunicações aeronáuticas, simulando situações reais de comunicação entre pilotos e controladores. Estes sinais serão então avaliados por um outro grupo de pessoas denominado Grupo 2 - Avaliação.

Ao aceitar este termo, você poderá participar desta pesquisa, integrando o Grupo 2 - Avaliação.

2. Objetivos da pesquisa.

Avaliar a degradação dos sinais de voz quando transmitidos através dos meios técnicos utilizados em telecomunicações aeronáuticas, através da elaboração de um experimento subjetivo. Neste experimento, serão gravados sinais de voz de referência por um grupo de participantes (Grupo 1 Locução), estes serão submetidos aos meios técnicos de telecomunicações aeronáuticas. Então avaliadores humanos, pertencentes a outro grupo de participantes (Grupo 2 -Avaliação), deverão classificar os diferentes sinais em uma escala de opinião de 1 a 5 , em sessões de duração aproximada de 20 minutos.

\section{Participação na pesquisa.}

O método proposto consiste na montagem de uma base de áudio de referência, realização de tratamentos nesta base de áudio e submissão dos sinais tratados a um número de avaliadores para classificação dos sinais.

Os sinais que passaram através dos meios técnicos utilizados nas telecomunicações aeronáuticas, juntamente com sinais de referência serão levados à análise de avaliadores, que deverão indicar a qualidade destes sinais de voz conforme uma escala de 1 a 5 . Serão formados grupos aleatórios levando em consideração um tempo de sessão de avaliação de aproximadamente 20 minutos, de maneira que os avaliadores não tenham o juízo prejudicado pelo cansaço. Cada sessão será composta por um período de instruções de cerca de 2 minutos, e uma composição de 50 grupos de frases. Cada um destes grupos será composto por 2 frases espaçadas de cerca de 2 segundos, com um período de 
avaliação de 7 segundos. O avaliador deverá escutar as três frases consecutivas e terá então 7 segundos para realizar a avaliação dos sinais, numa escala de 1 a 5 . A avaliação será através de marcação da nota em papel ou utilizando ferramenta computacional. Os resultados serão então compilados e analisados estatisticamente a fim de verificar a hipótese levantada

Sendo integrante do Grupo 2 - Avaliação, você deverá; a) apresentar-se no dia agendado no Estúdio BOOM Sound Design, localizado sito à Rua Prof. Rodolfo Belz, 913, Santa Cândida, e responder ao "Questionário do Avaliador", que solicita informações sobre a proficiência nos idiomas português e inglês, dados pessoais, entre outras informações conforme modelo; b) Receber as instruções detalhadas em papel (para que possa ler) e em voz alta em relação aos procedimentos do teste. Estes procedimentos serão apresentados somente no dia de execução do teste de maneira a não influenciar na avaliação; c) realizar o treinamento de avaliação, avaliando 4 conjuntos de sinais de voz a fim de que o avaliador consiga se habituar com o procedimento; d) realizar a avaliação de 36 a 50 grupos de frases de maneira e registrar no formulário entregue aos avaliadores.

Ao término da avaliação, sua participação no experimento se encerra. A partir deste momento, os formulários de avaliação serão identificados apenas por sua identificação numérica, de maneira a preservar a identidade do participante.

Caso concorde com a execução da pesquisa, você poderá ser fotografado e sua imagem poderá vir a ser publicada em revista digital interna do DECEA - Departamento de Controle do Espaço Aéreo.

\section{Confidencialidade.}

Será garantido o sigilo e privacidade ao participante da pesquisa. A coleta de dados terá caráter anônimo e as identidades dos participantes da pesquisa serão preservadas. As fichas de preenchimento não serão identificadas por nomes, mas utilizando códigos. A guarda dos documentos ficará a cargo do coordenador do experimento.

\section{Riscos e Benefícios.}

5a) Riscos: Riscos ergonômicos, relacionados à posição do avaliador e ao nível de exposição sonora. Convém ressaltar que serão utilizados mitigadores. No caso da posição do avaliador, o experimento foi projetado de maneira que tenha duração reduzida (inferior a 30 minutos), e serão realizados em ambiente próprio (estúdio de áudio) que possui cadeiras/poltronas adequados. Quanto ao nível de exposição sonora, será utilizado decibelímetro, de maneira que, em hipótese alguma, os avaliadores sejam submetidos à níveis superiores a 85 dB. (Conforme Anexo 1 da Norma Regulamentadora $\mathrm{N}^{\circ} 15$ ). Em caso de desconforto, será acionado o SAMU local.

5b) Benefícios: O experimento permitirá que seja compilada uma base de dados de sinais de áudios de referência e degradados que poderá ser utilizada em diferentes experimentos científicos. Aplicações da base de dados incluem: avaliação de qualidade de serviços de telecomunicações, avaliação de qualidade de áudio de equipamentos comerciais, sistemas de alta fidelidade, aparelhos auditivos, entre outros. Além disso, mais diretamente, possibilitará uma melhora da qualidade de áudio nas telecomunicações aeronáuticas.

\section{Critérios de inclusão e exclusão.}

6a) Inclusão: Controladores de voo ou colaboradores do CINDACTA II, com fluência em inglês e português, na faixa etária de 18 a 45 anos, sendo 50\% do sexo feminino e 50\% do sexo masculino, que passaram por inspeção de saúde oficial do Comando da Aeronáutica e que apresentem situação de aptidão para a atividade de controle de tráfego aéreo. Estas pessoas, para serem julgadas aptas ao controle de tráfego aéreo precisam apresentar perfeitas condições de saúde física e psicológica, não podem apresentar problemas de dicção ou audição.

6b) Exclusão: Pessoas que atestarem, no questionário preliminar à avaliação, que embora tenham avaliação de junta de saúde favorável, estejam, na data de realização da sessão de avaliação, formalmente afastadas do serviço de controle de tráfego aéreo; e pessoas que registrem no questionário que tenham participado de avaliações subjetivas de qualidade de áudio nos últimos 6 meses 
7. Direito de sair da pesquisa e a esclarecimentos durante o processo.

O participante poderá deixar o estudo a qualquer momento, bem como receber esclarecimentos em qualquer etapa da pesquisa. Poderá, outrossim, evidenciar a liberdade de recusar ou retirar o seu consentimento a qualquer momento sem penalização.

Declaro que:

( ) quero receber os resultados da pesquisa

(email para envio :

( ) não quero receber os resultados da pesquisa

8. Ressarcimento e indenização.

O participante fica ciente de que para qualquer despesa decorrente da participação na pesquisa, haverá ressarcimento. De igual maneira, caso ocorra algum dano decorrente da minha participação no estudo, serei devidamente indenizado, conforme determina a Resolução 466/12.

ESCLARECIMENTOS SOBRE O COMITÊ DE ÉTICA EM PESQUISA:

O Comitê de Ética em Pesquisa envolvendo Seres Humanos (CEP) é constituído por uma equipe de profissionais com formação multidisciplinar que está trabalhando para assegurar o respeito aos seus direitos como participante de pesquisa. Ele tem por objetivo avaliar se a pesquisa foi planejada e se será executada de forma ética. Se você considerar que a pesquisa não está sendo realizada da forma como você foi informado ou que você está sendo prejudicado de alguma forma, entre em contato com o Comitê de Ética em Pesquisa envolvendo Seres Humanos da Universidade Tecnológica Federal do Paraná (CEP/UTFPR). Endereço: Av. Sete de Setembro, 3165, Bloco N, Térreo, Bairro Rebouças, CEP 80230-901, Curitiba-PR, Telefone: (41) 3310-4494, e-mail: coep@utfpr.edu.br.

\section{B) CONSENTIMENTO}

Eu declaro ter conhecimento das informações contidas neste documento e ter recebido respostas claras às minhas questões a propósito da minha participação direta (ou indireta) na pesquisa e, adicionalmente, declaro ter compreendido o objetivo, a natureza, os riscos, benefícios, ressarcimento e indenização relacionados a este estudo.

Após reflexão e um tempo razoável, eu decidi, livre e voluntariamente, participar deste estudo, permitindo que os pesquisadores relacionados neste documento obtenham fotografia ou filmagem de minha pessoa para fins de pesquisa científica/ educacional. As fotografias, vídeos e gravações ficarão sob a propriedade do grupo de pesquisadores pertinentes ao estudo e sob sua guarda.

Concordo que o material e as informações obtidas relacionadas a minha pessoa possam ser publicados em aulas, congressos, eventos científicos, palestras ou periódicos científicos. Porém, não devo ser identificado por nome ou qualquer outra forma

Estou consciente que posso deixar o projeto a qualquer momento, sem nenhum prejuízo. Após reflexão e um tempo razoável, eu decidi, livre e voluntariamente, participar deste estudo.

Nome Completo:

RG: Data de Nascimento: 1

Telefones: 1

Endereço:

CEP:

Cidade: Estado: 
Assinatura:

Data:

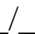

Eu declaro ter apresentado o estudo, explicado seus objetivos, natureza, riscos e benefícios e ter respondido da melhor forma possível às questões formuladas.

Nome completo: RODRIGO LUIZ FRIGOTTO

Assinatura pesquisador (a):

Data:

Para todas as questões relativas ao estudo ou para se retirar do mesmo, poderão se comunicar com Rodrigo, via e-mail: rodrigorlf@cindacta2.gov.br ou telefone: (41) 3251-5468 / (41) 99957-7755.

Contato do Comitê de Ética em Pesquisa que envolve seres humanos para denúncia, recurso ou reclamações do participante pesquisado:

Comitê de Ética em Pesquisa que envolve seres humanos da Universidade Tecnológica Federal do Paraná (CEP/UTFPR)

Endereço:Av. Sete de Setembro, 3165, Bloco N, Térreo, Rebouças, CEP 80230-901, Curitiba-PR, Telefone: 3310-4494,E-mail:coep@utfpr.edu.br

OBS: este documento deve conter 2 (duas) vias iguais, sendo uma pertencente ao pesquisador e outra ao participante da pesquisa. 
ANEXO E - FORMULÁRIOS DE ACOMPANHAMENTO DE GRAVAÇÃO 
Anexo III - FICHA DE ACOMPANHAMENTO DE GRAVAÇÃO - LOCUTOR 02 - Página 1/2

Data:

Observações

Nome:

\begin{tabular}{|c|c|c|}
\hline LISTA A & Grupo & Repetir ? \\
\hline Fritou a galinha na banha & \multirow{3}{*}{ G 5} & \\
\hline A comida está na mesa & & \\
\hline Quebrou o coco com as mãos & & \\
\hline O carneiro estava delicioso & \multirow{3}{*}{ G 6} & \\
\hline $\mathrm{O}$ aparelho não funcionava & & \\
\hline Seu depoimento foi fundamental & & \\
\hline A barragem se rompeu na madrugada & \multirow{3}{*}{ G 7} & \\
\hline Seus métodos o contradiziam & & \\
\hline Era relativamente pobre & & \\
\hline O acesso estava interditado & \multirow{3}{*}{ G 8} & \\
\hline O texto foi elaborado por especialistas & & \\
\hline Era reconhecido pela gastronomia & & \\
\hline Era portador de boas notícias & \multirow{3}{*}{ G 35} & \\
\hline Havia vida no novo mundo & & \\
\hline Agia com coerência e bondade & & \\
\hline A cortina era azul escuro. & \multirow{3}{*}{ G 36} & \\
\hline Seu cúmplice a abandonou & & \\
\hline As flores enchiam o jardim & & \\
\hline \multicolumn{3}{|l|}{ LISTA B } \\
\hline Western people eat too much meat. & \multirow{3}{*}{ G 56} & \\
\hline His was lying when he gave the statement & & \\
\hline The movie was amazing. & & \\
\hline Honey is good for the skin & \multirow{3}{*}{ G 57} & \\
\hline There was a sharp increase in crime & & \\
\hline Before sleep, she prayed & & \\
\hline It was his first day at his new job & \multirow{3}{*}{ G 58} & \\
\hline Try to ask your boss about your vacations & & \\
\hline She was called late that night & & \\
\hline He was told to stay outside of the house & \multirow{3}{*}{ G 59} & \\
\hline She had ice-cold lemonade. & & \\
\hline There were no streets in the village & & \\
\hline She opened the envelope and smiled & \multirow{3}{*}{ G 86} & \\
\hline Some of these songs are sad & & \\
\hline The criminal acted methodically & & \\
\hline Carnival in Bahia lasts two months & \multirow{3}{*}{ G 87} & \\
\hline The book has two-hundred pages & & \\
\hline Depression is a sad disease & & \\
\hline
\end{tabular}


Anexo III - FICHA DE ACOMPANHAMENTO DE GRAVAÇÃO - LOCUTOR 02 - Página 2/2

\begin{tabular}{|c|c|c|}
\hline LISTA C & Grupo & Repetir? \\
\hline Confirme proa azul cinco quatro seis zero & \multirow{3}{*}{ G 105} & \\
\hline Mantenha proa uno nove zero & & \\
\hline Proa três seis zero vinte milhas & & \\
\hline Gol cinco dois três cinco & \multirow{3}{*}{ G 106} & \\
\hline uno uno três quatro autorizado quatro uno zero & & \\
\hline Após nível dois nove zero usar critério & & \\
\hline \multicolumn{3}{|l|}{ LISTA D } \\
\hline The wind is calm & \multirow{3}{*}{ G } & \\
\hline Winds three-four-zero at one-zero & & \\
\hline Climb and maintain twelve thousand & & \\
\hline Contact ground on one-two-one decimal four & \multirow{3}{*}{ G 122} & \\
\hline Clear to take off & & \\
\hline join the final approach course & & \\
\hline
\end{tabular}

\section{Observações}




\section{ANEXO F - RESULTADOS DE PRÉ-PROCESSAMENTO DOS ÁUDIOS}

Legenda de tipos:

P - frases de padrão ITU, em português; E - frases de padrão ITU, em inglês; AP frases de ATC, em português; AE - frases de ATC, em inglês;

Legenda de nome de arquivos:

F - voz masculina M - voz feminina

Número após tipo de voz apresenta a identificação do locutor 


\begin{tabular}{|c|c|c|c|c|c|c|c|c|}
\hline \multicolumn{4}{|c|}{ Arquivo Pré-processado (Normalizado) } & \multicolumn{4}{|c|}{ Arquivo original } & \multirow[b]{2}{*}{ Tipo } \\
\hline Arquivo & Ganho & Arquivo Normaliz & Nível dBov & Arquivo & $\%$ Ativ. & Ganho dBov & DurAt & \\
\hline F1.01_02.wav & 1.32 & F1.01_02norm.raw & $-26,026$ & F1.01_02.wav & 50.94 & -28 & 1,969 & $\mathrm{p}$ \\
\hline F1.01_04.wav & 1.19 & F1.01_04norm.raw & $-26,003$ & F1.01_04.wav & 48.11 & -28 & 1,812 & $\mathrm{p}$ \\
\hline F1.01_05.wav & 1.52 & F1.01_05norm.raw & $-26,017$ & F1.01_05.wav & 43.17 & -30 & 1,516 & $\mathrm{p}$ \\
\hline F1.01_07.wav & 1.48 & F1.01_07norm.raw & $-26,03$ & F1.01_07.wav & 50.23 & -29 & 2,012 & $\mathrm{p}$ \\
\hline F1.01_11.wav & 1.49 & F1.01_11norm.raw & $-26,015$ & F1.01_11.wav & 47.60 & -29 & 1,736 & $\mathrm{p}$ \\
\hline F1.01_13.wav & 1.24 & F1.01_13norm.raw & $-26,009$ & F1.01_13.wav & 50.78 & -28 & 1,899 & $\mathrm{p}$ \\
\hline F1.01_15.wav & 1.18 & F1.01_15norm.raw & $-26,003$ & F1.01_15.wav & 50.03 & -27 & 1,861 & $\mathrm{p}$ \\
\hline F1.01_16.wav & 1.28 & F1.01_16norm.raw & $-26,017$ & F1.01_16.wav & 47.95 & -28 & 1,695 & $\mathrm{e}$ \\
\hline F1.01_17.wav & 1.13 & F1.01_17norm.raw & \begin{tabular}{l|}
$-26,009$ \\
\end{tabular} & F1.01_17.wav & 45.79 & -27 & 1,587 & $\mathrm{e}$ \\
\hline F1.01_18.wav & 1.28 & F1.01_18norm.raw & $-25,991$ & F1.01_18.wav & 44.92 & -28 & 1,689 & $\mathrm{e}$ \\
\hline F1.01_19.wav & 1.18 & F1.01_19norm.raw & \begin{tabular}{l|}
$-26,003$ \\
\end{tabular} & F1.01_19.wav & 49.12 & -27 & 2,019 & $\mathrm{e}$ \\
\hline F1.01_20.wav & 1.43 & F1.01_20norm.raw & $-26,015$ & F1.01_20.wav & 47.52 & -29 & 1,694 & $\mathrm{e}$ \\
\hline F1.01_21.wav & 1.18 & F1.01_21norm.raw & $-26,004$ & F1.01_21.wav & 53.84 & -27 & 2,239 & $\mathrm{e}$ \\
\hline F1.01_22.wav & 1.19 & F1.01_22norm.raw & $-26,004$ & F1.01_22.wav & 48.50 & -28 & 1,745 & $\mathrm{e}$ \\
\hline F1.01_23.wav & 1.0 & F1.01_23norm.raw & $-26,002$ & F1.01_23.wav & 45.8 & -26 & 1,649 & $\mathrm{e}$ \\
\hline F1.01_26.wav & 1.49 & F1.01_26norm.raw & $-26,077$ & F1.01_26.wav & 48.29 & -30 & 1,766 & $\mathrm{e}$ \\
\hline F1.01_28.wav & 1.23 & F1.01_28norm.raw & $-26,011$ & F1.01_28.wav & 50.32 & -28 & 1,872 & $\mathrm{e}$ \\
\hline F1.01_30.wav & 0.87 & F1.01_30norm.raw & $-26,032$ & F1.01_30.wav & 45.83 & -25 & 1,659 & $\mathrm{e}$ \\
\hline F1.01_31.wav & 1.05 & F1.01_31norm.raw & $-26,008$ & F1.01_31.wav & 53.06 & -26 & 2,130 & $\mathrm{e}$ \\
\hline F1.01_32.wav & 1.09 & F1.01_32norm.raw & \begin{tabular}{l|}
$-26,003$ \\
\end{tabular} & F1.01_32.wav & 54.51 & -27 & 2,303 & $\mathrm{e}$ \\
\hline F1.01_34.wav & 1.18 & F1.01_34norm.raw & $-26,002$ & F1.01_34.wav & 56.09 & -27 & 2,462 & $\mathrm{e}$ \\
\hline F1.01_35.wav & 1.10 & F1.01_35norm.raw & $-26,004$ & F1.01_35.wav & 51.24 & -27 & 1,965 & $\mathrm{e}$ \\
\hline F1.01_36.wav & 0.93 & F1.01_36norm.raw & $-26,01$ & F1.01_36.wav & 56.57 & -25 & 2,490 & ap \\
\hline F1.01_37.wav & 0.99 & F1.01_37norm.raw & \begin{tabular}{l|}
$-26,001$ \\
\end{tabular} & F1.01_37.wav & 56.42 & -26 & 2,390 & ap \\
\hline F1.01_38.wav & 0.98 & F1.01_38norm.raw & $-25,999$ & F1.01_38.wav & 54.78 & -26 & 2,319 & ap \\
\hline F1.01_39.wav & 1.0 & F1.01_39norm.raw & $-26,004$ & F1.01_39.wav & 42.9 & -26 & 1,506 & ap \\
\hline F1.01_40.wav & 1.03 & F1.01_40norm.raw & $-26,007$ & F1.01_40.wav & 50.33 & -26 & 1,914 & ap \\
\hline F1.01_41.wav & 1.06 & F1.01_41norm.raw & $-26,009$ & F1.01_41.wav & 61.18 & -27 & 3,010 & ap \\
\hline F1.01_43.wav & 0.95 & F1.01_43norm.raw & $-26,013$ & F1.01_43.wav & 48.99 & -26 & 1,843 & ae \\
\hline F1.01_44.wav & 0.97 & F1.01_44norm.raw & $-25,997$ & F1.01_44.wav & 50.43 & -26 & 1,936 & $\mathrm{ae}$ \\
\hline F1.01_45.wav & 0.8 & F1.01_45norm.raw & \begin{tabular}{l|}
$-26,009$ \\
\end{tabular} & F1.01_45.wav & 53.3 & -25 & 2,242 & ae \\
\hline F1.01_47.wav & 0.98 & F1.01_47norm.raw & $-25,998$ & F1.01_47.wav & 46.92 & -26 & 1,722 & $\mathrm{ae}$ \\
\hline F1.01_48.wav & 1.28 & F1.01_48norm.raw & $-26,017$ & F1.01_48.wav & 47.95 & -28 & 1,695 & $\mathrm{p}$ \\
\hline F2.01_02.wav & 1.24 & F2.01_02norm.raw & \begin{tabular}{l|}
$-26,009$ \\
\end{tabular} & F2.01_02.wav & 57.68 & -28 & 2,497 & $\mathrm{p}$ \\
\hline F2.01_03.wav & 1.29 & F2.01_03norm.raw & \begin{tabular}{l|}
$-26,029$ \\
\end{tabular} & F2.01_03.wav & 53.53 & -28 & 2,180 & $\mathrm{p}$ \\
\hline F2.01_04.wav & 0.98 & F2.01_04norm.raw & $-25,999$ & F2.01_04.wav & 54.98 & -26 & 2,415 & $\mathrm{p}$ \\
\hline F2.01_05.wav & 1.04 & F2.01_05norm.raw & $-26,012$ & F2.01_05.wav & 55.99 & -26 & 2,488 & $\mathrm{p}$ \\
\hline F2.01_06.wav & 0.93 & F2.01_06norm.raw & $-26,011$ & F2.01_06.wav & 57.67 & -25 & 2,602 & $\mathrm{p}$ \\
\hline F2.01_07.wav & 0.97 & F2.01_07norm.raw & $-25,998$ & F2.01_07.wav & 55.20 & -26 & 2,321 & $\mathrm{p}$ \\
\hline F2.01_08.wav & 0.70 & F2.01_08norm.raw & $-26,006$ & F2.01_08.wav & 46.62 & -23 & 1,697 & $\mathrm{p}$ \\
\hline F2.01_09.wav & 1.15 & F2.01_09norm.raw & -26 & F2.01_09.wav & 60.84 & -27 & 3,040 & $\mathrm{p}$ \\
\hline F2.01_10.wav & 1.03 & F2.01_10norm.raw & $-26,006$ & F2.01_10.wav & 52.49 & -26 & 2,206 & $\mathrm{p}$ \\
\hline F2.01_11.wav & 1.14 & F2.01_11norm.raw & $-26,011$ & F2.01_11.wav & 54.82 & -27 & 2,311 & $\mathrm{p}$ \\
\hline F2.01_12.wav & 1.10 & F2.01_12norm.raw & $-26,006$ & F2.01_12.wav & 56.93 & -27 & 2,515 & $\mathrm{p}$ \\
\hline F2.01_13.wav & 0.97 & F2.01_13norm.raw & $-25,996$ & F2.01_13.wav & 57.20 & -26 & 2,562 & $\mathrm{p}$ \\
\hline F2.01_14.wav & 0.81 & F2.01_14norm.raw & $-26,158$ & F2.01_14.wav & 47.41 & -24 & 1,872 & $\mathrm{p}$ \\
\hline F2.01_15.wav & 1.38 & F2.01_15norm.raw & $-26,001$ & F2.01_15.wav & 51.57 & -29 & 2,094 & $\mathrm{p}$ \\
\hline F2.01_16.wav & 0.88 & F2.01_16norm.raw & $-26,014$ & F2.01_16.wav & 54.55 & -25 & 2,264 & $\mathrm{p}$ \\
\hline F2.01_17.wav & 1.08 & F2.01_17norm.raw & $-26,016$ & F2.01_17.wav & 50.72 & -27 & 1,990 & $\mathrm{p}$ \\
\hline F2.01_18.wav & 1.12 & F2.01_18norm.raw & $-26,009$ & F2.01_18.wav & 57.31 & -27 & 2,563 & $\mathrm{p}$ \\
\hline F2.01_19.wav & 0.89 & F2.01_19norm.raw & $-26,012$ & F2.01_19.wav & 48.41 & -25 & 2,063 & $\mathrm{e}$ \\
\hline F2.01_20.wav & 1.09 & F2.01_20norm.raw & $-26,002$ & F2.01_20.wav & 55.23 & -27 & 2,349 & $\mathrm{e}$ \\
\hline F2.01_21.wav & 1.04 & F2.01_21norm.raw & \begin{tabular}{l|}
$-26,007$ \\
\end{tabular} & F2.01_21.wav & 52.96 & -26 & 2,171 & $\mathrm{e}$ \\
\hline F2.01_22.wav & 0.81 & F2.01_22norm.raw & $-26,013$ & F2.01_22.wav & 47.44 & -24 & 1,881 & $\mathrm{e}$ \\
\hline F2.01_23.wav & 1.09 & F2.01_23norm.raw & \begin{tabular}{l|}
$-26,003$ \\
\end{tabular} & F2.01_23.wav & 54.53 & -27 & 2,298 & $\mathrm{e}$ \\
\hline F2.01_24.wav & 0.90 & F2.01_24norm.raw & $-26,009$ & F2.01_24.wav & 53.49 & -25 & 2,369 & $\mathrm{e}$ \\
\hline F2.01_25.wav & 1.06 & F2.01_25norm.raw & $-26,006$ & F2.01_25.wav & 61.92 & -27 & 3,377 & $\mathrm{e}$ \\
\hline F2.01_26.wav & 1.08 & F2.01_26norm.raw & $-26,023$ & F2.01_26.wav & 45.26 & -27 & 1,668 & $\mathrm{e}$ \\
\hline F2.01_27.wav & 1.08 & F2.01_27norm.raw & $-26,023$ & F2.01_27.wav & 50.49 & -27 & 2,140 & $\mathrm{e}$ \\
\hline F2.01_28.wav & 0.85 & F2.01_28norm.raw & $-26,013$ & F2.01_28.wav & 54.77 & -25 & 2,357 & $\mathrm{e}$ \\
\hline F2.01_29.wav & 0.99 & F2.01_29norm.raw & $-26,001$ & F2.01_29.wav & 61.43 & -26 & 2,987 & $\mathrm{e}$ \\
\hline F2.01_30.wav & 1.27 & F2.01_30norm.raw & $-26,012$ & F2.01_30.wav & 48.49 & -28 & 1,954 & $\mathrm{e}$ \\
\hline F2.01_31.wav & 1.02 & F2.01_31norm.raw & $-26,005$ & F2.01_31.wav & 58.19 & -26 & 2,738 & $\mathrm{e}$ \\
\hline F2.01_32.wav & 0.85 & F2.01_32norm.raw & $-26,004$ & F2.01_32.wav & 50.22 & -25 & 2,022 & $\mathrm{e}$ \\
\hline F2.01_33.wav & 0.83 & F2.01_33norm.raw & $-26,006$ & F2.01_33.wav & 55.39 & -24 & 2,575 & $\mathrm{e}$ \\
\hline F2.01_34.wav & 0.87 & F2.01_34norm.raw & \begin{tabular}{l|}
$-26,031$ \\
\end{tabular} & F2.01_34.wav & 56.59 & -25 & 2,601 & $\mathrm{e}$ \\
\hline F2.01_35.wav & 0.88 & F2.01_35norm.raw & $-26,015$ & F2.01_35.wav & 50.65 & -25 & 2,079 & $\mathrm{e}$ \\
\hline F2.01_36.wav & 0.97 & F2.01_36norm.raw & \begin{tabular}{l|}
$-25,997$ \\
\end{tabular} & F2.01_36.wav & 51.65 & -26 & 2,121 & $\mathrm{e}$ \\
\hline
\end{tabular}




\begin{tabular}{|c|c|c|c|c|c|c|c|c|}
\hline F2.01_37.wav & 1.00 & F2.01_37norm.raw & $-26,002$ & F2.01_37.wav & 59.82 & -26 & 3,007 & ap \\
\hline F2.01_38.wav & 1.23 & F2.01_38norm.raw & $-26,009$ & F2.01_38.wav & 57.00 & -28 & 2,570 & ap \\
\hline F2.01_39.wav & \begin{tabular}{|l|}
0.97 \\
\end{tabular} & F2.01_39norm.raw & $-25,998$ & F2.01_39.wav & 59.74 & -26 & 2,906 & ap \\
\hline F2.01_40.wav & \begin{tabular}{|l|}
0.72 \\
\end{tabular} & F2.01_40norm.raw & $-26,026$ & F2.01_40.wav & 55.64 & -23 & 2,475 & ap \\
\hline F2.01_41.wav & 0.98 & F2.01_41norm.raw & -26 & F2.01_41.wav & 64.00 & -26 & 3,479 & ap \\
\hline F2.01_42.wav & 1.02 & F2.01_42norm.raw & $-26,006$ & F2.01_42.wav & 51.91 & -26 & 2,144 & ap \\
\hline F2.01_43.wav & 0.88 & F2.01_43norm.raw & $-26,01$ & F2.01_43.wav & 54.79 & -25 & 2,453 & ae \\
\hline F2.01_44.wav & 0.87 & F2.01_44norm.raw & $-26,009$ & F2.01_44.wav & 40.73 & -25 & 1,522 & ae \\
\hline F2.01_45.wav & \begin{tabular}{|l|}
0.93 \\
\end{tabular} & F2.01_45norm.raw & $-26,006$ & F2.01_45.wav & 55.51 & -25 & 2,468 & ae \\
\hline F2.01_46.wav & \begin{tabular}{|l|}
0.85 \\
\end{tabular} & F2.01_46norm.raw & $-26,014$ & F2.01_46.wav & 56.95 & -25 & 2,514 & ae \\
\hline F2.01_47.wav & 0.79 & F2.01_47norm.raw & -26 & F2.01_47.wav & 61.66 & -24 & 3,198 & ae \\
\hline F2.01_48.wav & \begin{tabular}{|l|}
0.79 \\
\end{tabular} & F2.01_48norm.raw & $-26,001$ & F2.01_48.wav & 46.05 & -24 & 1,749 & ae \\
\hline F3.01_02.wav & 0.8 & F3.01_02norm.raw & $-26,007$ & F3.01_02.wav & 47.3 & -25 & 1,661 & $\mathrm{p}$ \\
\hline F3.01_03.wav & 0.7 & F3.01_03norm.raw & $-25,969$ & F3.01_03.wav & 46.3 & -24 & 1,751 & $\mathrm{p}$ \\
\hline F3.01_04.wav & 0.6 & F3.01_04norm.raw & $-26,006$ & F3.01_04.wav & 45.9 & -23 & 1,701 & $\mathrm{p}$ \\
\hline F3.01_05.wav & 0.8 & F3.01_05norm.raw & $-26,011$ & F3.01_05.wav & 50.3 & -25 & 1,931 & $\mathrm{p}$ \\
\hline F3.01_06.wav & 1.0 & F3.01_06norm.raw & $-26,015$ & F3.01_06.wav & 45.8 & -27 & 1,706 & $\mathrm{p}$ \\
\hline F3.01_07.wav & 0.8 & F3.01_07norm.raw & $-25,999$ & F3.01_07.wav & 43.8 & -24 & 1,535 & $\mathrm{p}$ \\
\hline F3.01_08.wav & 0.92 & F3.01_08norm.raw & $-25,991$ & F3.01_08.wav & 48.18 & -25 & 1,873 & $\mathrm{p}$ \\
\hline F3.01_09.wav & 0.7 & F3.01_09norm.raw & $-25,996$ & F3.01_09.wav & 49.3 & -24 & 1,867 & $\mathrm{p}$ \\
\hline F3.01_10.wav & 0.8 & F3.01_10norm.raw & $-26,008$ & F3.01_10.wav & 56.0 & -25 & 2,561 & $\mathrm{p}$ \\
\hline F3.01_11.wav & 0.8 & F3.01_11norm.raw & $-26,045$ & F3.01_11.wav & 47.1 & -25 & 1,745 & $\mathrm{p}$ \\
\hline F3.01_12.wav & 0.8 & F3.01_12norm.raw & $-26,049$ & F3.01_12.wav & 50.3 & -24 & 1,997 & $\mathrm{p}$ \\
\hline F3.01_13.wav & 0.7 & F3.01_13norm.raw & $-26,009$ & F3.01_13.wav & 49.7 & -23 & 1,875 & $\mathrm{p}$ \\
\hline F3.01_14.wav & 0.8 & F3.01_14norm.raw & $-25,996$ & F3.01_14.wav & 45.8 & -24 & 1,854 & $\mathrm{p}$ \\
\hline F3.01_15.wav & 0.7 & F3.01_15norm.raw & $-25,996$ & F3.01_15.wav & 52.5 & -24 & 2,140 & $\mathrm{p}$ \\
\hline F3.01_16.wav & \begin{tabular}{|l|}
0.88 \\
\end{tabular} & F3.01_16norm.raw & $-25,831$ & F3.01_16.wav & 54.55 & -25 & 2,432 & $\mathrm{p}$ \\
\hline F3.01_17.wav & \begin{tabular}{|l|}
0.8 \\
\end{tabular} & F3.01_17norm.raw & $-26,007$ & F3.01_17.wav & 44.6 & -24 & 1,643 & $\mathrm{p}$ \\
\hline F3.01_18.wav & 0.8 & F3.01_18norm.raw & -26 & F3.01_18.wav & 53.6 & -24 & 2,335 & $\mathrm{p}$ \\
\hline F3.01_19.wav & 1.03 & F3.01_19norm.raw & $-26,006$ & F3.01_19.wav & 56.17 & -26 & 2,607 & $\mathrm{e}$ \\
\hline F3.01_20.wav & 1.0 & F3.01_20norm.raw & $-26,007$ & F3.01_20.wav & 59.9 & -26 & 2,866 & $\mathrm{e}$ \\
\hline F3.01_21.wav & \begin{tabular}{|l|}
0.99 \\
\end{tabular} & F3.01_21norm.raw & -26 & F3.01_21.wav & 53.47 & -26 & 2,305 & $\mathrm{e}$ \\
\hline F3.01_22.wav & 0.9 & F3.01_22norm.raw & $-26,006$ & F3.01_22.wav & 48.7 & -26 & 1,937 & $\mathrm{e}$ \\
\hline F3.01_23.wav & \begin{tabular}{|l|}
1.15 \\
\end{tabular} & F3.01_23norm.raw & -26 & F3.01_23.wav & 57.09 & -27 & 2,504 & $\mathrm{e}$ \\
\hline F3.01_24.wav & 0.9 & F3.01_24norm.raw & $-26,007$ & F3.01_24.wav & 54.0 & -25 & 2,362 & $\mathrm{e}$ \\
\hline F3.01_25.wav & 0.7 & F3.01_25norm.raw & $-26,015$ & F3.01_25.wav & 50.3 & -23 & 1,982 & $\mathrm{e}$ \\
\hline F3.01_26.wav & 0.9 & F3.01_26norm.raw & $-26,016$ & F3.01_26.wav & 60.8 & -26 & 3,419 & $\mathrm{e}$ \\
\hline F3.01_27.wav & 0.8 & F3.01_27norm.raw & $-26,006$ & F3.01_27.wav & 50.3 & -25 & 2,105 & $\mathrm{e}$ \\
\hline F3.01_28.wav & 1.04 & F3.01_28norm.raw & $-26,008$ & F3.01_28.wav & 52.60 & -26 & 2,148 & $\mathrm{e}$ \\
\hline F3.01_29.wav & 0.8 & F3.01_29norm.raw & $-26,014$ & F3.01_29.wav & 53.9 & -25 & 2,293 & $\mathrm{e}$ \\
\hline F3.01_30.wav & \begin{tabular}{|l|}
0.89 \\
\end{tabular} & F3.01_30norm.raw & $-26,019$ & F3.01_30.wav & 58.58 & -25 & 2,841 & $\mathrm{e}$ \\
\hline F3.01_31.wav & 0.8 & F3.01_31norm.raw & $-26,024$ & F3.01_31.wav & 53.7 & -25 & 2,281 & $\mathrm{e}$ \\
\hline F3.01_32.wav & 1.1 & F3.01_32norm.raw & $-26,009$ & F3.01_32.wav & 43.4 & -27 & 1,588 & $\mathrm{e}$ \\
\hline F3.01_33.wav & \begin{tabular}{|l|}
1.17 \\
\end{tabular} & F3.01_33norm.raw & -26 & F3.01_33.wav & 48.20 & -27 & 1,858 & $\mathrm{e}$ \\
\hline F3.01_34.wav & 0.82 & F3.01_34norm.raw & $-26,066$ & F3.01_34.wav & 54.74 & -24 & 2,469 & $\mathrm{e}$ \\
\hline F3.01_35.wav & 0.8 & F3.01_35norm.raw & $-26,008$ & F3.01_35.wav & 55.5 & -25 & 2,572 & $\mathrm{e}$ \\
\hline F3.01_36.wav & 0.8 & F3.01_36norm.raw & $-26,008$ & F3.01_36.wav & 48.3 & -25 & 1,841 & $\mathrm{e}$ \\
\hline F3.01_37.wav & 0.8 & F3.01_37norm.raw & $-25,999$ & F3.01_37.wav & 55.6 & -24 & 2,490 & ap \\
\hline F3.01_38.wav & \begin{tabular}{|l|}
0.95 \\
\end{tabular} & F3.01_38norm.raw & $-26,011$ & F3.01_38.wav & 48.58 & -26 & 1,838 & ap \\
\hline F3.01_39.wav & \begin{tabular}{|l|}
0.8 \\
\end{tabular} & F3.01_39norm.raw & $-26,017$ & F3.01_39.wav & 52.1 & -25 & 2,219 & ap \\
\hline F3.01_40.wav & 0.8 & F3.01_40norm.raw & $-25,926$ & F3.01_40.wav & 56.4 & -24 & 2,898 & ap \\
\hline F3.01_41.wav & \begin{tabular}{|l|}
0.80 \\
\end{tabular} & F3.01_41norm.raw & $-26,015$ & F3.01_41.wav & 55.01 & -24 & 2,432 & ap \\
\hline F3.01_42.wav & 0.8 & F3.01_42norm.raw & $-26,012$ & F3.01_42.wav & 53.6 & -25 & 2,467 & ap \\
\hline F3.01_43.wav & 0.7 & F3.01_43norm.raw & $-25,995$ & F3.01_43.wav & 47.0 & -24 & 1,742 & $\mathrm{ae}$ \\
\hline F3.01_44.wav & 1.13 & F3.01_44norm.raw & $-26,006$ & F3.01_44.wav & 47.54 & -27 & 1,960 & $\mathrm{ae}$ \\
\hline F3.01_45.wav & 0.8 & F3.01_45norm.raw & $-26,008$ & F3.01_45.wav & 52.1 & -24 & 2,224 & $\mathrm{ae}$ \\
\hline F3.01_46.wav & 0.8 & F3.01_46norm.raw & $-26,025$ & F3.01_46.wav & 54.3 & -25 & 2,398 & $\mathrm{ae}$ \\
\hline F3.01_47.wav & 0.8 & F3.01_47norm.raw & $-26,03$ & F3.01_47.wav & 58.8 & -25 & 2,830 & $\mathrm{ae}$ \\
\hline F3.01_48.wav & 0.9 & F3.01_48norm.raw & $-25,994$ & F3.01_48.wav & 50.7 & -26 & 2,118 & $\mathrm{ae}$ \\
\hline \begin{tabular}{|l} 
F4.01_03.wav \\
\end{tabular} & \begin{tabular}{|l|}
1.1 \\
\end{tabular} & F4.01_03norm.raw & $-25,996$ & F4.01_03.wav & 44.3 & -27 & 1,597 & $\mathrm{p}$ \\
\hline F4.01_04.wav & 0.92 & F4.01_04norm.raw & $-26,005$ & F4.01_04.wav & 46.08 & -25 & 1,615 & $\mathrm{p}$ \\
\hline F4.01_05.wav & 1.1 & F4.01_05norm.raw & $-26,01$ & F4.01_05.wav & 51.5 & -27 & 2,063 & $\mathrm{p}$ \\
\hline F4.01_06.wav & \begin{tabular}{|l|}
1.21 \\
\end{tabular} & F4.01_06norm.raw & $-26,007$ & F4.01_06.wav & 50.91 & -28 & 1,937 & $\mathrm{p}$ \\
\hline F4.01_07.wav & 0.9 & F4.01_07norm.raw & $-25,998$ & F4.01_07.wav & 52.6 & -26 & 2,069 & $\mathrm{p}$ \\
\hline F4.01_09.wav & \begin{tabular}{|l|}
1.09 \\
\end{tabular} & F4.01_09norm.raw & $-26,003$ & F4.01_09.wav & 54.51 & -27 & 2,200 & $\mathrm{p}$ \\
\hline F4.01_10.wav & 1.07 & F4.01_10norm.raw & $-26,011$ & F4.01_10.wav & 51.77 & -27 & 1,958 & $\mathrm{p}$ \\
\hline F4.01_11.wav & 1.0 & F4.01_11norm.raw & $-26,006$ & F4.01_11.wav & 52.9 & -26 & 2,144 & $\mathrm{p}$ \\
\hline F4.01_12.wav & 1.2 & F4.01_12norm.raw & $-26,024$ & F4.01_12.wav & 44.3 & -28 & 1,502 & $\mathrm{p}$ \\
\hline F4.01_13.wav & 0.9 & F4.01_13norm.raw & -26 & F4.01_13.wav & 50.1 & -26 & 1,914 & $\mathrm{p}$ \\
\hline F4.01_14.wav & \begin{tabular}{|l|}
1.0 \\
\end{tabular} & F4.01_14norm.raw & $-26,014$ & F4.01_14.wav & 44.7 & -26 & 1,529 & $\mathrm{p}$ \\
\hline F4.01_15.wav & 1.1 & F4.01_15norm.raw & $-26,037$ & F4.01_15.wav & 53.0 & -28 & 2,189 & $\mathrm{p}$ \\
\hline
\end{tabular}




\begin{tabular}{|c|c|c|c|c|c|c|c|c|}
\hline F4.01_16.wav & 0.98 & F4.01_16norm.raw & |-25,999 & F4.01_16.wav & 46.48 & \begin{tabular}{|c|}
-26 \\
\end{tabular} & 1,670 & $\bar{p}$ \\
\hline F4.01_17.wav & 0.97 & F4.01_17norm.raw & |-25,998 & F4.01_17.wav & 53.69 & -26 & 2,204 & $\mathrm{p}$ \\
\hline F4.01_18.wav & 0.92 & F4.01_18norm.raw & $-26,01$ & \begin{tabular}{|l|} 
F4.01_18.wav \\
\end{tabular} & 50.72 & -25 & 1,973 & $\mathrm{p}$ \\
\hline F4.01_19.wav & 1.23 & F4.01_19norm.raw & -26,013 & \begin{tabular}{|l|} 
F4.01_19.wav \\
\end{tabular} & 48.29 & -28 & 1,770 & $\mathrm{e}$ \\
\hline F4.01_20.wav & 1.39 & F4.01_20norm.raw & |-26,001 & \begin{tabular}{|l|l|} 
F4.01_20.wav \\
\end{tabular} & 52.87 & \begin{tabular}{|c|}
-29 \\
\end{tabular} & 2,089 & $\mathrm{e}$ \\
\hline F4.01_21.wav & 1.45 & F4.01_21norm.raw & $-26,041$ & F4.01_21.wav & 51.31 & -29 & 2,057 & $\mathrm{e}$ \\
\hline F4.01_22.wav & 1.46 & F4.01_22norm.raw & $-26,006$ & F4.01_22.wav & 52.71 & -29 & 2,209 & $\mathrm{e}$ \\
\hline F4.01_23.wav & 1.27 & F4.01_23norm.raw & $-26,01$ & F4.01_23.wav & 55.97 & -28 & 2,350 & $\mathrm{e}$ \\
\hline F4.01_24.wav & \begin{tabular}{|l|}
1.1 \\
\end{tabular} & F4.01_24norm.raw & $-26,184$ & F4.01_24.wav & 45.1 & -27 & 1,598 & $\mathrm{e}$ \\
\hline F4.01_25.wav & 1.21 & F4.01_25norm.raw & $-26,017$ & F4.01_25.wav & 44.97 & -28 & 1,559 & $\mathrm{e}$ \\
\hline F4.01_26.wav & 1.49 & F4.01_26norm.raw & $-26,063$ & F4.01_26.wav & 49.33 & -30 & 2,121 & $\mathrm{e}$ \\
\hline F4.01_28.wav & 1.32 & F4.01_28norm.raw & $-26,036$ & F4.01_28.wav & 46.30 & -28 & 1,667 & $\mathrm{e}$ \\
\hline F4.01_30.wav & 1.38 & F4.01_30norm.raw & $-26,001$ & F4.01_30.wav & 44.93 & -29 & 1,590 & $\mathrm{e}$ \\
\hline F4.01_31.wav & 1.51 & F4.01_31norm.raw & $-26,013$ & F4.01_31.wav & 46.92 & -30 & 1,755 & $\mathrm{e}$ \\
\hline F4.01_33.wav & 1.55 & F4.01_33norm.raw & $-25,996$ & F4.01_33.wav & 59.52 & -30 & 2,738 & $\mathrm{e}$ \\
\hline F4.01_34.wav & 1.24 & F4.01_34norm.raw & $-26,013$ & F4.01_34.wav & 49.72 & -28 & 1,917 & $\mathrm{e}$ \\
\hline F4.01_35.wav & 1.58 & F4.01_35norm.raw & $-25,924$ & F4.01_35.wav & 50.54 & -30 & 2,091 & $\mathrm{e}$ \\
\hline F4.01_36.wav & 1.20 & F4.01_36norm.raw & $-26,006$ & F4.01_36.wav & 51.92 & -28 & 2,068 & $\mathrm{e}$ \\
\hline F4.01_37.wav & 1.3 & F4.01_37norm.raw & $-26,058$ & F4.01_37.wav & 54.3 & -28 & 2,353 & $\mathrm{e}$ \\
\hline F4.01_38.wav & \begin{tabular}{|l|l|}
1.64 \\
\end{tabular} & F4.01_38norm.raw & -26 & F4.01_38.wav & 53.00 & -30 & 2,014 & ap \\
\hline F4.01_39.wav & 1.64 & F4.01_39norm.raw & $-26,004$ & F4.01_39.wav & 56.09 & -30 & 2,383 & ap \\
\hline F4.01_42.wav & 1.63 & F4.01_42norm.raw & $\begin{array}{l}-25,999 \\
\end{array}$ & F4.01_42.wav & 45.41 & -30 & 1,543 & ap \\
\hline F4.01_43.wav & 1.32 & F4.01_43norm.raw & $-26,025$ & F4.01_43.wav & 59.92 & -28 & 2,989 & ap \\
\hline F4.01_44.wav & 1.3 & F4.01_44norm.raw & $-26,027$ & F4.01_44.wav & 45.1 & -28 & 1,562 & ae \\
\hline F4.01_46.wav & 1.53 & F4.01_46norm.raw & $-26,013$ & F4.01_46.wav & 53.41 & -30 & 2,188 & ae \\
\hline F4.01_47.wav & 1.52 & F4.01_47norm.raw & $-26,013$ & F4.01_47.wav & 52.55 & -30 & 2,152 & ae \\
\hline F4.01_48.wav & 1.57 & F4.01_48norm.raw & $-25,994$ & F4.01_48.wav & 54.82 & -30 & 2,190 & ae \\
\hline M1.01_02.wav & 1.13 & M1.01_02norm.raw & $-26,007$ & M1.01_02.wav & 51.32 & -27 & 1,944 & $\mathrm{p}$ \\
\hline M1.01_03.wav & 1.34 & M1.01_03norm.raw & $-26,037$ & M1.01_03.wav & 44.81 & -29 & 1,524 & $\mathrm{p}$ \\
\hline M1.01_05.wav & 0.90 & M1.01_05norm.raw & $-26,014$ & M1.01_05.wav & 42.03 & -25 & 1,572 & $\mathrm{p}$ \\
\hline M1.01_06.wav & 1.06 & M1.01_06norm.raw & $-26,017$ & M1.01_06.wav & 45.52 & -27 & 1,607 & $\mathrm{p}$ \\
\hline M1.01_09.wav & 0.9 & M1.01_09norm.raw & $-26,029$ & M1.01_09.wav & 50.3 & -26 & 2,019 & $\mathrm{p}$ \\
\hline M1.01_10.wav & 0.92 & M1.01_10norm.raw & $-26,062$ & M1.01_10.wav & 43.28 & -25 & 1,516 & $\mathrm{p}$ \\
\hline M1.01_11.wav & 1.00 & M1.01_11norm.raw & $-26,003$ & M1.01_11.wav & 44.85 & -26 & 1,524 & $\mathrm{p}$ \\
\hline M1.01_12.wav & 0.99 & M1.01_12norm.raw & -26 & M1.01_12.wav & 46.39 & -26 & 1,674 & $\mathrm{p}$ \\
\hline M1.01_13.wav & 1.12 & M1.01_13norm.raw & $-26,022$ & M1.01_13.wav & 43.96 & -27 & 1,526 & $\mathrm{p}$ \\
\hline M1.01_14.wav & 1.04 & M1.01_14norm.raw & $-26,012$ & M1.01_14.wav & 47.48 & -26 & 1,749 & $\mathrm{p}$ \\
\hline M1.01_15.wav & \begin{tabular}{|l|l|}
0.8 \\
\end{tabular} & M1.01_15norm.raw & $-26,005$ & M1.01_15.wav & 44.7 & -25 & 1,705 & $\mathrm{p}$ \\
\hline M1.01_16.wav & 0.96 & M1.01_16norm.raw & $-26,015$ & M1.01_16.wav & 45.16 & -26 & 1,657 & $\mathrm{p}$ \\
\hline M1.01_17.wav & 0.92 & M1.01_17norm.raw & $-26,007$ & M1.01_17.wav & 43.57 & -25 & 1,612 & $\mathrm{p}$ \\
\hline M1.01_18.wav & 1.00 & M1.01_18norm.raw & $-26,002$ & M1.01_18.wav & 49.54 & -26 & 1,951 & $\mathrm{p}$ \\
\hline M1.01_19.wav & 0.89 & M1.01_19norm.raw & $-26,033$ & M1.01_19.wav & 43.17 & -25 & 1,542 & $\mathrm{e}$ \\
\hline M1.01_20.wav & 1.24 & M1.01_20norm.raw & $-26,008$ & M1.01_20.wav & 45.77 & -28 & 1,724 & $\mathrm{e}$ \\
\hline M1.01_21.wav & 1.15 & M1.01_21norm.raw & $-26,009$ & M1.01_21.wav & 58.12 & -27 & 2,681 & $\mathrm{e}$ \\
\hline M1.01_23.wav & 1.04 & M1.01_23norm.raw & $-26,006$ & M1.01_23.wav & 54.41 & -26 & 2,254 & $\mathrm{e}$ \\
\hline M1.01_24.wav & 1.00 & M1.01_24norm.raw & $-26,002$ & M1.01_24.wav & 47.50 & -26 & 1,722 & $\mathrm{e}$ \\
\hline M1.01_27.wav & 1.11 & M1.01_27norm.raw & $-26,006$ & M1.01_27.wav & 53.82 & -27 & 2,323 & $\mathrm{e}$ \\
\hline M1.01_29.wav & 0.8 & M1.01_29norm.raw & $-25,821$ & M1.01_29.wav & 54.8 & -24 & 2,407 & $\mathrm{e}$ \\
\hline M1.01_32.wav & 0.8 & M1.01_32norm.raw & $-26,029$ & M1.01_32.wav & 46.2 & -25 & 1,709 & $\mathrm{e}$ \\
\hline M1.01_33.wav & 0.8 & M1.01_33norm.raw & $-26,017$ & M1.01_33.wav & 42.9 & -25 & 1,651 & $\mathrm{e}$ \\
\hline M1.01_34.wav & 1.11 & M1.01_34norm.raw & $-26,005$ & M1.01_34.wav & 50.86 & -27 & 2,105 & $\mathrm{e}$ \\
\hline M1.01_36.wav & 1.10 & M1.01_36norm.raw & $-26,004$ & M1.01_36.wav & 50.07 & -27 & 2,037 & $\mathrm{e}$ \\
\hline M1.01_37.wav & 0.6 & M1.01_37norm.raw & $-26,029$ & M1.01_37.wav & 47.6 & -22 & 1,809 & ap \\
\hline M1.01_38.wav & 0.97 & M1.01_38norm.raw & $-25,994$ & M1.01_38.wav & 46.60 & -26 & 1,727 & ap \\
\hline M1.01_40.wav & 0.9 & M1.01_40norm.raw & $-26,071$ & M1.01_40.wav & 58.3 & -25 & 2,803 & ap \\
\hline M1.01_41.wav & 0.95 & M1.01_41norm.raw & $-26,009$ & M1.01_41.wav & 47.73 & -26 & 1,894 & ap \\
\hline M1.01_42.wav & 0.96 & M1.01_42norm.raw & $-26,011$ & M1.01_42.wav & 63.53 & -26 & 3,371 & ap \\
\hline M1.01_43.wav & 1.00 & M1.01_43norm.raw & $-26,002$ & M1.01_43.wav & 45.49 & -26 & 1,645 & ae \\
\hline M1.01_44.wav & 1.05 & M1.01_44norm.raw & $-26,011$ & M1.01_44.wav & 47.57 & -26 & 1,796 & ae \\
\hline M1.01_45.wav & 0.91 & M1.01_45norm.raw & $-26,026$ & M1.01_45.wav & 53.87 & -25 & 2,668 & ae \\
\hline M1.01_46.wav & 1.05 & M1.01_46norm.raw & $-26,01$ & M1.01_46.wav & 51.47 & -26 & 2,050 & ae \\
\hline M1.01_47.wav & 1.00 & M1.01_47norm.raw & $-26,002$ & M1.01_47.wav & 49.64 & -26 & 2,162 & ae \\
\hline M1.01_48.wav & 1.16 & M1.01_48norm.raw & $-26,012$ & M1.01_48.wav & 55.39 & -27 & 2,493 & ae \\
\hline M2.01_02.wav & 1.09 & M2.01_02norm.raw & $-26,003$ & M2.01_02.wav & 50.46 & -27 & 2,008 & $\mathrm{p}$ \\
\hline M2.01_03.wav & 1.21 & M2.01_03norm.raw & $-26,006$ & M2.01_03.wav & 47.82 & -28 & 1,851 & $\mathrm{p}$ \\
\hline M2.01_04.wav & 1.01 & M2.01_04norm.raw & $-26,005$ & M2.01_04.wav & 45.05 & -26 & 1,706 & $\mathrm{p}$ \\
\hline M2.01_05.wav & 1.28 & M2.01_05norm.raw & $-26,028$ & M2.01_05.wav & 49.41 & -28 & 1,897 & $\mathrm{p}$ \\
\hline M2.01_06.wav & 0.93 & M2.01_06norm.raw & $-26,002$ & M2.01_06.wav & 45.58 & -25 & 1,677 & $\mathrm{p}$ \\
\hline M2.01_07.wav & 0.80 & M2.01_07norm.raw & $-25,996$ & M2.01_07.wav & 46.22 & -24 & 1,713 & $\mathrm{p}$ \\
\hline M2.01_08.wav & 0.85 & M2.01_08norm.raw & $-26,006$ & M2.01_08.wav & 48.72 & -25 & 1,836 & $\mathrm{p}$ \\
\hline M2.01_09.wav & 0.8 & M2.01_09norm.raw & $-26,006$ & M2.01_09.wav & 52.0 & -25 & 2,213 & $\mathrm{p}$ \\
\hline
\end{tabular}




\begin{tabular}{|c|c|c|c|c|c|c|c|c|}
\hline M2.01_10.wav & 1.10 & M2.01_10norm.raw & |-26,005 & M2.01_10.wav & 53.44 & -27 & 2,285 & $\bar{p}$ \\
\hline M2.01_13.wav & 1.11 & M2.01_13norm.raw & $\mid-26,012$ & M2.01_13.wav & 50.49 & \begin{tabular}{l|}
-27 \\
\end{tabular} & 2,122 & $\mathrm{p}$ \\
\hline M2.01_14.wav & 1.12 & M2.01_14norm.raw & \begin{tabular}{|l|}
$-26,006$ \\
\end{tabular} & M2.01_14.wav & 52.48 & \begin{tabular}{|c|}
-27 \\
\end{tabular} & 2,156 & $\mathrm{p}$ \\
\hline M2.01_15.wav & 1.18 & M2.01_15norm.raw & -26 & M2.01_15.wav & 46.30 & \begin{tabular}{l|l|}
-27 \\
\end{tabular} & 1,661 & $\mathrm{p}$ \\
\hline M2.01_16.wav & 0.99 & M2.01_16norm.raw & $\begin{array}{l}-25,995 \\
\end{array}$ & M2.01_16.wav & 49.08 & -26 & 1,990 & $\mathrm{p}$ \\
\hline M2.01_17.wav & 1.18 & M2.01_17norm.raw & $-26,001$ & M2.01_17.wav & 49.43 & -27 & 1,889 & $\mathrm{p}$ \\
\hline M2.01_18.wav & 1.19 & M2.01_18norm.raw & $-25,918$ & M2.01_18.wav & 44.96 & -28 & 1,670 & $\mathrm{p}$ \\
\hline M2.01_19.wav & 0.87 & M2.01_19norm.raw & $-26,065$ & M2.01_19.wav & 54.87 & -25 & 2,404 & $\mathrm{e}$ \\
\hline M2.01_20.wav & 0.85 & M2.01_20norm.raw & $-26,014$ & M2.01_20.wav & 46.69 & -25 & 1,693 & $\mathrm{e}$ \\
\hline M2.01_21.wav & 1.00 & M2.01_21norm.raw & $-26,005$ & M2.01_21.wav & 51.18 & -26 & 2,092 & $\mathrm{e}$ \\
\hline M2.01_22.wav & 0.86 & M2.01_22norm.raw & $-26,008$ & M2.01_22.wav & 45.84 & -25 & 1,686 & $\mathrm{e}$ \\
\hline M2.01_23.wav & 0.8 & M2.01_23norm.raw & $-26,013$ & M2.01_23.wav & 46.1 & \begin{tabular}{l|l|}
-25 \\
\end{tabular} & 1,758 & $\mathrm{e}$ \\
\hline M2.01_24.wav & 1.20 & M2.01_24norm.raw & $-26,006$ & M2.01_24.wav & 45.74 & -28 & 1,644 & $\mathrm{e}$ \\
\hline M2.01_25.wav & 1.05 & M2.01_25norm.raw & $-26,011$ & M2.01_25.wav & 49.74 & -26 & 1,893 & $\mathrm{e}$ \\
\hline M2.01_26.wav & 0.98 & M2.01_26norm.raw & $-25,995$ & M2.01_26.wav & 46.43 & -26 & 1,739 & $\mathrm{e}$ \\
\hline M2.01_27.wav & 1.24 & M2.01_27norm.raw & $-26,023$ & M2.01_27.wav & 54.49 & -28 & 2,505 & $\mathrm{e}$ \\
\hline M2.01_28.wav & 1.02 & M2.01_28norm.raw & $-26,006$ & M2.01_28.wav & 49.68 & -26 & 1,947 & $\mathrm{e}$ \\
\hline M2.01_29.wav & 1.11 & M2.01_29norm.raw & $-26,003$ & M2.01_29.wav & 48.06 & -27 & 1,857 & $\mathrm{e}$ \\
\hline M2.01_30.wav & 1.17 & M2.01_30norm.raw & $-25,944$ & M2.01_30.wav & 51.34 & -27 & 2,485 & $\mathrm{e}$ \\
\hline M2.01_31.wav & 1.08 & M2.01_31norm.raw & $-26,025$ & M2.01_31.wav & 45.99 & -27 & 1,721 & $\mathrm{e}$ \\
\hline M2.01_32.wav & 1.11 & M2.01_32norm.raw & $-26,007$ & M2.01_32.wav & 57.30 & -27 & 2,790 & $\mathrm{e}$ \\
\hline M2.01_33.wav & 1.09 & M2.01_33norm.raw & $-26,003$ & M2.01_33.wav & 52.19 & \begin{tabular}{l|l|}
-27 \\
\end{tabular} & 2,173 & $\mathrm{e}$ \\
\hline M2.01_34.wav & 1.06 & M2.01_34norm.raw & $-26,01$ & M2.01_34.wav & 53.34 & \begin{tabular}{l|l}
-27 \\
\end{tabular} & 2,241 & $\mathrm{e}$ \\
\hline M2.01_35.wav & 1.31 & M2.01_35norm.raw & $-26,026$ & M2.01_35.wav & 44.92 & -28 & 1,584 & $\mathrm{e}$ \\
\hline M2.01_36.wav & 0.95 & M2.01_36norm.raw & $-26,053$ & M2.01_36.wav & 45.65 & -26 & 1,648 & $\mathrm{e}$ \\
\hline M2.01_37.wav & 0.95 & M2.01_37norm.raw & $-26,01$ & M2.01_37.wav & 53.19 & -26 & 2,200 & ap \\
\hline M2.01_38.wav & 0.90 & M2.01_38norm.raw & $-26,013$ & M2.01_38.wav & 62.83 & -25 & 3,257 & ap \\
\hline M2.01_39.wav & 0.99 & M2.01_39norm.raw & $-26,001$ & M2.01_39.wav & 58.69 & -26 & 2,758 & ap \\
\hline M2.01_40.wav & 1.07 & M2.01_40norm.raw & $-26,163$ & M2.01_40.wav & 55.38 & \begin{tabular}{l|l}
-27 \\
\end{tabular} & 2,552 & ap \\
\hline M2.01_41.wav & 1.02 & M2.01_41norm.raw & $-26,004$ & M2.01_41.wav & 62.00 & -26 & 3,112 & ap \\
\hline M2.01_42.wav & 1.01 & M2.01_42norm.raw & $-26,003$ & M2.01_42.wav & 56.72 & -26 & 2,757 & ap \\
\hline M2.01_43.wav & 0.90 & M2.01_43norm.raw & $-26,019$ & M2.01_43.wav & 46.83 & \begin{tabular}{l|l|}
-25 \\
\end{tabular} & 1,688 & ae \\
\hline M2.01_44.wav & 0.79 & M2.01_44norm.raw & $-25,994$ & M2.01_44.wav & 43.41 & -24 & 1,573 & ae \\
\hline M2.01_45.wav & 1.00 & M2.01_45norm.raw & $-26,002$ & M2.01_45.wav & 47.02 & -26 & 1,750 & ae \\
\hline M2.01_46.wav & 1.27 & M2.01_46norm.raw & $-26,048$ & M2.01_46.wav & 49.60 & -28 & 1,953 & $\mathrm{ae}$ \\
\hline M2.01_47.wav & 1.17 & M2.01_47norm.raw & $-26,001$ & M2.01_47.wav & 55.26 & -27 & 2,522 & ae \\
\hline M2.01_48.wav & 1.11 & M2.01_48norm.raw & $-26,012$ & M2.01_48.wav & 48.22 & -27 & 1,843 & $\mathrm{ae}$ \\
\hline M3.01_02.wav & 1.31 & M3.01_02norm.raw & $-25,981$ & M3.01_02.wav & 48.72 & -28 & 1,933 & $\mathrm{p}$ \\
\hline M3.01_03.wav & 1.08 & M3.01_03norm.raw & $-26,014$ & M3.01_03.wav & 53.00 & -27 & 2,114 & $\mathrm{p}$ \\
\hline M3.01_04.wav & 1.58 & M3.01_04norm.raw & $-25,994$ & M3.01_04.wav & 46.30 & -30 & 1,561 & $\mathrm{p}$ \\
\hline M3.01_05.wav & 1.32 & M3.01_05norm.raw & $-26,02$ & M3.01_05.wav & 51.99 & -28 & 2,238 & $\mathrm{p}$ \\
\hline M3.01_07.wav & 1.21 & M3.01_07norm.raw & $-26,017$ & M3.01_07.wav & 48.35 & -28 & 1,909 & $\mathrm{p}$ \\
\hline M3.01_08.wav & 1.00 & M3.01_08norm.raw & $-26,001$ & M3.01_08.wav & 53.09 & -26 & 2,188 & $\mathrm{p}$ \\
\hline M3.01_09.wav & 0.91 & M3.01_09norm.raw & $-26,076$ & M3.01_09.wav & 54.05 & \begin{tabular}{l|l|}
-25 \\
\end{tabular} & 2,254 & $\mathrm{p}$ \\
\hline M3.01_10.wav & 1.11 & M3.01_10norm.raw & $-26,004$ & M3.01_10.wav & 51.43 & \begin{tabular}{l|l}
-27 \\
\end{tabular} & 2,086 & $\mathrm{p}$ \\
\hline M3.01_11.wav & 0.97 & M3.01_11norm.raw & $-25,997$ & M3.01_11.wav & 55.49 & -26 & 2,445 & $\mathrm{p}$ \\
\hline M3.01_12.wav & 0.86 & M3.01_12norm.raw & $-26,016$ & M3.01_12.wav & 56.83 & -25 & 2,540 & $\mathrm{p}$ \\
\hline M3.01_13.wav & 1.10 & M3.01_13norm.raw & $-26,008$ & M3.01_13.wav & 46.51 & \begin{tabular}{l|l|}
-27 \\
\end{tabular} & 1,720 & $\mathrm{p}$ \\
\hline M3.01_14.wav & 0.98 & M3.01_14norm.raw & -26 & M3.01_14.wav & 56.79 & -26 & 2,544 & $\mathrm{p}$ \\
\hline M3.01_15.wav & 0.91 & M3.01_15norm.raw & $-26,023$ & M3.01_15.wav & 46.69 & \begin{tabular}{l|l|}
-25 \\
\end{tabular} & 1,746 & $\mathrm{p}$ \\
\hline M3.01_16.wav & 1.05 & M3.01_16norm.raw & $-26,016$ & M3.01_16.wav & 52.41 & -26 & 2,188 & $\mathrm{p}$ \\
\hline M3.01_17.wav & 0.78 & M3.01_17norm.raw & $-25,996$ & M3.01_17.wav & 57.51 & \begin{tabular}{l|l|}
-24 & \\
\end{tabular} & 2,714 & $\mathrm{p}$ \\
\hline M3.01_18.wav & 0.87 & M3.01_18norm.raw & $-26,118$ & M3.01_18.wav & 52.38 & \begin{tabular}{l|l|}
-25 \\
\end{tabular} & 2,174 & $\mathrm{p}$ \\
\hline M3.01_19.wav & 0.94 & M3.01_19norm.raw & $-25,644$ & M3.01_19.wav & 53.49 & -26 & 2,354 & $\mathrm{p}$ \\
\hline M3.01_20.wav & 1.07 & M3.01_20norm.raw & $-26,016$ & M3.01_20.wav & 50.40 & \begin{tabular}{l|l|}
-27 \\
\end{tabular} & 2,017 & $\mathrm{e}$ \\
\hline M3.01_21.wav & 1.06 & M3.01_21norm.raw & $-26,014$ & M3.01_21.wav & 45.69 & \begin{tabular}{l|l}
-27 \\
\end{tabular} & 1,705 & $\mathrm{e}$ \\
\hline M3.01_22.wav & 1.08 & M3.01_22norm.raw & $-26,041$ & M3.01_22.wav & 50.76 & \begin{tabular}{l|l|}
-27 \\
\end{tabular} & 2,069 & $\mathrm{e}$ \\
\hline M3.01_23.wav & 0.98 & M3.01_23norm.raw & $-25,997$ & M3.01_23.wav & 50.05 & -26 & 1,989 & $\mathrm{e}$ \\
\hline M3.01_24.wav & 1.31 & M3.01_24norm.raw & $-26,019$ & M3.01_24.wav & 51.32 & -28 & 2,076 & $\mathrm{e}$ \\
\hline M3.01_25.wav & 1.28 & M3.01_25norm.raw & $-26,03$ & M3.01_25.wav & 51.00 & -28 & 2,125 & $\mathrm{e}$ \\
\hline M3.01_26.wav & 1.39 & M3.01_26norm.raw & $-25,997$ & M3.01_26.wav & 46.34 & \begin{tabular}{l|l|}
-29 \\
\end{tabular} & 1,848 & $\mathrm{e}$ \\
\hline M3.01_27.wav & 1.01 & M3.01_27norm.raw & $-26,004$ & M3.01_27.wav & 45.01 & -26 & 1,641 & $\mathrm{e}$ \\
\hline M3.01_28.wav & 1.08 & M3.01_28norm.raw & $-26,021$ & M3.01_28.wav & 56.88 & \begin{tabular}{l|l}
-27 \\
\end{tabular} & 2,591 & $\mathrm{e}$ \\
\hline M3.01_29.wav & 1.13 & M3.01_29norm.raw & $\begin{array}{l}-26,009 \\
\end{array}$ & M3.01_29.wav & 45.86 & \begin{tabular}{l|l|}
-27 \\
\end{tabular} & 1,670 & $\mathrm{e}$ \\
\hline M3.01_30.wav & 1.13 & M3.01_30norm.raw & $-26,008$ & M3.01_30.wav & 59.40 & -27 & 3,048 & $\mathrm{e}$ \\
\hline M3.01_31.wav & 1.01 & M3.01_31norm.raw & $-26,006$ & M3.01_31.wav & 46.25 & -26 & 1,724 & $\mathrm{e}$ \\
\hline M3.01_32.wav & 1.00 & M3.01_32norm.raw & $-26,003$ & M3.01_32.wav & 53.49 & -26 & 2,278 & $\mathrm{e}$ \\
\hline M3.01_33.wav & 1.08 & M3.01_33norm.raw & $-26,017$ & M3.01_33.wav & 44.44 & -27 & 1,728 & $\mathrm{e}$ \\
\hline M3.01_34.wav & 0.95 & M3.01_34norm.raw & $-26,018$ & M3.01_34.wav & 52.14 & -26 & 2,201 & $\mathrm{e}$ \\
\hline M3.01_35.wav & 0.93 & M3.01_35norm.raw & $-26,001$ & M3.01_35.wav & 43.65 & -25 & 1,578 & $\mathrm{e}$ \\
\hline M3.01_37.wav & 1.25 & M3.01_37norm.raw & $-26,012$ & M3.01_37.wav & 54.05 & $-28 \mid$ & 2,225 & $\mathrm{e}$ \\
\hline
\end{tabular}




\section{Resultado do Pré-processamento dos Audios Gravados}

\begin{tabular}{|c|c|c|c|c|c|c|c|c|}
\hline M3.01_38.wav & 1.05 & M3.01_38norm.raw & |-26,009 & M3.01_38.wav & 55.92 & \begin{tabular}{|c|}
-26 \\
\end{tabular} & 2,360 & ap \\
\hline M3.01_39.wav & 0.93 & M3.01_39norm.raw & $\mid-26,007$ & M3.01_39.wav & 59.17 & -25 & 2,912 & ap \\
\hline M3.01_40.wav & 0.96 & M3.01_40norm.raw & $\mid-26,014$ & M3.01_40.wav & 61.57 & -26 & 3,240 & ap \\
\hline M3.01_41.wav & 0.89 & M3.01_41norm.raw & $\mid-26,012$ & M3.01_41.wav & 54.99 & -25 & 2,559 & ap \\
\hline M3.01_42.wav & 0.85 & M3.01_42norm.raw & $\mid-26,007$ & M3.01_42.wav & 54.14 & -25 & 2,310 & ap \\
\hline \begin{tabular}{|l|} 
M3.01_43.wav \\
\end{tabular} & 1.26 & M3.01_43norm.raw & $-26,034$ & M3.01_43.wav & 63.17 & -28 & 3,422 & ap \\
\hline \begin{tabular}{|l} 
M3.01_44.wav \\
\end{tabular} & \begin{tabular}{|l|}
1.01 \\
\end{tabular} & M3.01_44norm.raw & $-26,004$ & M3.01_44.wav & 51.90 & -26 & 2,132 & $\mathrm{ae}$ \\
\hline M3.01_45.wav & \begin{tabular}{|l|}
1.04 \\
\end{tabular} & M3.01_45norm.raw & $\mid-26,01$ & M3.01_45.wav & 48.55 & -26 & 1,859 & $\mathrm{ae}$ \\
\hline \begin{tabular}{|l} 
M3.01_46.wav \\
\end{tabular} & 0.98 & M3.01_46norm.raw & -25,999 & M3.01_46.wav & 52.66 & -26 & 2,203 & $\mathrm{ae}$ \\
\hline \begin{tabular}{|l|} 
M3.01_47.wav \\
\end{tabular} & 0.73 & M3.01_47norm.raw & $\begin{array}{l}-26,025 \\
\end{array}$ & M3.01_47.wav & 43.15 & -23 & 1,588 & $\mathrm{ae}$ \\
\hline M3.01_48.wav & 0.94 & M3.01_48norm.raw & $-26,007$ & M3.01_48.wav & 61.81 & -26 & 3,192 & ae \\
\hline M4.01_02.wav & 1.02 & M4.01_02norm.raw & $-26,012$ & M4.01_02.wav & 45.53 & -26 & 1,676 & ae \\
\hline M4.01_04.wav & \begin{tabular}{|l}
0.8 \\
\end{tabular} & M4.01_04norm.raw & -26 & M4.01_04.wav & 42.5 & -25 & 1,520 & $\mathrm{p}$ \\
\hline M4.01_05.wav & 1.0 & M4.01_05norm.raw & $-26,007$ & M4.01_05.wav & 47.6 & -26 & 1,788 & $\mathrm{p}$ \\
\hline M4.01_06.wav & 0.8 & M4.01_06norm.raw & $-26,009$ & M4.01_06.wav & 45.2 & -25 & 1,571 & $\mathrm{p}$ \\
\hline M4.01_07.wav & 0.90 & M4.01_07norm.raw & $-25,987$ & M4.01_07.wav & 47.01 & -25 & 1,791 & $\mathrm{p}$ \\
\hline M4.01_08.wav & 0.8 & M4.01_08norm.raw & $-26,002$ & M4.01_08.wav & 53.3 & -24 & 2,167 & $\mathrm{p}$ \\
\hline M4.01_09.wav & \begin{tabular}{|l|l|}
0.8 \\
\end{tabular} & M4.01_09norm.raw & $-26,012$ & M4.01_09.wav & 50.2 & -25 & 1,904 & $\mathrm{p}$ \\
\hline M4.01_10.wav & \begin{tabular}{|l|}
0.8 \\
\end{tabular} & M4.01_10norm.raw & $-26,003$ & M4.01_10.wav & 45.2 & -24 & 1,613 & $\mathrm{p}$ \\
\hline M4.01_11.wav & 0.83 & M4.01_11norm.raw & $-26,115$ & M4.01_11.wav & 51.92 & -24 & 1,953 & $\mathrm{p}$ \\
\hline M4.01_12.wav & \begin{tabular}{|l|}
0.9 \\
\end{tabular} & M4.01_12norm.raw & $-26,002$ & M4.01_12.wav & 57.2 & -25 & 2,523 & $\mathrm{p}$ \\
\hline M4.01_13.wav & 0.90 & M4.01_13norm.raw & $-26,015$ & M4.01_13.wav & 50.98 & -25 & 1,989 & $\mathrm{p}$ \\
\hline M4.01_14.wav & 0.81 & M4.01_14norm.raw & -26 & M4.01_14.wav & 49.80 & -24 & 1,955 & $\mathrm{p}$ \\
\hline M4.01_15.wav & 0.7 & M4.01_15norm.raw & $-26,01$ & M4.01_15.wav & 48.0 & -23 & 1,783 & $\mathrm{p}$ \\
\hline M4.01_16.wav & \begin{tabular}{|l|}
0.7 \\
\end{tabular} & M4.01_16norm.raw & $-26,149$ & M4.01_16.wav & 46.9 & -23 & 1,804 & $\mathrm{p}$ \\
\hline M4.01_17.wav & 0.88 & M4.01_17norm.raw & $-26,012$ & M4.01_17.wav & 47.41 & -25 & 1,716 & $\mathrm{p}$ \\
\hline M4.01_18.wav & 0.84 & M4.01_18norm.raw & $-26,002$ & M4.01_18.wav & 45.34 & -25 & 1,649 & $\mathrm{p}$ \\
\hline M4.01_19.wav & \begin{tabular}{|l|}
0.8 \\
\end{tabular} & M4.01_19norm.raw & $-26,005$ & M4.01_19.wav & 45.5 & -25 & 1,641 & $\mathrm{p}$ \\
\hline M4.01_20.wav & 1.13 & M4.01_20norm.raw & $-26,036$ & M4.01_20.wav & 48.49 & -27 & 1,946 & $\mathrm{e}$ \\
\hline M4.01_21.wav & \begin{tabular}{|l|}
0.9 \\
\end{tabular} & M4.01_21norm.raw & $-26,003$ & M4.01_21.wav & 54.0 & -25 & 2,421 & $\mathrm{e}$ \\
\hline M4.01_23.wav & 1.20 & M4.01_23norm.raw & $-26,003$ & M4.01_23.wav & 44.47 & -28 & 1,595 & $\mathrm{e}$ \\
\hline M4.01_24.wav & 0.9 & M4.01_24norm.raw & $-25,998$ & M4.01_24.wav & 50.7 & -26 & 2,044 & $\mathrm{e}$ \\
\hline M4.01_26.wav & 1.07 & M4.01_26norm.raw & $-26,031$ & M4.01_26.wav & 42.94 & -27 & 1,628 & $\mathrm{e}$ \\
\hline M4.01_27.wav & 1.00 & M4.01_27norm.raw & $-26,002$ & M4.01_27.wav & 55.16 & -26 & 2,479 & $\mathrm{e}$ \\
\hline M4.01_28.wav & 1.01 & M4.01_28norm.raw & $-26,003$ & M4.01_28.wav & 56.52 & -26 & 2,547 & $\mathrm{e}$ \\
\hline M4.01_29.wav & 1.04 & M4.01_29norm.raw & $-26,007$ & M4.01_29.wav & 53.08 & -26 & 2,330 & $\mathrm{e}$ \\
\hline M4.01_30.wav & 0.8 & M4.01_30norm.raw & $-26,021$ & M4.01_30.wav & 46.0 & -25 & 1,846 & $\mathrm{e}$ \\
\hline M4.01_31.wav & 0.81 & M4.01_31norm.raw & $-25,997$ & M4.01_31.wav & 44.83 & -24 & 1,706 & $\mathrm{e}$ \\
\hline M4.01_32.wav & 0.92 & M4.01_32norm.raw & $-26,01$ & M4.01_32.wav & 49.07 & -25 & 2,056 & $\mathrm{e}$ \\
\hline M4.01_33.wav & 0.86 & M4.01_33norm.raw & $-26,011$ & M4.01_33.wav & 45.61 & -25 & 1,680 & $\mathrm{e}$ \\
\hline M4.01_34.wav & 1.04 & M4.01_34norm.raw & $-26,008$ & M4.01_34.wav & 50.52 & -26 & 2,033 & $\mathrm{e}$ \\
\hline M4.01_35.wav & 1.07 & M4.01_35norm.raw & $-26,014$ & M4.01_35.wav & 50.56 & -27 & 2,105 & $\mathrm{e}$ \\
\hline M4.01_36.wav & \begin{tabular}{|l|}
0.9 \\
\end{tabular} & M4.01_36norm.raw & $-25,989$ & M4.01_36.wav & 47.1 & -26 & 1,773 & $\mathrm{e}$ \\
\hline M4.01_37.wav & 1.24 & M4.01_37norm.raw & $-26,025$ & M4.01_37.wav & 52.52 & -28 & 2,131 & $\mathrm{e}$ \\
\hline M4.01_38.wav & 0.90 & M4.01_38norm.raw & $-26,035$ & M4.01_38.wav & 50.74 & -25 & 2,025 & ap \\
\hline M4.01_39.wav & \begin{tabular}{|l|}
0.9 \\
\end{tabular} & M4.01_39norm.raw & $\begin{array}{l}-26,007 \\
\end{array}$ & M4.01_39.wav & 60.8 & -26 & 3,054 & ap \\
\hline M4.01_40.wav & 0.8 & M4.01_40norm.raw & $-26,001$ & M4.01_40.wav & 51.1 & -24 & 2,000 & ap \\
\hline M4.01_41.wav & 0.89 & M4.01_41norm.raw & $-26,011$ & M4.01_41.wav & 50.66 & -25 & 1,970 & ap \\
\hline M4.01_42.wav & 0.9 & M4.01_42norm.raw & $-26,008$ & M4.01_42.wav & 64.2 & -25 & 3,355 & ap \\
\hline M4.01_43.wav & \begin{tabular}{|l|}
0.8 \\
\end{tabular} & M4.01_43norm.raw & $-26,046$ & M4.01_43.wav & 56.8 & -25 & 2,587 & ap \\
\hline M4.01_45.wav & 1.21 & M4.01_45norm.raw & $-26,005$ & M4.01_45.wav & 55.51 & -28 & 2,401 & ae \\
\hline M4.01_46.wav & 1.18 & M4.01_46norm.raw & $-26,003$ & M4.01_46.wav & 47.85 & -27 & 1,751 & ae \\
\hline M4.01_47.wav & 1.0 & M4.01_47norm.raw & $-26,004$ & M4.01_47.wav & 60.0 & -26 & 3,236 & ae \\
\hline
\end{tabular}

\begin{tabular}{|l|l|}
\hline Média nível & $-26,01009$ \\
\hline
\end{tabular} 
Resultado do Pré-processamento dos Audios Gravados

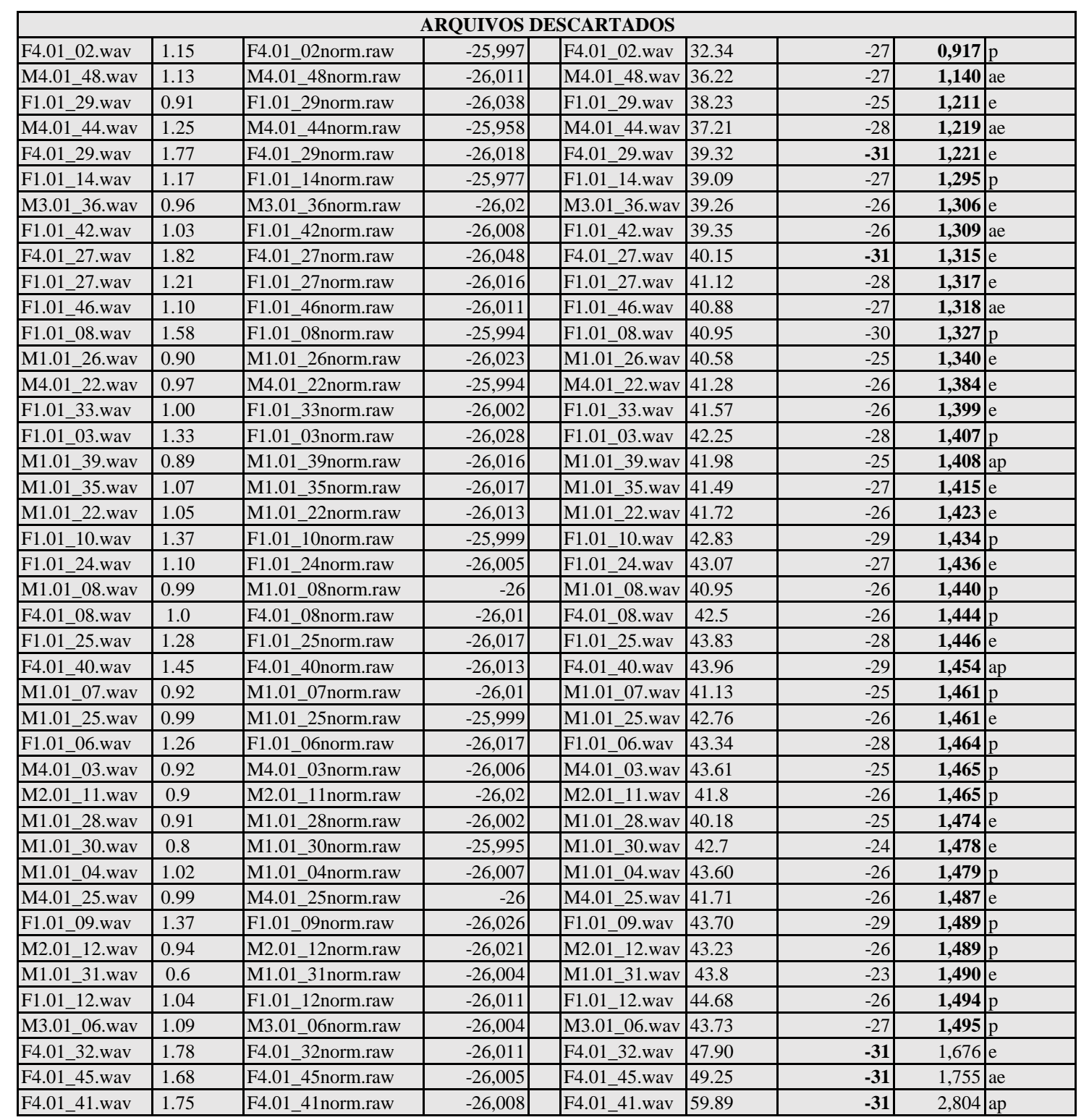


ANEXO G - DIVISÃO DE FRASES EM GRUPOS DE TRATAMENTO 
Grupos ITU

Grupo 1 F4.01_34norm.wav F4.01_35norm.wav F2.01_02norm.wav F2.01_03norm.wav M1.01_19norm.wav M1.01_20norm.wav M2.01_02norm.wav M2.01_03norm.wav

Grupo 4 F1.01_22norm.wav F1.01_23norm.wav F2.01_08norm.wav F2.01_09norm.wav M1.01_29norm.wav M1.01_32norm.wav M2.01_08norm.wav M2.01_09norm.wav

Grupo 7 F1.01_32norm.wav F1.01_34norm.wav F2.01_14norm.wav F2.01 15norm.wav M3.01_22norm.wav M3.01_23norm.wav M2.01_16norm.wav M2.01_17norm.wav

Grupo 10 F3.01_23norm.wav F3.01_24norm.wav F1.01_05norm.wav F1.01_07norm.wav M3.01_28norm.wav M3.01_29norm.wav M4.01_08norm.wav M4.01_09norm.wav

Grupo 13 F3.01_29norm.wav F3.01_30norm.wav F4.01_03norm.wav F4.01_04norm.wav M3.01_34norm.wav M3.01_35norm.wav M4.01_14norm.wav M4.01_15norm.wav

Grupo 16 F3.01_35norm.wav F3.01_36norm.wav F4.01_10norm.wav F4.01_11 norm.wav M2.01_23norm.wav M2.01_24norm.wav M3.01_02norm.wav M3.01_03norm.wav

Grupo 19 F2.01_23norm.wav F2.01_24norm.wav F4.01_16norm.wav F4.01_17norm.wav M2.01_29norm.wav M2.01_30norm.wav M3.01_09norm.wav M3.01_10norm.wav

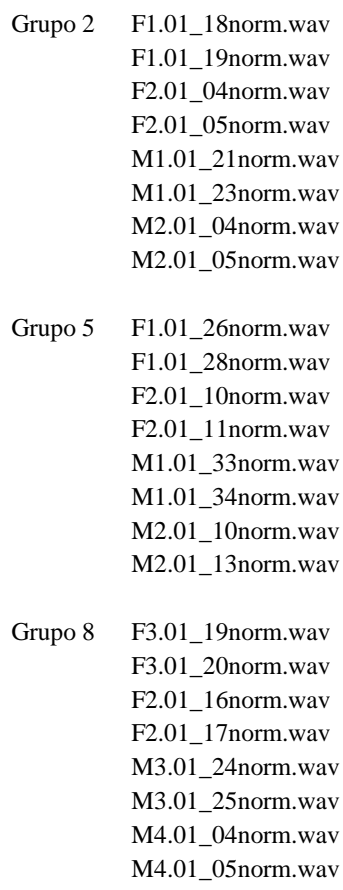

Grupo 5 F1.01_26norm.wav F1.01_28norm.wav F2.01_10norm.wav F2.01_11 norm.wav M1.01_33norm.wav M1.01_34norm.wav M2.01_10norm.wav M2.01_13norm.wav

Grupo 8 F3.01_19norm.wav F3.01_20norm.wav F2.01_16norm.wav F2.01_17norm.wav M3.01_24norm.way M3.01_25norm.wav M4.01_04norm.wav M4.01_05norm.wav

Grupo 11 F3.01_25norm.wav F3.01_26norm.wav F1.01_11 norm.wav F1.01_13norm.wav M3.01_30norm.wav M3.01_31norm.wav M4.01_10norm.wav M4.01_11norm.wav

Grupo 14 F3.01_31norm.wav F3.01_32norm.wav F4.01_05norm.wav F4.01_06norm.wav M2.01_19norm.wav M2.01_20norm.wav M4.01_16norm.wav M4.01_17norm.wav

Grupo 17 F2.01_19norm.wav F2.01_20norm.wav F4.01_12norm.wav F4.01_13norm.wav M2.01_25norm.wav M2.01_26norm.wav M3.01_04norm.wav M3.01_05norm.wav

Grupo 20 F2.01_25norm.wav F2.01_26norm.wav F3.01_02norm.wav F3.01_03norm.wav M2.01_31norm.wav M2.01_32norm.wav M3.01_11norm.wav M3.01_12norm.wav
Grupo 3 F1.01_20norm.wav F1.01_21norm.wav F2.01_06norm.wav F2.01_07norm.wav M4.01_36norm.wav M4.01_37norm.wav M2.01_06norm.wav M2.01_07norm.wav

Grupo6 F1.01_30norm.wav F1.01_31 norm.wav F2.01_12norm.wav F2.01_13norm.wav M3.01_20norm.wav M3.01_21norm.wav M2.01_14norm.wav M2.01_15norm.wav

Grupo 9 F3.01_21norm.wav F3.01_22norm.wav F1.01_02norm.wav F1.01_04norm.wav M3.01_26norm.wav M3.01_27norm.wav M4.01_06norm.wav M4.01_07norm.wav

Grupo 12 F3.01_27norm.wav F3.01_28norm.wav F1.01_15norm.wav F1.01_48norm.wav M3.01_32norm.wav M3.01_33norm.wav M4.01_12norm.wav M4.01_13norm.wav

Grupo 15 F3.01_33norm.wav F3.01_34norm.wav F4.01_07norm.wav F4.01_09norm.wav M2.01_21norm.wav M2.01_22norm.wav M4.01_18norm.wav M4.01_19norm.wav

Grupo 18 F2.01_21norm.wav F2.01_22norm.wav F4.01_14norm.wav F4.01_15norm.wav M2.01_27norm.wav M2.01_28norm.wav M3.01_07norm.way M3.01_08norm.wav

Grupo 21 F2.01_27norm.wav F2.01_28norm.wav F3.01_04norm.wav F3.01_05norm.wav M2.01_33norm.wav M2.01_34norm.wav M3.01_13norm.wav M3.01_14norm.wav 
Grupo 22 F2.01_29norm.wav F2.01_30norm.wav F3.01 06norm.wav F3.01_07norm.wav M2.01_35norm.wav M2.01_36norm.wav M3.01_15norm.way M3.01_16norm.wav

Grupo 25 F2.01_35norm.wav F2.01_36norm.wav F3.01_12norm.wav F3.01 13norm.wav M4.01_26norm.wav M4.01_27norm.wav M1.01_05norm.wav M1.01_06norm.wav

Grupos ATC

Grupo 1a F1.01_43.wav F1.01_44.wav F2.01_37.wav F2.01 38.wav M1.01_43.wav M1.01_44.wav M2.01_37.wav M2.01_38.wav

Grupo 4a F2.01_45.wav F2.01 46.wav F3.01_39.wav F3.01_40.wav M2.01_43.wav M2.01_44.wav M3.01_38.wav M3.01 39.wav

Grupo 7a F3.01_45.wav F3.01_46.wav F1.01_38.wav F1.01_39.wav M3.01_44.wav M3.01_45.wav M4.01_38.wav M4.01_39.wav
Grupo 23 F2.01_31norm.wav F2.01_32norm.wav F3.01 08norm.wav F3.01_09norm.wav M4.01_20norm.wav M4.01_21norm.wav M3.01_17norm.wav M3.01_18norm.wav

$\begin{aligned} & \text { Grupo } 24 \text { F2.01_33norm.wav } \\ & \text { F2.01_34norm.wav } \\ & \text { F3.01_10norm.wav } \\ & \text { F3.01_11norm.wav } \\ & \text { M4.01_23norm.wav } \\ & \text { M4.01_24norm.wav } \\ & \text { M1.01_02norm.wav } \\ & \text { M1.01_03norm.wav }\end{aligned}$

$\begin{array}{cl}\text { Grupo 2a } & \text { F1.01_45.wav } \\ & \text { F1.01_47.wav } \\ & \text { F2.01_39.wav } \\ & \text { F2.01_40.wav } \\ & \text { M1.01_45.wav } \\ & \text { M1.01_46.wav } \\ & \text { M2.01_39.wav } \\ & \text { M2.01_40.wav } \\ & \\ \text { Grupo 5a } & \text { F2.01_47.wav } \\ & \text { F2.01_48.wav } \\ & \text { F3.01_41.wav } \\ & \text { F3.01_42.wav } \\ & \text { M2.01_45.wav } \\ & \text { M2.01_46.wav } \\ & \text { M3.01_40.wav } \\ & \text { M3.01_41.wav } \\ & \text { F3.01_47.wav } \\ \text { F3.01_48.wav } \\ \text { F1.01_40.wav } \\ \text { F1.01_41.wav } \\ \text { M3.01_46.wav } \\ \text { M3.01_47.wav } \\ \text { M4.01_40.wav } \\ \text { M4.01_41.wav }\end{array}$
Grupo 3a F2.01_43.wav F2.01_44.wav F3.01_37.wav F3.01_38.wav M1.01_47.wav M1.01_48.wav M2.01_41.wav M2.01_42.wav
Grupo 6a F3.01_43.wav F3.01_44.wav F1.01_36.wav F1.01_37.wav M2.01_47.wav M2.01_48.wav M3.01_42.wav M3.01_43.way


ANEXO H - CONDIÇÕES METEOROLÓGICAS - TESTES EM VÔO 


\section{Condicões Climáticas durante os Testes em Vôo}

\section{Dia 11 OUT 2017 - Vôo Santa Catarina:}

Considerações do Previsor: baixa nebulosidade próximo à Morro da Igreja (MDI) e Curitiba no período de 13 horas a 16 horas (horário local). Temperatura de $26^{\circ} \mathrm{C}$ (SBLJ/ METAR 11/10/2017 18:00 UTC- METAR SBJV 111800Z 13022KT 9999 FEW040TCU 26/20 Q1012=), $24^{\circ} \mathrm{C}$ (SBCT/ METAR 11/10/2017 18:00UTC - METAR SBCT 111800Z 15009KT 9999 4000NW TS VCSH BKN050 FEW060CB BKN100 24/21 Q1015=), sem precipitação nas localidades.

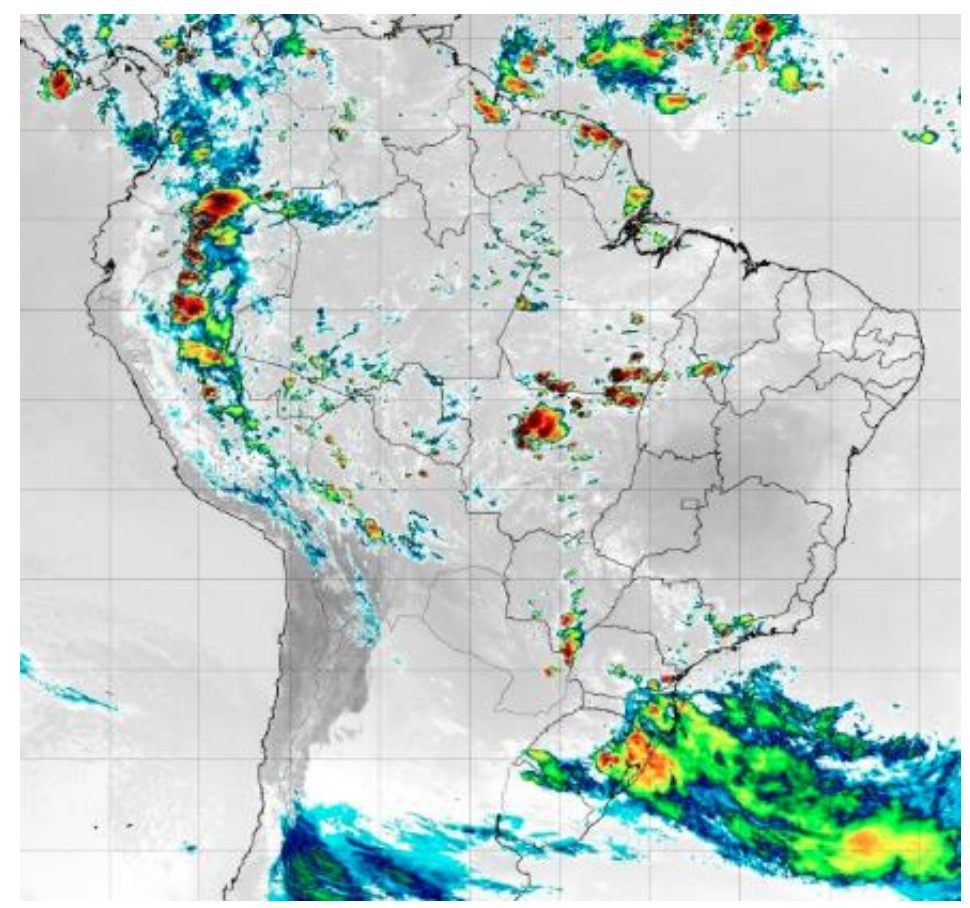

Imagem de satélite 1 - GOES 16, Canal_16 (13,30 microns) - 14h30min. Fonte DECEA/INPE

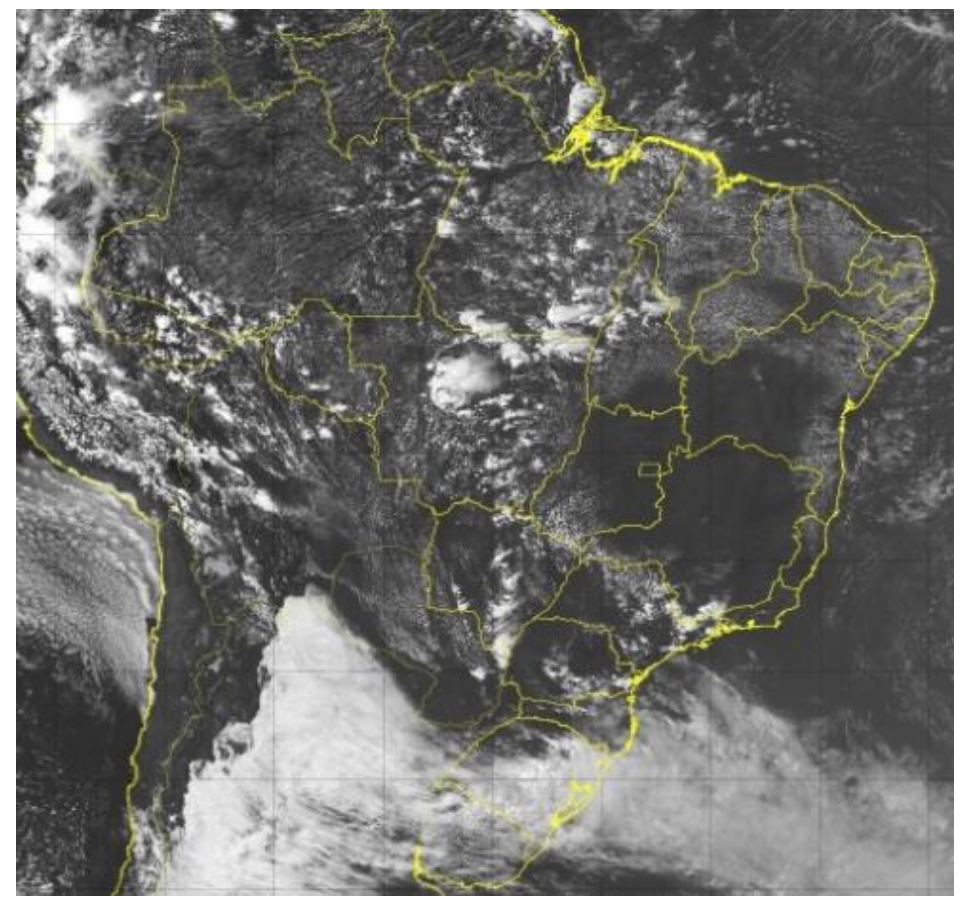

Imagem de satélite 2 - GOES 16, Canal_01 (0,47 microns) - 14h30min. Fonte DECEA/INPE 


\section{Dia 17 OUT 2017 - Vôo GEIV}

Considerações do Previsor: baixa nebulosidade próximo à, Campos (CAM), Pico do Couto (PCO), Varginha (VARG), Piedade (PIE) e Curitiba no período de 9 horas a 13 horas (horário local). Temperatura de $18^{\circ} \mathrm{C}$ (Curitiba - METAR SBCT 171400Z 08010KT 9999 SCT010 BKN013 18/14 Q1025=), 28 ${ }^{\circ} \mathrm{C}$ (Varginha - METAR SBVG 171600Z //I//KT CAVOK 28/14 Q1024=) sem precipitação nas localidades, $26^{\circ} \mathrm{C}$ (Campos - METAR SBCP 171400Z 21002KT 9999 BKN020 26/19 Q1024=), sem precipitações.

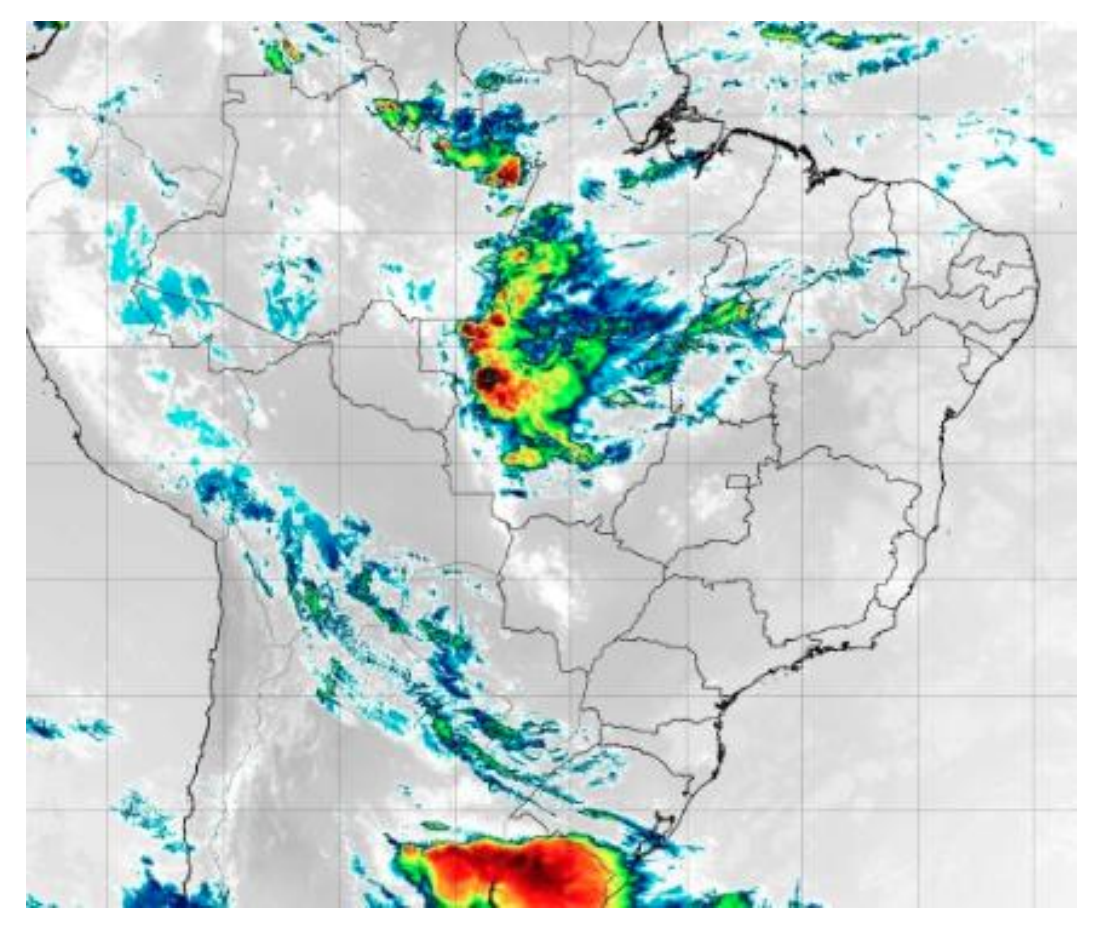

Imagem de satélite 3 - GOES 16, Canal_16 (13,30 microns) - 9h30min. Fonte DECEA/INPE

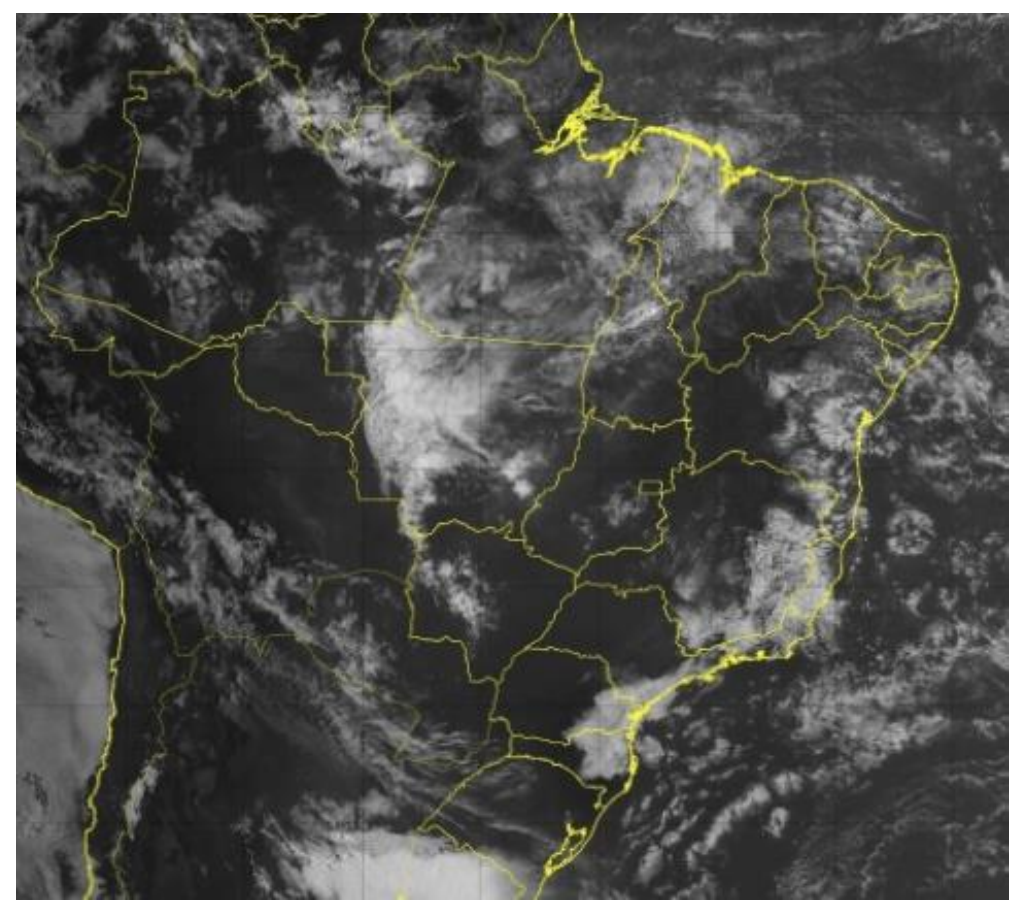

Imagem de satélite 4 - GOES 16, Canal_1 (0,47 microns) -9h30min. Fonte DECEA/INPE 
ANEXO I - MODELO DE QUESTIONÁRIOS DE AVALIAÇÃO 


\section{Anexo II - Instrucões aos Avaliadores}

Tipo de Teste: ACR - Absolute Category Rating

\section{"Avaliação de qualidade de voz em telecomunicações aeronáuticas"}

Você irá escutar, através de sistema de reprodução de alto-falantes adequadamente posicionado na sala, amostras de sinais de fala gravados em diferentes situações de ruídos.

Cada amostra é constituída de duas frases separadas por uma pausa de aproximadamente dois segundos. Após o término desta amostra, você deverá fornecer sua opinião sobre a qualidade da amostra que escutou de acordo com a seguinte escala:

$$
\begin{aligned}
& \text { 5-Qualidade Excelente } \\
& \text { 4-Qualidade Boa } \\
& \text { 3-Qualidade Regular } \\
& \text { 2-Qualidade Ruim } \\
& \text { 1-Qualidade Péssima }
\end{aligned}
$$

Você terá 7 segundos para registrar a sua resposta no formulário de avaliação, marcando um "X" no respectivo campo que corresponde à sua opinião.

Iniciaremos a sessão com um treinamento de maneira que você possa se familiarizar com o procedimento. A sessão de teste levará aproximadamente 20 minutos. 


\section{Anexo II - Questionário de Avaliação Subjetiva}

Identificacãa do Avaliador:

SESSÃO DE TREINAMENTO

AMOSTRA 1

\begin{tabular}{|c|c|c|c|c|}
\hline 5 - Excelente & 4 - Bom & 3-Regular & 2- Ruim & 1 - Péssimo \\
\hline & & & & \\
\hline
\end{tabular}

AMOSTRA 2

\begin{tabular}{|l|l|l|l|l|}
\hline 5 - Excelente & 4 - Bom & 3-Regular & 2- Ruim & 1 - Péssimo \\
\hline & & & & \\
\hline
\end{tabular}

AMOSTRA 3

\begin{tabular}{|c|c|c|c|c|}
\hline 5 - Excelente & 4 - Bom & 3-Regular & 2- Ruim & 1 - Péssimo \\
\hline & & & & \\
& & & & \\
\hline
\end{tabular}

AMOSTRA 4

\begin{tabular}{|c|c|c|c|c|}
\hline 5 - Excelente & 4 - Bom & 3-Regular & 2- Ruim & 1 - Péssimo \\
\hline & & & & \\
\hline
\end{tabular}




\section{SESSÃO DE AVALIAÇÃo}

\section{AMOSTRA 1}

\begin{tabular}{|c|c|c|c|c|}
\hline 5 - Excelente & 4 - Bom & 3-Regular & 2- Ruim & 1 - Péssimo \\
\hline & & & & \\
\hline
\end{tabular}

AMOSTRA 2

\begin{tabular}{|c|c|c|c|c|}
\hline 5 - Excelente & 4 - Bom & 3-Regular & 2- Ruim & 1 - Péssimo \\
\hline & & & & \\
\hline
\end{tabular}

AMOSTRA 3

\begin{tabular}{|l|l|l|l|l|}
\hline 5 - Excelente & 4- Bom & 3-Regular & 2- Ruim & 1 - Péssimo \\
\hline & & & & \\
\hline
\end{tabular}

AMOSTRA 4

\begin{tabular}{|c|c|c|c|c|}
\hline 5 - Excelente & 4 - Bom & 3 - Regular & 2- Ruim & 1 - Péssimo \\
\hline & & & & \\
\hline
\end{tabular}

AMOSTRA 36

\begin{tabular}{|c|c|c|c|c|}
\hline 5 - Excelente & 4 - Bom & 3-Regular & 2- Ruim & 1 - Péssimo \\
\hline & & & & \\
\hline
\end{tabular}




\section{ANEXO J - LISTAS DE REPRODUÇÃO DAS SESSÕES SUBJETIVAS}

\section{Legenda:}

\section{La_bb_Gcc_de.ee_ffgggg}

La - indica o número de identificação de lista (1-4); bb - o número sequencial de reprodução; cc - identificação do grupo/condição/tratamento; d - indica o tipo de voz (M para masculina e F para feminina); e.ee - identificação do locutor; ff - identificação da frase; gggg tipo de tratamento/condição de teste. 


\section{LISTA DE REPRODUÇÃO 1 - SESSÃO 1}

D. L1_01_G2_M2.01_04MNRU10R.wav D. L1_01_G2_M2.01_05MNRU10R.wav (D) L1_02_G3_F1.01_20MNRU15R.wav D) L1_02_G3_F1.01_21MNRU15R.wav D) L1_03_G7A_F3.01_45_PCO_CAM_PIE_1336.wav D) L1_03_G7A_F3.01_46_PCO_CAM_PIE_1336.wav D) L1_04_G23_M3.01_17_PCO_VARG_PIE_12535S.wav D) L1_04_G23_M3.01_18_PCO_VARG_PIE_12535S.wav D. L1_05_G10_M4.01_08G726.wav D) L1_05_G10_M4.01_09G726.wav D) L1_06_G8A_M4.01_40_PCO_VARG_PIE_12535S.wav D. L1_06_G8A_M4.01_41_PCO_VARG_PIE_12535S.wav D) L1_07_G1_F4.01_34MNRU05R.wav (D) L1_07_G1_F4.01_35MNRU05R.wav d) L1_08_G13_F3.01_29_ACC_CAV_1275.wav D) L1_08_G13_F3.01_30_ACC_CAV_1275.wav D) L1_09_G12_M4.01_12_ACC_ACC.wav D) L1_09_G12_M4.01_13_ACC_ACC.wav D) L1_10_G4A_F2.01_45_CAV_ACC_1275.wav D) L1_10_G4A_F2.01_46_CAV_ACC_1275.wav D) L1_11_G5A_M3.01_40_ACC_FL_CT_MDI.wav D) L1_11_G5A_M3.01_41_ACC_FL_CT_MDI.wav D) L1_12_G6_M2.01_14MNRU30R.wav D) L1_12_G6_M2.01_15MNRU30R.wav D. L1_13_G16_F3.01_35_ACC_FL_CT.wav d) L1_13_G16_F3.01_36_ACC_FL_CT.way D) L1_14_G14_M4.01_16_CAV_ACC_1275.wav D) L1_14_G14_M4.01_17_CAV_ACC_1275.wav
D. L1_15_G20_F2.01_25_PCO_CAM_PIE_1336S.wav D. L1_15_G20_F2.01_26_PCO_CAM_PIE_1336S.wav D. L1_16_G1A_M2.01_37_ACC_APP_TF1.wav D. L1_16_G1A_M2.01_38_ACC_APP_TF1.wav D) L1_17_G3A_M2.01_41_ACC_CAV_1275.wav D) L1_17_G3A_M2.01_42_ACC_CAV_1275.wav D) L1_18_G9_F3.01_21G711.wav D) L1_18_G9_F3.01_22G711.wav D) L1_19_G22_F2.01_29_PCO_VARG_12535.wav D) L1_19_G22_F2.01_30_PCO_VARG_12535.wav D. L1_20_G21_M3.01_13_PCO_PIE_1336.wav D) L1_20_G21_M3.01_14_PCO_PIE_1336.wav D) L1_21_G5_F1.01_26MNRU25R.wav D) L1_21_G5_F1.01_28MNRU25R.wav D) L1_22_G4_M2.01_08MNRU20R.wav D. L1_22_G4_M2.01_09MNRU20R.wav D) L1_23_G17_M3.01_04_ACC_FL_CT_MDI.wav D) L1_23_G17_M3.01_05_ACC_FL_CT_MDI.wav D) L1_24_F2.01_35norm.wav D) L1_24_F2.01_36norm.wav D) L1_25_G11_F3.01_25_ACC_APP_TF1.wav D) L1_25_G11_F3.01_26_ACC_APP_TF1.wav D) L1_26_G19_M3.01_09_PCO_CAM_1336.wav D) L1_26_G19_M3.01_10_PCO_CAM_1336.wav D) L1_27_G7_F1.01_32MNRU35R.wav d) L1_27_G7_F1.01_34MNRU35R.wav D) L1_28_G2A_F1.01_45_ACC_ACC.wav D) L1_28_G2A_F1.01_47_ACC_ACC.wav

\section{LISTA DE REPRODUÇÃO 2 - SESSÃO 2}

D) L2_01_G6_F2.01_12MNRU30R.wav D. L2_01_G6_F2.01_13MNRU30R.wav D. L2_02_G20_M2.01_31_PCO_CAM_PIE_1336S.wav D) L2_02_G20_M2.01_32_PCO_CAM_PIE_1336S.wav D) L2_03_G17_F4.01_12_ACC_FL_CT_MDI.wav D) L2_03_G17_F4.01_13_ACC_FL_CT_MDI.wav D. L2_04_G2_F2.01_04MNRU10R.wav D) L2_04_G2_F2.01_05MNRU10R.wav D. L2_05_G13_M3.01_34_ACC_CAV_1275.wav D) L2_05_G13_M3.01_35_ACC_CAV_1275.wav d) L2_06_G8_F2.01_16MNRU50R.wav D. L2_06_G8_F2.01_17MNRU50R.wav D. L2_07_G2A_M1.01_45_ACC_ACC.wav D. L2_07_G2A_M1.01_46_ACC_ACC.wav D) L2_08_G12_F1.01_15_ACC_ACC.wav D. L2_08_G12_F1.01_48_ACC_ACC.wav D) L2_09_G18_M2.01_27_FL_ACC_CT_MDI.wav d) L2_09_G18_M2.01_28_FL_ACC_CT_MDI.wav D) L2_10_G9_M3.01_26G711.wav D. L2_10_G9_M3.01_27G711.wav D) L2_11_G21_F3.01_04_PCO_PIE_1336.wav D) L2_11_G21_F3.01_05_PCO_PIE_1336.wav D) L2_12_G11_M3.01_30_ACC_APP_TF1.wav D) L2_12_G11_M3.01_31_ACC_APP_TF1.wav D. L2_13_G22_M2.01_35_PCO_VARG_12535.way D. L2_13_G22_M2.01_36_PCO_VARG_12535.wav D. L2_14_G23_F3.01_08_PCO_VARG_PIE_12535S.wav D. L2_14_G23_F3.01_09_PCO_VARG_PIE_12535S.wav d) L2_15_G24_M4.01_23_PCO_PIE_12535.wav D) L2_15_G24_M4.01_24_PCO_PIE_12535.wav D) L2_16_G16_M2.01_23_ACC_FL_CT.wav D. L2_16_G16_M2.01_24_ACC_FL_CT.wav D. L2_17_G4_F2.01_08MNRU20R.wav D. L2_17_G4_F2.01_09MNRU20R.wav D) L2_18_G10_F1.01_05G726.wav d) L2_18_G10_F1.01_07G726.wav D) L2_19_G7A_M3.01_44_PCO_CAM_PIE_1336.wav D) L2_19_G7A_M3.01_45_PCO_CAM_PIE_1336.wav D) L2_20_G7_M3.01_22MNRU35R.wav D) L2_20_G7_M3.01_23MNRU35R.wav D. L2_21_G4A_M2.01_43_CAV_ACC_1275.wav D) L2_21_G4A_M2.01_44_CAV_ACC_1275.wav D) L2_22_G19_F4.01_16_PCO_CAM_1336.wav D) L2_22_G19_F4.01_17_PCO_CAM_1336.wav D) L2_23_M4.01_26norm.wav D) L2_23_M4.01_27norm.wav D. L2_24_G3_M4.01_36MNRU15R.wav d. L2_24_G3_M4.01_37MNRU15R.wav D) L2_25_G14_F4.01_05_CAV_ACC_1275.wav d) L2_25_G14_F4.01_06_CAV_ACC_1275.wav (D) L2_26_G5_M1.01_33MNRU25R.wav D) L2_26_G5_M1.01_34MNRU25R.wav D. L2_27_G8A_F1.01_40_PCO_VARG_PIE_12535S.wav D) L2_27_G8A_F1.01_41_PCO_VARG_PIE_12535S.wav d) L2_28_G1_M1.01_19MNRU05R.wav d. L2_28_G1_M1.01_20MNRU05R.wav
D) L1_29_G8_M4.01_04MNRU50R.wav D) L1_29_G8_M4.01_05MNRU50R.wav D. L1_30_G18_F2.01_21_FL_ACC_CT_MDI.wav D) L1_30_G18_F2.01_22_FL_ACC_CT_MDI.wav D) L1_31_G24_F2.01_33_PCO_PIE_12535.wav D) L1_31_G24_F2.01_34_PCO_PIE_12535.wav
D) L2_29_G1A_F2.01_37_ACC_APP_TF1.wav D. L2_29_G1A_F2.01_38_ACC_APP_TF1.wav D) L2_30_G3A_F3.01_37_ACC_CAV_1275.wav D. L2_30_G3A_F3.01_38_ACC_CAV_1275.wav D) L2_31_G5A_F3.01_41_ACC_FL_CT_MDI.wav D) L2_31_G5A_F3.01_42_ACC_FL_CT_MDI.wav 


\section{LISTA DE REPRODUÇÃO 3 - SESSÃO 3}

D) L3_01_G4A_F3.01_39_CAV_ACC_1275.wav D) L3_01_G4A_F3.01_40_CAV_ACC_1275.wav D) L3_02_F3.01_12norm.wav

D) L3_02_F3.01_13norm.wav

D) L3_03_G17_M2.01_25_ACC_FL_CT_MDI.wav D) L3_03_G17_M2.01_26_ACC_FL_CT_MDI.wav D) L3_04_G3_F2.01_06MNRU15R.wav D) L3_04_G3_F2.01_07MNRU15R.wav [D) L3_05_G4_M1.01_29MNRU20R.wav D) L3_05_G4_M1.01_32MNRU20R.wav D) L3_06_G9_F1.01_02G711.wav D) L3_06_G9_F1.01_04G711.wav D) L3_07_G3A_M1.01_47_ACC_CAV_1275.wav (D) L3_07_G3A_M1.01_48_ACC_CAV_1275.wav [D) L3_08_G8_M3.01_24MNRU50R.wav (D) L3_08_G8_M3.01_25MNRU50R.wav D. L3_09_G1A_M1.01_43_ACC_APP_TF1.wav (D) L3_09_G1A_M1.01_44_ACC_APP_TF1.wav (D) L3_10_G6_M3.01_20MNRU30R.wav (D) L3_10_G6_M3.01_21MNRU30R.wav D) L3_11_G7A_F1.01_38_PCO_CAM_PIE_1336.wav D) L3_11_G7A_F1.01_39_PCO_CAM_PIE_1336.wav D. L3_12_G11_F1.01_11_ACC_APP_TF1.wav D) L3_12_G11_F1.01_13_ACC_APP_TF1.wav D) L3_13_G5_F2.01_10MNRU25R.wav D) L3_13_G5_F2.01_11MNRU25R.wav D. L3_14_G7_F2.01_14MNRU35R.wav D. L3_14_G7_F2.01_15MNRU35R.wav
D. L3_15_G21_M2.01_33_PCO_PIE_1336.wav D) L3_15_G21_M2.01_34_PCO_PIE_1336.wav D) L3_16_G14_M2.01_19_CAV_ACC_1275.wav D) L3_16_G14_M2.01_20_CAV_ACC_1275.wav D) L3_17_G12_M3.01_32_ACC_ACC.wav D) L3_17_G12_M3.01_33_ACC_ACC.wav D) L3_18_G2A_F2.01_39_ACC_ACC.wav D) L3_18_G2A_F2.01_40_ACC_ACC.wav D. L3_19_G20_F3.01_02_PCO_CAM_PIE_1336S.wav D) L3_19_G20_F3.01_03_PCO_CAM_PIE_1336S.wav D) L3_20_G18_F4.01_14_FL_ACC_CT_MDI.wav D) L3_20_G18_F4.01_15_FL_ACC_CT_MDI.wav D) L3_21_G5A_M2.01_45_ACC_FL_CT_MDI.wav D) L3_21_G5A_M2.01_46_ACC_FL_CT_MDI.wav D) L3_22_G10_M3.01_28G726.wav D) L3_22_G10_M3.01_29G726.wav D) L3_23_G23_M4.01_20_PCO_VARG_PIE_12535S.wav D) L3_23_G23_M4.01_21_PCO_VARG_PIE_12535S.wav 1) L3_24_G22_F3.01_06_PCO_VARG_12535.wav D) L3_24_G22_F3.01_07_PCO_VARG_12535.wav d) L3_25_G13_F4.01_03_ACC_CAV_1275.wav D) L3_25_G13_F4.01_04_ACC_CAV_1275.wav D) L3_26_G19_M2.01_29_PCO_CAM_1336.wav d) L3_26_619_M2.01_30_PCO_CAM_1336.wav D) L3_27_G2_M1.01_21MNRU10R.wav D. L3_27_G2_M1.01_23MNRU10R.wav D) L3_28_G1_F2.01_02MNRU05R.wav d) L3_28_G1_F2.01_03MNRU05R.wav

\section{LISTA DE REPRODUÇÃO 4 - SESSÃO 4}

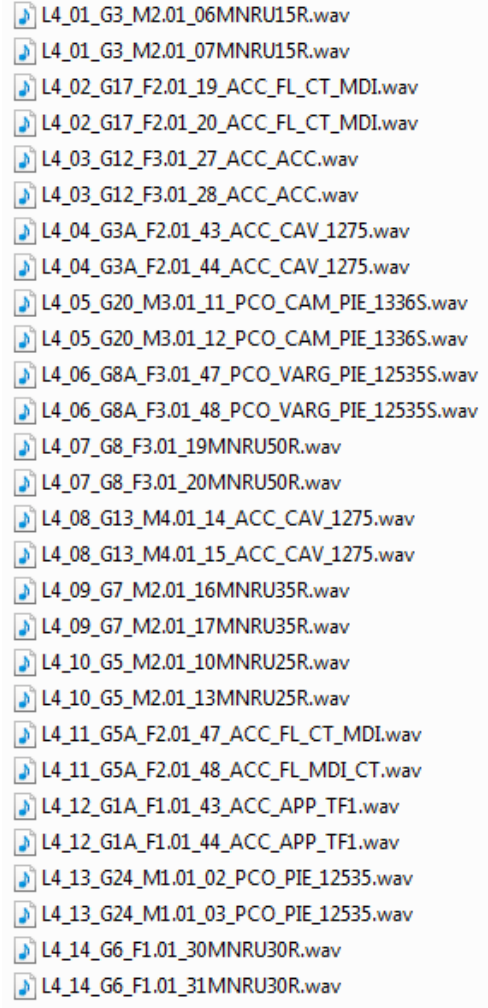

D) L4_15_G4A_M3.01_38_CAV_ACC_1275.wav D) L4_15_G4A_M3.01_39_CAV_ACC_1275.wav D) L4_16_G2A_M2.01_39_ACC_ACC.wav D) L4_16_G2A_M2.01_40_ACC_ACC.wav D) L4_17_G16_M3.01_02_ACC_FL_CT.wav D) L4_17_G16_M3.01_03_ACC_FL_CT.wav D) L4_18_G23_F2.01_31_PCO_VARG_PIE_12535S.wav D) L4_18_G23_F2.01_32_PCO_VARG_PIE_12535S.wav D) L4_19_G18_M3.01_07_FL_ACC_CT_MDI.wav D) L4_19_G18_M3.01_08_FL_ACC_CT_MDI.wav D) L4_20_G2_F1.01_18MNRU10R.wav D) L4_20_G2_F1.01_19MNRU10R.wav D) L4_21_G10_F3.01_23G726.wav D) L4_21_G10_F3.01_24G726.wav D) L4_22_G4_F1.01_22MNRU20R.wav D) L4_22_G4_F1.01_23MNRU20R.wav D. L4_23_G9_M4.01_06G711.wav D) L4_23_G9_M4.01_07G711.wav D) L4_24_G11_M4.01_10_ACC_APP_TF1.wav D) L4_24_G11_M4.01_11_ACC_APP_TF1.wav D) L4_25_G19_F2.01_23_PCO_CAM_1336.wav D) L4_25_G19_F2.01_24_PCO_CAM_1336.wav D) L4_26_G1_M2.01_02MNRU05R.wav D) L4_26_G1_M2.01_03MNRU05R.wav D) L4_27_G7A_M4.01_38_PCO_CAM_PIE_1336.wav D) L4_27_G7A_M4.01_39_PCO_CAM_PIE_1336.wav D) L4_28_M1.01_05norm.wav D. L4_28_M1.01_06norm.wav
D) L3_29_G16_F4.01_10_ACC_FL_CT.wav D) L3_29_G16_F4.01_11_ACC_FL_CT.wav D) L3_30_G24_F3.01_10_PCO_PIE_12535.wav D) L3_30_G24_F3.01_11_PCO_PIE_12535.wav D) L3_31_G8A_M3.01_46_PCO_VARG_PIE_12535S.wav D) L3_31_G8A_M3.01_47_PCO_VARG_PIE_12535S.wav

\author{
d] L4_29_G22_M3.01_15_PCO_VARG_12535.wav \\ D) L4_29_G22_M3.01_16_PCO_VARG_12535.wav \\ D. L4_30_G21_F2.01_27_PCO_PIE_1336.wav \\ D) L4_30_G21_F2.01_28_PCO_PIE_1336.wav \\ D) L4_31_G14_F3.01_31_CAV_ACC_1275.wav \\ D) L4_31_G14_F3.01_32_CAV_ACC_1275.wav
}

